AVALIAÇÃo DE ÍNDICES PARA FINS DE MONITORAMENTO E PREVISÃo DE SECAS NO NORDESTE SETENTRIONAL

ERICA ACIOLI CANAMARY

DISSERTAÇÃO DE MESTRADO EM TECNOLOGIA AMBIENTAL E RECURSOS HÍDRICOS

DEPARTAMENTO DE ENGENHARIA CIVIL E AMBIENTAL 
UNIVERSIDADE DE BRASÍLIA

FACULDADE DE TECNOLOGIA

DEPARTAMENTO DE ENGENHARIA CIVIL E AMBIENTAL

\title{
AVALIAÇÃO DE ÍNDICES PARA FINS DE MONITORAMENTO E PREVISÃO DE SECAS NO NORDESTE SETENTRIONAL
}

\author{
ERICA ACIOLI CANAMARY
}

\author{
ORIENTADOR: DIRCEU SILVEIRA REIS JUNIOR \\ CO-ORIENTADOR: EDUARDO SÁVIO PASSOS RODRIGUES \\ MARTINS
}

DISSERTAÇÃO DE MESTRADO EM TECNOLOGIA AMBIENTAL E RECURSOS HÍDRICOS

PUBLICAÇÃO: PTARH.DM - 174/15

BRASÍLIA/DF: JULHO - 2015 


\author{
UNIVERSIDADE DE BRASÍLIA \\ FACULDADE DE TECNOLOGIA \\ DEPARTAMENTO DE ENGENHARIA CIVIL
}

AVALIAÇÃO DE ÍNDICES PARA FINS DE MONITORAMENTO E PREVISÃO DE SECAS NO NORDESTE SETENTRIONAL

\title{
ERICA ACIOLI CANAMARY
}

DISSERTAÇÃO SUBMETIDA AO DEPARTAMENTO DE ENGENHARIA CIVIL E AMBIENTAL DA FACULDADE DE TECNOLOGIA DA UNIVERSIDADE DE BRASÍLIA COMO PARTE DOS REQUISÍTOS NECESSÁRIOS PARA A OBTENÇÃO DO GRAU DE MESTRE EM TECNOLOGIA AMBIENTAL E RECURSOS HÍDRICOS.

APROVADA POR:

Prof ${ }^{\mathrm{a}}$ Dirceu Silveira Reis Junior, Doutor (ENC-UnB)

(Orientador)

Prof. Eduardo Sávio P. Rodrigues Martins, Doutor (FUNCEME)

(Co-orientador)

Prof. Oscar de Moraes Cordeiro Netto, Doutor (ENC-UnB)

(Examinador Interno)

Prof. Francisco de Assis de Souza Filho, Doutor (DEHA-UFC)

(Examinador Externo)

BRASÍLIA/DF, JULHO DE 2015. 


\section{FICHA CATALOGRÁFICA}

\section{CANAMARY, ERICA ACIOLI}

Avaliação de índices para fins de monitoramento e previsão de secas no Nordeste setentrional [Distrito Federal] 2015.

xvi, 133p., 210 x 297 mm (ENC/FT/UnB, Mestre, Tecnologia Ambiental e Recursos

Hídricos, 2015).

Dissertação de Mestrado - Universidade de Brasília. Faculdade de Tecnologia.

Departamento de Engenharia Civil e Ambiental.
1. Seca
2. Índice
3. Monitoramento
4. Previsão
I. ENC/FT/UnB
II. Título (série)

\section{REFERÊNCIA BIBLIOGRÁFICA}

CANAMARY, E. A. (2015). Avaliação de índices para fins de monitoramento e previsão de secas no Nordeste setentrional. Dissertação de Mestrado em Tecnologia Ambiental e Recursos Hídricos, Publicação PTARH.DM-174/15, Departamento de Engenharia Civil e Ambiental, Universidade de Brasília, Brasília, DF, 133p.

\section{CESSÃO DE DIREITOS}

AUTOR: Erica Acioli Canamary.

TÍTULO: Avaliação de índices para fins de monitoramento e previsão de secas no Nordeste setentrional.

GRAU: Mestre

ANO: 2015

É concedida à Universidade de Brasília permissão para reproduzir cópias desta dissertação de mestrado e para emprestar ou vender tais cópias somente para propósitos acadêmicos e científicos. $\mathrm{O}$ autor reserva outros direitos de publicação e nenhuma parte dessa dissertação de mestrado pode ser reproduzida sem autorização por escrito do autor.

Erica Acioli Canamary erica_accioli@hotmail.com 


\section{AGRADECIMENTOS}

Gostaria primeiramente de agradecer a minha família que acreditou em mim e me ajudou em mais essa etapa da minha vida. Principalmente aos meus pais que sempre confiaram em $\operatorname{mim}$.

Em todas as etapas do trabalho foi de fundamental importância a ajuda do meu orientador, o professor Dirceu. Além de ter me apresentado uma área da engenharia, que eu achava que eu não gostava, de uma forma mais interessante, ele foi muito participativo no desenvolvimento da minha dissertação, sempre propondo ideias para que o trabalho ficasse mais interessante e de melhor qualidade.

Os amigos que eu fiz durante a graduação também foram muito importantes, porque eu sei que vocês estão sempre torcendo por mim, para que eu alcance meus objetivos e seja feliz nas minhas escolhas.

Como eu tive que mudar de cidade, foi muito importante o apoio dos novos amigos que eu fiz aqui. A Ana e o Ricardo que me ajudaram nas minhas trapalhadas em relação aos assuntos domésticos, além de se revelaram ótimas companhias. As meninas da sala 4 Sara, Carolina, Fernanda, Tatiana, Bruna - e o José, com quem eu consegui desenvolver uma amizade sincera e que eu sei que sempre vou poder confiar. As meninas da sala quatro (4 também tenho que agradecer por sempre estarem interessadas em me ajudar e tornarem meus dias mais leves e descontraídos.

Durante o desenvolvimento do meu trabalho precisei de muitos dados, por isso gostaria de agradecer as pessoas da FUNCEME que me ajudaram direta ou indiretamente, principalmente o Robson e o Eduardo Martins que sempre tiveram paciência para responder minhas dúvidas. 


\section{RESUMO}

A seca é um evento que sempre causou inúmeros prejuízos às populações de diversas regiões do mundo, principalmente em áreas carentes e menos preparadas aos seus efeitos. A mesma é descrita por muitos autores como um fenômeno de elevada complexidade, por ser influenciada por fatores diversos. Esse evento ocorre com grande frequência no Nordeste brasileiro, em virtude, dentre outros fatores, da elevada variabilidade climática verificada nessa região. Apesar dessa elevada susceptibilidade, as medidas de combate à seca implementadas nessa região ainda têm um caráter reativo, não havendo uma priorização por planos que tornem a sociedade mais resiliente a esse evento. Tendo em vista esse cenário, o presente trabalho foi proposto com o intuito de avaliar a aplicabilidade de índices na identificação da seca, possibilitando o monitoramento e a previsão desse fenômeno. Esses índices são ferramentas que estão sendo desenvolvidas por diversos autores na tentativa de caracterizar as secas, por meio da definição da sua intensidade, duração e frequência. Com esse intuito, foram escolhidos alguns índices, que são amplamente utilizados no desenvolvimento de pesquisas de identificação das secas, para o desenvolvimento do presente trabalho. Para a análise da capacidade de monitoramento, além da análise da série histórica dos índices, foi feita uma comparação do comportamento dessas ferramentas com variáveis que indicam a ocorrência da seca, como a vazão e a umidade do solo. Já a possibilidade de utilização de um desses instrumentos, o índice de precipitação padronizada (no inglês, Standard Precipitation Index - SPI), na previsão das secas, foi verificada por meio de ferramentas estatísticas que comparam os valores previstos aos observados. Os resultados mostraram que todos os índices apresentaram um comportamento semelhante na indicação das secas históricas, mas o SPI e o índice de precipitação-evapotranspiração padronizado (no inglês, Standardized Precipitation Evapotranspiration Index - SPEI) de 12 meses foram os que apresentaram uma maior similaridade com as variáveis que indicam os impactos da deficiência de chuva no meio. Em relação à capacidade de previsão das secas por meio do SPI mensal e trimestral, percebeu-se que esse índice consegue antecipar os eventos de seca com uma melhor qualidade que a climatologia.

Palavras Chaves: seca, índice, monitoramento, previsão. 


\begin{abstract}
Drought is an event that always caused numerous losses to the populations in various regions of the world, especially in poor areas and less prepared to its effects. The drought is described by many authors as a phenomenon of high complexity, being influenced by several factors. This event frequently occurs in the Brazilian Northeast, due, for example, the high climate variability observed in this region. Despite this high susceptibility, the drought responses implemented in this region are just reactive, with no prioritization for plans that make the society more prepared to this event. Given this scenario, this study was proposed in order to evaluate the applicability of indices in drought identification, enabling the monitoring and forecasting of this phenomenon. These indices are tools that have being developed by many authors in an attempt to characterize droughts, by defining its intensity, duration and frequency. We choose some indices, which are widely used in researches and early warning systems, for the development of this work. For the analysis of the monitoring capacity, we observe the behavior of the time series indices and compare these tools with variables that indicate the occurrence of drought, flow and soil moisture, for example. The possibility to use one of these instruments, the standardized precipitation index (SPI) in prediction of drought was verified by statistical tools that compare the predicted values to the observed. The results showed that all indices have a similar behavior in indicating the historical droughts, but the SPI and the Standardized Precipitation Evapotranspiration Index (SPEI) of 12 months have the greater similarity to the variables that indicate rainfall deficiency impacts on the environment. Regarding the drought forecasting capacity through the monthly and quarterly SPI, it was noted that this indice can anticipate drought events with a better quality than the climatology.
\end{abstract}

Key words: drought, indices, monitoring, prediction. 


\section{SUMARIO}

1- INTRODUÇÃ

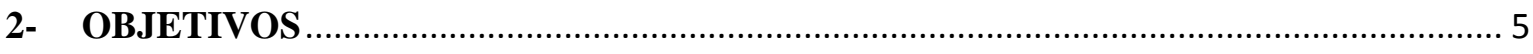

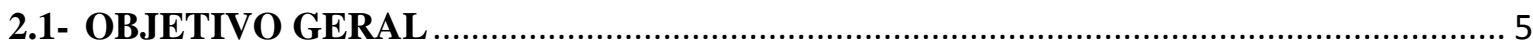

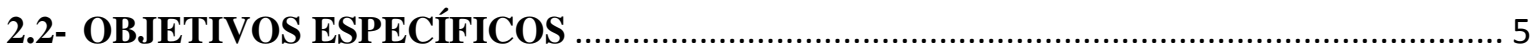

3- MARCO CONCEITUAL E REVISÃO BIBLIOGRÁFICA …………........................... 6

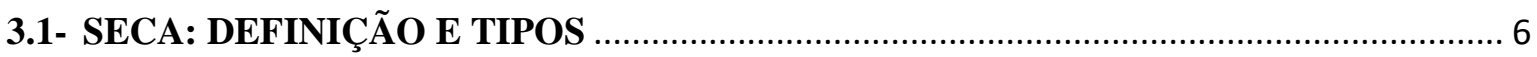

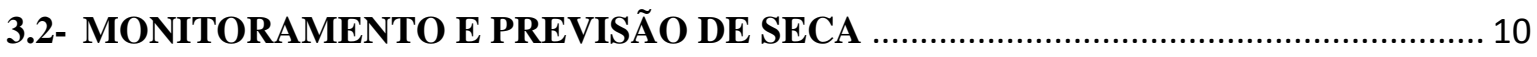

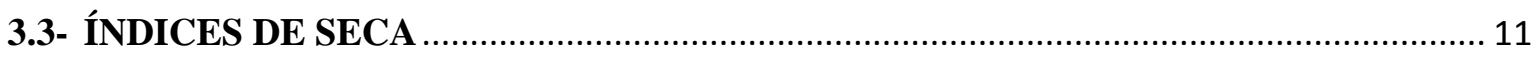

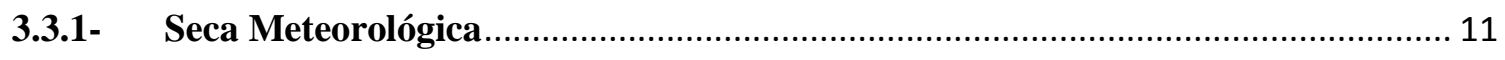

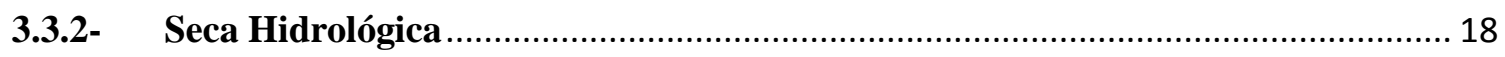

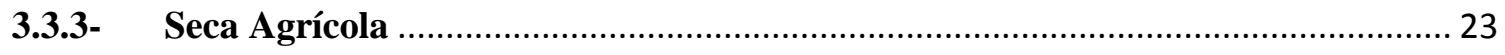

3.3.4- Índice Elaborado para a Região Nordeste ............................................................. 27

3.4- ALGUMAS APLICAÇÕES REAIS DOS ÍNDICES DE SECA ……............................ 28

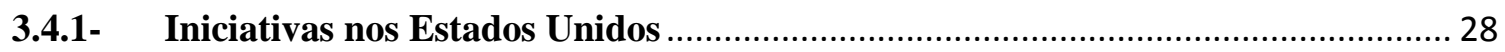

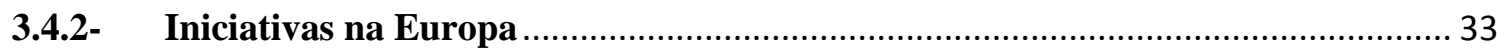

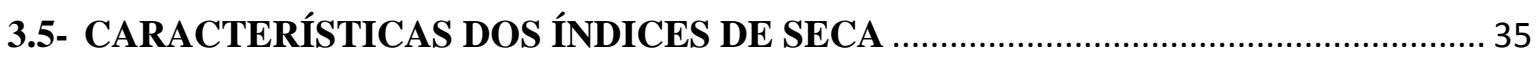

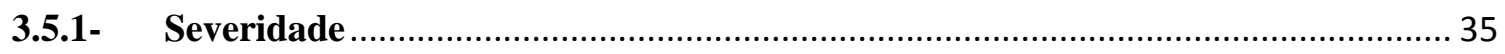

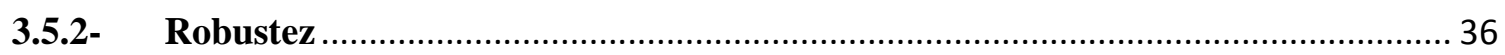

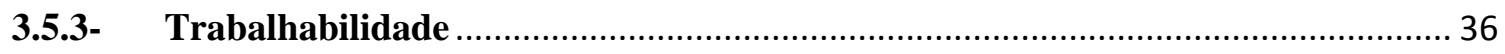

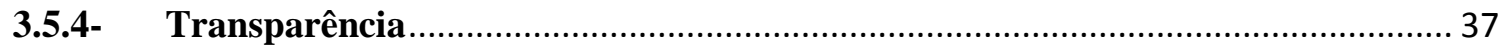

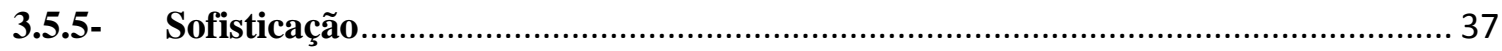

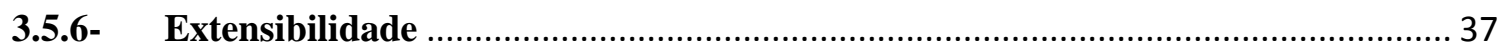

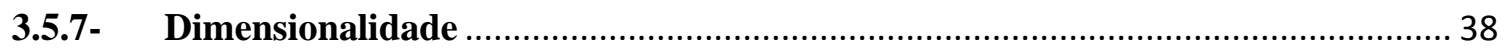

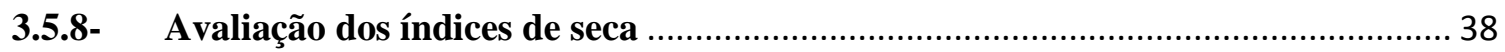

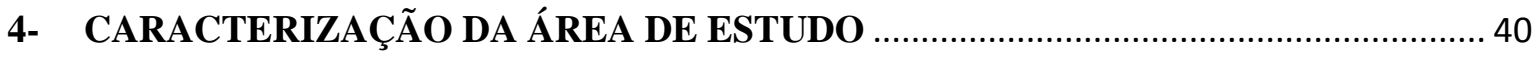

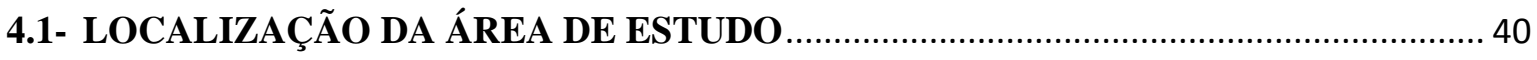

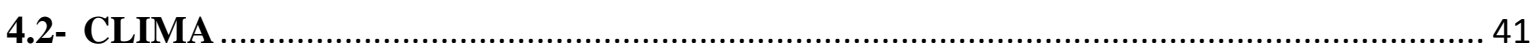

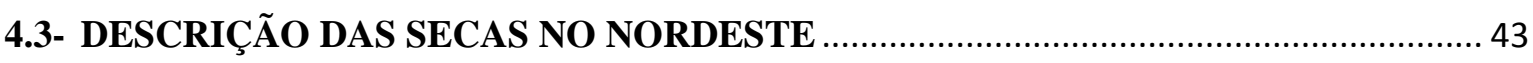

4.4- ESTRATÉGIAS CONTRA A SECA NO NORDESTE .................................................. 45

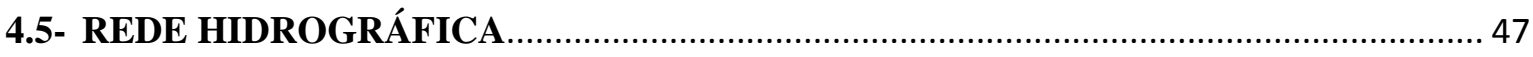

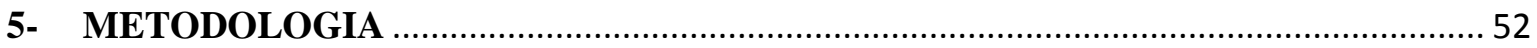

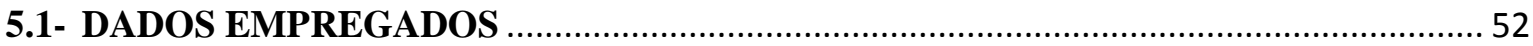




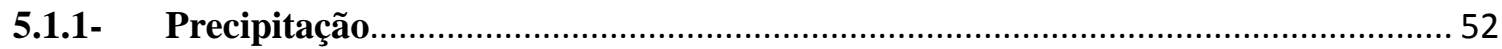

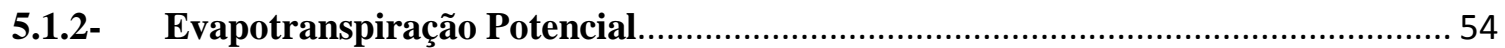

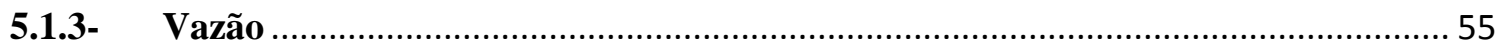

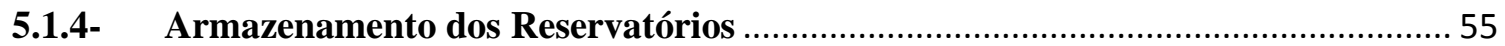

5.1.5- Capacidade de Armazenamento de Água no Solo ................................................... 56

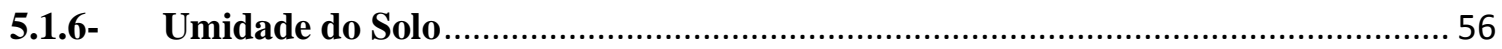

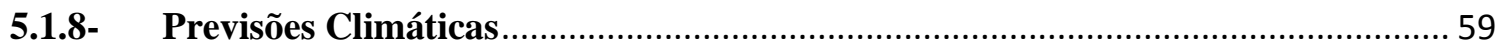

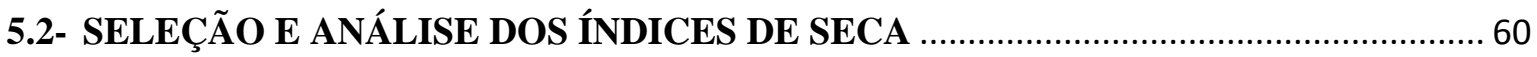

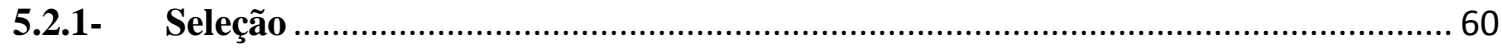

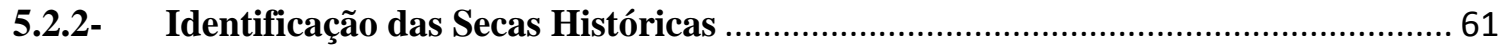

5.2.3- Comparação dos Índices com Variáveis e Ferramentas que Indicam as Variações

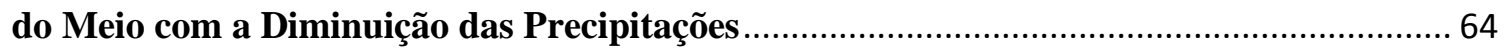

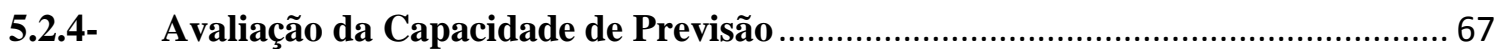

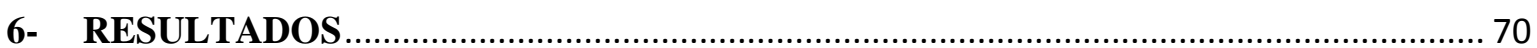

6.1- IDENTIFICAÇÃO DAS SECAS HISTÓRICAS COM OS ÍNDICES DE SECA ............ 70

6.2- IDENTIFICAÇÃO DAS SECAS HISTÓRICAS COM O USO DO NDVI E DA

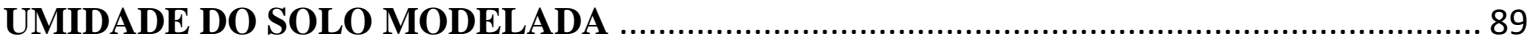

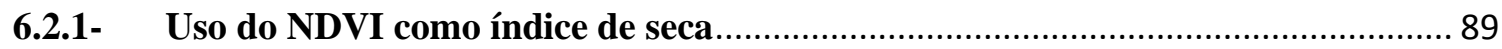

6.2.2- Uso da Umidade do Solo como índice de seca........................................................ 90

6.3- VERIFICAÇÃO DA CAPACIDADE DE OS ÍNDICES DE SECA DE

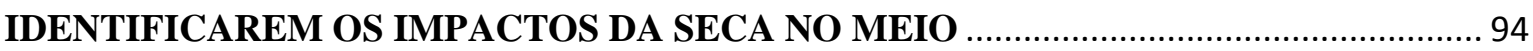

6.4- DETERMINAÇÃO DA SIMILARIDADE ENTRE OS ÍNDICES DE SECA ............... 113

6.5- VERIFICAÇÃO DA CAPACIDADE DE PREVISÃO DO SPI ...................................... 117

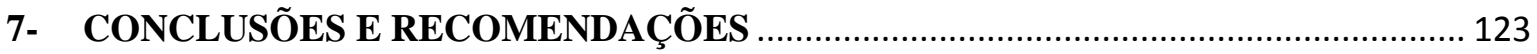

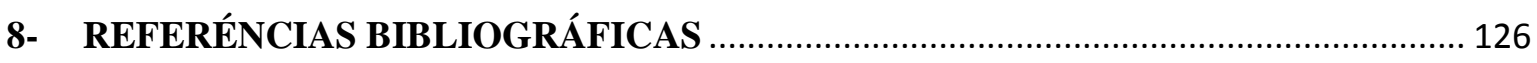




\section{SUMARIO DE TABELAS}

Tabela 1 - Classificação das secas segundo os decis (Fonte: Gibbs e Maher, 1967 apud Barua 2010, modificado)

Tabela 2 - Classes da severidade da seca (Fonte: Mckee et al. 1993, modificado)

Tabela 3 - Caracterização dos valores do SWSI (Fonte: Shafer e Dezman 1982, modificada).

Tabela 4 - Definição da severidade dos períodos úmidos (Fonte: Mu et al. 2013, modificado)

Tabela 5 - Definição da severidade dos períodos secos (Fonte: Mu et al. 2013, modificado).

Tabela 6 - Melhores índices para cada tipo de seca.

.28

Tabela 7 - Classificação da severidade da seca segundo o Monitor de Secas (Fonte: Svododa 2000, modificado)

Tabela 8 - Ocorrência das secas no Nordeste semiárido brasileiro (Fonte: Souza Filho, 2003, modificado).

Tabela 9 - População do Nordeste afetada pelas secas e recursos e recursos aplicados pelo governo federal nos programas de emergência. Período 1958, 1970, 1979-83 (Fonte: Carvalho (1988) apud Senado (1997), modificado). 44

Tabela 10 - Valores do percentil 30 dos dados de precipitação, em mm/mês, das Bacias contribuintes a cada reservatório.

Tabela 11 - Tabela de contingência que investigou os erros e acertos dos índices na determinação da seca em cada instante.

Tabela 12 - Tabela de contingência que investigou os erros e acertos dos índices na determinação da seca durante uma transição de tempo. 63

Tabela 13 - Limites das classes de referência do cálculo do RPS. 68

Tabela 14 - Relação das secas históricas mais severas segundo os índices avaliados. .76 Tabela 15 - Verificação dos erros e acertos dos índices na determinação da ocorrência da seca. 80 


\section{SUMARIO DE FIGURAS}

Figura 1 - Sequência de processos e impactos verificados durante a ocorrência de diferentes tipos de seca (Fonte: Organização Meteorológica Mundial (WMO), 2006, modificado)

Figura 2 - Relação entre os diferentes tipos de seca (Fonte: Wilhite, D. A. e BuchananSmith, M., 2005).

Figura 3 - Características do método do nível de referência (Fonte: Fleig et al., 2006).... 19

Figura 4 - Percentiles do ADI característicos de San Joaquin Drainage, na Califórnia (Fonte: Keyantash e Dracup, 2004). .23

Figura 5 - Exemplo do monitor de secas (Fonte: http://droughtmonitor.unl.edu/). 30

Figura 6 - Caracterização das secas no Sudoeste Europeu, segundo o SPI trimestral, calculado em maio de 2015 (Fonte: DMCSEE, 2015). 33

Figura 7 - Distribuição da porção de área afetada pela seca na Europa segundo o RDI e o RSPI (Fonte: Hannaford et al. 2010).

Figura 8 - Definição da severidade da seca (Fonte: Keyantash e Dracup 2002, modificado). 36

Figura 9 - Isoietas anuais médias compreendidas entre os anos de 1977 a 2006. 40

Figura 10 - Valor médio da diferença entre as taxas de precipitação e evaporação diárias (mm/dia) (Fonte: Nobre 2012). 42

Figura 11 - Delimitação da região analisada. 48

Figura 12 - Série de precipitação de Jan/1993 a Dez/1998, sendo a linha pontilhada referente à Bacia contribuinte ao Castanhão, a sólida ao Orós e a tracejada a do Banabuiú.

Figura 13 - Série de precipitação de Jan/1993 a Dez/1998, sendo a linha tracejada referente aos dados das bacias que contribuem para o açude Açu e a sólida das bacias que contribuem para o Coremas.

Figura 14 - Totais anuais da precipitação de 1970 a 2012, sendo as linhas tracejadas preta e roxa referentes à precipitação e evapotranspiração potencial, respectivamente, a Bacia do Banabuiú, as continuas preta e roxa referentes à precipitação e evapotranspiração potencial, respectivamente, do Alto Jaguaribe e as pontilhadas preta e roxa referentes à precipitação e evapotranspiração potencial, respectivamente, do Médio Jaguaribe. 50

Figura 15 - Totais anuais da precipitação de 1970 a 2012, sendo as linhas tracejadas preta e roxa referentes à precipitação e evapotranspiração potencial, respectivamente, das bacias 
que contribuem para o açude Açu e as continuas preta e roxa referentes à precipitação e evapotranspiração potencial, respectivamente, das bacias que contribuem para o açude Coremas.

Figura 16 - Etapas e dados da metodologia de análise dos índices. 66

Figura 17 - SPI12 da bacia contribuinte ao reservatório do Banabuiú................................ 71

Figura 18 - SPEI12 da bacia contribuinte ao reservatório do Banabuiú. ............................. 72

Figura 19 - PDSI da bacia contribuinte ao reservatório do Banabuiú.................................. 72

Figura 20 - PHDI da bacia contribuinte ao reservatório do Banabuiú. …………................. 73

Figura 21 - SPI24 da bacia contribuinte ao reservatório do Orós. ...................................... 74

Figura 22 - Série temporal do índice da FUNCEME. ........................................................... 75

Figura 23 - SPI12 da bacia contribuinte ao reservatório do Castanhão. Área em verde corresponde ao período úmido, em lilás, é uma seca moderada e em cinza, uma seca

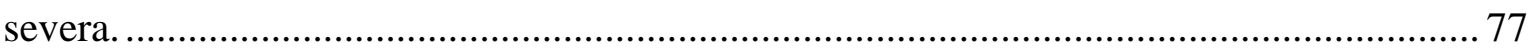

Figura 24 - SPEI12 da bacia contribuinte ao reservatório do Castanhão. Área em verde corresponde ao período úmido, em lilás, é uma seca moderada e em cinza, uma seca severa.

Figura 25 - PDSI da bacia contribuinte ao reservatório do Castanhão. Área em verde corresponde ao período úmido, em lilás, é uma seca moderada e em cinza, uma seca severa. .78

Figura 26 - PHDI da bacia contribuinte ao reservatório do Castanhão. Área em verde corresponde ao período úmido, em lilás, é uma seca moderada e em cinza, uma seca severa.

Figura 27 - Índice da FUNCEME da bacia contribuinte ao reservatório do Castanhão. Área em verde corresponde ao período úmido, em lilás, é uma seca moderada e em cinza, uma seca severa.

Figura 28 - Percentuais de erros e acertos na indicação da ocorrência da seca na bacia do Orós, segundo o SPI.

Figura 29 - Percentuais de erros e acertos na indicação da mudança ou não da condição de período seco ou úmido na bacia do Orós, segundo o SPI. 84 Figura 30 - Percentuais de erros e acertos na indicação da ocorrência da seca na bacia do Orós, segundo o SPEI.

Figura 31 - Percentuais de erros e acertos na indicação da mudança ou não da condição de período seco ou úmido na bacia do Orós, segundo o SPEI. .85 
Figura 32 - Percentuais de erros e acertos na indicação da ocorrência da seca na bacia do Orós, segundo o PDSI.

Figura 33 - Percentuais de erros e acertos na indicação da mudança ou não da condição de período seco ou úmido na bacia do Orós, segundo o PDSI

Figura 34 - Percentuais de erros e acertos na indicação da ocorrência da seca na bacia do Orós, segundo o PHDI.

Figura 35 - Percentuais de erros e acertos na indicação da mudança ou não da condição de período seco ou úmido na bacia do Orós, segundo o PHDI.

Figura 36 - Percentuais de erros e acertos na indicação da ocorrência da seca na bacia do Orós, segundo o índice da FUNCEME.

Figura 37 - Percentuais de erros e acertos na indicação da mudança ou não da condição de período seco ou úmido na bacia do Orós, segundo o índice da FUNCEME 88

Figura 38 - Série temporal do NDVI. 90

Figura 39 - Comparação das séries temporais dos valores máximos anuais da umidade do solo padronizados disponibilizado pela ESRL e obtidos pelo MUSAG na bacia do Orós. 91 Figura 40 - Percentuais de erros e acertos na indicação da ocorrência da seca na bacia do Orós, segundo a umidade disponibilizada pela ESRL

Figura 41 - Percentuais de erros e acertos na indicação da ocorrência da seca na bacia do Orós, segundo a umidade modelada pelo MUSAG. 92

Figura 42 - Coeficiente de Spearman entre o índice da FUNCEME das bacias do Banabuiú, Castanhão, Orós, e a vazão (Q) afluente, o volume (V) desses reservatórios e a umidade do solo. 94

Figura 43 - Coeficiente de Spearman entre variáveis hidrológicas e o índice da FUNCEME.

Figura 44 - Coeficiente de Spearman entre a umidade do solo disponibilizada pelo ESRL e os índices de seca médios das bacias. 97

Figura 45 - Coeficiente de Spearman entre a umidade do solo gerada pelo MUSAG e os índices de seca das bacias do Ceará

Figura 46 - Coeficiente de Spearman entre SPI, o SPEI médios das bacias e a umidade do solo disponibilizada pela ESRL

Figura 47 - Coeficiente de Spearman entre SPI, o SPEI médios das bacias e a umidade do solo gerada pelo MUSAG.

Figura 48 - Coeficiente de Spearman entre os índices de seca e a umidade do solo disponibilizado pelo ESRL nos pontos do CRU. 100 
Figura 49 - Coeficiente de Spearman entre os índices de seca e a umidade do solo gerada pelo MUSAG nos pontos referentes aos postos pluviométricos da FUNCEME.

Figura 50 - Coeficiente de correlação de Spearman do mês de maio entre a umidade do solo gerada pelo MUSAG e os índices de seca (o intervalo de -0,099 a 0,201 representa as regiões onde os valores de correlação não são significativos). 103

Figura 51 - Coeficiente de Spearman entre os índices de seca e a umidade do solo disponibilizada pela ESRL nos pontos da bacia Piranhas Açu. 104 Figura 52 - Coeficiente de Spearman entre o SPI, SPEI e a umidade do solo disponibilizada pelo ESRL. 105

Figura 53 - Coeficiente de Spearman entre o SPI, SPEI e a umidade do solo gerada pelo MUSAG. 105

Figura 54 - Coeficiente de correlação de Spearman entre o SPEI12, SPI12 e a umidade do solo gerada pelo MUSAG (o intervalo de $-0,217$ a 0,00 representa as regiões onde os valores de correlação entre o índice da FUNCEME e a umidade do MUSAG não são significativos). 106

Figura 55 - Variação do coeficiente de Spearman do SPI e SPEI com as vazões (Q) afluentes e os volumes (V) dos reservatórios.

Figura 56 - Variação dos coeficientes de Spearman entre os SPI, por pontos, acumulados em diversas escalas de tempo e as vazões afluentes aos reservatórios do Castanhão, Banabuiú e Orós. 109

Figura 57 - Variação do coeficiente de Spearman entre os SPI, por pontos, acumulados em diversas escalas de tempo e as vazões afluentes aos reservatórios do Açu e Coremas..... 109 Figura 58 - Coeficiente de Spearman entre os índices de Palmer das bacias, o volume (V) armazenado nos reservatórios e as vazões (Q) afluentes aos mesmos.

Figura 59 - Coeficiente de Spearman entre os índices de Palmer nos pontos da base de dados do CRU e as vazões afluentes aos reservatórios.

Figura 60 - Variação do coeficiente de Spearman entre os SPI, por pontos, acumulados em diversas escalas de tempo e os volumes dos reservatórios do Castanhão, Banabuiú e Orós.

Figura 61 - Variação do coeficiente de Spearman entre os SPI, por pontos, acumulados em diversas escalas de tempo e os volumes dos reservatórios do Açu e Coremas. Figura 62 - Coeficiente de Spearman, por pontos, entre os índices de Palmer, por pontos, e o volume dos reservatórios. 
Figura 63 - Coeficiente de Spearman entre o SPI das bacias do Banabuiú, Castanhão, Orós, Açu e Coremas, e os índices de seca.

Figura 64 - Coeficiente de Spearman entre o SPI e os índices de seca por pontos.

Figura 65 - Coeficiente de Spearman entre os índices de seca e o SPI da bacia do Piranhas Açu por pontos.

Figura 66 - Coeficiente de Spearman entre o índice da FUNCEME das bacias do Banabuiú, Castanhão, Orós, e os índices de seca médio na bacia. 116

Figura 67 - Coeficiente de Spearman entre os índices de seca e o índice da FUNCEME por pontos.

Figura 68 - Comparação do SPI mensal previsto, da bacia do Banabuiú, gerado com a TSM persistida e o observado (linha azul pontilhada: climatologia, linha preta contínua: SPI observado)

Figura 69 - Comparação do SPI mensal previsto, da bacia do Castanhão, gerado com a TSM persistida e o observado (linha azul pontilhada: climatologia, linha preta contínua: SPI observado)

Figura 70 - Comparação do SPI mensal previsto gerado, da bacia do Castanhão, com a TSM prevista e o observado (linha azul pontilhada: climatologia, linha preta contínua: SPI observado)

Figura 71 - Comparação do SPI mensal persistida gerado, da bacia do Orós, com a TSM prevista e o observado (linha azul pontilhada: climatologia, linha preta contínua: SPI observado).

Figura 72 - Comparação do SPI trimestral previsto, da bacia do Banabuiú, gerado com a TSM prevista e o observado (linha azul pontilhada: climatologia, linha preta contínua: SPI observado)

Figura 73 - Comparação do SPI trimestral previsto, da bacia do Orós, gerado com a TSM prevista e o observado (linha azul pontilhada: climatologia, linha preta contínua: SPI observado)

Figura 74 - Comparação do SPI trimestral previsto, da bacia do Castanhão, gerado com a TSM persistida e o observado (linha azul pontilhada: climatologia, linha preta contínua: SPI observado). 


\section{LISTA DE ABREVIATURAS E SIGLAS}

ANA

CAFEC

CAMS

CCI

CMI

COGERH

CRU

DAI

DEM

DNOCS

DSI

DROUGHT-

$R \& S P I$

$\mathrm{ECV}$

EDR

EP

ESRL

ETDI

FUNCEME

GCM

GHCN

HRUs

IBGE

ISSS

ISRIC

MGCA

MODIS

MRE

NAO

NASA/EOS

NASA's
Agência Nacional de Águas

Processo climaticamente apropriada para as condições existentes

Climate Anomaly Monitoring System

Iniciativa de Mudanças Climáticas

Índice de umidade da cultura

Companhia de Gestão dos Recursos Hídricos

Climatic Research Unit

Índice de área de seca

Modelo digital do terreno

Departamento Nacional de Obras Contra a Seca

Remotely Sensed Global Drought Index

Fostering European Drought Research and Science-Policy

Interfacing

Variáveis Climáticas Essenciais

European Drought Reference

Precipitação efetiva

Earth System Research Laboratory

Índice de déficit de evapotranspiração

Fundação Cearense de Meteorologia e Recursos Hídricos

Modelo de Circulação Global

Global Historical Climatology Network

Unidades de resposta hidrológica

Instituto Brasileiro de Geografia e Estatística

Sociedade Internacional de Ciências do Solo

International Soil Reference and Information Centre

Modelo de Circulação Geral Atmosférico

Espectroradiômetro de Resolução de Imagem Moderada

Modelo Regional Espectral

North Atlantic Oscilation

NASA Earth Observing System

National Aeronautics and Space Administration's 


\begin{tabular}{|c|c|}
\hline NDMC & Centro Nacional de Mitigação de Seca \\
\hline NDPC & Comissão Nacional de Política de Seca \\
\hline NDVI & Índice de vegetação por diferença normalizada \\
\hline NOAA & National Oceanic and Atmospheric Administration \\
\hline NTSG & Numerical Terradynamic Simulation Group \\
\hline PDSI & Índice de Severidade de Seca de Palmer \\
\hline PHDI & Índice Hidrológico de Seca de Palmer \\
\hline $\mathrm{P}-\mathrm{M}$ & Equação de Penman-Monteith \\
\hline PNRH & Plano Nacional de Recursos Hídricos \\
\hline PSD & Physical Sciences Division \\
\hline RAI & Índice de anomalia de chuva \\
\hline RASM & Regional Atmospheric Modeling System \\
\hline RDI & Índice de deficiência regional \\
\hline RSM & Regional Spectral Model \\
\hline RSPI & Regional standardized precipitation index \\
\hline sc-PDSI & Self-calibrating Índice de Severidade de Seca de Palmer \\
\hline SMDI & Índice de deficiência de umidade do solo \\
\hline SPEI & Índice de precipitação-evapotranspiração padronizado \\
\hline SPI & Índice de Precipitação Padronizada \\
\hline SWAT & Hydrologic model soil and water assessment tool \\
\hline SWSI & Índice de abastecimento de água em superfície \\
\hline UNESCO & $\begin{array}{l}\text { Organização das Nações Unidas para a Educação, a Ciência e a } \\
\text { Cultura }\end{array}$ \\
\hline USDA & Departamento de Agricultura dos Estados Unidos \\
\hline VCI & Índice de condição da vegetação \\
\hline WMO & Organização Meteorológica Mundial \\
\hline WP & West pacific pattern \\
\hline ZCIT & Zona de Convergência Intertropical \\
\hline Z-index & Índice de anomalia de umidade \\
\hline$\rho$ & Coeficiente de correlação linear de Pearson \\
\hline
\end{tabular}




\section{1- INTRODUÇÃO}

A seca é considerada por Keyantash e Dracup (2002) o desastre natural mais caro do mundo, sendo responsável por uma média de $\$ 6$ a $\$ 8$ bilhões em prejuízos anuais. Dentre os eventos meteorológicos extremos, as secas são possivelmente os que se desenvolvem mais lentamente, tendo, muitas vezes, a mais longa duração (Mishra e Singh, 2010).

Segundo a lei 13153, de 30 de julho de 2015, que institui a Política Nacional de Combate e Prevenção à Desertificação e Mitigação dos Efeitos da Seca e seus Instrumentos, a seca é definida como um processo que ocorre naturalmente quando a precipitação é significativamente inferior aos valores normais, provocando um sério desequilíbrio hídrico que afeta negativamente os sistemas de produção e de consumo;

Os impactos desse evento podem ainda ser intensificados em decorrência do aumento significativo da demanda por água, o qual está associado, dentre outros fatores, ao crescimento populacional desordenado e à expansão da capacidade de produção agrícola. Outro fator que agrava essa situação é a utilização indiscriminada dos corpos d'água para a descarga de poluentes, impossibilitando seu uso em decorrência da elevada poluição.

Uma região conhecida pela frequente ocorrência desses eventos extremos é o Nordeste brasileiro, onde tais eventos estão associados à grande variabilidade climática, a qual pode ser observada na elevada amplitude dos índices pluviométricos.

Um fato que ocorreu durante um episódio de seca nessa região e merece ser destacado, foi a morte de 1.004 pessoas no dia 10 de dezembro de 1877 em Fortaleza, devido a uma epidemia de varíola. O desenvolvimento da doença foi facilitado, segundo Garcia e Neves (2003), pelo alojamento de centenas de retirantes, que estavam fugindo da seca, em locais que não possuíam condições mínimas de moradia.

Apesar de a seca frequentemente incidir sobre muitas localidades, causando inúmeros impactos, ela ainda é um fenômeno pouco entendido, conforme relatado por Cunha et al. (1983), o que torna importante o estímulo de estudos que desenvolvam planos de ação para minimização dos seus efeitos. 
Almejando reduzir os impactos desencadeados pela seca, algumas pesquisas que tentam entender seu comportamento estão sendo direcionadas para o desenvolvimento de índices capazes de caracterizá-la, definindo seu início, sua severidade, sua duração e os impactos a ela associados.

O monitoramento desses índices pode indicar o nível de severidade da seca que ocorre em um dado instante, podendo estar atrelado a um conjunto de ações previamente determinados num plano de preparação para seca. Esses planos de preparação fazem parte de uma abordagem proativa da gestão da seca, sendo formulados em períodos com condições climáticas normais, com o envolvimento de instituições governamentais e da sociedade. O principal objetivo de tais planos é permitir que a sociedade possa realizar ações racionais durante a ocorrência do fenômeno, reduzindo assim seus impactos negativos.

A adoção dessas ferramentas pode, portanto, ajudar a responder importantes questões que comumente são feitas por pessoas que auxiliam no processo decisório. Svoboda (2000) apresentou alguns exemplos dessas questões, como: com que frequência nós vemos uma seca dessa magnitude? Ela ocorre com uma frequência suficiente para que nós devêssemos nos planejar ao invés de simplesmente reconhecer quando ela ocorre? Em resumo, nós podemos definir a diferença entre percepção e realidade?

A maior parte desses instrumentos, entretanto, foi elaborada com base em características de determinadas áreas, o que dificulta a sua larga utilização em virtude da grande variabilidade de fatores que influenciam nas secas, gerando uma grande incerteza, para cientistas e gestores, na escolha das ferramentas que mais bem se aplicam a cada estudo.

Um exemplo de um plano de estudo desenvolvido, na União Europeia, com o auxílio dessas ferramentas, foi o Fostering European Drought Research and Science-Policy Interfacing (DROUGHT-R\&SPI). Esse trabalho, de acordo com Lanen et al. (2015), tenta, dentre outros objetivos, entender o processo de ocorrência do fenômeno da seca, seus impactos, e elaborar uma política de planos de gestão. 
Uma das ferramentas desenvolvidas por esse projeto foi um banco de dados onde foram relacionadas informações acerca de secas históricas que ocorreram na Europa, o qual foi denominado de European Drought Reference (EDR). Lanen et al. (2015) caracterizam o EDR como um sumário detalhado dos 11 principais eventos, além de uma ferramenta que mostra as condições diárias as quais estão submetidas regiões sujeitas a uma seca, segundo dois índices de seca.

Outro exemplo de um estudo que tenta criar ferramentas que permitam uma melhor convivência com a seca, é descrita no estudo realizado por Marton et al. (2015), cujo objetivo é melhorar o projeto e a operação de reservatórios. Segundo os pesquisadores, as incertezas existentes na determinação da recarga dessas reservas, as quais são agravadas por fatores como eventos de secas e mudanças climáticas, podem desencadear falhas inesperadas no sistema de operação dos reservatórios, sendo, assim, de fundamental importância o entendimento e a descrição desses eventos.

Na região Nordeste, uma iniciativa recente do governo Brasileiro, juntamente com o Banco Mundial, e que contou com a participação de instituições estaduais, foi a elaboração de um projeto que tenta desenvolver uma gestão mais proativa nessa área. Dentre as etapas desse trabalho, destaca-se a criação de um monitor de secas para o Nordeste e de planos de ação operacionais de preparação para as secas (Nys et al., 2014).

Assim, na tentativa de avaliar a aplicabilidade de índices na região do Nordeste semiárido brasileiro, o presente trabalho irá calcular algumas dessas ferramentas com a utilização de dados dessa área. Os valores obtidos serão verificados por meio da comparação com relatos de secas que ocorreram no passado e com séries de dados fornecidos por entidades nacionais e internacionais, que podem indicar a ocorrência da seca, como a umidade do solo e o volume armazenado em reservatórios.

Além de analisar a incidência das secas em uma região por meio de índices de seca, deve também existir uma preocupação em produzir instrumentos capazes de prever, mesmo que em um pequeno horizonte, a sua ocorrência e severidade. Isso facilitaria a aplicação prévia de planos de ação que minimizariam os problemas gerados pela seca. 
Os próximos capítulos do presente trabalho apresentam os seguintes conteúdos: o seguinte mostra os objetivos gerais e específicos, o terceiro aborda a revisão bibliográfica em que se fundamenta o estudo, o quarto debate sobre a caracterização da área escolhida para aplicação da pesquisa, o quinto descreve a metodologia que resume as etapas a serem seguidas para realização do estudo, o sexto mostra os resultados extraídos dos cálculos efetuados ao logo da pesquisa, o sétimo apresenta as conclusões e recomendações finais do trabalho e o último mostra a referências bibliográficas utilizadas para o desenvolvimento do mesmo. 


\section{2- OBJETIVOS}

\section{1- OBJETIVO GERAL}

Avaliar a aplicabilidade e desempenho de índices na realização do monitoramento e previsão de secas meteorológicas, hidrológicas e agrícolas no Nordeste semiárido brasileiro.

\section{2- OBJETIVOS ESPECÍFICOS}

- Selecionar e avaliar a capacidade dos índices de seca em identificar início, fim e severidade de secas que ocorreram na região do Nordeste semiárido do Brasil, bem como sua distribuição espacial.

- Avaliar a adequação dos índices selecionados na análise dos diferentes tipos de secas: meteorológica, agrícola e hidrológica.

- Verificar se a previsão climática para o Nordeste brasileiro, realizada operacionalmente pela Fundação Cearense de Meteorologia e Recursos Hídricos (FUNCEME), pode ser empregada para identificar início, fim ou desenvolvimento de secas, e sua distribuição espacial. 


\section{3- MARCO CONCEITUAL E REVISÃO BIBLIOGRÁFICA}

No presente capitulo será apresentada uma breve contextualização sobre o problema da seca, por meio da definição dos principais tipos desse fenômeno e os diversos tipos de impactos gerados. Serão também mostradas algumas das ferramentas disponíveis na literatura que fazem a identificação e caracterização das secas, além de projetos, em diferentes regiões do mundo, que fazem uso desses índices no combate aos problemas decorrentes da seca.

\section{1- SECA: DEFINIÇÃO E TIPOS}

A seca é um desastre ambiental observado em diversas partes do mundo, sendo definida como um longo período com escassez de eventos de precipitação, desencadeando inúmeros problemas para importantes segmentos da sociedade, como a agricultura, a gestão de recursos hídricos e a geração de energia. Esse fenômeno, porém, tem duração limitada, devendo ser diferenciada da aridez, observada em alguns ecossistemas, que é uma característica permanente.

Existem variações dessa definição de acordo com as formas que a seca pode ser sentida pelos diferentes setores de uma sociedade. Enquanto a população, inicialmente, identifica esse processo em decorrência de um déficit de chuva, as companhias responsáveis pela gestão de recursos hídricos irão perceber seus efeitos caso haja uma redução nos níveis dos reservatórios, por exemplo. Outro fator que influência nessa grande heterogeneidade de formas de incidência é o fato de que a mesma quantidade de precipitação pode ter consequências diferentes dependendo das características de cada região, como os elementos meteorológicos, o tipo de ecossistema e das atividades econômicas desenvolvidas.

De acordo com Mishara e Singh (2010), ao contrário de outros desastres naturais, as atividades humanas podem diretamente induzir a manifestação da seca. $O$ uso indiscriminado do solo para a atividade agrícola e o desflorestamento, por exemplo, pode desencadear uma diminuição da disponibilidade de água, em virtude da alteração da capacidade do meio de capturá-la e retê-la. 
Um exemplo dessa característica foi evidenciado no Colorado, Estados Unidos. Cunha et al. (1983) relatam que, em 1977, ocorreu uma das melhores safras agrícolas, apesar de nessa época ter sido registrada uma deficiência de precipitação em relação aos valores considerados normais. Isso ocorreu em virtude das intensidades da chuva e da neve, associadas a uma boa distribuição da precipitação, favorecerem a elevada infiltração, possibilitando o desenvolvimento dos cultivos.

Os pesquisadores definem diversos tipos de seca, sendo as mais comumente relatadas as seguintes: meteorológica, agrícola, hidrológica, as quais são apresentadas de forma resumida na Figura 1. Essa variedade de configurações da seca, também é confirmada por Wilhite, D. A. e Buchanan-Smith, M. (2005), ao explicarem que cada evento a seca é único em suas características climáticas, extensão espacial e impactos gerados, não existindo, portanto, duas secas idênticas.

Segundo a Organização Meteorológica Mundial (no inglês, World Meteorological Organization - WMO) (2006), uma condição primordial para a ocorrência de uma a seca meteorológica, é quando se evidência uma deficiência de precipitação em relação aos valores normais de uma região. Já a seca agrícola ocorre caso essa carência se mantenha por um longo período, sendo verificada uma redução da umidade do solo até um ponto que comece a prejudicar o desenvolvimento dos cultivos, ocasionando o estresse hídrico.

A WMO (2006) define que a seca hidrológica é desencadeada por uma diminuição da infiltração e do escoamento e, consequentemente, da recarga do lençol freático e das reservas hídricas superficiais. Essa situação tende a desencadear uma redução do volume de reservatórios, como rios, lagos, aquíferos, dentre outros. 


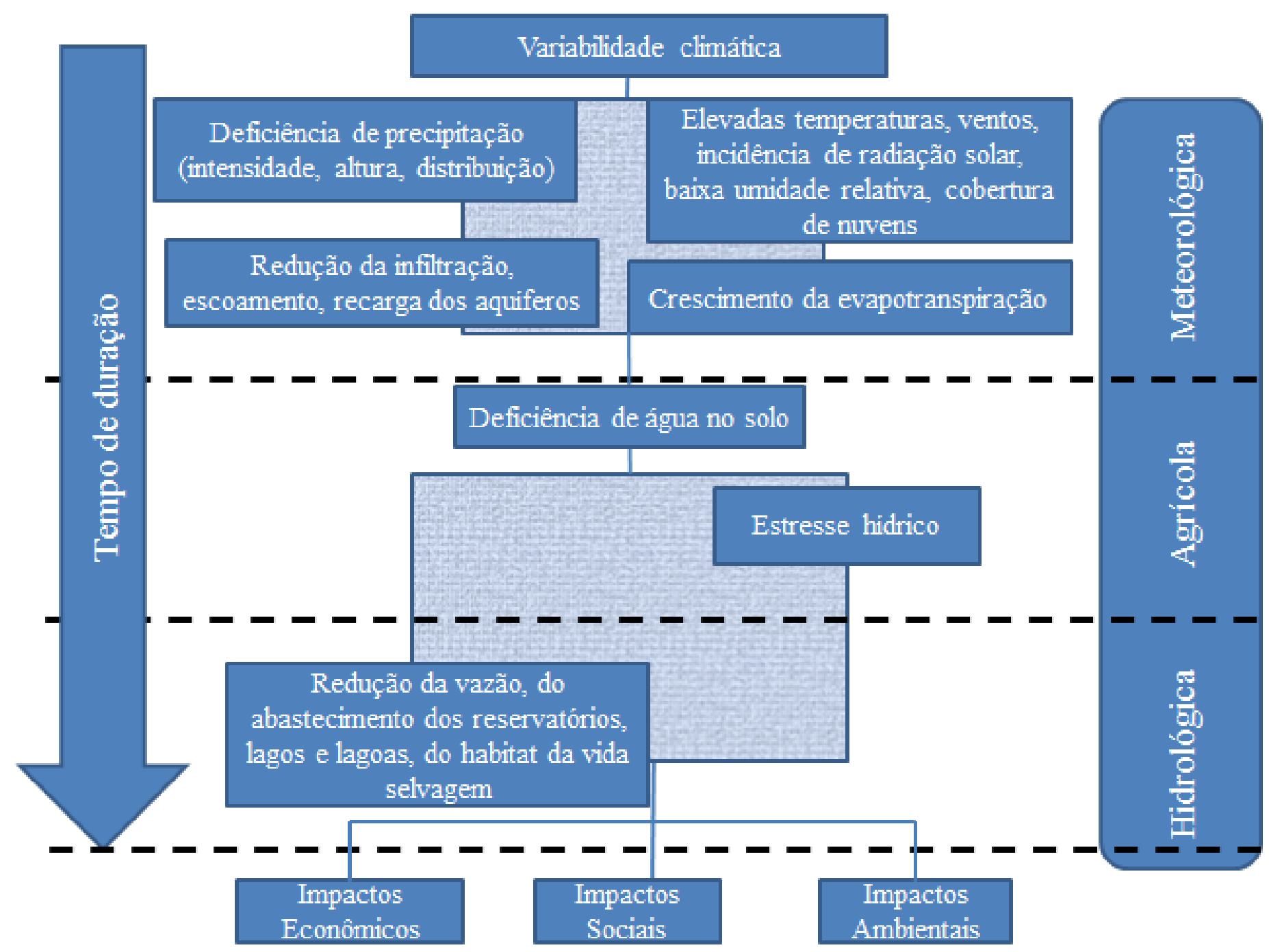

Figura 1 - Sequência de processos e impactos verificados durante a ocorrência de diferentes tipos de seca (Fonte: Organização Meteorológica Mundial (WMO), 2006, modificado). 
A Figura 1 mostra a sequência mais intuitiva de processos que desencadeiam as secas, bem como a sequência das secas observadas. Ressalta-se, entretanto, que, dependendo das características de cada região, podem ser observadas configurações diferentes desses processos. Na região do Nordeste semiárido brasileiro, por exemplo, existe uma predominância de solos rasos, que possuem uma baixa capacidade de armazenamento de água. Assim, grande parcela do volume precipitado escoa sobre a superfície do solo. Em virtude dessas características, uma redução das chuvas, ocasiona, de forma simultânea, uma redução na umidade do solo e nos níveis dos reservatórios, ocorrendo, portanto a secas agrícolas concomitantemente à hidrológica.

A WMO (2006) apresenta ainda outro tipo de seca intitulada socioeconômica. Essa modalidade é evidenciada quando a deficiência no suprimento de água começa a afetar a produção de bens ofertados para a população. Ela é, portanto, associada à questão monetária e dependente dos tipos de uso da água, da densidade de usuários e da sua distribuição. A forma como esse tipo de seca se associa as explicadas anteriormente pode ser visualizado na Figura 2.

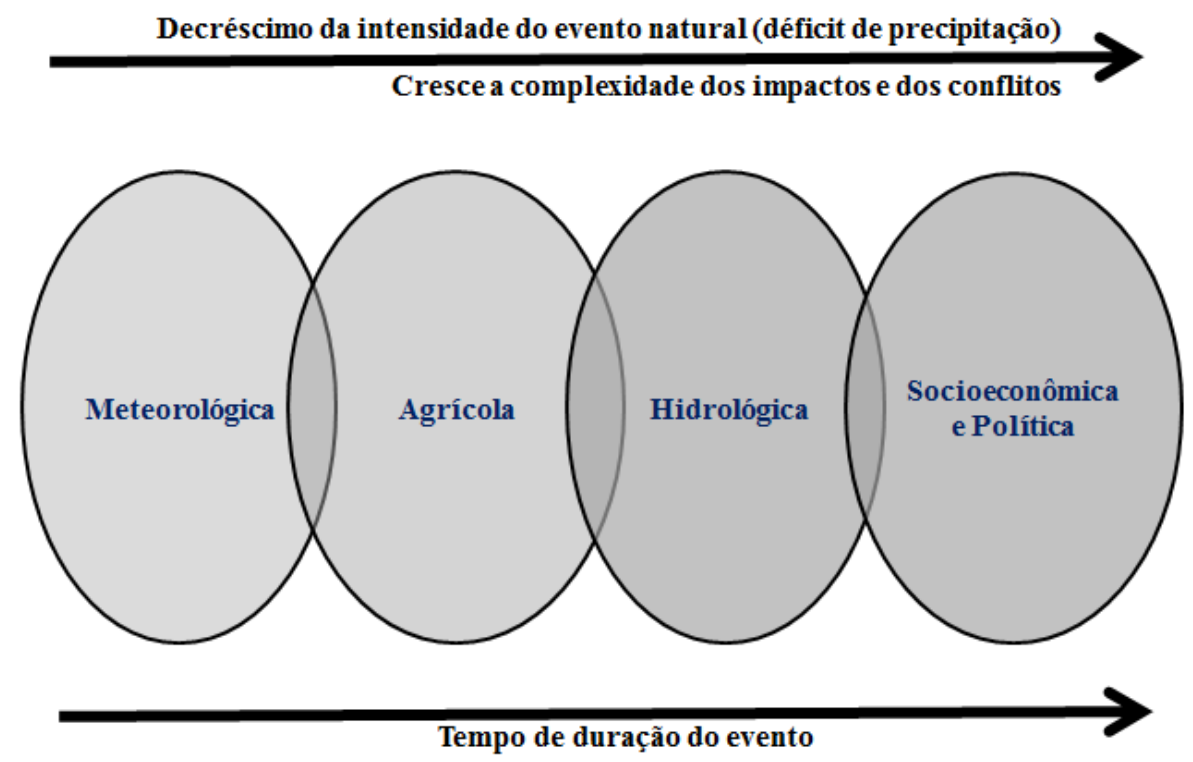

Figura 2 - Relação entre os diferentes tipos de seca (Fonte: Wilhite, D. A. e BuchananSmith, M., 2005).

Wilhite, D. A. e Buchanan-Smith, M. (2005) também destacam que esse último tipo de seca pode ocorrer em virtude de esse fenômeno desencadear diferentes impactos nos diversos setores da sociedade, dependendo do acesso de cada parcela da população aos 
recursos naturais, como a terra. Um exemplo dessa situação pode ser verificado na África, onde pastores nômades, em busca de pastagem, e agricultores disputam a mesma terra para o cultivo.

As secas meteorológicas ocorrem com uma maior frequência que as demais, em virtude do tempo necessário para que os impactos gerados pelo déficit de chuva sejam percebidos no meio, como redução da umidade do solo. Destaca-se ainda que, quando essa condição de seca persistir, pode chegar um momento em que as secas, agrícolas, hidrológicas e socioeconômicas ocorram simultaneamente, produzindo efeitos associados e, consequentemente, mais graves para a sociedade (WMO, 2006).

\section{2- MONITORAMENTO E PREVISÃO DE SECA}

A elevada complexidade de avaliação da seca, por ser um fenômeno capaz de se manifestar de diferentes formas e gerar uma grande gama de impactos, estimulou a realização de pesquisas, visando o desenvolvimento de instrumentos que procuram caracterizar esse evento por meio de um único valor. Essas ferramentas, conhecidas como índices de seca, são capazes de extrair informações desse desastre natural, auxiliando no processo de tomada de decisão, como a severidade, a extensão geográfica e a duração. Alguns exemplos dessas ferramentas são apresentados no item a seguir, de acordo com o tipo de seca que eles são capazes de identificar.

Existe uma grande variabilidade de índices de seca disponíveis na literatura. Assim a escolha da melhor ferramenta para cada tipo de estudo deve considerar fatores como as características hidroclimáticas da região analisada, o tipo de seca, a proposta do trabalho, os dados disponíveis e a vulnerabilidade da sociedade.

Um cenário em que esses índices poderiam apoiar o sistema de gestão é quando se quer verificar qual a melhor tecnologia a ser adotada em uma obra hidráulica a ser instalada em determinada localidade. A análise dos índices calculados a partir dos dados históricos permite a identificação dos locais mais afetados pelos déficits de água.

Esses valores podem ser utilizados tanto em análises de acompanhamento do desenvolvimento de um evento de seca, efetuando o seu monitoramento, como, também, 
de previsão da seca. A possibilidade de antecipação desses eventos permite que as autoridades competentes possam colocar em prática planos de ação antes que o problema esteja instalado, reduzindo possíveis impactos.

\section{3- ÍNDICES DE SECA}

\subsection{1- Seca Meteorológica}

A porcentagem normal (PN) trabalha com um enfoque meteorológico, sendo calculada pelo quociente percentual entre uma dada precipitação e a normal. É aconselhado que o cálculo da média utilize, pelo menos, os dados dos últimos trinta anos. Barua (2010) relata que, normalmente, os valores de PN inferiores a 100\% são utilizados como indicativos de períodos secos.

A principal vantagem desse índice é a sua simplicidade e transparência, o que o torna favorável para a comunicação dos níveis de seca para o público (Keyantash e Dracup 2002 apud Zargar et al., 2011). Destaca-se ainda a possibilidade de se avaliar em diferentes períodos de tempo.

Zargar et al. (2011) relatam alguns problemas desse índice, como a falta de um tratamento estatístico do conjunto de dados de precipitação. Uma diferença significativa entre a mediana e a média, em virtude da presença de outliers, por exemplo, pode influenciar no resultado do índice. Outra dificuldade para utilização dessa ferramenta, que também é destacada pelos autores, é a impossibilidade de emprega-lo para comparar a seca ao longo do tempo e do espaço, como o mesmo não considera as variações das distribuições dos valores de precipitação nas diferentes estações.

Os decis são um tipo de quantil, uma ferramenta de análise estatística de uma série de dados, que pode ser utilizado como método de estudo da seca. Para aplicar esse parâmetro deve-se, primeiramente, ordenar os dados de precipitação de forma crescente e, depois fracioná-los em partes de 10 por cento cada. A Tabela 1 mostra os limites de classificação das secas segundo essa métrica. 
Tabela 1 - Classificação das secas segundo os decis (Fonte: Gibbs e Maher, 1967 apud Barua 2010, modificado).

\begin{tabular}{|c|c|}
\hline Categoria & Classificação \\
\hline Abaixo dos primeiros $20 \%$ & Muito abaixo do normal \\
\hline Entre $20 \%$ e $40 \%$ & Abaixo do normal \\
\hline Entre $40 \%$ e $60 \%$ & Próximo ao normal \\
\hline Entre $60 \%$ e $80 \%$ & Acima do normal \\
\hline Entre $80 \%$ e $100 \%$ & Muito acima do normal \\
\hline
\end{tabular}

O índice de precipitação padronizada (no inglês, Standard Precipitation Index - SPI) é outro índice meteorológico que se baseia, unicamente, em dados de precipitação, mas, de acordo com Mckee et al. (1993), sua metodologia pode ser adaptada para outras variáveis. A ideia dessa ferramenta é obter uma precipitação normalizada, que mostre o quanto um dado valor de altura de chuva se distância da média em função do desvio-padrão de uma série de dados, baseando-se assim na distribuição normal padrão.

Para calcular o SPI deve-se previamente definir a escala de tempo a ser adotada, que normalmente é de 3, 6, 12, 24 ou 48 meses, dependendo do tipo de análise a ser realizada. Os dados, que devem, preferencialmente, ter uma extensão de pelo menos 30 anos, são acumulados segundo o período escolhido. Posteriormente, eles são ajustados à distribuição Gamma, proposta por Mckee et al. (1993), sendo o valor do índice obtido pelo cálculo da normal padrão inversa. Essa padronização da distribuição faz com que os valores inferiores a zero representem períodos secos e os superiores, úmidos.

Uma vantagem dessa ferramenta é a sua capacidade de avaliar os impactos da seca em várias escalas de tempo, possibilitando a utilização desse valor em diversas análises. $\mathrm{O}$ estudo da seca agrícola, por exemplo, está intimamente relacionado à umidade do solo, sendo, portanto aconselhável à utilização de períodos mais curtos, já que essa variável muda o seu valor em pequenos períodos de tempo.

Segundo McKee (1993), uma situação de seca para uma determinada escala de tempo será evidenciada quando o cálculo do SPI for continuamente negativo e atingir valores de -1 ou inferiores. Os graus de severidade da seca de acordo com os valores do SPI são apresentados na Tabela 2. 
Tabela 2 - Classes da severidade da seca (Fonte: Mckee et al. 1993, modificado).

\begin{tabular}{|c|c|}
\hline Valores de SPI & Categoria de seca \\
\hline $0 \mathrm{a}-0,99$ & Seca média \\
\hline$-1 \mathrm{a}-1,49$ & Seca moderada \\
\hline$-1,5 \mathrm{a}-1,99$ & Seca severa \\
\hline$\leq-2$ & Seca extrema \\
\hline
\end{tabular}

Uma grande desvantagem do SPI é que seu cálculo considera apenas dados de precipitação, desprezando outras variáveis que podem influenciar na severidade da seca. A justificativa da adoção dessa metodologia é que o SPI se baseia na ideia de que a variabilidade da precipitação é superior à dos demais fatores.

Um aperfeiçoamento do SPI é o regional standardized precipitation index (RSPI), que foi aplicado por Hannaford et al. (2010) em diversas regiões da Europa, como França e Alemanha. Como uma mesma altura pluviométrica pode ter diversos impactos quando incide em regiões e em períodos distintos, dependendo das características climáticas de cada local, um mesmo valor do SPI pode ter significados diferentes. A metodologia do RPSI propõe, portanto, agrupar os valores do SPI segundo a área de influência dos postos de medição dos dados de precipitação. Essa delimitação foi feita com o método dos Polígonos de Thiessen, sendo os valores do RPSI definidos como a porção das células, as quais pertencem a uma a cada região delimitada, que apresentaram SPI $<-1$.

O índice de Severidade de Seca de Palmer (no inglês, Palmer Drought Severity Index PDSI), idealizado por Palmer, tem uma ampla utilização nos Estados Unidos, já que foi desenvolvido com base em características de cidades norte americanas, como Iowa e Ohio. Palmer (1965) definiu uma metodologia para estimar a quantidade de chuva que deve ocorrer em uma área sujeita às condições climáticas normais. Posteriormente, obtêm-se o déficit de precipitação ao se comparar a chuva que ocorreu no período analisado com a considerada climaticamente apropriada para as condições existentes, como mostra a equação 1 .

$$
d=P-\hat{P}
$$


No cálculo da umidade do solo, necessária na obtenção dessa precipitação estimada, utilizou-se uma metodologia desenvolvida em um estudo experimental realizado por Marlatt (1961) apud Palmer (1965), na qual o solo é dividido em duas camadas independentes. Convenciona-se que a fração superior tenha 1 in. $(2,54 \mathrm{~cm})$ de capacidade de armazenamento de água no solo.

Destaca-se que, nesse estudo, optou-se por trabalhar com taxas potenciais de evapotranspiração, as quais são caracterizadas por um suprimento ilimitado de água. $\mathrm{O}$ valor dessa taxa é obtido a partir da solução gráfica que Palmer-Havens elaboraram para a fórmula de Thornthwaite, apresentada pela equação 2 .

$$
e=1,6(10 T / I)^{a}
$$

em que $e$ é a evapotranspiração potencial mensal $(\mathrm{cm}), \mathrm{T}$ é a temperatura média mensal $\left({ }^{\circ} \mathrm{C}\right)$, I é o índice de calor, que é uma constante que varia segundo as temperaturas mensais da região analisada, a é um expoente determinado empiricamente pela seguinte função: $a=6,75 \cdot 10^{-7} \cdot I^{3}-7,71 \cdot 10^{-5} \cdot I^{2}+1,79 \cdot 10^{-2} \cdot I+0,49$.

Nesse modelo hidrológico adotado por Palmer, os fenômenos de precipitação e evapotranspiração irão atuar, primeiramente, na camada superior do solo. Assim, somente após a completa eliminação da umidade disponível nessa área, se dará início à perda de umidade na camada seguinte. Caso a precipitação seja superior à evapotranspiração potencial, a água só irá infiltrar na camada inferior, quando a superior atingir a saturação.

Um ponto desse modelo bastante criticado é a convenção de que o escoamento superficial só irá ocorrer após a saturação dessas duas camadas de solo, o que não corresponde à realidade, já que o volume de escoamento varia de acordo a diversos fatores, como o tipo de solo e a topografia.

Para que esses valores pudessem ser comparados no tempo e no espaço, foram também desenvolvidos pesos que permitissem a padronização do índice de seca, os quais são calculados pelas equações 3 e 4. Essas relações foram obtidas a partir da verificação das relações empíricas entre os diversos fatores considerados no desenvolvimento do índice, como o déficit de precipitação, a umidade perdida pelo solo e a evapotranspiração 
potencial. Já a formulação final do PDSI, proposta por Palmer (1965) para o cálculo do PDSI, exposta pela equação 5, foi elaborada com base nos valores acumulados do índice de anomalia de umidade, apresentado na equação 6 , obtidos durante períodos secos que ocorreram nas cidades de Kansas e Iowa.

$$
\begin{gathered}
K^{\prime}=1,5 \log _{10}\left[\left(\frac{\overline{P E}+\bar{R}+\overline{R O}}{\bar{P}+\bar{L}}+2,80\right) / \bar{D}\right]+0,50 \\
K=\frac{17,67}{\sum_{1}^{12} \bar{D} K^{\prime}} \cdot K^{\prime}
\end{gathered}
$$

em que $\overline{\mathrm{PE}}, \bar{R}, \overline{R O}, \overline{\mathrm{P}}$ e $\overline{\mathrm{L}}$ são as médias dos valores da evapotranspiração potencial, da infiltração, do escoamento, da precipitação observada e das perdas de umidade pelo solo, já $\bar{D}$ é a média dos valores absolutos de d.

$$
\begin{gathered}
X_{i}=X_{i-1}+\frac{z_{i}}{3}-0,103 X_{i-1} \\
z=K * d
\end{gathered}
$$

em que $\mathrm{X}_{\mathrm{i}}$ é o PDSI que se deseja calcular referente ao mês $\mathrm{i}, \mathrm{X}_{\mathrm{i}-1}$ é o PDSI do mês anterior e $z_{i}$ é o índice de anomalia de umidade referente ao mês i.

Para sair do período de seca, Palmer convencionou que, antes de calcular o valor da equação 5, deve-se verificar se a quantidade de umidade presente no meio é suficiente para finalizar a seca, por meio da equação 7 .

$$
P_{e}=\frac{\sum_{j=0}^{j=j^{*}} U_{i-j}}{Z_{e}+\sum_{j=0}^{j=j^{*}} U_{i-j}-U_{i}} \times 100
$$

em que $\mathrm{P}_{\mathrm{e}}$ é a probabilidade de que a seca tenha terminado, $\mathrm{U}$ é a umidade, i é o mês anterior ao avaliado, $\mathrm{j}$ é mês avaliado e $\mathrm{Z}_{\mathrm{e}}$ é o valor de $\mathrm{z}$ necessário para finalizar uma seca Ao longo do trabalho desenvolvido por Palmer (1965), foi elaborado um grupo de índices que posteriormente ficou conhecido como Índices Palmer. Além do PDSI, esse conjunto é 
composto pelo índice hidrológico de seca de Palmer (no inglês, Palmer Hydrological Drought Index - PHDI) e o índice Z.

O índice Z, obtido pela equação 6, representa a anomalia de umidade calculada pela ponderação do déficit de umidade, d. Dentre os índices de Palmer, o mesmo é o mais afetado por situações de deficiência de água de curto prazo. O PHDI quantifica os impactos de longo prazo gerados pela seca em sistemas hidrológicos, permanecendo com um valor negativo mesmo por vários meses depois que o PDSI tenha voltado a assumir valores que indicam o fim da seca.

Devido à ampla utilização desse parâmetro, muitos estudos têm sido feitos para avaliar a eficácia e aplicabilidade dos seus resultados, o que permitiu a detecção de algumas falhas, como as simplificações feitas pelo modelo hidrológico adotado no cálculo da umidade do solo. Destaca-se, porém, que apesar desses inúmeros problemas, o PDSI, segundo VicenteSerrano et al. (2012), ainda é considerado como o índice de seca mais largamente utilizado.

Outra fragilidade desse modelo é que o mesmo não considera variações nas capacidades de armazenamento de água em função das mudanças de vegetação que ocorrem ao longo do ano. $\mathrm{O}$ fato de o modelo assumir uma capacidade de armazenamento máxima na camada superior de 25,4 mm é outra grande arbitrariedade. Esse valor de umidade é normalmente pequeno quando comparado ao resultado das diferenças entre a evapotranspiração potencial e a precipitação do período, o que faz com que facilmente essa água disponível seja completamente removida dessa camada em um mês.

É importante ressaltar também que, para se calcularem os índices propostos por Palmer, deve-se dispor de uma boa base de dados, pois, quanto maiores forem os períodos de calibração, mais consistentes serão os resultados. Heim (2002) ressalta que, caso esse período de calibração seja modificado, os índices também devem ser recalculados para manter a consistência dos resultados. Para estudos que fazem uma comparação espacial, o mesmo período de calibração deveria ser utilizado para todas as localidades.

Como relatado anteriormente, a composição da equação do peso do PDSI se baseou em relações empíricas com a utilização de dados de algumas regiões dos Estados Unidos, o 
que gera incertezas na análise dos resultados desse índice. Na tentativa de minorar essa deficiência, Wells et al. (2004) desenvolveram o self-calibrating PDSI (sc-PDSI), a partir da proposição de uma técnica que calcula os pesos com base nas características do clima da localidade avaliada.

Essa nova metodologia permite que os cálculos do PDSI sejam baseados no conjunto de dados de déficit de umidade e não apenas nas características climáticas de determinadas localidades. A sequência das etapas necessárias para sua obtenção desse índice é apresentada a seguir.

1) Calcular os déficits de umidade;

2) Calcular as anomalias de umidade utilizando o peso $K^{\prime}$;

3) Calcular os fatores de duração utilizando as anomalias de umidade calculadas na etapa 2, por meio da calibração do índice com a categoria das secas extremas;

4) Calcular o PDSI utilizando os dados computados nos passos 2 e 3;

5) Determinar os valores dos $2^{\circ}$ e o $98^{\circ}$ percentiles do PDSI;

6) Determinar os novos valores das anomalias de umidade com os dados do procedimento 5;

7) Calcular o sc-PDSI;

O índice de precipitação-evapotranspiração padronizado (no inglês, Standardized Precipitation Evapotranspiration Index - SPEI), de acordo com Vicente-Serrano (2009), surgiu a partir da ideia de tentar combinar a sensibilidade do PDSI em relação às variações da evapotranspiração, já que o mesmo considera dados de temperatura, e a simplicidade do SPI, que permite a realização de análises em diversas escalas de tempo.

A composição desse índice é feita a partir da verificação do balanço hídrico climatológico (D) por meio da diferença, como mostra a equação 8 , entre a precipitação $(\mathrm{P})$ e a evapotranspiração potencial (PET). A última variável, como ocorre no PDSI, também é calculada pela equação de Thornthwaite. Como o cálculo do SPEI se baseia na metodologia proposta para o SPI, os resultados do balanço hídrico são agregados em diferentes escalas de tempo. 


$$
D_{i}=P_{i}-P E T_{i}
$$

Uma diferença para o SPI, é que no cálculo do SPEI os valores de D são ajustados à uma distribuição à distribuição log-logística modificada de probabilidade, a qual possui três parâmetros, permitindo que a diferença entre a precipitação e a evapotranspiração potencial assuma valores negativos.

\subsection{2- Seca Hidrológica}

$\mathrm{Na}$ análise da seca hidrológica, é importante o entendimento do comportamento das séries temporais de vazão, em virtude de essa variável ser capaz de incorporar a resposta de diferentes subsistemas que influência nesse tipo de seca, como o escoamento superficial e o fluxo de base proveniente dos aquíferos.

Um exemplo de metodologia que faz uso dessa variável na indicação da ocorrência de secas hidrológicas é o threshold level method (TLM). Esse conceito baseia-se na ideia de que a seca ocorre quando o suprimento de água - $\mathrm{S}(\mathrm{t})$ - é inferior à demanda $-\mathrm{D}(\mathrm{t})$ - sendo esse evento, portanto, definido como o período em que a vazão é inferior a um nível de referência. As variáveis utilizadas por esse método são apresentadas na Figura 3 , sendo $\mathrm{Q}_{z}$ o nível de referência, $t_{i}$ o tempo em que a seca se inicia, $d_{i}$ a duração, $v_{i}$ é o déficit de volume ou a severidade e $\mathrm{Q}_{\min , \mathrm{i}}$ o fluxo mínimo durante o evento.

A definição do nível de referência no TLM deve estar associada aos valores de demanda por água necessária para o desenvolvimento de atividades realizadas na área estudada ou a fronteira existente entre as vazões normais e baixas. No caso da segunda opção, pode-se adotar os percentiles da curva de permanência das vazões. Segundo Fleig et al. (2006), constantemente são empregados os valores do $\mathrm{Q}_{75}$ e $\mathrm{Q}_{90}$, quando se estuda rios perenes por meio do TLM. Já nos sistemas intermitentes, deve-se considerar o período em que o rio tem vazão nula. 


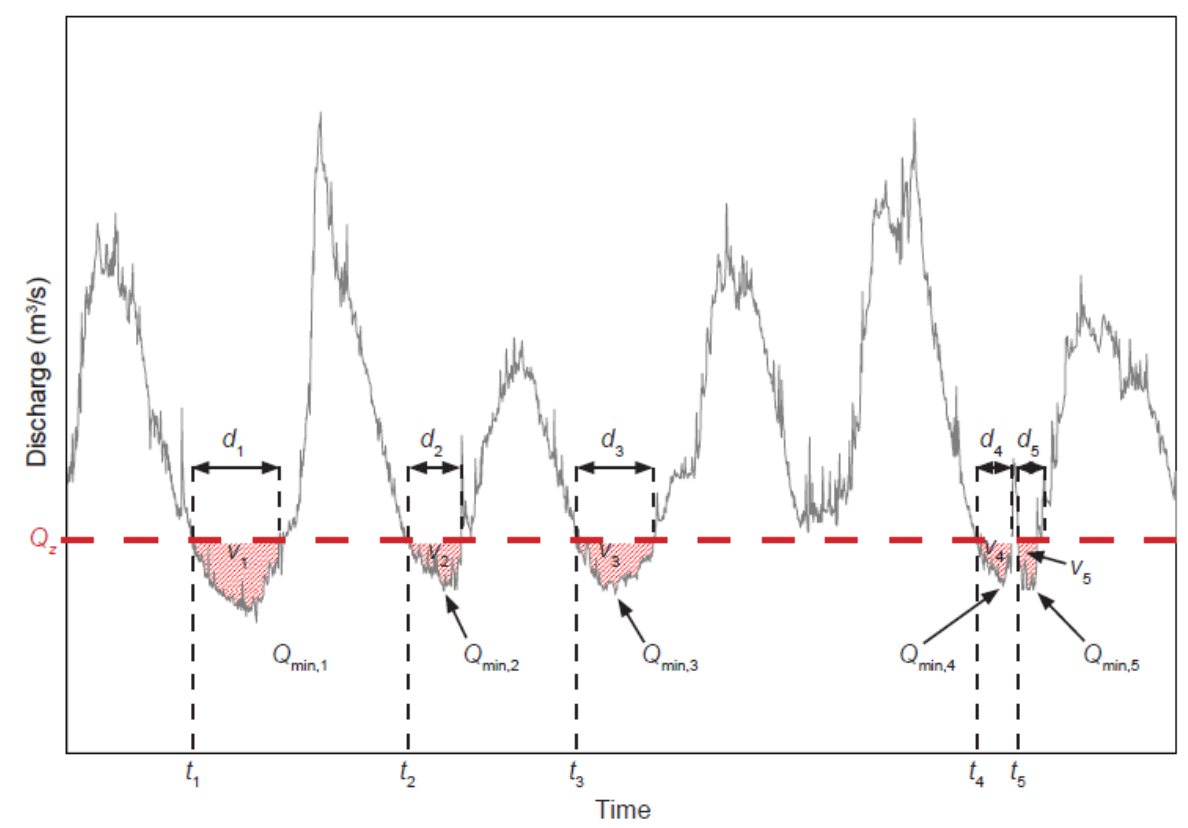

Figura 3 - Características do método do nível de referência (Fonte: Fleig et al., 2006).

O índice de abastecimento de água em superfície (no inglês, Surface Water Supply Index SWSI) foi desenvolvido na tentativa de indicar a deficiência de água em regiões dos Estados Unidos onde o degelo é a principal fonte hídrica. O SWSI surgiu a partir da constatação de que PDSI, apesar de ser largamente adotado em estudos nos Estados Unidos, não mostrou eficiência ao ser aplicado em regiões com uma elevada acumulação de neve.

Um grande advento do SWSI é a utilização do conceito de probabilidade mensal de não excedência, o que permite o acompanhamento da disponibilidade hídrica em diferentes regiões. Ao expressar o abastecimento de água como uma probabilidade obtida a partir da distribuição histórica dos dados, dá-se a mesma importância para todas as áreas.

Segundo Shafer e Dezman (1982), para realizar o cálculo do SWSI é necessário seguir os seguintes passos:

1) Somar os dados mensais de cada estação que consideram a água proveniente de reservatórios de armazenamento de água, neve e precipitação, obtendo uma base de dados composta.

2) Padronizar esses dados para uma única escala, a probabilidade de não excedência (PN), a partir da quantificação da frequência dos dados. 
3) As probabilidades encontradas são utilizadas, juntamente com pesos na Equação 9, que calcula o SWSI da bacia avaliada.

$$
S W S I=\frac{\left[\left(a \cdot P N_{S P}\right)+\left(b \cdot P N_{P C P}\right)+\left(c \cdot P N_{R S}\right)-50\right]}{12}
$$

em que a, b e c são os pesos de cada componente, que são característicos para cada bacia, os quais devem obedecer a condição de que $a+b+c=1$, SP, PCP e RS se referem à água proveniente da neve, precipitação e reservatórios.

Destaca-se que, durante os períodos de verão, os valores das probabilidades de não excedência das vazões dos córregos $\left(P N_{S F}\right)$ podem substituir o componente referente à neve na equação do SWSI. A determinação dos pesos de cada parcela das probabilidades está relacionada ao impacto gerado por esses componentes na disponibilidade de água na bacia. A escala de variação do SWSI, juntamente com a definição da situação caracterizada por esses valores é apresentada na Tabela 3.

Tabela 3 - Caracterização dos valores do SWSI (Fonte: Shafer e Dezman 1982, modificada).

\begin{tabular}{|c|c|}
\hline \multicolumn{2}{|c|}{ Escala SWSI } \\
\hline Valor & Descrição \\
\hline$+4-+2$ & Suprimento em abundancia \\
\hline$+2--2$ & Próximo ao normal \\
\hline$-2--3$ & Seca moderada \\
\hline$-3--4$ & Seca severa \\
\hline-4 ou inferior & Seca extrema \\
\hline
\end{tabular}

Um problema associado ao uso do SWSI é a subjetividade na determinação do conjunto de pesos das probabilidades. A inexistência de um critério especifico para a definição dessas variáveis impossibilita a sua optimização.

Ao se estudar o fenômeno da seca, percebe-se que o mesmo é influenciado por uma grande variedade de processos físicos, os quais, muitas vezes, não são medidos. Esses parâmetros, 
porém, podem ser simulados com o auxílio de modelo hidrológicos, sendo o hydrologic model soil and water assessment tool (SWAT) um exemplo desse tipo de ferramenta.

De forma simplificada, segundo Abbaspour et al. (2006), o SWAT é um modelo semidistribuído, contínuo no tempo, que analisa, em um passo de tempo diário, o impacto de políticas de gestão e da ação do clima nos recursos hídricos. Espacialmente, o SWAT divide a área analisada em unidades menores, as quais são conhecidas como unidades de resposta hidrológica (no inglês, Hydrologic Response Unit - HRUs), nas quais se verifica a mesma declividade, uso do solo e tipo de solo. Em virtude dessa variabilidade espacial, o balanço hidrológico é aplicado para cada HRU, gerando o volume de diversos compostos e variáveis, como nutrientes e escoamento, os quais são posteriormente somados.

Narasimhan e Srinivasan (2005) utilizaram o modelo SWAT na composição de alguns índices de seca, como o índice de deficiência de umidade do solo (no inglês, Soil Moisture Deficit Index - SMDI).

O SMDI faz uma média, a cada sete dias, dos valores diários da capacidade de água disponível no solo, os quais foram fornecidos pelo modelo SWAT para cada uma das subbacias analisadas. Esse procedimento é realizado para as 52 semanas do ano.

Esses cálculos são feitos para um período de 70 anos, sendo posteriormente determinadas a mediana, que é utilizada para representar o valor normal da capacidade de armazenamento de água no solo, e os valores máximos e mínimos. A partir dessas informações, calcula-se o percentual semanal de déficit de umidade do solo, a partir das Equações 10 e 11, e o valor do SMDI, segundo a Equação 12.

$$
\begin{gathered}
S D_{i, j}=\frac{S W_{i, j}-M S W_{j}}{M S W_{j}-\operatorname{minS} W_{j}} \times 100 \text { se } S W_{i, j}=M S W_{j} \\
S D_{i, j}=\frac{S W_{i, j}-M S W_{j}}{\max S W_{j}-M S W_{j}} \times 100 \text { se } S W_{i, j}>M S W_{j} \\
S M D I_{j}=S M D I_{j-1}+\frac{S D_{j}}{50}-0,5 S M D I_{j-1}
\end{gathered}
$$


em que $\mathrm{SD}_{\mathrm{i}, \mathrm{j}}$ é a deficiência de agua no solo (\%), $\mathrm{SW}_{\mathrm{i}, \mathrm{j}}$ é a média semanal de água no solo $(\mathrm{mm}), \mathrm{MSW}_{\mathrm{j}}$ é a mediana de longo termo da quantidade de água disponível no solo $(\mathrm{mm})$, $\max _{\mathrm{j}}$ é o máximo de longo termo de água disponível no solo $(\mathrm{mm})$, minSWj é o mínimo de longo termo de água disponível no solo (mm).

Keyantash e Dracup (2004) formularam um índice, o aggregate drought index (ADI), capaz de trabalhar com variáveis relacionadas aos três tipos principais de seca: meteorológica, agrícola e hidrológica. A proposta dessa ferramenta é correlacionar variáveis com diferentes unidades, as quais representam as parcelas de água contidas em diferentes sistemas.

A obtenção do ADI utiliza, como dados de entrada, os valores de seis grandezas que fazem parte do ciclo hidrológico de uma área: precipitação, evapotranspiração, vazão, volume armazenado dos reservatórios, umidade do solo e neve. A esse conjunto de parâmetros é aplicada a técnica estatística de componentes principais (PCs), que tenta, por meio de combinações lineares, reduzir o volume de informações e criar uma nova matriz de dados, que acumula o máximo de informações relacionadas à variação dos dados iniciais. Esses cálculos permitem, segundo Keyantash e Dracup (2004), a identificação das informações hidrológicas dominantes dos dados observados.

A fim de determinar a intensidade da seca associada aos valores do ADI, Keyantash e Dracup (2004) propuseram que determinados percentiles da função cumulativa de distribuição de probabilidade desse índice representassem os limiares das classes de severidade das secas. Portanto, baseando-se nos valores de referência para a severidade da seca do SPI definidos pelo Centro Nacional de Mitigação de Seca dos Estados Unidos (-2, 0, 1,5 e -1), fixou-se que os valores do segundo, do sétimo e o décimo sexto percentiles representariam esses limites. Um exemplo dessas divisões é apresentado na Figura 4. 


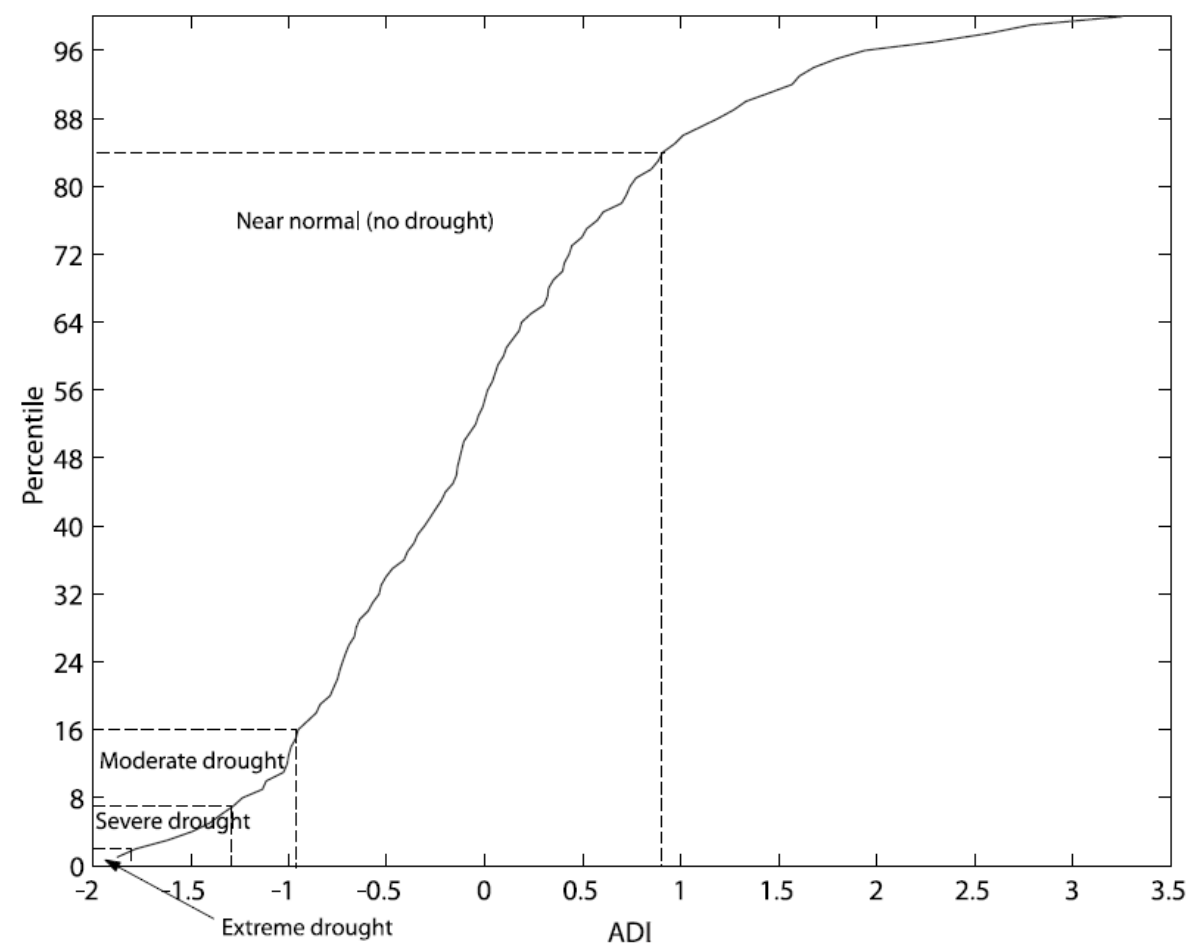

Figura 4 - Percentiles do ADI característicos de San Joaquin Drainage, na Califórnia (Fonte: Keyantash e Dracup, 2004).

\subsection{3- Seca Agrícola}

Palmer também foi responsável pela introdução de uma ferramenta que é largamente utilizado na identificação da seca agrícola, o índice de umidade da cultura (no inglês, Crop Moisture Index - CMI). Ele verifica a variação da umidade de curto prazo do solo por meio da obtenção de dados semanais de precipitação e temperatura. Esses resultados são comparados com as médias de longo prazo, sendo, posteriormente, trabalhados com a utilização de relações empíricas para obter o valor do CMI.

Como foi feito no trabalho de Palmer, no cálculo do CMI, a temperatura é utilizada para calcular a evapotranspiração potencial pela fórmula de Thornthwaite. Outra similaridade com os índices de Palmer é o modelo adotado para quantificar as variáveis hidrológicas, que é semelhante ao utilizado no desenvolvimento desses índices.

Deve-se tomar cuidado para não adotar essa metodologia quando se objetiva monitorar secas de logo prazo, em virtude de ele ser sensível à variação de condições de curto prazo. Hein (2002) destaca que o CMI resulta em melhores resultados quando é aplicado para a 
avaliação da seca agrícola durante a estação úmida, isto é, a fase de desenvolvimento da cultura.

Juhasz e Kornfield (1978) observaram, por meio da análise das equações do CMI, que uma elevação no valor desse índice, que deveria estar relacionada a uma taxa de umidade maior, pode ser desencadeada pelo aumento da evapotranspiração potencial. Essa relação não está de acordo com as leis físicas, já que uma elevação dessa grandeza deve desencadear uma redução da umidade disponível.

Uma sugestão feita para evitar essa inconsistência foi à utilização da diferença entre as razões dos valores semanais da evapotranspiração do período e seu valor potencial, com os valores dessas grandezas em condições climatologicamente normais, para se obter a anomalia da evapotranspiração, como mostrado na equação 13.

$$
D E=f(E T / P E-\overline{E T} / \overline{P E})
$$

A possibilidade de aumentar a disponibilidade de dados e de reduzir os erros embutidos nos mesmos estimulou a elaboração de índices de vegetação que utilizassem informações coletadas por satélites. Essas ferramentas também são frequentemente utilizadas em estudos de caracterização das secas.

Um exemplo bastante conhecido em que esses dados são adotados, é o índice de vegetação por diferença normalizada (no inglês, Normalized Difference Vegetation Index - NDVI), que averigua a condição de saúde da vegetação por meio de operações aritméticas realizadas em imagens provenientes de sistemas de sensoriamento remoto. Essa forma de processamento de informações é feito por meio da combinação de imagens, dando origem a uma nova matriz de dados, em virtude das operações serem realizadas em cada pixel.

Para a obtenção do NDVI emprega-se a equação 14. A mesma se baseia na capacidade das plantas, em condições saudáveis, de absorver grandes quantidades de radiação eletromagnética, cujo comprimento de onda está situado na região visível da luz vermelha (R), e de ter uma elevada refletância do infravermelho próximo (NIR). É importante destacar que, frequentemente, o cálculo do NDVI deve ser seguido pela aplicação de uma técnica capaz de reduzir o ruído das imagens. Esses problemas são definidos como um erro 
no valor digital do pixel que compõe a imagem, gerado pela presença de nuvens e o posicionamento do satélite, dentre outros fatores.

$$
N D V I=\frac{N I R-R}{N I R+R}
$$

Outro importante instrumento de detecção da seca é o índice de condição da vegetação (no inglês, Vegetation Condition. Index - VCI), o qual foi desenvolvido pela National Oceanic and Atmospheric Administration (NOAA). A produção do VCI se deu a partir da percepção de que os valores do NDVI eram influenciados pelas condições climáticas e ecológicas de cada região avaliada. Entretanto, quando Kogan (1995) quantificou a ação desses dois fatores nos valores do NDVI para diversas regiões dos Estados Unidos, ele percebeu que, em áreas com maior incidência de vegetação, a parcela ecológica de contribuição no NDVI era significativamente superior à climática. Assim, elaborou-se a equação 15, que aumenta a influência do componente climático no cálculo do NDVI.

$$
V C I=100 \cdot\left(N D V I-N D V I_{\min }\right) /\left(N D V I_{\max }-N D V I_{\min }\right)
$$

em que NDVI, NDVI $I_{\max }$ e NDVI $I_{\min }$ são os valores calculados para cada pixel do NDVI suavizados e os valores máximo e mínimo do mesmo.

O remotely sensed global drought index (DSI) se baseia em dados provenientes de um instrumento conhecido como MODIS (Espectroradiômetro de Resolução de Imagem Moderada), o qual está acoplado aos satélites Terra e Aqua da National Aeronautics and Space Administration's (NASA's). Para obter esse índice, inicialmente, calcula-se a evapotranspiração real (ET) e a potencial (PET) a partir do modelo MODIS ET. Depois se associam os resultados do MODIS ET/PET e do MODIS NDVI, para obter o valor do DSI, o qual pode ter uma escala de tempo de oito dias, mensal e anual, além de uma resolução espacial de $1 \mathrm{Km}$.

Os valores da ET e da PET são utilizados para obter uma razão, como mostrado na equação 16, que, segundo Mu et al. (2013), pode indicar a disponibilidade terrestre de água e, assim, ser correlacionada à seca. As equações 17 a 20 mostram os demais cálculos envolvidos na obtenção do DSI, que oscila entre $-\infty$ a $+\infty$, onde a primeira situação identifica condições mais secas que o normal e a segunda as mais úmidas. 


$$
\begin{gathered}
\text { Ratio }=\frac{E T}{P E T} \\
Z_{\text {Ratio }}=\frac{\text { Ratio }-\overline{\text { Ratlo }}}{\sigma_{\text {Ratio }}} \\
Z_{N D V I}=\frac{N D V I-\overline{N D V I}}{\sigma_{N D V I}} \\
Z=Z_{\text {Ratio }}+Z_{N D V I} \\
D S I=\frac{z-\bar{z}}{\sigma_{z}}
\end{gathered}
$$

em que $\sigma_{\text {Ratio }}$ e $\overline{\text { Ratıo }}$ são respectivamente o desvio padrão e a média do Ratio, calculados

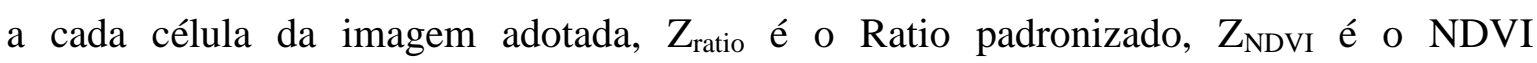
padronizado e o DSI é o valor da padronização de Z.

A capacidade de detecção da seca, como vista nos índices anteriores, deve incluir a caracterização da severidade de cada evento. Com esse objetivo, foi elaborada uma escala dos valores do DSI, segundo as categorias de severidade do PDSI, a qual é apresentada nas Tabelas 4 e 5.

Tabela 4 - Definição da severidade dos períodos úmidos (Fonte: Mu et al. 2013, modificado).

\begin{tabular}{|c|c|c|c|}
\hline \multicolumn{4}{|c|}{ Períodos úmidos } \\
\hline Categoria & Descrição & PDSI & DSI \\
\hline W5 & Umidade extrema & 4,00 ou maior & 1,5 ou maior \\
\hline W4 & Muito úmido & 3,00 a 3,99 & 1,2 a 1,49 \\
\hline W3 & Umidade moderada & 2,00 a 2,99 & 0,9 a 1,19 \\
\hline W2 & Ligeiramente úmida & 1,00 a 1,99 & 0,60 a 0,89 \\
\hline W1 & Fraco período úmido & 0,50 a 0,99 & 0,30 a 0,59 \\
\hline WD & Próximo ao normal & 0,49 a $-0,49$ & 0,29 a $-0,29$ \\
\hline
\end{tabular}


Tabela 5 - Definição da severidade dos períodos secos (Fonte: Mu et al. 2013, modificado).

\begin{tabular}{|c|c|c|c|}
\hline \multicolumn{4}{|c|}{ Períodos secos } \\
\hline Categoria & Descrição & PDSI & DSI \\
\hline D1 & Seca fraca & $-0,50$ a $-0,99$ & $-0,30$ a $-0,59$ \\
\hline D2 & Seca média & $-1,00$ a $-1,99$ & $-0,60$ a $-0,89$ \\
\hline D3 & Seca moderada & $-2,00 \mathrm{a}-2,99$ & $-0,90 \mathrm{a}-1,19$ \\
\hline D4 & Seca severa & $-3,00 \mathrm{a}-3,99$ & $-1,20 \mathrm{a}-1,49$ \\
\hline D5 & Seca extrema & $\leq-4,00$ & $\leq-1,50$ \\
\hline
\end{tabular}

\subsection{4- Índice Elaborado para a Região Nordeste}

Uma pesquisa realizada por Sun et al. (2006) relatou que estudos anteriores mostraram que variações diárias da precipitação podem afetar a produtividade de culturas de milho. Sun et al. (2006), também observou que o comprimento do veranico na região do Sertão Central geralmente varia de 3 a 15 dias. Esses períodos são caracterizados por baixos níveis de precipitação em relação ao esperado, que persistem por mais de dez (10) dias, sendo capazes de induzir as plantações de milho a um estresse hídrico, devido à redução da disponibilidade de água no solo.

Baseando-se nessas proposições, Sun et al. (2006) desenvolveram um índice que tenta reconhecer a ação da seca sobre as culturas de milho. Essa ferramenta caracteriza, os períodos secos como intervalos de tempo em que a precipitação diária é inferior a 2 $\mathrm{mm} /$ dia, sendo a severidade descrita pela equação 21 .

$$
D=\sum_{i=1}^{n} L_{i} W
$$

em que $n$ é o número total de períodos secos em um ano, $\mathrm{L}_{\mathrm{i}}$ é o comprimento do enésimo período seco em dias, $\mathrm{W}=1$, se $\mathrm{L}_{\mathrm{i}}<11$ e $\mathrm{W}=5$, se $\mathrm{L}_{\mathrm{i}} \geq 11$.

Destaca-se que o $\mathrm{L}_{\mathrm{i}}$ pode ser interpretado como o peso dado a cada período seco. Assim, as secas que perduram por mais tempo em uma região, terão uma maior importância, em virtude dos danos que elas causam à produção agrícola serem mais significativos. 


\section{4- ALGUMAS APLICAÇÕES REAIS DOS ÍNDICES DE SECA}

\subsection{1- Iniciativas nos Estados Unidos}

Ao se realizar uma pesquisa bibliográfica sobre os índices de seca, verifica-se a existência de uma grande gama de estudos que apresentam as vantagens e desvantagens dessas ferramentas. O mesmo não se pode dizer, entretanto para a elaboração de pesquisas que analisam estatisticamente quais são os melhores índices para cada região e condições especificas.

Tentando compor um banco de dados de maior qualidade, já que os fatores que influenciam na incidência da seca e de seus impactos ocorrem de forma integrada, diversos países estão tentando criar um sistema conjunto de acompanhamento da seca.

Essa problemática impulsionou a realização, dentre outras conferências, da Inter-Regional Workshop on Indices and Early Warning Systems for Drought, onde se reuniram os representantes de países que fazem parte da Organização Meteorológica Mundial (WMO). Durante as reuniões, tentou-se definir quais eram os melhores índices que deveriam ser adotados no estudo de cada tipo de seca, os mesmos são apresentados na Tabela 6 .

Tabela 6 - Melhores índices para cada tipo de seca.

\begin{tabular}{|c|c|}
\hline Tipos de seca & Melhores Índices \\
\hline Meteorológica & $\begin{array}{l}\text { SPI, PN, índice de umidade do solo, percentile ranking methods (decils e } \\
\text { quartis), PDSI e índice K }\end{array}$ \\
\hline Hidrológica & $\begin{array}{c}\text { Nível do reservatório, PN, SPI, SWSI, Aggregate dryness index (ADI), ADI } \\
\text { normalizado, NADI e índice de fluxo de base }\end{array}$ \\
\hline Agrícola & Índice de umidade do solo, PN, NDVI, balanço de agua, estresse hídrico \\
\hline
\end{tabular}

A aplicação desses índices já pode ser verificada em diversos países. Um importante exemplo dessas iniciativas é um projeto criado a partir de uma associação entre entidades dos Estados Unidos - o Centro Nacional de Mitigação de Seca (NDMC), o Departamento de Agricultura dos Estados Unidos (USDA) e a National Oceanic and Atmospheric Administration (NOAA) - que utiliza diversos índices de seca na composição de uma ferramenta que auxilia no processo de tomada de decisão. 
Essa proposta é conhecida como monitor de seca, que se fundamentou na elaboração de critérios de classificação desse fenômeno, os quais são utilizados em mapas e textos que caracterizam as secas. O desenvolvimento dessa ferramenta foi fortemente impulsionado pela assinatura do Ato da Política Nacional de Secas e, posteriormente, pela formação da Comissão Nacional de Política de Seca (NDPC) dos Estados Unidos.

As instituições contratadas para fornecer as informações necessárias para a composição dos índices utilizados no monitor foram a National Weather Service e os seis centros regionais de clima da NOAA. O resultado desses trabalhos, segundo Svododa (2000), foram mapas semanais, como o mostrado na Figura 5, que apresentam as regiões dos Estados Unidos onde se verifica a ocorrência de vários graus de seca, além de uma narrativa que descreve os impactos desencadeados por esse fenômeno, as ameaças futuras e as perspectivas de melhorias.

Svododa et al. (2000) cita que os principais parâmetros utilizados na composição desse mapa são o PDSI, o CPC soil moisture model percentiles, US geological survey daily streamflow percentiles, a precipitação porcentagem normal, o SPI e o remotely sensed satellite vegetation health index.

A partir da análise da Figura 5, percebe-se a existência de uma escala, descrita na Tabela 7, que caracteriza os diversos tipos de seca e varia de zero a quatro (D0 a D4). A primeira classe indica a incidência de uma seca anormal, já na última, a região está vivenciando um evento de seca excepcional. A escala D0, apesar de ser a menos intensa, mostra uma área que está se dirigindo para a ocorrência da seca ou se recobrando desse fenômeno, mas ainda vivenciando alguns impactos.

Outra classificação feita pelo monitor tenta enquadrar os principais impactos gerados pela seca em determinados setores da sociedade. As classes são A, W e F, onde a primeira está associada à agricultura, a segunda à água, onde são alocados os impactos hidrológicos, e à última indica um elevado risco de incêndio. Além da identificação e do acompanhamento do processo de seca, essa ferramenta também se preocupou em permitir a previsão do comportamento desse fenômeno, ao informar se a seca que está ocorrendo nas diversas regiões do país é de curto prazo, perdurando por menos de seis (6) meses, ou de longo prazo, caso ela persista por períodos maiores. 
U.S. Drought Monitor

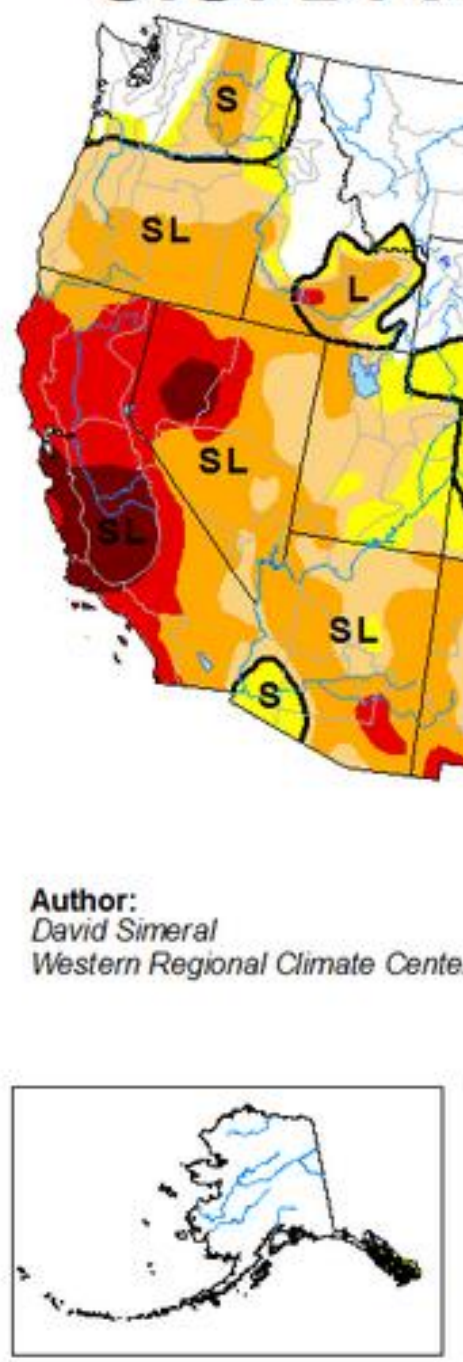

March 25, 2014

(Released Thursday, Mar. 27, 2014) Valid 8 a.m. EDT

Figura 5 - Exemplo do monitor de secas (Fonte: http://droughtmonitor.unl.edu/). 
Tabela 7 - Classificação da severidade da seca segundo o Monitor de Secas (Fonte: Svododa 2000, modificado).

\begin{tabular}{|c|c|c|c|c|c|c|c|c|}
\hline Categoria & Descrição & Impactos & $\begin{array}{c}\text { PDSI ou } \\
\text { CMI }\end{array}$ & $\begin{array}{c}\text { CPC Soil } \\
\text { Moisture } \\
\text { Models } \\
\text { (percentiles) }\end{array}$ & $\begin{array}{c}\text { Daily } \\
\text { Streamflow } \\
\text { (percentiles) }\end{array}$ & $\mathrm{PN}$ & $\begin{array}{c}\text { USDA/NASS } \\
\text { Topsoil } \\
\text { Moisture (\% } \\
\text { short \& very } \\
\text { short) }\end{array}$ & $\begin{array}{c}\text { Satelite } \\
\text { Vegetation } \\
\text { Health Index }\end{array}$ \\
\hline D0 & $\begin{array}{c}\text { Anormalmente } \\
\text { seco }\end{array}$ & $\begin{array}{l}\text { Seca de curto prazo reduz o } \\
\text { plantio, o crescimento das } \\
\text { culturas e o pasto de forma } \\
\text { lenta, risco de fogo acima da } \\
\text { média ou recente recuperação } \\
\text { da seca, a existência de } \\
\text { alguns déficits de agua } \\
\text { remanescentes, pasto não } \\
\text { cobertos completamente }\end{array}$ & $-0,6--1,9$ & $21-30$ & $21-30$ & $\begin{array}{c}<50 \% 30 \\
\text { dias }\end{array}$ & $25-50 \%$ & $36-45$ \\
\hline D1 & Seca & $\begin{array}{c}\text { Alguns danos nas culturas e } \\
\text { pastos, risco elevado de fogo, } \\
\text { córregos, reservatórios ou } \\
\text { poços baixos, algum } \\
\text { desenvolvimento da escassez } \\
\text { de agua ou restrições de agua } \\
\text { em algumas localizações }\end{array}$ & $-2,0--2,9$ & $11-20$ & $11-20$ & $\begin{array}{c}50-60 \% \\
2-3 \text { meses }\end{array}$ & $51-65 \%$ & $26-35$ \\
\hline
\end{tabular}


Tabela 7. Continuação.

\begin{tabular}{|c|c|c|c|c|c|c|c|c|}
\hline D2 & Seca severa & \begin{tabular}{|} 
Cultura moderada, possíveis \\
perdas no pasto, risco de fogo \\
muito elevado, escassez \\
comum de agua ou a \\
imposição de restrições em \\
muitas áreas
\end{tabular} & $-3--3,9$ & $6-10$ & $6-10$ & $\begin{array}{c}40-50 \% 3 \\
-4 \text { meses }\end{array}$ & $66-80 \%$ & $16-25$ \\
\hline D3 & Seca extrema & $\begin{array}{l}\text { Principais perdas de cultura } \\
\text { ou pasto, risco extremo de } \\
\text { fogo, generalização da } \\
\text { escassez ou restrições de agua }\end{array}$ & $-4,0--5,0$ & $2-5$ & $2-5$ & $\begin{array}{c}30-40 \% 4 \\
-5 \text { meses }\end{array}$ & $81-90 \%$ & $6-15$ \\
\hline D4 & $\begin{array}{c}\text { Seca } \\
\text { excepcional }\end{array}$ & $\begin{array}{c}\text { Excepcionais e generalizadas } \\
\text { perdas da cultura e pasto, } \\
\text { excepcional risco de fogo, } \\
\text { escassez de agua nos } \\
\text { reservatórios, córregos, poços } \\
\text { criando uma situação de } \\
\text { emergência }\end{array}$ & $\begin{array}{l}-5,0 \text { ou } \\
\text { menos }\end{array}$ & $0-1$ & $0-1$ & $\begin{array}{c}<40 \% 6 \\
\text { meses }\end{array}$ & $>90 \%$ & $1-5$ \\
\hline
\end{tabular}




\subsection{2- Iniciativas na Europa}

Outra região que também demonstra preocupação com a seca é o continente Europeu, onde foi criado o Observatório de Seca Europeu, que é considerado uma referência de informação e desenvolvimento de sistemas de conhecimento das secas. Essa iniciativa impulsionada, segundo Gregoric e Susnik (2015), por uma grande onda de calor que ocorreu em 2003 e afetou uma região de largas proporções na Europa. Posteriormente, em 2006, foi criado o Centro do Sudeste Europeu de Gestão da Seca (no inglês, Drought Management Centre for South-Eastern Europe - DMCSEE). Essa entidade é formada por uma rede de colaboração que tenta aumentar a resiliência de comunidades europeias aos impactos gerados pelas secas.

O DMCSEE elaborou uma plataforma virtual que reúne diversas informações e mapas utilizados no monitoramento e detecção das secas no Sudeste Europeu. Uma das ferramentas disponíveis na base de dados do DMCSEE é apresentada na Figura 6, que mostra a graduação das secas que estão incidindo sobre o Sudoeste Europeu, segundo o SPI trimestral, em maio de 2015.

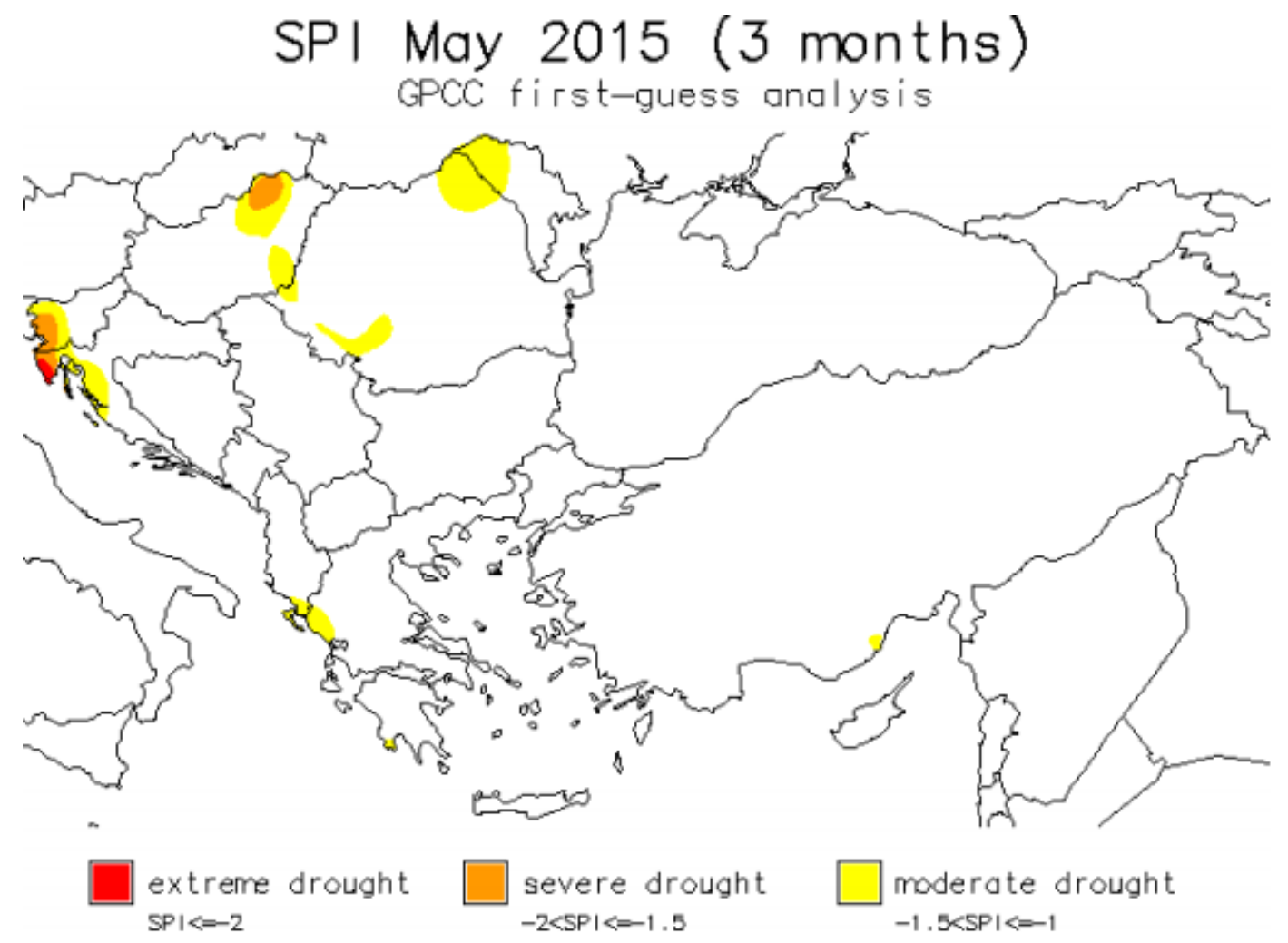

Figura 6 - Caracterização das secas no Sudoeste Europeu, segundo o SPI trimestral, calculado em maio de 2015 (Fonte: DMCSEE, 2015). 
Um exemplo de pesquisas relacionadas à caracterização das secas na Europa foi a desenvolvida por Hannaford et al. (2010). Esses pesquisadores elaboraram ferramentas que tentaram possibilitar a redução dos impactos desencadeados pela seca por meio de um maior conhecimento dos processos associados a esse fenômeno.

Para a composição dessa pesquisa, dados diários de vazão oriundos de 579 estações distribuídas em países europeus foram agrupados, para avaliar as secas, com a utilização de dois índices, o RDI e o RSPI. Hannaford et al. (2010) afirmam que, apesar das diverenças entre esses dois índices, ambos permitem a comparação entre áreas com diferentes características climáticas, além de incorporarem a variabilidade do regime de fluxo de rios e das chuvas.

Um dos produtos desse trabalho é apresentado na Figura 7. A mesma mostra os valores do RDI e RSPI em algumas regiões da Europa, além da quantificação da correspondência entre esses índices, por meio dos valores do coeficiente de correlação linear de Pearson $(\rho)$.
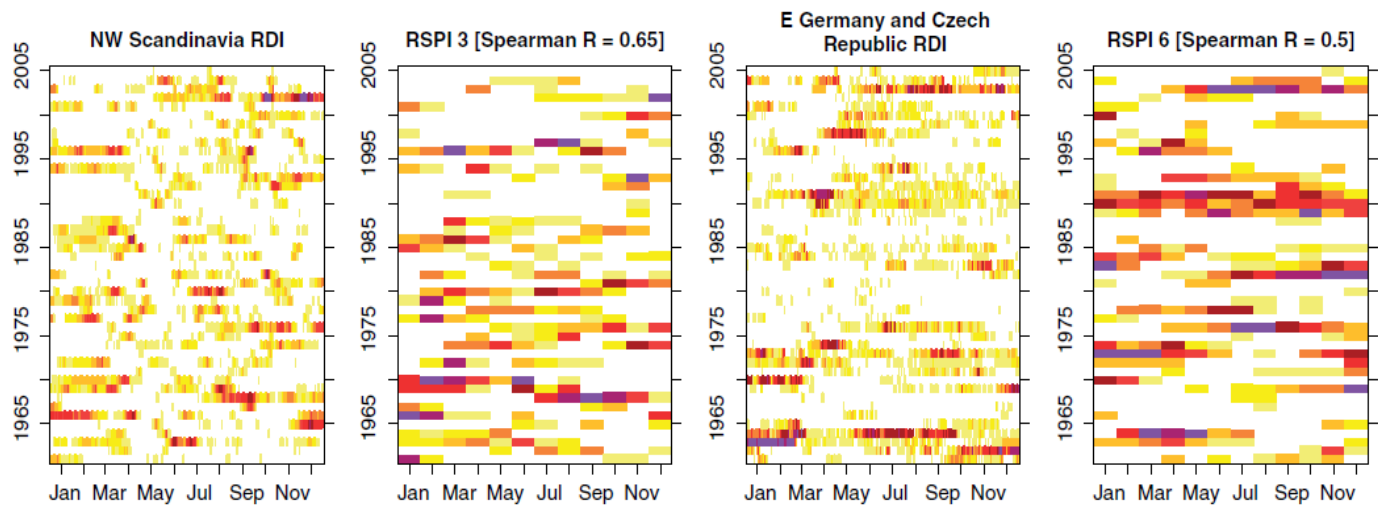

Figura 7 - Distribuição da porção de área afetada pela seca na Europa segundo o RDI e o RSPI (Fonte: Hannaford et al. 2010).

Os resultados obtidos nas avaliações exemplificadas pela Figura 7, sugerem que esses índices sejam capazes de caracterizar as secas meteorológicas e hidrológicas em uma escala regional. Essa verificação possibilitou a realização de estudos em grande escala, quando se percebeu que algumas regiões apresentavam elevados valores de RDI e RSPI durante o mesmo período de tempo.

Esses resultados podem ser utilizados para auxiliar no desenvolvimento de sistemas de alerta precoce. Como a seca normalmente se propaga lentamente, caso uma região já esteja 
sujeita a esse fenômeno, outras áreas, que apresentem uma coerência com a mesma, podem ser avisadas sobre os possíveis riscos.

\section{5- CARACTERÍSTICAS DOS ÍNDICES DE SECA}

Ao se fazer uma revisão bibliográfica dos índices de seca, percebe-se que existe uma grande variedade de metodologias que se propõem a identificar esse fenômeno. Como apresentado anteriormente, em geral, esses índices caracterizam as secas por meio da determinação da sua severidade, a qual será explicada no item a seguir.

Muitas dessas ferramentas, entretanto, foram desenvolvidas com base em características de determinadas regiões, o que restringe a sua larga aplicação. Outro fator que limita o uso dos índices é o fato de que, a maior parte dos autores, não faz algumas considerações iniciais, antes da elaboração dessas ferramentas, como o propósito do índice e o público que o mesmo está direcionado.

$\mathrm{Na}$ tentativa de melhorar a aplicabilidade desses índices, Redmond (2002) listou algumas questões que deveriam ser verificadas ao longo da composição dos mesmos, como a verificação da disponibilidade dos dados e a importância de avaliar previamente as propriedades estatísticas utilizadas nos cálculos.

Na tentativa de simplificar essa análise, em virtude da grande complexidade dos eventos de seca, Keyantash e Dracup (2002) propuseram alguns critérios para determinar a utilidade dos índices: robustez, trabalhabilidade, transparência, sofisticação, extensibilidade e dimensionalidade.

\subsection{1- Severidade}

Como visto anteriormente, normalmente, os índices caracterizam a seca por meio da definição da sua severidade (S). Essa métrica é obtida a partir do produto entre a duração (D) - período de tempo em que os valores do índice de seca são inferiores a um nível de referência - e a magnitude (M) média verificada ao longo do período de incidência da seca, como mostra a Figura 8. 


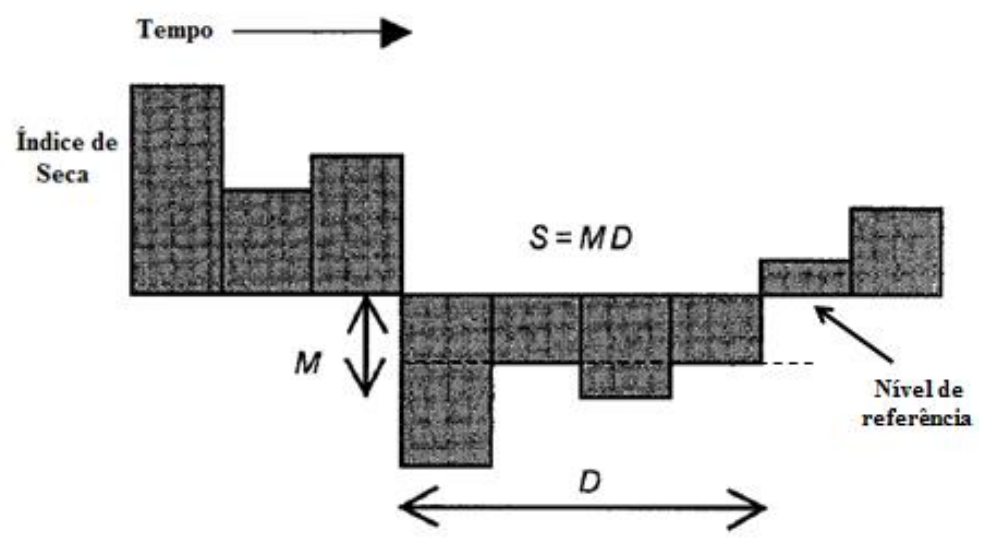

Figura 8 - Definição da severidade da seca (Fonte: Keyantash e Dracup 2002, modificado).

\subsection{2- Robustez}

A definição estatística de robustez é a capacidade de um determinado método, por exemplo, de não variar frente a pequenos desvios dos fatores que nele influenciam.

No que se refere à seca, como esse fenômeno é capaz de afetar diversos segmentos da sociedade, estando sua ocorrência associada a uma grande diversidade de fatores, como meteorológicos, hidrológicos e socioeconômicos, para identificar suas várias formas, o índice, deve, portanto, ser capaz de perceber as alterações desses parâmetros.

A robustez está, assim, associada à utilidade do índice frente à vasta gama de condições físicas capazes de influenciar na ocorrência da seca. O índice deve permitir uma variabilidade dos parâmetros utilizados no seu cálculo.

\subsection{3- Trabalhabilidade}

Os índices de seca são amplamente utilizados para auxiliar a tomada de decisão, fornecendo informações que permitam o desenvolvimento de ferramentas que minimizem os impactos gerados pela mesma.

A trabalhabilidade está associada ao aspecto prático dessas ferramentas, os quais devem possibilitar um fácil entendimento para os usuários. Nesse sentido, deve-se avaliar se o cálculo do índice demanda algumas considerações que complicam a sua utilização, como um elevado esforço computacional ou uma extensa base de dados. 


\subsection{4- Transparência}

Para que um índice seja considerado eficiente no reconhecimento de qualquer evento, deve-se, primeiramente, entender a metodologia dos mesmos. A transparência está associada à clareza e lógica da sua proposta.

A seca é um fenômeno de larga escala, capaz de atingir extensas áreas, habitadas pelas mais diferentes comunidades. Assim, como as pessoas sujeitas aos impactos da seca fazem parte de diferentes grupos da sociedade, a metodologia na qual se baseiam os índices de seca deve permitir o entendimento dos mesmos não apenas pela comunidade científica, mas também pela população afetada.

\subsection{5- Sofisticação}

Constantemente são desenvolvidas tecnologias para realizar a coleta de informações do meio que permitem um melhor entendimento dos processos que ocorrem nesse ambiente. Nesse contexto, também são realizados estudos que tentam associar essas tecnologias à metodologias cada vez mais sofisticadas, que buscam extrair informações confiáveis desses dados.

Percebe-se, entretanto, que, apesar da importância de se apresentar uma metodologia clara e lógica para os usuários, deve existir, também, uma preocupação em explorar as tecnologias disponíveis, criando índices sofisticados e capazes de avaliar de forma mais completa e consistente os processos do meio.

Ressalta-se que essa sofisticação normalmente está associada à exigência de uma maior quantidade e qualidade de dados de entrada no modelo, os quais não estão disponíveis em muitas regiões estudadas.

\subsection{6- Extensibilidade}

Como relatado anteriormente, em virtude do constante desenvolvimento tecnológico, podese perceber o surgimento de índices de seca cada vez mais elaborados, que utilizam esses novos conhecimentos na sua composição. 
A extensibilidade, entretanto, mostra a necessidade de se ter cuidado na aplicação dessas tecnologias. Quando se trabalha com técnicas de sensoriamento remoto, por exemplo, os dados coletados descrevem apenas as últimas décadas. Já as observações de precipitação e temperatura podem caracterizar longos períodos históricos.

Essa preocupação pode ser relacionada com o fato de que, para se entender grande parte dos processos que incidem no meio, é de fundamental importância analisar o comportamento de sua tendência ao longo de grandes intervalos de tempo. Essa característica é, portanto, entendida como a capacidade do índice de avaliar a seca ao longo do tempo, passando por secas que ocorreram em diferentes períodos.

\subsection{7- Dimensionalidade}

O critério de dimensionalidade pode ser confundido com o de transparência. Ele se define como a relação do índice e os processos físicos, observando se o mesmo consegue representar as unidades fundamentais do sistema de medidas, $\mathrm{L}, \mathrm{M}$ ou $\mathrm{T}$, ou, pelo menos, uma fração das mesmas.

\subsection{8- Avaliação dos índices de seca}

Ao examinar alguns dos índices descritos anteriormente quanto aos critérios propostos por Keyantash e Dracup (2002), não se verifica a adequabilidade dos mesmos a todas as premissas propostas pelos autores.

No caso do SPI e do SPEI, que são ferramentas de simples utilização e entendimento, percebe-se que não se respeita apenas as ideias de sofisticação e robustez, em decorrência dos mesmos se basearem em conceitos estatísticos amplamente conhecidos e utilizarem informações de fácil acesso. De forma semelhante o índice da FUNCEME também combina as mesmas premissas dos anteriores, considerando apenas a altura da precipitação diária e o tamanho do veranico em sua obtenção.

As ferramentas elaboradas por Palmer, apesar de terem uma maior sofisticação que os demais índices, são difíceis de serem calculados e entendidos, o que dificulta sua 
operacionalização em um sistema de alerta. Os mesmos não obedecem, portanto, as ideias de trabalhabilidade e transparência.

Já em relação à extensibilidade, por precisarem de dados de séries históricas de variáveis simples, a precipitação e a evapotranspiração, podem ser calculados para longos períodos de tempo.

Essas últimas ferramentas, no caso do PDSI e do PHDI, por terem uma metodologia que considera dados de meses anteriores no seu cálculo, além da necessidade de se verificar a cada instante se a umidade do mês de análise é suficiente para finalizar a seca, podem ser considerados robustos, sendo esses cuidados não verificados no cálculo dos demais. 


\section{4- CARACTERIZAÇÃO DA ÁREA DE ESTUDO}

\section{1- LOCALIZAÇÃO DA ÁREA DE ESTUDO}

As bacias avaliadas no presente estudo, as quais serão descritas no item 4.5, estão localizadas na região semiárida do Nordeste Setentrional brasileiro. Essa região está inserida no semiárido brasileiro, que é composto por 1133 municípios, pertencentes a nove (9) estados: Piauí, Ceará, Rio Grande do Norte, Paraíba, Pernambuco, Alagoas, Sergipe, Bahia e Minas Gerais. A definição dessa área foi feita por um Grupo de Trabalho Interministerial (GTI), criado em 2004 pelo Ministério da Integração Nacional (MI). Os critérios adotados nesse trabalho foram: níveis de precipitação média anual inferior a 800 $\mathrm{mm}$, índice de aridez de até 0,5 e um risco de seca maior que $60 \%$, tomando-se por base o período entre 1970 e 1990 (Pereira Jr, 2007).

As secas são um fenômeno frequente no Nordeste, afetando, principalmente, segundo Nobre (2012), a porção semiárida na parte norte do Nordeste. Um dos principais fatores que induzem a ocorrência das secas nessa área é a elevada variabilidade climática. Um exemplo dessa característica é apresentado na Figura 9, que mostra as isoietas anuais médias compreendidas entre os anos de 1977 a 2006 no Nordeste semiárido. Observa-se uma variação de 600 a $1800 \mathrm{~mm}$.
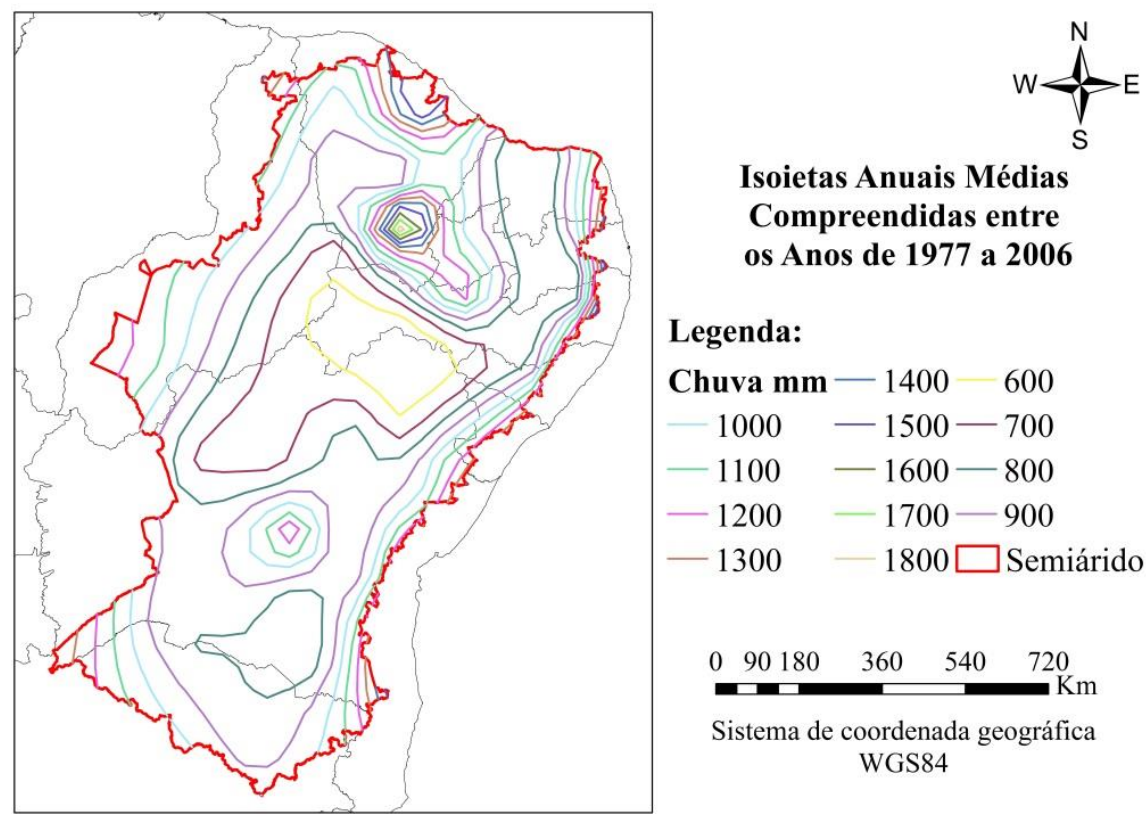

Isoietas Anuais Médias

Compreendidas entre

os Anos de 1977 a 2006

Legenda:

Chuva mm - $1400-600$

$-1000-1500-700$

$-1100-1600-800$

$-1200-1700-900$

$-1300-1800 \square$ Semiárido

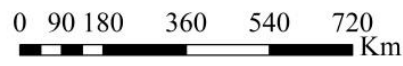

Sistema de coordenada geográfica WGS84

Figura 9 - Isoietas anuais médias compreendidas entre os anos de 1977 a 2006. 
A elevada incidência desse desastre natural também pode estar vinculada ao posicionamento da região Nordeste, que está situada entre uma área de elevados índices pluviométricos, a Amazônia, e a zona central do Atlântico Sul, onde se verificam níveis inferiores a $300 \mathrm{~mm} / \mathrm{ano}$, segundo Nobre (2012).

Essa ocorrência de eventos secos, segundo Finan e Nelson (2001), tem historicamente afligido a população local, retirando as pessoas das suas casas, dispersando-as pela Amazônia e regiões industrializadas do sul do país. O impacto desse fenômeno ainda é intensificado em virtude da grande vulnerabilidade da população local. A maioria das famílias de agricultores é muito pobre, estando sujeitas a dificuldades para suprir suas necessidades básicas, mesmo em um cenário climático considerado normal.

\section{2- CLIMA}

O Nordeste brasileiro é marcado por um clima semiárido, que combina diversos fatores responsáveis por limitar a disponibilidade de água. Dentre essas características, pode-se citar um balanço hidrológico com elevadas taxas de evapotranspiração, que se igualam as de precipitação em algumas regiões, como se observa na Figura 10, além da grande incidência de solos rasos, com baixa capacidade de armazenamento de água.

Outro fator que influência nessa baixa disponibilidade hídrica é o regime de chuvas concentrado em determinada época do ano. O mesmo tem três subdivisões no Nordeste. $\mathrm{Na}$ porção delimitada pelos estados Maranhão, Piauí, Ceará e Rio Grande do Norte, o oeste da Paraíba, Pernambuco, Alagoas e o norte-nordeste da Bahia, por exemplo, Nobre (2012), afirma que o regime pluviométrico anual é centrado no período de janeiro a abril. 


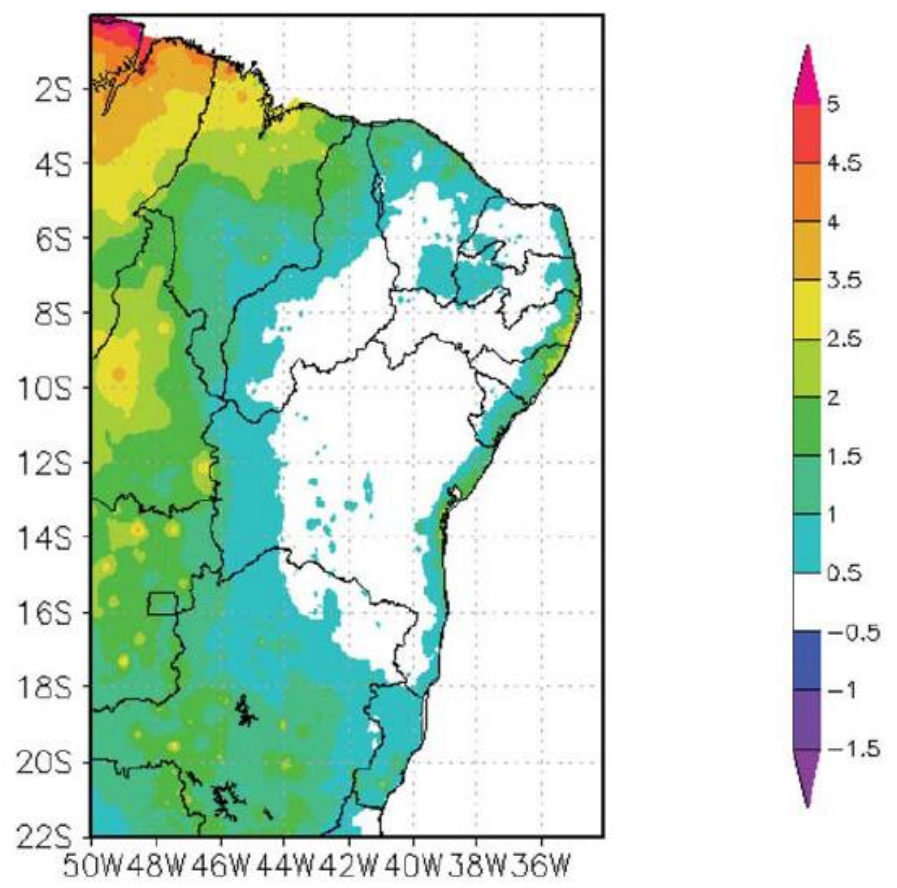

Figura 10 - Valor médio da diferença entre as taxas de precipitação e evaporação diárias (mm/dia) (Fonte: Nobre 2012).

Essas características estão relacionadas, principalmente, com o posicionamento da ZCIT, que é determinado, dentre outros fatores, pela variação das temperaturas da superfície do mar. Ao longo do ano, a ZCIT se movimenta entre os hemisférios sul e norte, atingindo a costa norte do Nordeste em fevereiro e voltando a se movimentar para o norte em maio.

Em virtude dessas características climáticas, predomina na região a utilização de técnicas agrícolas tradicionais, conhecidas como cultura de sequeiro. Os principais tipos de alimentos produzidos são o feijão e o milho, os quais apresentam um ciclo produtivo curto, sendo plantados durante o período chuvoso.

Observa-se, portanto, que a combinação de diversos fatores determina a elevada susceptibilidade à ocorrência de secas do Nordeste brasileiro. A distribuição desse fenômeno ao longo dos séculos, segundo diversos autores, é apresentada por Souza Filho (2003) na Tabela 8. 
Tabela 8 - Ocorrência das secas no Nordeste semiárido brasileiro (Fonte: Souza Filho, 2003, modificado).

\begin{tabular}{|c|c|c|c|c|}
\hline Década & Século XVII & Século XVIII & Século XIX & Século XX \\
\hline $\mathbf{0 0}$ & 1603,1606 & 1707 & $1804,1808 / 09$ & 1900,1903 \\
\hline $\mathbf{1 0}$ & 1614 & $1710 / 11$ & 1814 & 1915,1919 \\
\hline $\mathbf{2 0}$ & - & $1721 / 1727$ & $1824 / 25$ & - \\
\hline $\mathbf{3 0}$ & - & $1730,1736 / 37$ & $1829 / 1830,1833$, & 1932 \\
\hline $\mathbf{4 0}$ & 1645 & $1744 / 1747$ & $1835 / 1837$ & 1942 \\
\hline $\mathbf{5 0}$ & 1652 & 1751,1754 & $1844 / 45$ & $1951 / 53,1958$ \\
\hline $\mathbf{6 0}$ & - & 1760,1766 & - & 1966 \\
\hline $\mathbf{7 0}$ & - & $1771 / 72,1777 / 78$ & $1870,1876 / 78$ & 1970 \\
\hline $\mathbf{8 0}$ & - & $1783 / 84$ & $1888 / 89$ & 1993,1997 \\
\hline $\mathbf{9 0}$ & 1692 & $1791 / 92$ & 1891,1898 & \\
\hline
\end{tabular}

\section{3- DESCRIÇÃO DAS SECAS NO NORDESTE}

Segundo Campos (1994), com base em estudos desenvolvidos por consultores do Bureau of Reclamation para o DNOCS, a seca crítica do século XX aconteceu durante os anos de 1974 a 1983. Inicialmente, o período entre 1975 e 1978 foram anos com deflúvios fracos, sucedidos por cinco (5) anos de secas, de 1979 a 1983.

Marengo (2008) também cita esse evento ao descrever a seca entre os anos de 1979 a 1983 como a mais longa do século XX. Esses e outros anos de secas também foram caracterizados por Carvalho (1988) apud Senado (1997), com o auxílio da Tabela 9. A mesma mostra a área e o número de pessoas afetadas, além dos gastos que, em resposta, foram realizados pelo governo federal.

Outros autores que também analisaram as secas do Nordeste são Pompeu Sobrinho (1982), Souza e Medeiros Filho (1983). Eles fizeram um estudo comparativo de algumas das principais secas históricas que ocorreram no século XX. 
Tabela 9 - População do Nordeste afetada pelas secas e recursos e recursos aplicados pelo governo federal nos programas de emergência. Período 1958, 1970, 1979-83 (Fonte:

Carvalho (1988) apud Senado (1997), modificado).

\begin{tabular}{|c|c|c|c|c|c|c|c|}
\hline $\begin{array}{c}\text { Anos } \\
\text { de } \\
\text { Seca }\end{array}$ & $\begin{array}{c}\mathrm{N}^{\mathrm{o}} \text { Mun. } \\
\text { (Total) }\end{array}$ & $\begin{array}{c}\mathrm{N}^{\mathrm{o}} \text { Mun. } \\
\text { Afetados }\end{array}$ & $\begin{array}{c}\text { Área } \\
\text { Total } \\
\left(\mathrm{Km}^{2}\right)\end{array}$ & $\begin{array}{c}\text { Área } \\
\text { Afetada } \\
\left(\mathrm{Km}^{2}\right)\end{array}$ & $\begin{array}{c}\text { Pop. Total } \\
(\text { hab. })\end{array}$ & $\begin{array}{c}\text { Pop. } \\
\text { Afetada } \\
\text { (hab. })\end{array}$ & $\begin{array}{c}\text { Recursos } \\
\text { Gastos }\end{array}$ \\
\hline 1958 & - & 618 & - & 500.000 & - & 10.000 .000 & 422.050 \\
\hline 1970 & - & 605 & - & 578.400 & - & 9.176 .000 & 225.999 \\
\hline 1979 & 1.416 & 513 & 1.660 .333 & 538.709 & 32.930 .263 & 9.114 .314 & 234.768 \\
\hline 1980 & 1.416 & 988 & 1.660 .333 & 1.399 .086 & 32.930 .263 & 19.487 .201 & 740.056 \\
\hline 1981 & 1.416 & 1100 & 1.660 .333 & 1.441 .624 & 35.922 .621 & 23.256 .979 & 1.018 .841 \\
\hline 1982 & 1.423 & 898 & 1.660 .333 & 1.391 .479 & 35.922 .621 & 15.483 .587 & 408.298 \\
\hline 1983 & 1.426 & 1328 & 1.660 .333 & 1.591 .050 & 35.921 .000 & 28.954 .000 & 1.558 .592 \\
\hline
\end{tabular}

Pompeu Sobrinho (1982) define que a seca de 1919 como um período seco curto, comparada com a que ocorreu em 1915, não sendo um ano de grandes prejuízos para a população. A conclusão desse autor baseia-se, porém, não apenas em fatores climáticos, mas também nos impactos sofridos pela população. Pompeu Sobrinho (1982) afirma que o gado já era escasso em 1919, pois a maior parte já tinha morrido em 1915, sendo necessário pouco pasto para alimentá-lo.

Um fato interessante, também relatado pelo mesmo autor, é que no ano de 1919 o açude Riacho do Sangue, localizado na cidade de Solonópole, que está dentro da área analisada, além de reservatórios situados em cidades próximas, o de Caio Prado em Santa Quitéria e o de Tucundubas, perto de Canindé, possuíam reservas hídricas suficientes para suprir as necessidades das comunidades locais.

Outra seca que causou inúmeros prejuízos à região Nordeste foi a que ocorreu no ano de 1958. Esse evento foi descrito por Souza e Medeiros Filho (1983), como a grande seca da década de 1950. 


\section{4- ESTRATÉGIAS CONTRA A SECA NO NORDESTE}

Segundo Gutiérrez et al. (2014), o Brasil começou a desenvolver trabalhos de mitigação contra a seca depois de um evento extremo que ocorreu entre os anos de 1877 e 1879. Posteriormente, foram criadas diversas ferramentas e instituições de combate a esse evento e gestão dos recursos hídricos.

O primeiro passo, no âmbito tecnológico, para tentar minimizar os problemas gerados pela seca, foi a iniciativa de reservar água, sendo construído, em 1886, o primeiro açude público, o Cedro, em Quixadá, Ceará. Posteriormente, entre os anos de 1909 e 1983, foram construídas 275 grandes barragens.

Apesar dessas iniciativas, a construção dessas barragens, entretanto, não foi capaz de impulsionar o crescimento da agricultura irrigada, segundo Finan e Nelson (2001). Diversos problemas organizacionais e técnicos são constatados nos locais onde os grandes projetos foram implementados.

A Inspetoria de Obras Contra as Secas (IOCS), criada em 1909 e atualmente denominada Departamento Nacional de Obras Contra as Secas (DNOCS), é um exemplo das instituições criadas para "combater" os efeitos das secas. O DNOCS é responsável pela construção da infraestrutura no Nordeste do país, como barragens, pontes e estradas.

No desenvolvimento dessa política, o governo tentou se aliar a instituições financeiras que promovessem o crescimento econômico da região, como o Banco do Nordeste do Brasil (BNB), criado em 1952. O mesmo disponibilizou crédito para os fazendeiros e investiu em projetos de abastecimento de água.

Mostrando preocupação com o desenvolvimento do setor agrícola, entre os anos de 1945 e 1950, instituições governamentais tentaram disseminar a adesão a culturas que tivessem maior resistência às condições impostas pela seca. Essa educação dos fazendeiros é importante, pois ela permite que os mesmos conheçam alternativas que os tornem menos vulneráveis a esse fenômeno. 
Nos anos de 1980, houve uma expansão da economia rural por meio da atuação do Banco Mundial, juntamente com a colaboração de instituições nacionais, que investiu em projetos que tentavam garantir um crescimento sócio econômico sustentável. São exemplos de ações associadas a esse processo, a expansão do acesso à água, desenvolvimento da educação da população e de fontes de renda que não sejam associadas ao setor agrícola.

Avanços no conhecimento sobre o comportamento dos processos climáticos também permitiram uma redução dos impactos gerados pela seca. Isso pôde ser evidenciado no Ceará. Finan e Nelson (2001) relatam que a FUNCEME previu a ocorrência da seca 1998, ao antecipar que a chuva desse ano seria inferior à média esperada para esse período. Isso permitiu que o governo pudesse alertar antecipadamente os fazendeiros sobre a necessidade de utilizar culturas resistentes nas suas plantações.

Essas iniciativas, entretanto, atingem as comunidades afetadas pela seca de formas diferentes. Existem aquelas pessoas que residem em áreas conectadas às fontes perenizadas de água, que foram diretamente beneficiadas com esses projetos, e os agricultores localizados em áreas que dependem da água da chuva para produzir. Esse segundo grupo é assistido por planos reativos aos impactos da seca, como a operação carro-pipa e o programa bolsa Estiagem.

Em algumas dessas áreas que não estão interligadas aos sistemas perenizados existem pequenas barragens, que não são capazes de acumular água suficiente para suprir as necessidades da população local. O subdimensionamento dessas estruturas associado a outros problemas, como a falta de manutenção, a erosão do solo e o acúmulo de lixo reduzem ainda mais a disponibilidade de água de qualidade para a população.

Essas diferenças na região Nordeste puderam ser combatidas por meio da implantação de uma política pioneira de gestão descentralizada dos recursos hídricos. Uma importante iniciativa que pode ser citada, como exemplo desse sistema, é o Programa Um Milhão de Cisternas (P1MC). O objetivo desse programa é permitir, no semiárido, o acesso das comunidades mais isoladas à água, por meio da construção de cisternas, possibilitando, assim, uma convivência mais sustentável com o semiárido. 
Ao longo do desenvolvimento dessa política, pode-se, também, destacar a integração entre diversas entidades para implantação de projetos e coleta de dados. Um exemplo recente é a associação que começou em novembro de 2013, com a participação de várias instituições federais e estaduais, visando inicialmente a formatação de uma Política Nacional de Secas, que tem como primeiro pilar o desenvolvimento do monitoramento da seca, a partir da criação do Monitor de secas do Nordeste.

\section{5- REDE HIDROGRÁFICA}

A área avaliada pelo presente trabalho, a qual é apresentada resumidamente na Figura 11, é formada por parte da Bacia do rio Jaguaribe e a do Piranhas-Açu. A mesma é constituída pelas bacias contribuintes aos reservatórios do Banabuiú, Castanhão, Orós, Coremas Mãe D’Água e Engenheiro Armando Ribeiro Gonçalves. Os três primeiros encontram-se no Ceará e os dois últimos nos estados da Paraíba e Rio Grande do Norte, respectivamente. A escolha desses sistemas está relacionada à iniciativa recente do Governo Brasileiro, com suporte técnico do Banco Mundial, que consiste na construção do Monitor de Secas do Nordeste, com o intuito de desenvolver uma gestão mais proativa de combate às secas (Nys et al., 2014).

As bacias abordadas no presente trabalho, que estão inseridas no estado cearense, compõem a bacia do rio Jaguaribe. Segundo o Plano de Gerenciamento das águas da bacia do rio Jaguaribe, essa bacia ocupa 50 por cento do território Cearense, onde residem cerca de um terço da população do estado. Dentre os diversos açudes construídos no estado, os principais, em função da natureza estratégica, estão localizados nessa área, sendo o Castanhão o que possui maior capacidade de reservação. O Orós e Castanhão são os responsáveis para garantir as maiores demandas da bacia do Jaguaribe e, no caso do Castanhão, da Região Metropolitana de Fortaleza e do Complexo Industrial e Portuário do Pecém em períodos de estiagem. No âmbito dos rios que contribuem para o Jaguaribe, o Banabuiú é o mais importante, possuindo uma área de drenagem de $19.810 \mathrm{~km}^{2}$.

No caso da bacia do Piranhas-Açu, localizada entre os estados da Paraíba e do Rio Grande do Norte, os reservatórios Coremas Mãe D’água e Engenheiro Armando Ribeiro Gonçalves são responsáveis pela perenização do seu principal rio. 

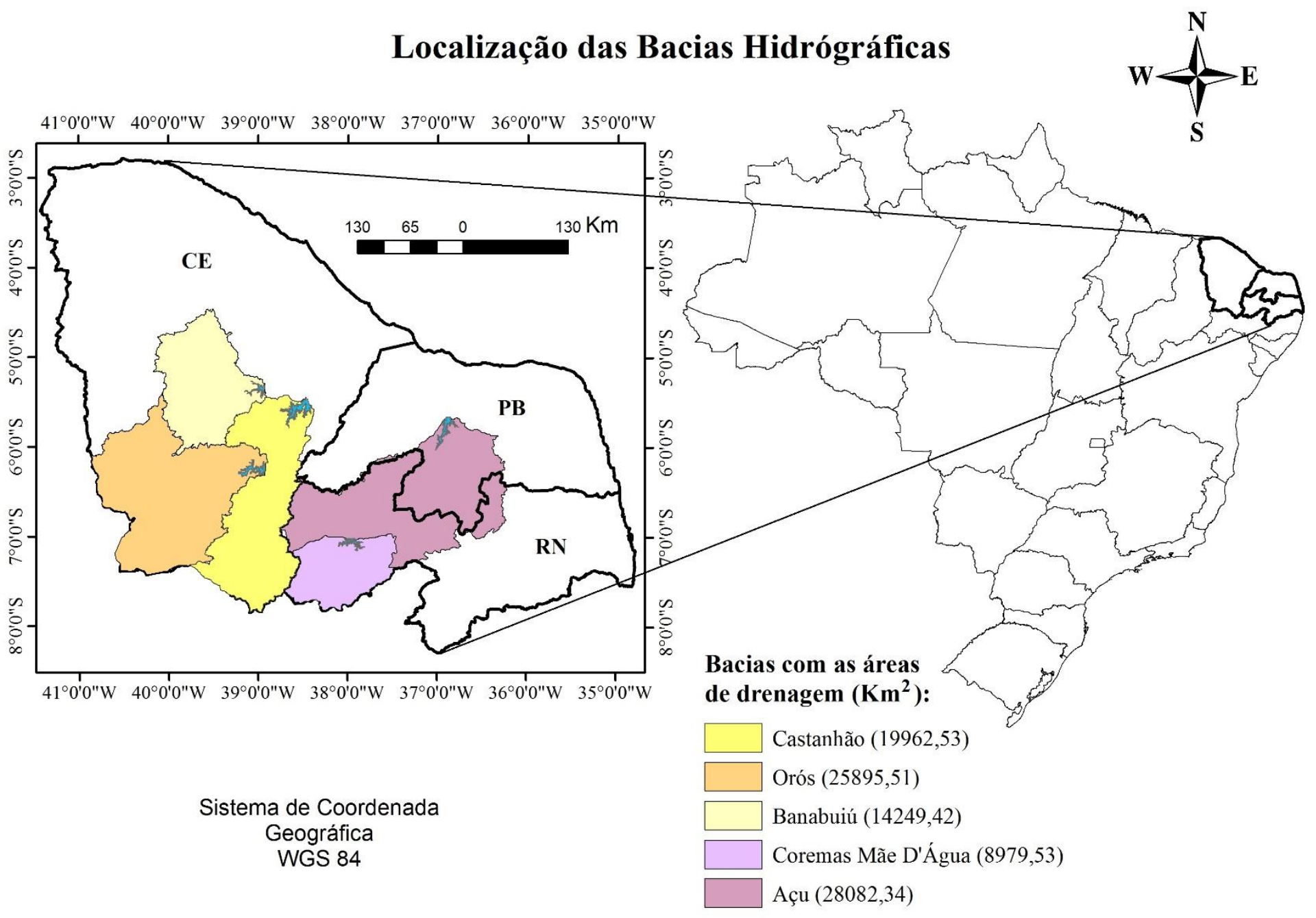

Figura 11 - Delimitação da região analisada. 
Ao se analisarem os dados de precipitação médios de determinados períodos, referentes as bacias contribuintes aos reservatórios relatados anteriormente, percebe-se que eles seguem tendências semelhantes e, como relatado anteriormente, mostram a grande variabilidade das taxas de precipitação no Nordeste brasileiro. Essas características podem ser notadas ao se analisar a série de dados das Figuras 12 e 13.

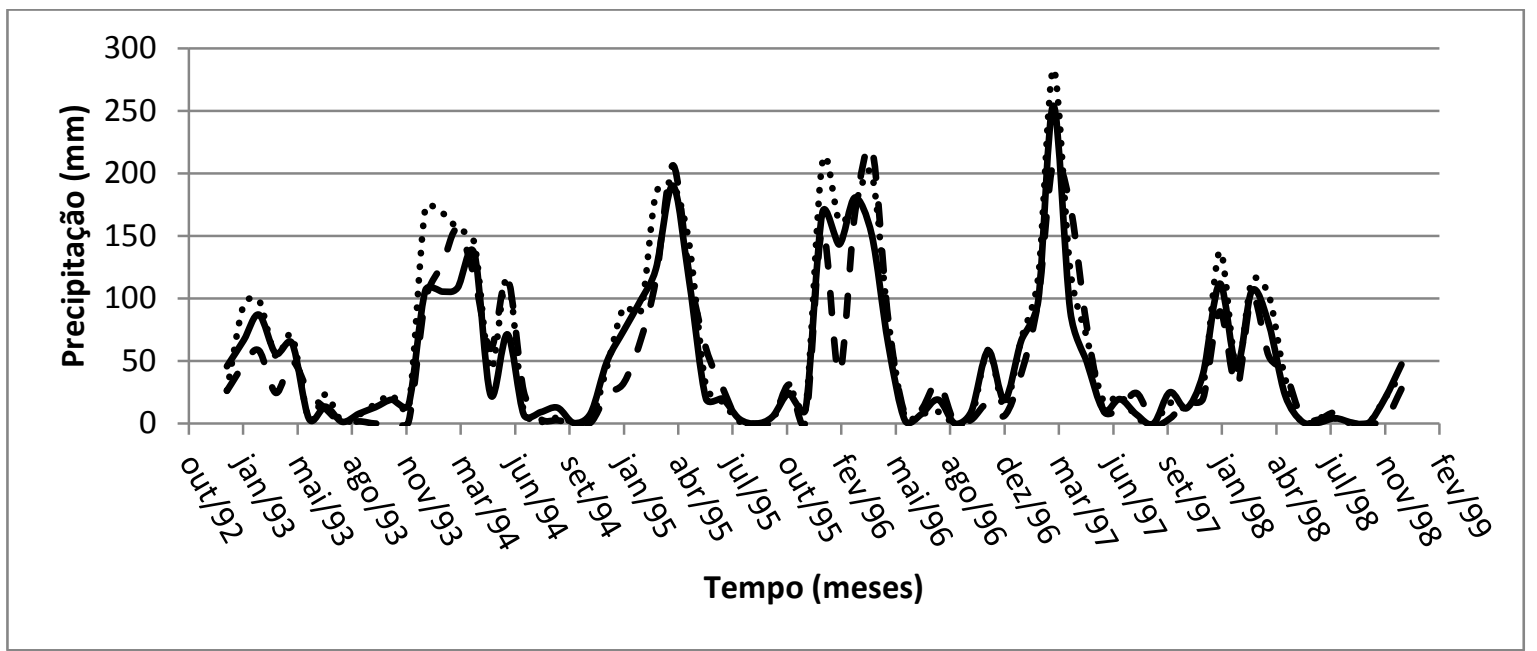

Figura 12 - Série de precipitação de Jan/1993 a Dez/1998, sendo a linha pontilhada referente à Bacia contribuinte ao Castanhão, a sólida ao Orós e a tracejada a do Banabuiú.

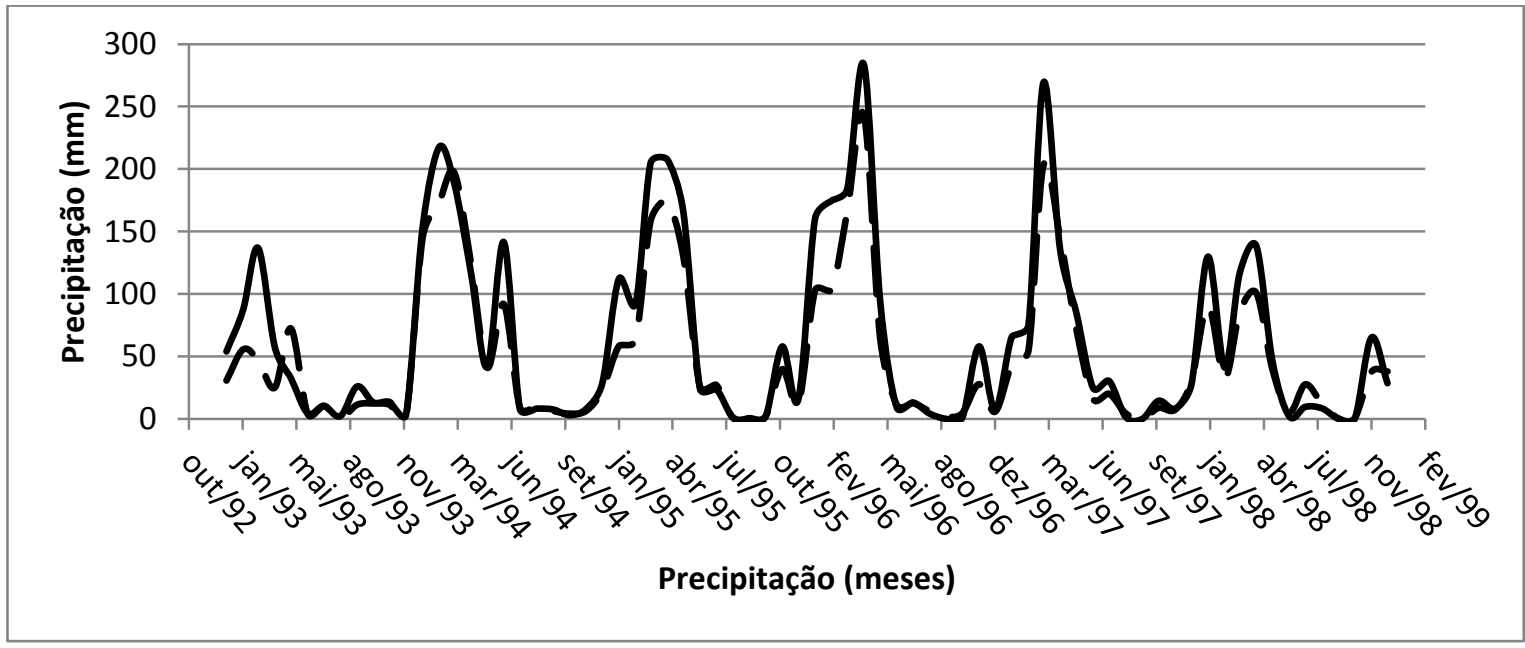

Figura 13 - Série de precipitação de Jan/1993 a Dez/1998, sendo a linha tracejada referente aos dados das bacias que contribuem para o açude Açu e a sólida das bacias que contribuem para o Coremas.

Essa grande variabilidade dos dados de chuva também pode ser verificada nas Figura 14 e 15, as quais mostram com mais clareza os anos em que houve uma redução significativa da precipitação. Esses anos são compatíveis com as secas apresentadas na Tabela 8, já que, 
por exemplo, nos anos de 1993 e 1997, além do período entre 1979 e 1984, ocorre uma significativa diminuição nos valores de precipitação.

A pequena magnitude dos valores mínimos de precipitação em relação aos demais da série temporal pode ser verificada ao se calcular o percentil 30 dos dados de precipitação mensais entre os anos de 1993 a 1998. A partir desse cálculo, foram obtidos os valores da Tabela 10.

Tabela 10 - Valores do percentil 30 dos dados de precipitação, em mm/mês, das Bacias contribuintes a cada reservatório.

\begin{tabular}{|c|c|c|c|c|}
\hline Castanhão & Orós & Banabuiú & Açu & Coremas \\
\hline 9,48 & 11,04 & 5,10 & 10,07 & 8,63 \\
\hline
\end{tabular}

Outra informação explicitada pelas Figuras 14 e 15 é a significativa diferença entre os valores de evapotranspiração potencial e precipitação. Verifica-se que um grande potencial de água é perdida para a atmosfera por evapotranspiração.

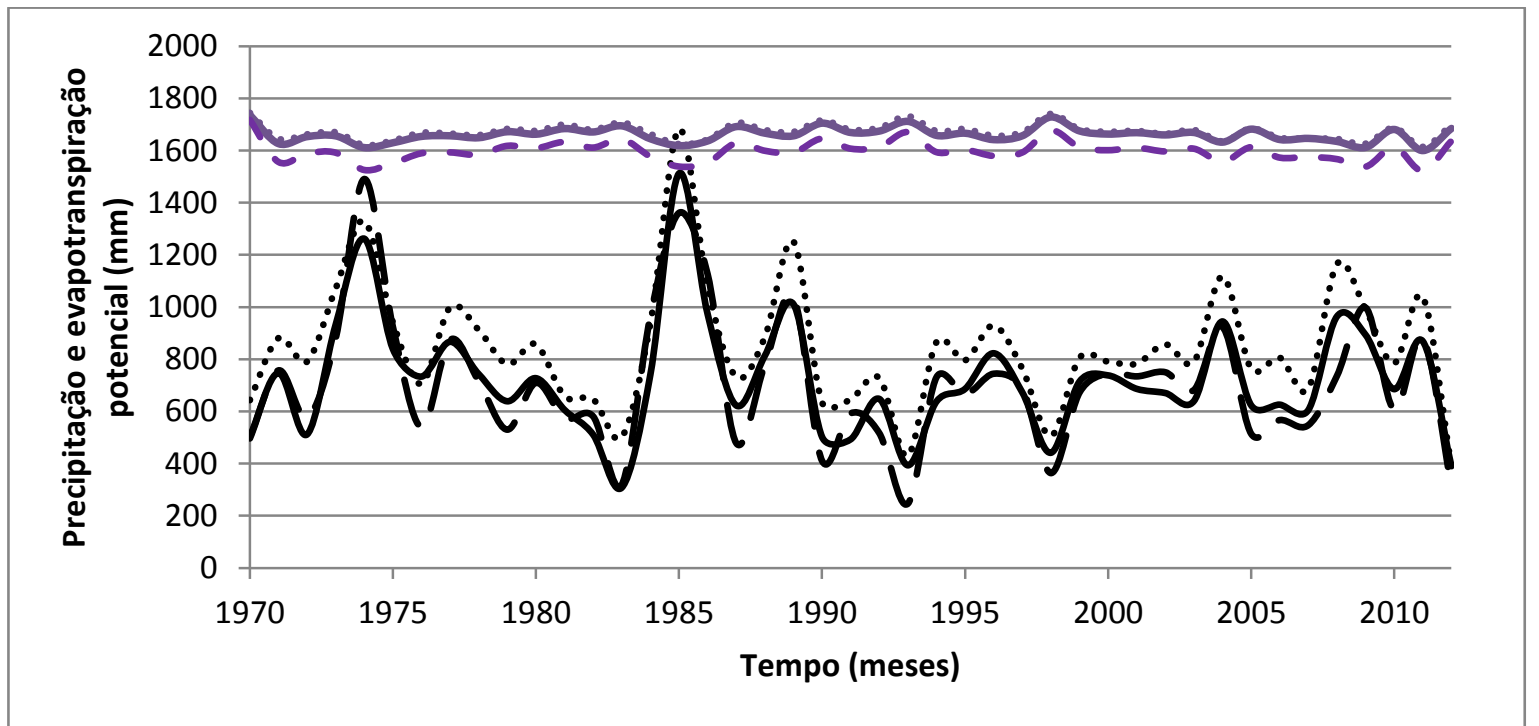

Figura 14 - Totais anuais da precipitação de 1970 a 2012, sendo as linhas tracejadas preta e roxa referentes à precipitação e evapotranspiração potencial, respectivamente, a Bacia do

Banabuiú, as continuas preta e roxa referentes à precipitação e evapotranspiração potencial, respectivamente, do Alto Jaguaribe e as pontilhadas preta e roxa referentes à precipitação e evapotranspiração potencial, respectivamente, do Médio Jaguaribe. 


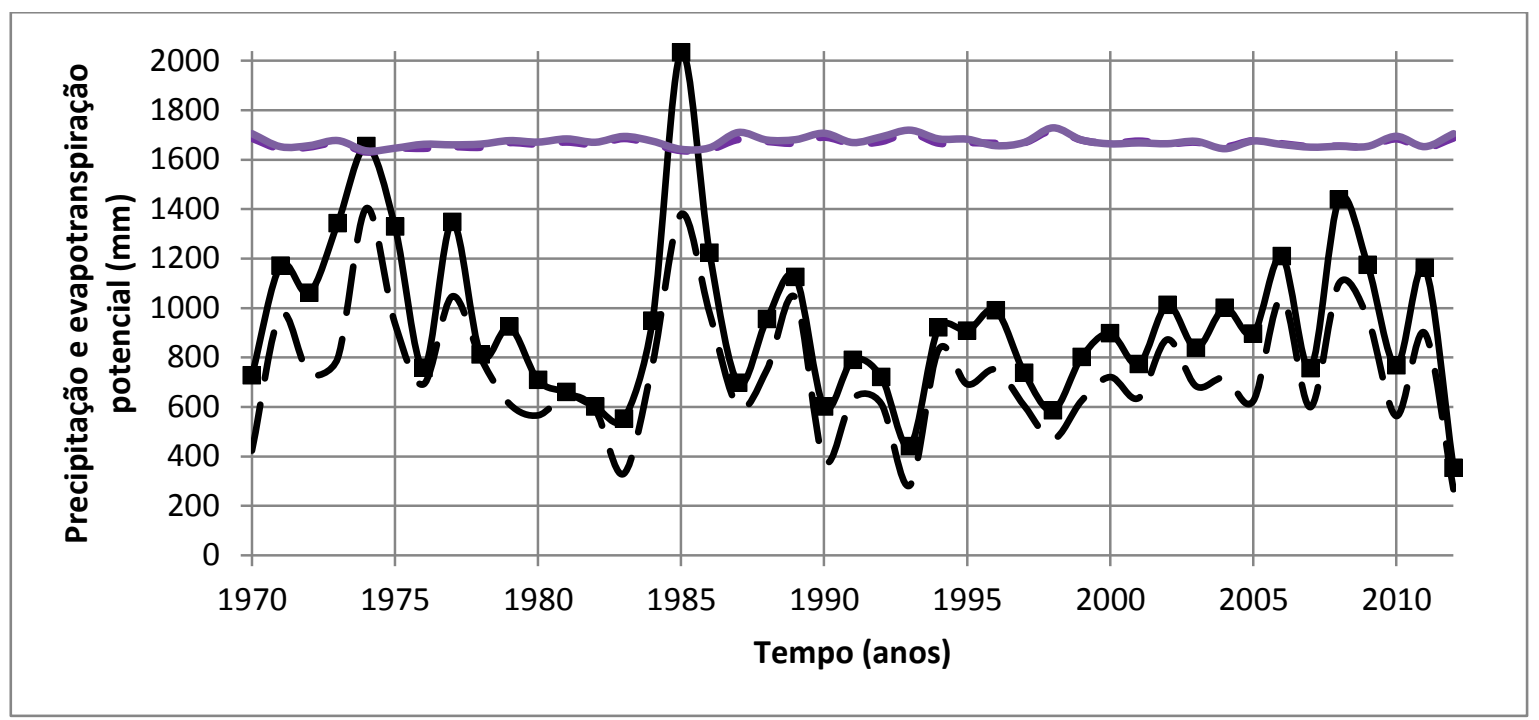

Figura 15 - Totais anuais da precipitação de 1970 a 2012, sendo as linhas tracejadas preta e roxa referentes à precipitação e evapotranspiração potencial, respectivamente, das bacias que contribuem para o açude Açu e as continuas preta e roxa referentes à precipitação e evapotranspiração potencial, respectivamente, das bacias que contribuem para o açude Coremas. 


\section{5- METODOLOGIA}

\section{1- DADOS EMPREGADOS}

\subsection{1- Precipitação}

Séries de precipitação mensal são imprescindíveis para o cálculo de diversos índices de seca. No caso do estado do Ceará, os valores de precipitação mensal foram extraídos do banco de dados de chuva da FUNCEME, que possui uma densidade adequada de postos pluviométricos, quando comparada com outros estados da região (Martins et al., 2013).

Por outro lado, no caso do estado da Paraíba e Rio Grande do Norte, devido à baixa densidade de postos, foram empregadas séries mensais de precipitação fornecidas pela Unidade de Pesquisa Climática (Climate Research Unit - CRU) da Universidade de East Anglia, mais especificamente o produto CRU TS3.20, com informações de chuva e outras variáveis meteorológicas numa escala de $0,5^{\circ} \times 0,5^{\circ}$, no período compreendido entre $1901 \mathrm{e}$ 2012. A estratégia de empregar os dados do CRU para os referidos estados também foi adotada num estudo de mudanças climáticas realizado na região sob demanda da Agência Nacional de Água e fomentado pelo Banco Mundial (Martins et al., 2013).

Essa instituição elaborou um banco de dados que vem sendo utilizado intensamente na realização de pesquisas que demandam informações climáticas. Dentre esses dados, os utilizados no presente trabalho são séries temporais compostas pela junção de informações coletadas por dezenas de estações espalhadas pelo mundo. Essas fontes de dados são de responsabilidade de diversas entidades, como agências meteorológicas nacionais (AMN), a Organização Meteorológica Mundial (OMM) e o Centro Internacional de Agricultura Tropical.

Esses dados não são homogêneos, já que os mesmos foram obtidos por diferentes tipos de estações, sendo importante a realização de uma verificação prévia dos mesmos por meio de uma análise de consistência. Posteriormente é feita uma interpolação dessas informações para compor a grade de pontos em escala de $0,5^{\circ}$ x $0,5^{\circ}$, como relatado anteriormente. 
Como a avaliação dos índices de seca foi realizada tanto por bacia hidrográfica, quanto por pontos de grade na região, houve a necessidade de se manipular as séries oriundas da FUNCEME e do CRU. A análise das precipitações por pontos de grade seguiu os pontos geográficos da série do CRU e das estações pluviométricas da FUNCEME, sendo necessária, na primeira situação, a realização de uma interpolação espacial, no estado do Ceará, dos dados de chuva provenientes dos postos pluviométricos da FUNCEME.

Para encontrar o valor dessa variável nas coordenadas do CRU, realizou-se uma interpolação por meio da ponderação do inverso da distância, conhecida como IDW. Essa técnica baseia-se na ideia de que os pontos mais distantes do ponto explorado são menos importantes na estimação do seu valor, sendo essa diferenciação feita por meio da ponderação dos mesmos pelo inverso da distância, como mostra a equação 22.

$$
z_{j}=\frac{\sum_{i} \frac{z_{i}}{d_{i j}^{n}}}{\sum_{i} \frac{1}{d_{i j}^{n}}}
$$

em que $\mathrm{z}_{\mathrm{j}}$ é o valor do ponto pesquisado, $\mathrm{z}_{\mathrm{i}}$ é o valor do ponto conhecido, $\mathrm{d}_{\mathrm{ij}}$ é a distância entre os pontos anteriores e n é o expoente da distância, sendo, no presente estudo, adotado o valor de 2 .

No caso da análise por bacia hidrográfica, foi necessário o cálculo da chuva média na bacia, sendo utilizado o método de Thiessen. No caso do estado do Ceará, as séries de precipitação mensal por bacia hidrográfica, obtidas pelo método de Thiessen, já estão calculadas e disponibilizadas no sítio da FUNCEME.

Destaca-se que apenas os índices elaborados por Palmer foram calculados nos pontos da base de dados do CRU utilizando valores de precipitação da mesma instituição e da FUNCEME. Essa escolha está relacionada à disponibilização, por essa entidade, de uma série de precipitação por pontos mais longa.

Como relatado anteriormente, a metodologia de obtenção dessas ferramentas propõe o cálculo de parâmetros com uma parcela dos dados observados. Portanto, no caso do 
presente trabalho, esses valores foram calibrados com metade do período das séries de dados. Pressupõe-se, assim que quanto mais extensa for a base de dados, melhores serão os resultados finais.

\subsection{2- Evapotranspiração Potencial}

A evapotranspiração potencial é uma variável hidrológica primordial na relação entre oferta e demanda de água numa região, pois expressa a demanda de água da atmosfera. Diversos fatores interferem na magnitude da evapotranspiração potencial, são eles: radiação líquida disponível na superfície, temperatura do ar, umidade relativa, velocidade do vento e tipo de vegetação. Essa é uma lista relativamente extensa, e dificilmente essas informações estão disponíveis numa dada localidade. Essas informações são geralmente obtidas em estações climáticas convencionais, entretanto, a densidade dessas estações na região de estudo é baixa (por exemplo: apenas 6 no estado do Ceará), o que dificulta a estimativa para a região como um todo.

Existem diversas estratégias para estimar a evapotranspiração potencial numa região, desde a expressão de Penman-Montieth, considerada a mais completa do ponto de vista de representação física do processo, até equações empíricas derivadas especificamente para uma região.

Neste estudo, foi empregada a equação de Hargreaves (Shuttleworth, 2012), apresentada na equação 23, a qual é baseada apenas nas temperaturas mínima, máxima e média, e na radiação solar incidente no local de interesse, que depende apenas da coordenada do ponto e da época do ano. A equação de Hargreaves costuma ser indicada quando não há informação sobre a radiação líquida disponível na superfície, velocidade do vento e umidade relativa, por apresentar desempenho, na escala mensal, tão bom quanto equações alternativas existentes na literatura (Shuttleworth, 2012).

$$
\mathrm{E}_{R C}=0,0023 \cdot(\mathrm{T}+17,78) \cdot\left(\delta_{\mathrm{T}}\right)^{0,5} \cdot S_{0}^{d}
$$

em que $E_{R C}$ é a evapotranspiração $\mathrm{em} \mathrm{mm} \cdot \mathrm{d}^{-1}, \mathrm{~S}_{0}{ }^{\mathrm{d}}$ é a radiação solar incidente no topo da atmosfera em $\mathrm{mm} \cdot \mathrm{d}^{-1}, \delta_{\mathrm{T}}$ é a diferença entre as médias mensais das temperaturas máximas e mínimas em ${ }^{\circ} \mathrm{C}$, T é a temperatura em ${ }^{\circ} \mathrm{C}$. 
As séries mensais de temperaturas máxima, mínima e média empregadas na estimativa da evapotranspiração potencial foram aquelas constantes no produto CRU TS3.20, disponibilizadas pelo CRU.

Para a realização da análise dos índices nos pontos dos postos pluviométricos da FUNCEME foi necessária à interpolação dos valores de evapotranspiração localizados na grade do CRU, utilizando a técnica do IDW, descrita anteriormente.

\subsection{3- Vazão}

As séries mensais de vazão nas bacias hidrográficas selecionadas para o estudo serviram para verificar a severidade das secas, segundo os índices estudados, nas diferentes bacias hidrográficas.

Os dados de vazão necessários são aqueles afluentes aos reservatórios selecionados, são eles: Orós, Castanhão, Banabuiú, localizados na bacia hidrográfica do rio Jaguaribe, e Coremas-Mãe d'Água e Armando Ribeiro Gonçalves, ambos localizados na bacia hidrográfica do rio Piranhas-Açu. As séries mensais de vazão afluentes a esses reservatórios foram estimadas em estudos anteriores via modelagem hidrológica, com exceção do Orós, tendo sido compilados em Martins et al. (2013).

\subsection{4- Armazenamento dos Reservatórios}

Tanto a bacia do rio Jaguaribe, quanto a bacia do rio Piranhas-Açu, possui um número elevado de reservatórios de acumulação. A quantidade de água armazenada nos reservatórios representa a oferta hídrica na região, num determinado momento, pelo menos para aqueles municípios ou localidades que tenham acesso aos reservatórios. Sendo assim, a série mensal de volumes armazenados nos reservatórios pôde ser empregada na verificação de índices de seca.

No estado do Ceará, a Companhia de Gestão dos Recursos Hídricos (COGERH) realiza o monitoramento diário de 155 reservatórios, e já conta com um histórico de mais de 10 anos de dados para a maior parte destes. 
No estado do Rio Grande do Norte, os volumes do reservatório do Açu foram disponibilizados pela Coordenadoria de Gestão de Recursos Hídricos, já os volumes do sistema Coremas Mãe-D’água, localizado na Paraíba, foram extraídos dos boletins mensais da ANA de acompanhamento dos reservatórios do Nordeste do Brasil.

\subsection{5- Capacidade de Armazenamento de Água no Solo}

O cálculo do PDSI requer a definição da capacidade de armazenamento de água do solo, que também é imprescindível para estimativa da série mensal da umidade do solo via modelagem hidrológica.

No estado do Ceará, existe um mapa, elaborado pela FUNCEME, com as informações sobre a capacidade de armazenamento de água do solo. Nos demais estados, foram empregadas informações disponíveis no Centro Internacional de Informação e de Referência de Solos (ISRIC).

O ISRIC é uma instituição fundada em 1966, após recomendação da Sociedade Internacional de Ciências do Solo (ISSS) e da UNESCO. O banco de dados da ISRIC contém informações sobre solo de todo o globo terrestre numa grade de $0,5^{\circ} \times 0,5^{\circ}$, e que inclui, entre outras coisas, a capacidade de armazenamento de água do solo (Batjes, 2000).

\subsection{6- Umidade do Solo}

O comportamento da umidade do solo numa região está diretamente relacionado à seca agrícola, sendo uma das mais difíceis de monitorar e prever. Medições in situ do teor de umidade do solo são praticamente restritas a experimentos científicos, com exceção de algumas redes de monitoramento em alguns países desenvolvidos, mas ainda assim bastante incipientes. No Nordeste brasileiro, não há uma rede de monitoramento de umidade do solo, restando apenas duas formas de estima-la ao longo do tempo, via modelagem hidrológica ou por meio de sensoriamento remoto.

Este estudo fez uso de informações disponibilizadas pela Earth System Research Laboratory (ESRL). O objetivo de usar esses dados consiste em avaliar se essas 
informações podem ser empregadas no monitoramento das secas, especialmente da seca agrícola, e para ajudar no processo de verificação de índices.

A Physical Sciences Division (PSD) da ESRL fornece dados globais de umidade média mensal do solo durante os anos de 1948 a 2012, a qual é expressa na forma de altura de água média equivalente e tem uma resolução de $0,5^{\circ}$. Esses valores são extraídos de um modelo hidrológico, apresentado pela equação 24, que, de acordo com Huang et al. (1995), calcula a umidade do solo a partir da precipitação e da temperatura.

$$
\frac{d W(t)}{d t}=P(t)-E(t)-R(t)-G(t)
$$

em que $\mathrm{W}(\mathrm{t})$ é a umidade do solo no instante $\mathrm{t}$ em uma coluna de 1,6m de profundidade, $\mathrm{P}(\mathrm{t})$ é a precipitação que ocorreu sobre uma área $\mathrm{A}, \mathrm{E}(\mathrm{t})$ é a evapotranspiração observada sobre uma área $A, R(t)$ é o escoamento observado sobre uma área $A$ e $G(t)$ é a infiltração que ocorreu em uma área $\mathrm{A}$.

Os dados de globais de precipitação mensal são definidos a partir de uma interpolação das precipitações observadas em 17000 estações localizadas sobre a superfície terrestre e a reconstituição de chuvas que ocorreram sobre os oceanos. Já a temperatura mensal é obtida a partir da interpolação de duas bases de dados de sensoriamento remoto: a versão 2 da Global Historical Climatology Network (GHCN) e o Climate Anomaly Monitoring System (CAMS).

Destaca-se, porém que a profundidade de 1,6 m do solo, segundo Dool et al. (2003), foi determinada por meio da aplicação de um modelo de escoamento em diversas pequenas bacias localizadas no leste de Oklahoma. O resultado foi uma capacidade máxima de armazenamento de água no solo de $760 \mathrm{~mm}$. Admitindo uma porosidade de 0,47; obteve-se uma coluna de solo de 1,6 m. Essa profundidade foi considerada satisfatória, com base na ideia de que a evapotranspiração em profundidades maiores ocorre em taxas muito pequenas.

Outra fonte dessa variável no estado do Ceará, cuja localização dos pontos corresponde às estações pluviométricas da FUNCEME, é o modelo de umidade do solo para atividades 
agrícolas, o MUSAG, operado pela FUNCEME. O desenvolvimento desse modelo permitiu um avanço da agricultura em sequeiro, a partir de um maior conhecimento da umidade do solo na região, além de possibilitar a implantação de programas de assistência a pequenos agricultores.

Segundo Molinas e Andrade (1993), esse modelo considera a umidade inicial e os volumes infiltrados, percolados e evapotranspirado para calcular a umidade ao final de cada dia analisado, os quais consideram as características do solo da região analisada. As equações de balanço hídrico, apresentadas a seguir.

$$
\begin{gathered}
\mathrm{USf}=\mathrm{USi}+\mathrm{VI}-\mathrm{VP}-\mathrm{VEVT} \\
\text { VESC }=\operatorname{Pr}-\mathrm{VI}
\end{gathered}
$$

em que USf e USi são as umidades finais e iniciais de cada período avaliado em mm, VI, VP, VEVT e VESC são os volumes infiltrado, percolado, evapotranspirado e escoado, respectivamente, em mm, e Pr é a precipitação.

\subsection{7- Índice de Vegetação por Diferença Normalizada}

Como relatado anteriormente, o NDVI é um índice que tenta representar a condição de saúde da vegetação, por meio da razão entre a diferença e a soma de duas bandas, o infravermelho próximo e o vermelho. Essa ferramenta frequentemente é utilizada em estudos que tentam identificar os impactos da seca no meio e, consequentemente, sua ocorrência.

Um projeto que mantêm satélites em contínua orbita ao redor do globo terrestre, permitindo a coleta dos dados para o cálculo desse índice, é o NASA Earth Observations (NEO). O intuito desse programa, que faz parte do NASA's Earth Observing System (EOS), é capturar as mudanças ambientais e climáticas que ocorrem no meio em tempo real.

Os dados utilizados no presente trabalho, para o cálculo do NDVI pelo NEO, foram produzidos com a utilização das informações coletadas pelo Moderate Resolution Imaging Spectroradiometer (MODIS), que é um instrumento acoplado ao satélite Terra da NASA. 
A série histórica do NDVI, utilizada no presente trabalho, se estende entre os anos de 2000 a 2012 .

\subsection{8- Previsões Climáticas}

O adiantamento dos eventos de seca, não é uma tarefa simples. Segundo Wilks (2006), os processos atmosféricos são caracterizados como um grande caos, impossibilitando o conhecimento de forma precisa do comportamento futuro desse sistema. Essas incertezas geram erros nas condições iniciais que são introduzidas nos sistemas de previsão, os quais se acumulam ao longo das interações realizadas nos cálculos dos modelos de previsão, sendo incorporados aos resultados.

Reis et al. (2007) afirmam que, na tentativa de representar essas incertezas, a FUNCEME adotou a previsão climática probabilística, conhecida como previsão por conjunto. Nessa metodologia, as condições iniciais que cada membro do conjunto está sujeito no início do período avaliado diferem entre si apenas por uma perturbação randômica sobreposta à análise do modelo global.

Segundo Reis et al. (2007), a previsão climática adotada pela FUNCEME é produzida pelo modelo de circulação global (no inglês, Global Circulation Model - GCM) ECHAN4.6, desenvolvido e operado pelo Instituto Max Planck, o qual é delimitado por dois modelos regionais, o Regional Atmospheric Modeling System (RAMS) e o Regional Spectral Model (RSM).

Dentre os fatores que influenciam no clima do Nordeste Brasileiro, Souza Filho (2003) relata que a zona de convergência intertropical (ZCIT) é o processo de maior importância para deflagrar a incidência das chuvas nessa região. $\mathrm{O}$ autor destaca ainda que os campos de temperatura da superfície do mar (TSM) são primordiais para o posicionamento da ZCIT em virtude da mesma ocorrer predominantemente sobre os oceanos.

Essa dependência do clima do Nordeste em relação à ZCIT e as TSMs, explica o fato de a FUNCEME adotar, como dado de entrada no seu sistema de previsão, dois tipos de TSM, prevista ou persistida, gerando dois resultados. 
Essa previsão é feita com base na técnica "dynamical downscaling", que se fundamenta na associação de modelos numéricos dinâmicos de previsão, ou mais especificamente, um Modelo Regional de Clima (MRC), no caso o Regional Spectral Model 1997 (RSM97), forçado a partir de um GCM, no caso o ECHAM4.6.

Sun et al. (2005) caracterizam o RSM como um modelo com resolução espacial de $60 \mathrm{Km}$ no Nordeste brasileiro. O mesmo está localizado em uma área distante das fronteiras laterais, evitando, assim, os ruídos gerados nessa região.

A possibilidade de utilização desses índices como ferramentas de previsão de secas foi verificada por meio da aplicação dos resultados de previsões climáticas passadas das bacias do Banabuiú, Castanhão e Orós, realizadas operacionalmente pela FUNCEME, como dados de entrada para o cálculo do SPI mensal e trimestral. Ressalta-se que a validação das informações produzidas por esses cálculos foi feita com o SPI obtido com a utilização dos dados de precipitação observada da FUNCEME.

Apesar de a FUNCEME também fazer uso do Regional Atmospheric Modeling System (RAMS) na realização das suas previsões climáticas, serão utilizados apenas os resultados provenientes do RSM no presente trabalho, em virtude do mesmo possuir um período de dados disponíveis mais extenso.

\section{2- SELEÇÃO E ANÁLISE DOS ÍNDICES DE SECA}

\subsection{1- Seleção}

Para fazer uma avaliação da utilidade de índices no monitoramento e previsão das secas meteorológicas, hidrológicas e agrícolas, foi realizada, primeiramente, uma extensa revisão bibliográfica dessas ferramentas, observado, dentre outras características, quais das três variações desse fenômeno elas são capazes de identificar.

Em virtude da grande variedade, a seleção teve como critério a preferência por índices que já tenham sido largamente revistos, validados e que serviram de base para o desenvolvimento de outros índices. Outra consideração importante foi à disponibilidade dos dados necessários para realização dos cálculos. 
Os índices adotados na presente pesquisa foram os desenvolvidos por Palmer - o PDSI, o PHDI e o índice Z - o SPI e o SPEI, que são largamente conhecidos e explorados em trabalhos relacionados ao estudo de secas.

Outra ferramenta também escolhida foi o índice desenvolvido pela FUNCEME, o qual foi calculado apenas para as bacias circunscritas no estado do Ceará, em decorrência do mesmo utilizar dados diários de precipitação, os quais foram obtidos apenas nessa região.

Como nesse estado as chuvas se concentram nos meses de fevereiro, março, abril e maio, o que se conhece como quadra chuvosa, optou-se por utilizar os dados de chuva desses quatros meses no cálculo do índice da FUNCEME.

\subsection{2- Identificação das Secas Históricas}

A capacidade dessas ferramentas de monitorar a seca foi avaliada, primeiramente, por meio da comparação das séries temporais dos mesmos com os relatos históricos desse fenômeno, os quais foram extraídos das publicações de Souza Filho (2003), Marengo (2006), Carvalho (2012), Pompeu Sobrinho (1982), Souza e Medeiros Filho (1983).

Para um melhor entendimento do comportamento desses índices ao longo do período avaliado, além da análise visual dos gráficos das séries temporais dos mesmos, decidiu-se realizar uma análise quantitativa do desempenho dos índices tendo como base uma descrição dos diferentes tipos de erros envolvidos no processo. Essa avaliação é baseada em tabelas de contingência, como será explicado na sequência.

Dois tipos de análises foram realizadas. Na primeira, a preocupação é avaliar se os índices são capazes de identificar as secas em cada período histórico, tendo sido elaboradas tabelas de contingência como as apresentadas na Tabela 11. Na segunda análise (Tabela 12), o objetivo é avaliar se os índices são capazes de identificar transições de estado ao longo do tempo, ou seja, se os mesmos possuem bom desempenho em identificar o início (passagem de uma situação normal para uma situação de seca) e o fim (passagem de uma seca para uma situação normal) das secas ao longo dos períodos históricos. Em cada uma das análises, há diferentes tipos de erros envolvidos, o que é discutido a seguir. 
Tabela 11 - Tabela de contingência que investigou os erros e acertos dos índices na determinação da seca em cada instante.

\begin{tabular}{|c|c|c|c|}
\hline & & \multicolumn{2}{|c|}{ Índice } \\
\hline & & 1 & 0 \\
\hline \multirow{2}{*}{ 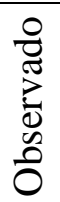 } & - & $\mathrm{a}$ & $\mathrm{b}$ \\
\hline & 0 & $\mathrm{c}$ & $\mathrm{d}$ \\
\hline
\end{tabular}

Na Tabela 11, o evento de seca é indicado pelo número um (1) e a situação oposta pelo zero (0). Essa primeira configuração da tabela de contingência permitiu a quantificação de três tipos de situações. A primeira refere-se à identificação correta da situação, ou seja, quando o índice identifica corretamente a ocorrência ou não de uma seca. Já a segunda situação, denominada aqui de Alarme Falso, é aquela quando o índice identifica a ocorrência de uma seca, mas ela de fato não ocorreu. Por último, temos a situação em que a seca foi de fato relatada, mas o índice não foi capaz de identificá-la, sendo denominado neste estudo de Missed. Essas três situações foram quantificadas pelas equações que seguem.

$$
\begin{gathered}
1^{a} \text { (Correto) } \rightarrow \frac{a+d}{a+b+c+d} \\
2^{a} \text { (Falso Alarme) } \rightarrow \frac{c}{c+d} \\
3^{a} \text { (Missed) } \rightarrow \frac{b}{a+b}
\end{gathered}
$$

Diferente da Tabela 11, a Tabela 12 mostra os possíveis erros e acertos que podem ocorrer durante as transições de um ano para o outro, tendo sido identificadas 16 situações possíveis. A partir dessas situações, criaram-se 5 (cinco) métricas distintas que procuram medir o desempenho dos índices em diferentes situações. A primeira métrica refere-se à proporção de acertos na transição de um ano para o outro. As outras 4 (quatro) métricas estão associadas com a capacidade dos índices identificarem corretamente as transições de condição normal para seca e vice-versa, sendo denominadas de Término Correto, Término Incorreto, Início Correto e Início Incorreto. As equações para o cálculo dos referidos índices são apresentados na sequência. 
Tabela 12 - Tabela de contingência que investigou os erros e acertos dos índices na determinação da seca durante uma transição de tempo.

\begin{tabular}{|c|c|c|c|c|c|}
\hline & & \multicolumn{4}{|c|}{ Índice } \\
\hline & & $(0,0)$ & $(0,1)$ & $(1,0)$ & $(1,1)$ \\
\hline \multirow{4}{*}{ 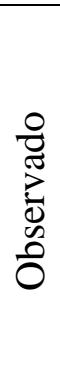 } & $\begin{array}{l}\hat{\theta} \\
\hat{e}\end{array}$ & A & b & $\mathrm{c}$ & d \\
\hline & $\widehat{\vec{e}}$ & $\mathrm{E}$ & $\mathrm{f}$ & $\mathrm{g}$ & $\mathrm{h}$ \\
\hline & $\stackrel{\sigma}{=}$ & I & $\mathrm{j}$ & $\mathrm{k}$ & 1 \\
\hline & 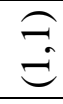 & $\mathrm{M}$ & $\mathrm{n}$ & o & $\mathrm{p}$ \\
\hline
\end{tabular}

PROB.DE ACERTOS

$$
\begin{gathered}
=\frac{a+f+k+p}{a+b+c+d+e+f+g+h+i+j+k+l+m+n+o+p} \\
\text { TÉRMINO CORRETO }=\frac{k}{k+l} \\
\text { TÉRMINO INCORRETO }=\frac{o}{k+o} \\
\text { INICÍO CORRETO }=\frac{f}{e+f} \\
\text { INICÍO INCORRETO }=\frac{b}{b+f}
\end{gathered}
$$

Como a maior parte dos índices, com exceção do elaborado pela FUNCEME, é calculada para cada mês do ano, e as secas descritas na literatura são caracterizadas como um evento anual, foi necessário construir novas séries para cada índice, com discretização anual, em que apenas dois resultados são possíveis, a ocorrência ou a não de uma seca. Para isso, se convencionou que a ocorrência da seca em um dado ano estava associada aos valores dos índices nos meses referentes à estação chuvosa da região estudada. Para o ano ser considerado seco, uma das duas situações apresentadas a seguir deve ocorrer. Caso o ano se inicie em situação de seca (janeiro seco), o mesmo será considerado como seco apenas quando o índice indicar seca para os meses de maio e junho, garantindo assim que o total precipitado durante a quadra chuvosa não foi suficiente para retornar a situação de normalidade. Caso o ano se inicie em situação de normalidade, o mesmo será considerado seco caso pelo menos um mês da quadra chuvosa seja indicado como seco pelo índice. 
No caso dos índices que podem ser calculados de forma acumulada, para diferentes períodos (SPI e SPEI), foram adotados nessa análise os obtidos com os dados acumulados em um (1) ano. Essa escolha, como será mostrada posteriormente, deu-se ao fato de que essa forma desses índices consegue expressar melhor os eventos de seca.

\subsection{3- Comparação dos Índices com Variáveis e Ferramentas que Indicam as Variações do Meio com a Diminuição das Precipitações}

Outra forma de analisar a aplicabilidade desses instrumentos no monitoramento de secas foi por meio de uma comparação dos valores dos mesmos com variáveis que indicam a ocorrência desse evento: volume armazenado nos reservatórios, umidade do solo, vazões afluentes aos reservatórios e o NDVI.

Destaca-se que essas associações foram feitas, dependendo das variáveis empregadas e da região estudada, a nível da bacia hidrográfica contribuinte aos reservatórios relatados anteriormente, por pontos da grade de dados da base CRU e em cada um dos pontos referentes aos postos pluviométricos da FUNCEME.

Além da utilização de variáveis com diferentes localizações, também foram empregados distintos períodos de análise. Como alguns índices podem ser calculados para diferentes períodos de tempo e não se sabe previamente qual o tempo de manifestação das diversas formas da seca, foram adotados períodos de análise de 1 a 48 meses.

Como as variáveis tem uma discretização mensal, diferente de alguns índices (SPI e SPEI), que são calculados para diferentes períodos acumulados, utilizou-se metodologias distintas de comparação dessas variáveis com os índices. No caso do volume dos reservatórios cujas variações ocorrem mais lentamente ao longo do tempo, os índices acumulados foram comparados com o dado dessa variável referente ao último mês de cada período analisado.

Em comparação ao volume dos reservatórios, as vazões apresentam um comportamento mais instável. Assim, as avaliações relacionadas a essa variável foram feitas com a média aritmética da mesma durante o período em que o índice foi calculado. Ressalta-se que, em virtude da característica intermitente dos rios da região avaliada, com vazões 
frequentemente atingindo valores nulos, optou-se por considerar nesse cálculo apenas os meses de janeiro a maio.

Por fim, em relação à umidade do solo, cujos dados aumentam sua magnitude durante os meses da quadra chuvosa e diminuem no restante do ano, sendo esse comportamento apresentado no próximo item, optou-se por comparar os índices acumulados com os máximos valores da umidade em cada período correspondente.

Ainda em relação à umidade do solo, deve-se destacar ainda que, como foram utilizadas duas fontes dessa variável, cujos pontos têm localizações diferentes, as correlações foram calculadas para os pontos correspondentes a grade do CRU e as estações pluviométricas da FUNCEME.

O índice desenvolvido pela FUNCEME também é considerado uma ferramenta acumulada, assim as associações dessa ferramenta com as variáveis que indicam a ocorrência das secas foram, portanto, feitas da mesma forma que os demais índices acumulados. O mesmo, entretanto, diferente do SPI e do SPEI, utiliza no seu cálculo as precipitações diárias dos meses de fevereiro a maio, referentes à quadra chuvosa. Assim, optou-se por compará-lo com o SPI e o SPEI de 6 e 12 meses, sendo o término desses intervalos sempre no mês de maio. Isso se deve ao fato de que esses índices não foram calculados para um período de quatro (4) meses, como é feito com a ferramenta em questão, ao se fixar esse limite, podese, assim, garantir que o valor final do índice será influenciado pela mesma quadra chuvosa utilizada na obtenção do índice da FUNCEME.

Em relação à análise por bacias, como o NDVI e a umidade do solo foram obtidos apenas na forma de pontos de grade, com resolução de $0,5^{\circ}$, foi necessário, então o cálculo dos valores médios dessas variáveis em cada uma das bacias avaliadas. Para obter esses valores foi utilizada a metodologia dos polígonos de Thiessen.

Baseando-se em estudos realizados por Vicente-Serrano et al. (2012), Lorenzo-Lacruz et al. (2010) e Choi et al. (2013), se propôs fazer a comparação entre essas diferentes variáveis por meio do cálculo da correlação de Spearman. Essa medida permite verificar se os índices de seca conseguem representar as variações do meio, expostas pelos dados descritos anteriormente, de forma eficiente, indicando, portanto, a ocorrência da seca. 
O Coeficiente Spearman, obtido pela equação 35, mede o grau de associação entre duas variáveis. Por considerar no seu cálculo, ao invés do valor, o posicionamento dos dados avaliados em uma sequência crescente, não faz qualquer suposição prévia sobre a relação entre as variáveis, conseguindo, assim detectar a existência de relações monotônicas não lineares.

$$
r_{\text {rank }}=1-\frac{6 \sum_{i=1}^{n} D_{i}^{2}}{n\left(n^{2}-1\right)}
$$

em que $\mathrm{D}_{\mathrm{i}}$ é a diferença entre as posições do par de valores avaliados e $\mathrm{n}$ é o tamanho do conjunto de previsões avaliados.

Essas etapas das análises da capacidade de monitoramento dos índices são resumidas pelo fluxograma da Figura 16. Para a obtenção e a análise dos índices de seca adotados no presente trabalho utilizou-se o aplicativo MatLab. O único código que não foi desenvolvido ao longo do presente trabalho foi o adotado na obtenção dos índices de Palmer, sendo empregado o programa desenvolvido no trabalho de Jacobi et al. (2013).

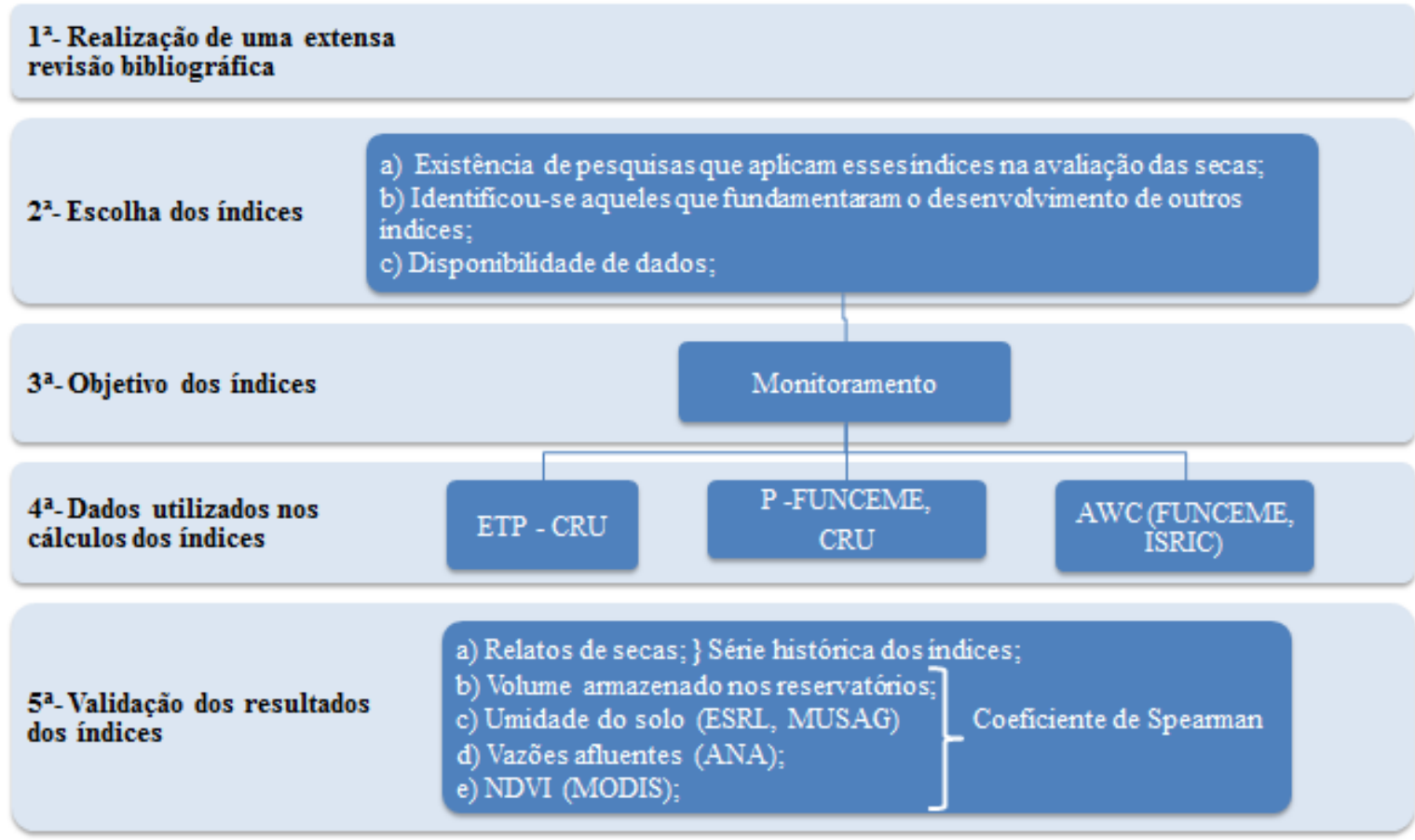

Figura 16 - Etapas e dados da metodologia de análise dos índices. 


\subsection{4- Avaliação da Capacidade de Previsão}

A previsão dos eventos de seca foi avaliada por meio do cálculo do SPI mensal e trimestral, tendo como dados de entrada as previsões climáticas realizadas pela FUNCEME nas bacias contribuintes aos reservatórios do Banabuiú, Castanhão e Orós. Esse estudo só foi, portanto, feita a nível de bacia hidrográfica.

O desempenho dos resultados foi verificado por meio da comparação dos índices calculados com as previsões climáticas da FUNCEME e com os dados observados, por meio do cálculo do brier score (BS), do coeficiente de correlação de Spearman e do skill score (SS).

Dessas métricas, o RPSS, que é necessário para o calculo do SS, e o BS consideram a totalidade dos valores do conjunto, já que a correlação se baseia na estimação da média dos valores previstos. Isso torna essas medidas fundamentais para o entendimento do resultado, uma vez que elas consideram o afastamento de cada um dos membros do conjunto da previsão em relação ao evento observado.

O BS, como apresentado na equação 36, é entendido como o erro médio quadrático da probabilidade de uma dada previsão de exceder um limiar, verificando, portanto, se o evento avaliado foi confirmado pela previsão. Esse valor foi definido como o limite, estipulado por Mckee et al. (1993), para a ocorrência de uma seca severa, segundo o SPI.

$$
B S_{i}(L)=\frac{1}{N} \sum_{i=1}^{N}\left(F_{P_{i}}(L)-I\left(O_{i} \leq L\right)\right)^{2}
$$

em que L é o limiar de referência, $\mathrm{N}$ é a quantidade de previsões, i é a previsão avaliada, $\mathrm{O}$ é o valor observado, $F_{P_{i}}$ é a probabilidade de ocorrência de um determinado valor de severidade de seca, I é um valor binário, que identifica se o que foi observado corresponde ao previsto, isto é, se a severidade da seca observada foi inferior a prevista, sendo zero (0) caso o evento ocorra e um (1) o oposto.

Para se obter o SS é necessário que, anteriormente se obtenha o Ranked Probability Score (RPS), determinado a partir do somatório dos quadrados das diferenças entre as funções de 
probabilidades acumuladas das previsões e as respectivas observações, como mostrada a equação 37. A ideia dessa métrica é atribuir uma maior penalidade aos desvios mais largos entre o previsto e o que realmente foi verificado.

$$
R P S_{h, n}=\sum_{n=1}^{N}\left(F_{p}-F_{o}\right)^{2}
$$

em que $F_{P}$ é a probabilidade acumulada da previsão estar em determinada classe, $F_{O}$ é a probabilidade da observação estar em determinada categoria, assumindo o valor unitário caso $P_{h, n}$ seja superior ou igual ao verificado e zero (0), caso ocorra o oposto. Foram adotadas cinco classes de referência para o cálculo do RPS, as quais são apresentadas na Tabela 13.

Tabela 13 - Limites das classes de referência do cálculo do RPS.

\begin{tabular}{|c|c|}
\hline $\mathrm{N}^{\mathbf{o}}$ & Limites \\
\hline 0 & $0 ;-1 ;-1,5 ;-2$ \\
\hline 1 & $1 ; 0 ;-1$ \\
\hline
\end{tabular}

O RPS deve ser obtido para cada par de valores previstos e observados, sendo, caso se disponha de um conjunto de previsões para um determinado horizonte de tempo, calculada uma média dos RPS obtidos para cada par avaliado, como apresentado na equação 38.

$$
R P S=\frac{1}{N} \sum_{n=1}^{N} R P S_{h, n}
$$

O SS, calculado pela equação 39, é uma medida de precisão relativa que compara o RPS médio calculado com os dados observados como referência, e o estimado tendo como padrão os valores climatológicos.

$$
S S_{R P S}=1-\frac{R P S}{R P S_{\text {clim }}}
$$

Ao se analisar as previsões concedidas pela FUNCEME, percebeu-se que as mesmas eram caracterizadas por um baixo período de extensão, estando disponíveis durante os anos de 
2007 a 2014, além de um pequeno número de componentes do conjunto, sendo formadas por apenas dez (10) valores cada previsão.

Müler et al. (2005) afirmam que o RPS calculado com dados que apresentem esses atributos pode originar diversos erros. No estudo elaborado por esses pesquisadores, o SS calculado com previsões por conjunto com 40 membros apresentou intervalos de confiança significativamente mais próximos que quando se trabalhou com conjuntos com cinco (5) membros. Esse trabalho resultou na equação 40, que permite a remoção do negativo viés presente nos valores do RPSS, quando se analisa esse segundo tipo de previsões.

$$
S S_{D}=1-\frac{\sum_{k=1}^{N} R P S}{\frac{1}{q} \sum_{k=1}^{N} \sum_{l=1}^{q} R P S_{c l i m}}
$$

em que q é o número de reamostragens realizadas, o qual foi igual a 1000 no presente estudo para garantir que a climatologia seja completamente representada. 


\section{6- RESULTADOS}

\section{1- IDENTIFICAÇÃO DAS SECAS HISTÓRICAS COM OS ÍNDICES DE SECA}

O primeiro passo na avaliação dos índices de seca foi o de verificar se os mesmos foram capazes de identificar e caracterizar os episódios de secas históricas, o que inclui a identificação do início, fim e severidade das mesmas. Para isto, se contrapôs as séries temporais dos mesmos com eventos extremos de seca relatados na literatura.

É importante destacar que os índices abordados no presente trabalho foram propostos para identificar apenas um tipo de seca. O SPI, por exemplo, está associado à seca meteorológica. Entretanto, não foi feita uma caracterização detalhada das secas consideradas no presente trabalho, determinando se as mesmas foram meteorológicas, agrícolas ou hidrológicas. Também é importante salientar que muitos dos relatos de secas históricas, como mostrado anteriormente, estão associados a impactos que não são perceptíveis aos índices, como a quantidade de pessoas afetadas e de animais mortos devido a escassez de água. Outra dificuldade nesse estudo é a identificação das áreas afetadas por cada evento, já que a densidade de monitoramento muitas vezes não é adequada.

Como a discretização temporal mínima desses relatos é anual, foi necessário reorganizar as séries de cada índice de forma que houvessem apenas dois resultados possíveis num dado ano, a ocorrência ou não ocorrência de uma seca. A identificação da ocorrência de seca em cada ano foi baseada, num primeiro momento, nos limites pré-estabelecidos pelos autores de cada índice. Na sequência, a fim de avaliar se outros limites seriam mais adequados à região de estudo, realizou-se uma análise mais detalhada dos erros e acertos na identificação das secas históricas, variando os limites de cada índice. Nessa análise, adotaram-se as métricas definidas na seção 5.2.2, de forma que fosse possível entender melhor a capacidade de tais índices em identificar o início, o fim, e a severidade das secas.

Ao se fazer essa comparação usando as séries históricas do SPI e do SPEI para diferentes períodos de acumulação, observou-se que o desempenho dos mesmos na identificação das 
secas foi melhor quando acumulados para o período de um (1) ano, além de terem se assemelhado mais aos valores do PDSI e do PHDI. As Figuras 17 a 20, referentes à bacia contribuinte ao reservatório do Banabuiú, ilustram esse fato.

Em cada um dos gráficos, existe uma linha horizontal que representa o limiar sugerido pelo autor de cada uma dessas ferramentas, o qual indica o início e o fim do evento de seca. Ao se fazer uma análise visual dos gráficos, percebe-se que os valores do SPI e SPEI são muito similares. Porém, como os limiares adotados são diferentes, as taxas de identificação das secas históricas são distintas. Pode-se observar que o SPEI foi capaz de identificar todas as secas históricas relatadas, tendo um desempenho superior ao SPI, entretanto a taxa de Falso Alarme foi relativamente mais alta. O SPI, por sua vez, apesar de apresentar uma taxa de Alarme Falso pequena, não foi capaz de identificar alguns eventos relatados na literatura. Esses erros de identificação estão relacionados com os limiares utilizados na análise. Mais a frente, serão apresentados os resultados quantitativos desses erros e acertos para diferentes valores de limiares. Destaca-se ainda que, apesar da diferença desse valor limite entre o SPEI e os índices de PALMER, muitos dos erros verificados no reconhecimento das secas por esses índices ocorreram em períodos similares.

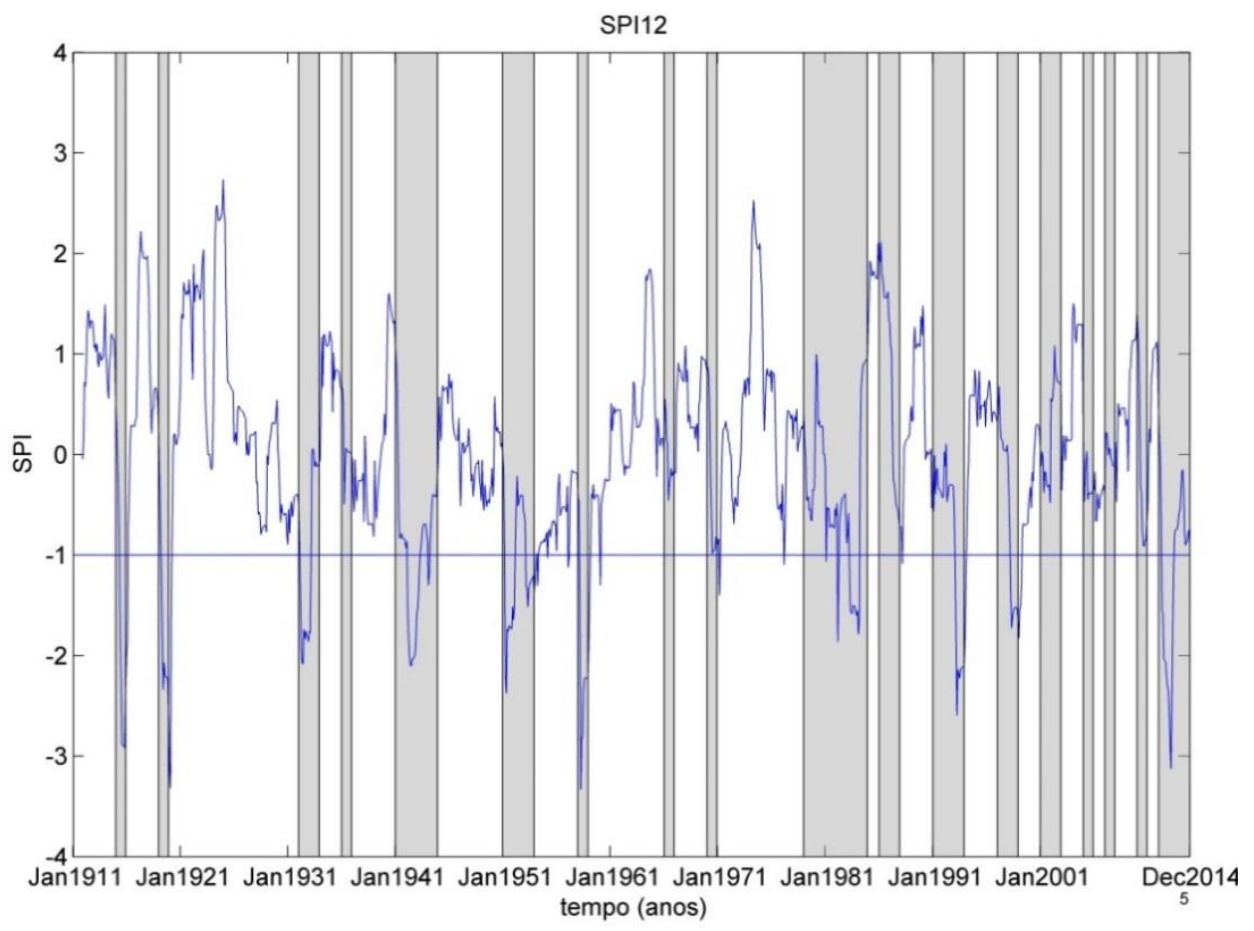

Figura 17 - SPI12 da bacia contribuinte ao reservatório do Banabuiú. 


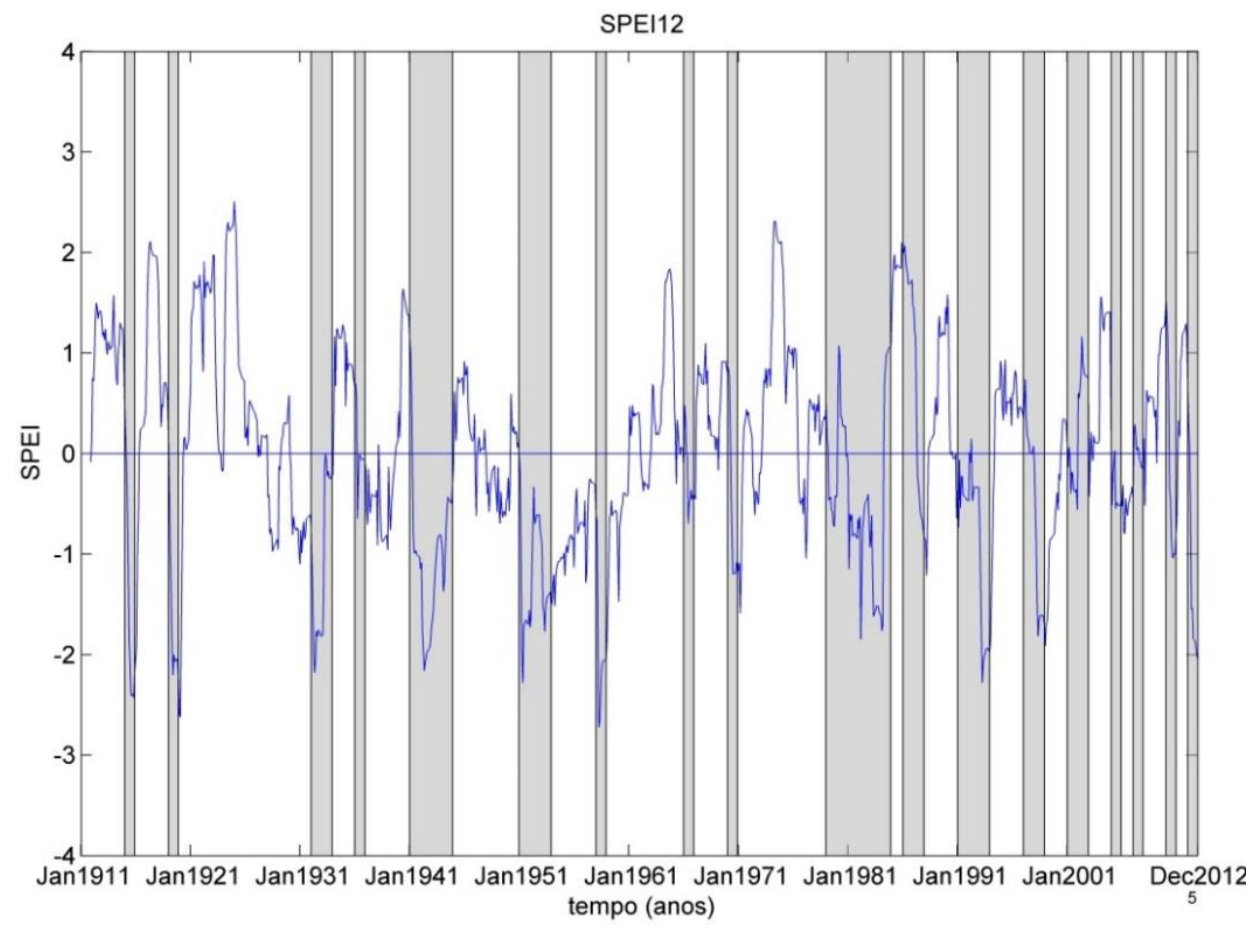

Figura 18 - SPEI12 da bacia contribuinte ao reservatório do Banabuiú.

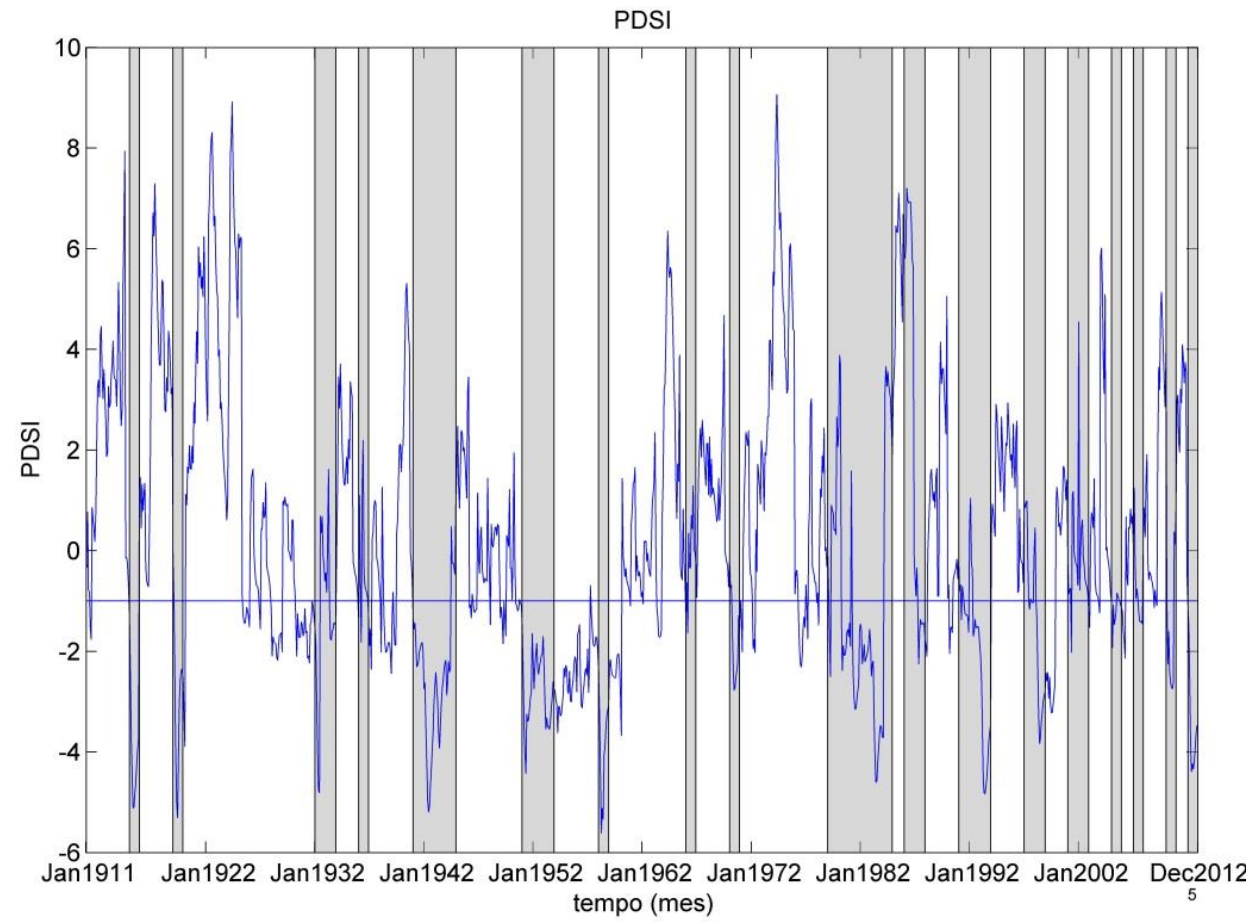

Figura 19 - PDSI da bacia contribuinte ao reservatório do Banabuiú. 


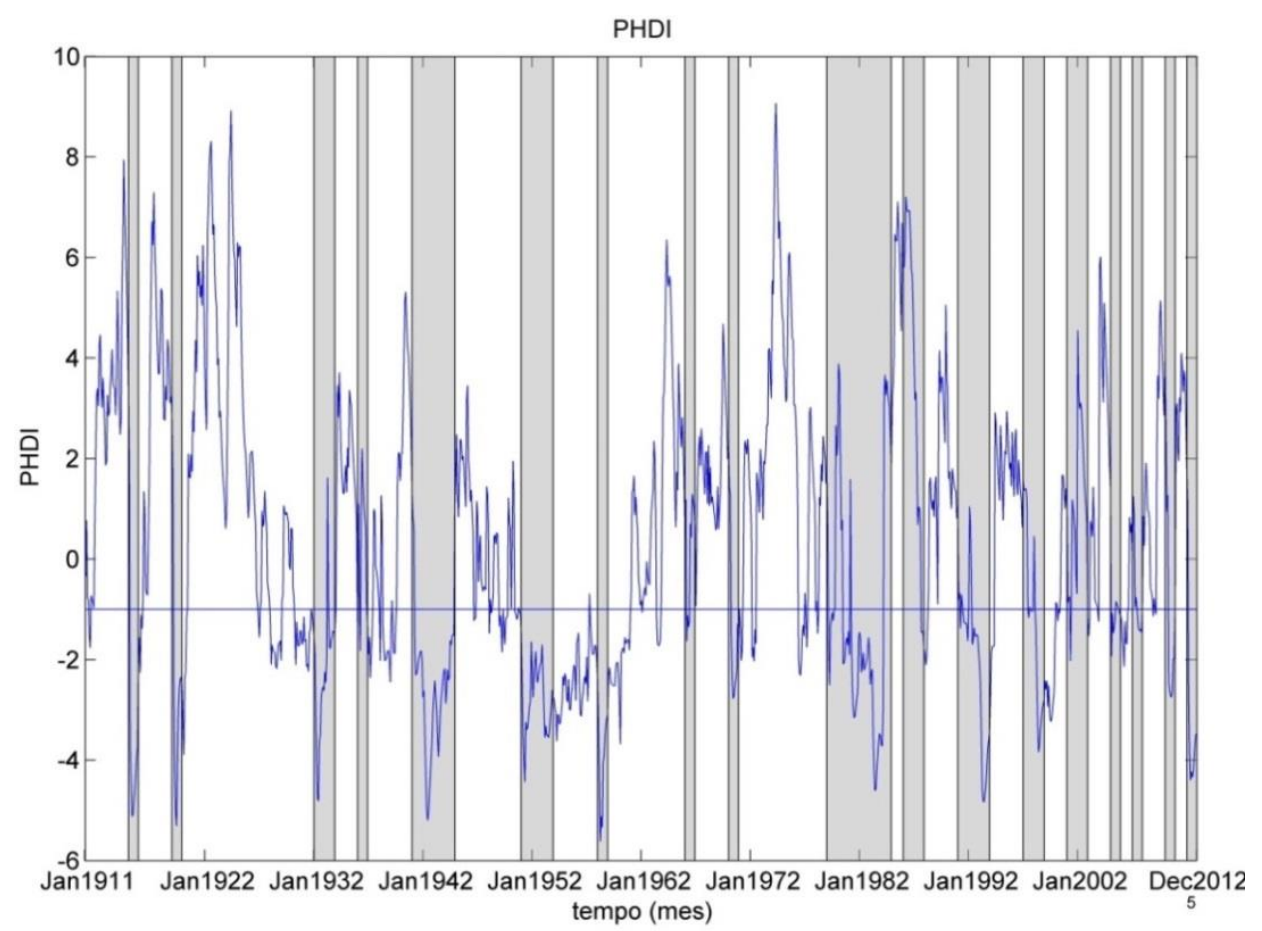

Figura 20 - PHDI da bacia contribuinte ao reservatório do Banabuiú.

Como relatado anteriormente, no calculo dos índices de Palmer, parte das séries dos dados é utilizada na obtenção de determinados parâmetros. O período utilizado na obtenção desses valores foi desconsiderado no cálculo das correlações desses índices. Entretanto, a comparação das séries completas do PDSI e do PHDI com as secas históricas, mostra que, diversos períodos secos, foram identificados nesse período de calibração, como se observa nas Figuras 19 e 20.

$\mathrm{O}$ índice $\mathrm{Z}$ não foi considerado nessa comparação com as secas históricas porque ele apresenta uma alta frequência de variação, quando comparado com os outros índices de Palmer. $\mathrm{O}$ índice $\mathrm{Z}$ se assemelha ao SPI e ao SPEI mensais, o que prejudica a identificação da seca a nível anual.

Como aconteceu com o SPEI, os índices de Palmer conseguem capturar todas as secas relatadas na literatura. Entretanto, também se verifica uma maior quantidade de Falso Alarme, em comparação ao SPI. Outro problema, que visualmente é mais frequente no SPEI e nos índices de Palmer, é a maior quantidade de erros na determinação do início e do término das secas, o que poderia desencadear diversos erros em um sistema de assistência aos municípios afetados pela seca, por exemplo. 
É importante salientar que, apesar de os valores mínimos do PDSI e do PHDI serem diferentes aos alcançados pelo SPI e o SPEI, eles possuem escalas distintas. Assim, a seca severa, no primeiro caso, é identificada ao serem atingidos valores iguais ou inferiores à -3, já no segundo, o limiar desse evento é -2 .

Apesar do relato de diversos autores, apresentados anteriormente, de que a seca que ocorreu entre os anos de 1979 a 1983 foi a mais severa do século XX, apenas o SPI de 24 meses referente à bacia do reservatório do Orós apresentou valores de severidade desse período sensivelmente mais elevados que os demais, como se verifica na Figura 21.

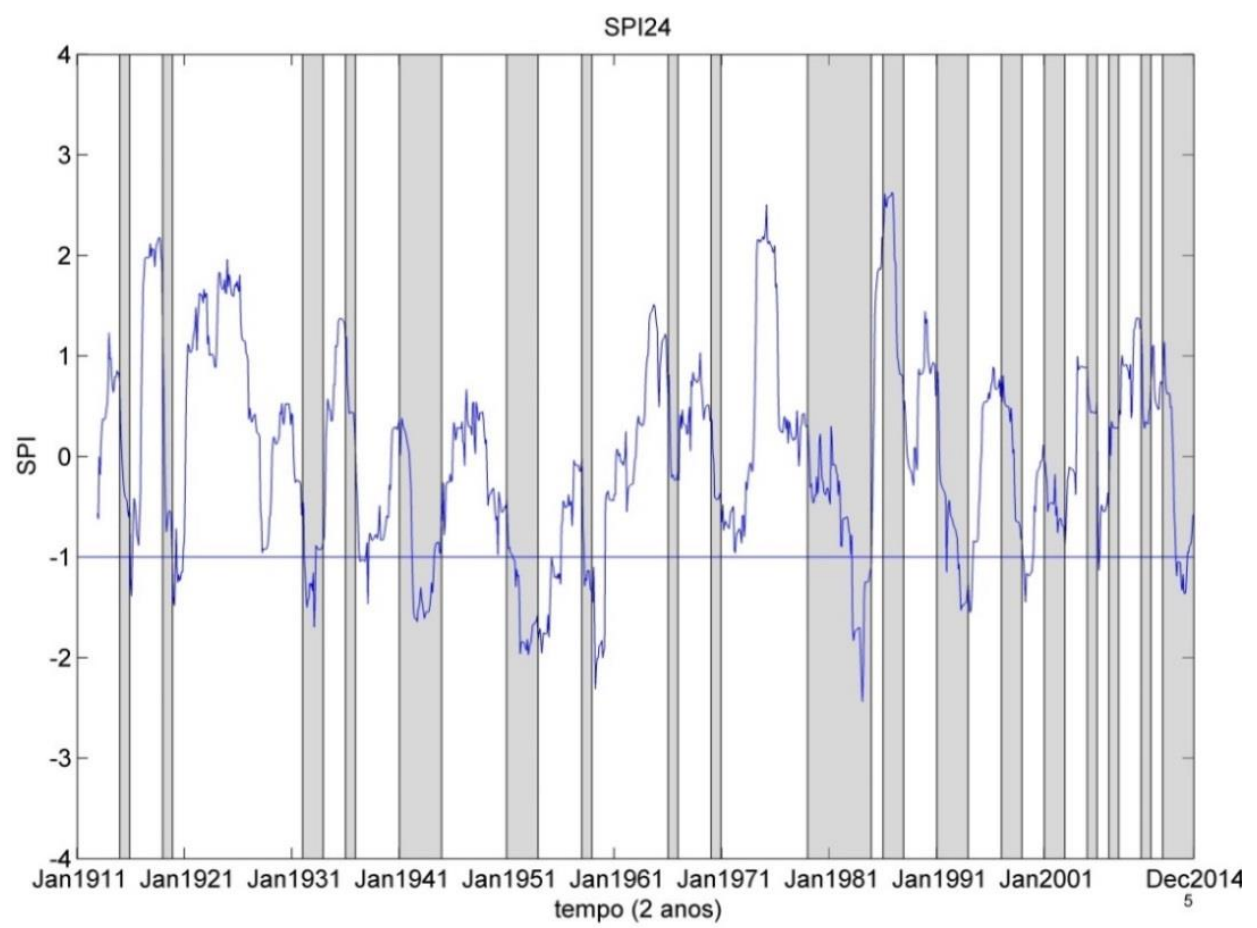

Figura 21 - SPI24 da bacia contribuinte ao reservatório do Orós.

A Figura 21 também mostra que, quando se adotam o SPI e o SPEI acumulados em períodos maiores que 12 meses, ocorre uma redução dos valores de severidade da seca, em virtude de se considerar mais de uma quadra chuvosa. Essa característica determina uma menor variabilidade dos valores desses índices, fazendo com que, apesar da eliminação de alguns falsos alarmes, sejam indicados períodos de seca maiores que os relatados na literatura. Percebe-se, portanto, que, dentre as opções de acumulação desses índices, é preferível se adotarem períodos de um (1) ano. 
A Figura 22 mostra a série temporal do índice elaborado pela FUNCEME, calculado nas três bacias pertencentes ao estado do Ceará. Ao se identificarem os períodos de seca nesse gráfico, os quais são representados pelas áreas sombreadas de cinza, nota-se que a maior parte dos mesmos coincide com os maiores picos do índice.

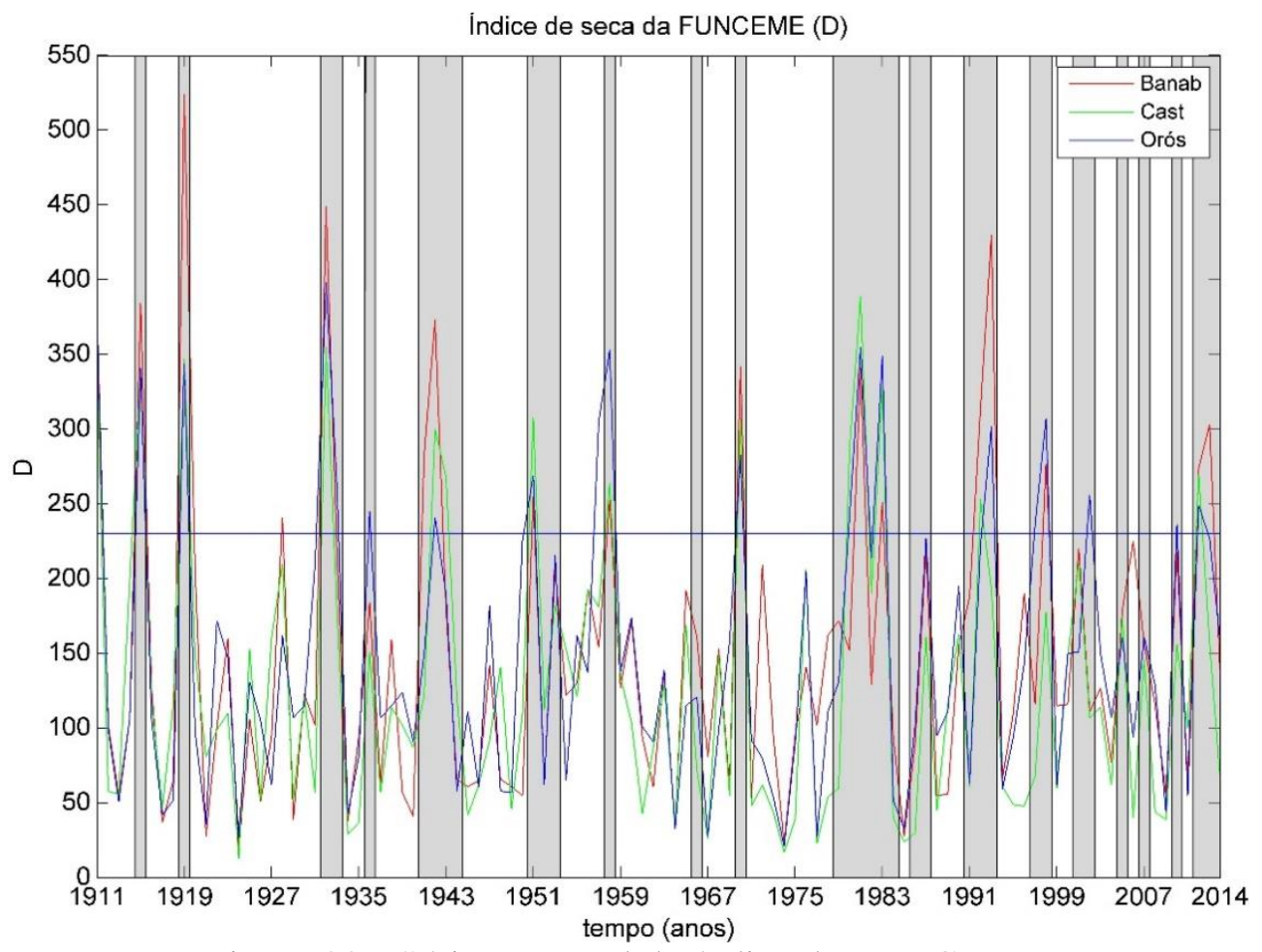

Figura 22 - Série temporal do índice da FUNCEME.

Novamente, de forma semelhante ao SPI, verifica-se que algumas secas não foram identificadas pelo índice. Apesar de que, visualmente, a quantidade de Falso Alarme é significativamente inferior às apresentadas pelo SPEI e os índices de Palmer.

Como verificado com a grande maioria das séries dos demais instrumentos de caracterização das secas, o índice da FUNCEME também não consegue identificar o episódio que ocorreu entre os anos de 1979 a 1983, como o mais severo do século XX.

Apesar de não haver um limiar pré-estabelecido, a partir do qual o índice da FUNCEME reconhece a ocorrência de uma seca, a fronteira que separa a maior parte dos eventos extremos que foram indicados corretamente e os demais valores do índice está entre 200 e 250. Assim, foi proposto um limiar de 235 para esse índice, o qual é delimitado pela linha azul horizontal mostrada na Figura 22. 
Como relatado anteriormente, o índice da FUNCEME foi elaborado na tentativa de reconhecer a ação da seca sobre as culturas de milho, podendo, portanto, ser considerado um índice agrícola. Essa característica torna fundamental a coleta de dados que indiquem se todos os eventos destacados na Figura 22 foram, realmente, secas agrícolas. Pompeu Sobrinho (1982) relata que, em 1915, a menor incidência de chuvas no estado do Ceará, desencadeou a redução da vegetação que em condições normais se desenvolve nessa região. Esse relato confirma, assim, a ocorrência de uma seca agrícola nesse ano, a qual é confirmada pela Figura 22. Pompeu Sobrinho (1982) também confirma a incidência da seca agrícola nesse ano em locais próximos à área de estudo, ao afirmar que a redução dos níveis de chuva não permitiu o crescimento das lavouras no baixo Jaguaribe e ribeira do Apodí.

A similaridade entre os resultados desses índices também pode ser verificada ao se listarem, em ordem crescente, as dez secas históricas mais severas, segundo cada uma dessas ferramentas. Essa relação é apresentada na Tabela 14.

Tabela 14 - Relação das secas históricas mais severas segundo os índices avaliados.

\begin{tabular}{|c|c|c|c|c|c|}
\hline ORDEM & SPI12 & SPEI12 & PDSI & PHDI & D \\
\hline 1 & 1958 & 1958 & 1958 & 1958 & 1919 \\
\hline 2 & 1919 & 1919 & 1919 & 1919 & $1932 / 33$ \\
\hline 3 & 1915 & 1915 & $1941 / 44$ & $1941 / 44$ & $1991 / 92 / 93$ \\
\hline 4 & $1991 / 92 / 93$ & $1951 / 53$ & 1915 & 1915 & 1915 \\
\hline 5 & $1951 / 1953$ & $1991 / 92 / 93$ & $1991 / 92 / 93$ & $1991 / 92 / 93$ & $1941 / 44$ \\
\hline 6 & 2012 & $1932 / 33$ & $1932 / 33$ & $1932 / 33$ & 1970 \\
\hline 7 & $1941 / 44$ & $1941 / 44$ & $1979 / 84$ & $1979 / 84$ & $1979 / 84$ \\
\hline 8 & $1932 / 33$ & 2012 & $1951 / 53$ & $1951 / 53$ & $1997 / 98$ \\
\hline 9 & $1979 / 1984$ & $1997 / 98$ & $1997 / 98$ & $1997 / 98$ & 2012 \\
\hline 10 & $1997 / 1998$ & $1979 / 1984$ & 1970 & 1970 & $1951 / 53$ \\
\hline
\end{tabular}

Ao se compararem os eventos históricos que foram capturados pelos índices, pode-se concluir que a seca de 2012 não foi identificada pelo PDSI e o PHDI. Os índices de Palmer, entretanto, atribuíram uma elevada severidade a seca de 2012, mas os maiores valores desse evento foram desconsiderados na composição da Tabela 14, em virtude de o SPEI12 se estender apenas até janeiro de 2012, sendo eliminados dessa análise os dados dos outros índices que representassem períodos depois dessa data, com exceção do índice da FUNCEME, para o qual se observaram os anos entre 1911 e 2012. 
O índice da FUNCEME, segundo a Tabela 14, não observou a seca de 1958. O mesmo, entretanto, atribuiu um alto valor de severidade para esse evento, o qual é muito próximo ao do evento de 1951/53, mas ele ocupa a décima primeira posição da listagem das secas mais severas, segundo essa ferramenta, fazendo com que a mesma não apareça na Tabela 14.

A comparação entre as secas relatadas por Pompeu Sobrinho (1982) e Souza e Medeiros Filho (1983) também permitiu a avaliação da eficiência dos índices de seca. Um exemplo dessa análise é apresentado nas Figuras 23 a 27, cujos dados são referentes à bacia contribuinte ao reservatório do Castanhão.

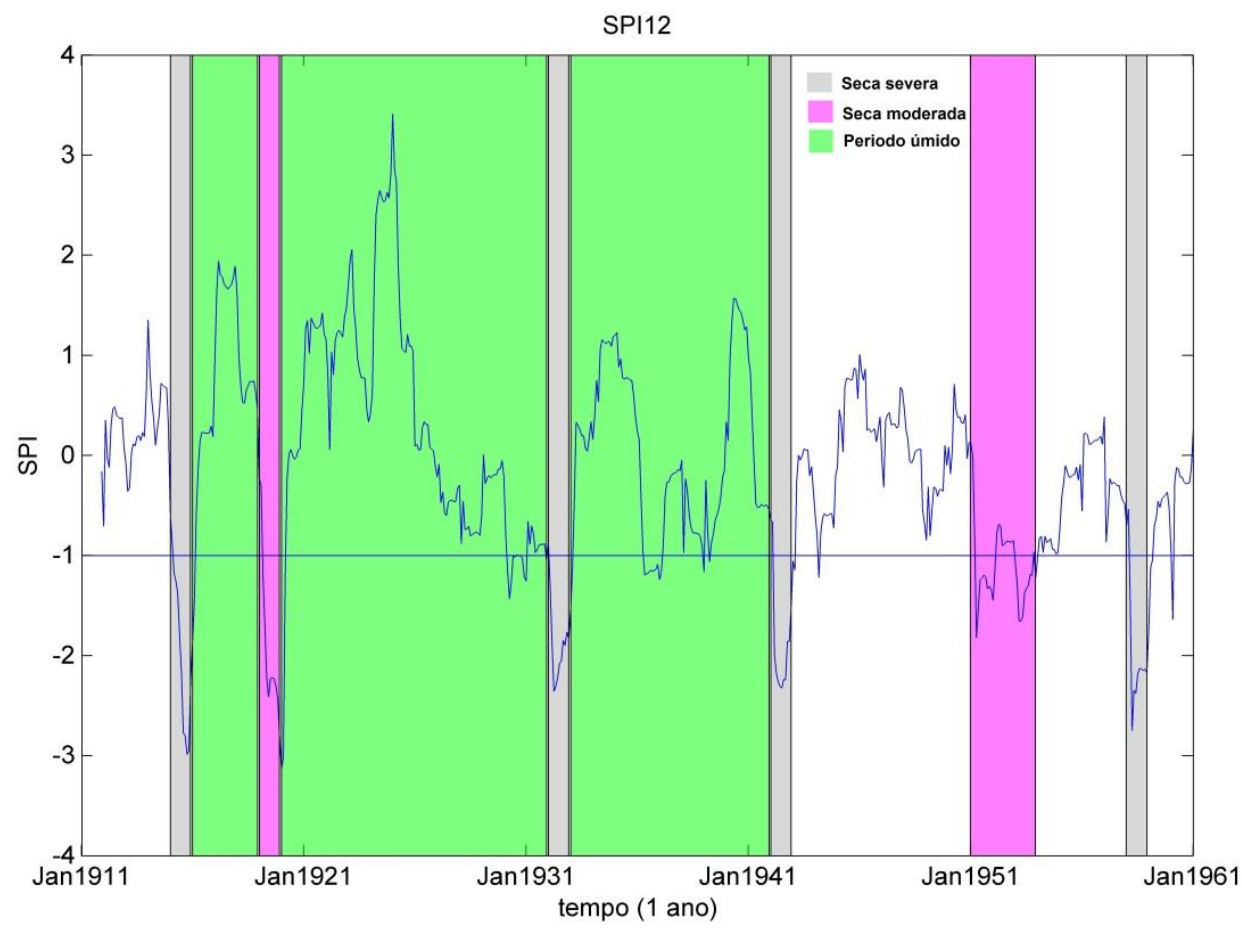

Figura 23 - SPI12 da bacia contribuinte ao reservatório do Castanhão. Área em verde corresponde ao período úmido, em lilás, é uma seca moderada e em cinza, uma seca severa. 


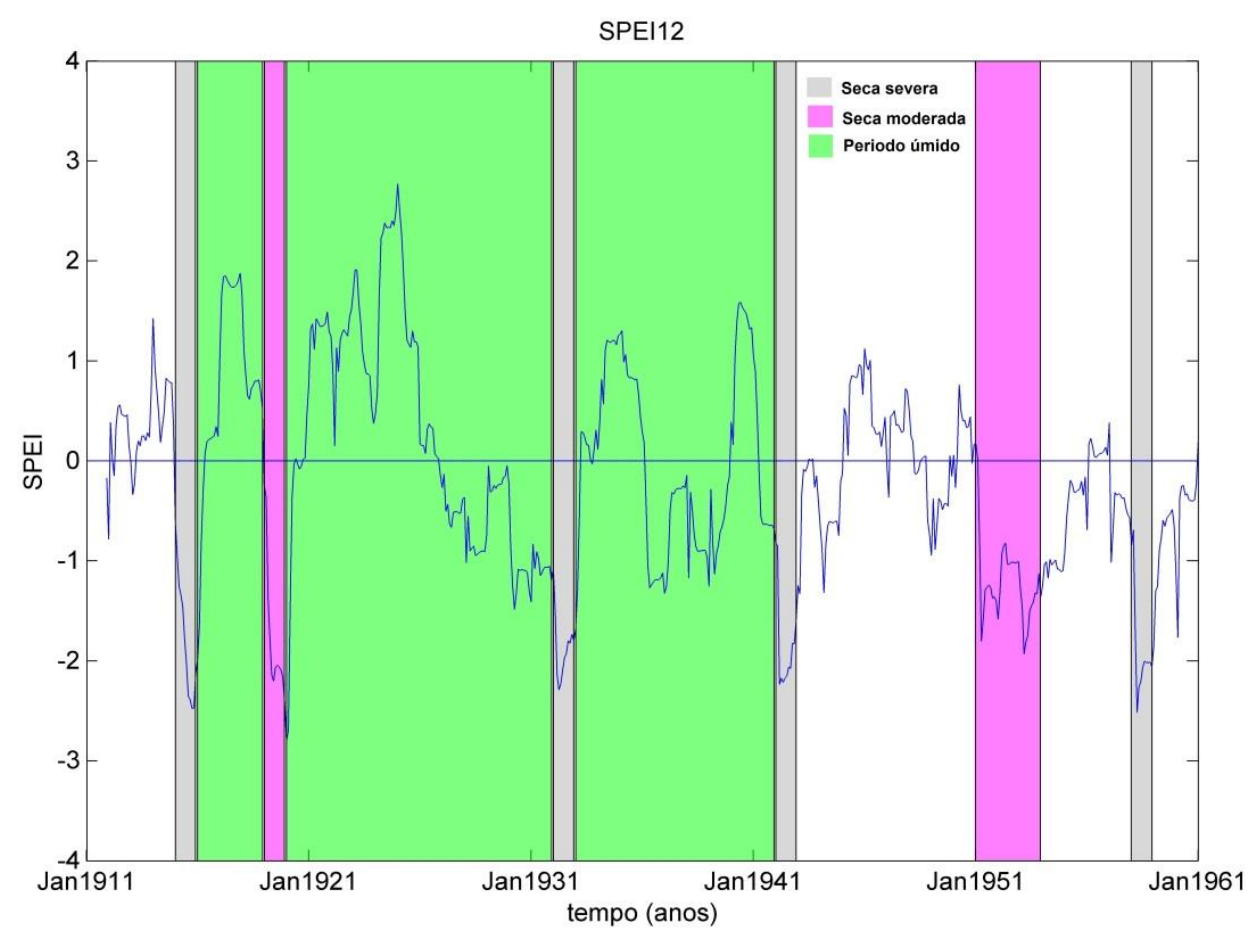

Figura 24 - SPEI12 da bacia contribuinte ao reservatório do Castanhão. Área em verde corresponde ao período úmido, em lilás, é uma seca moderada e em cinza, uma seca severa.

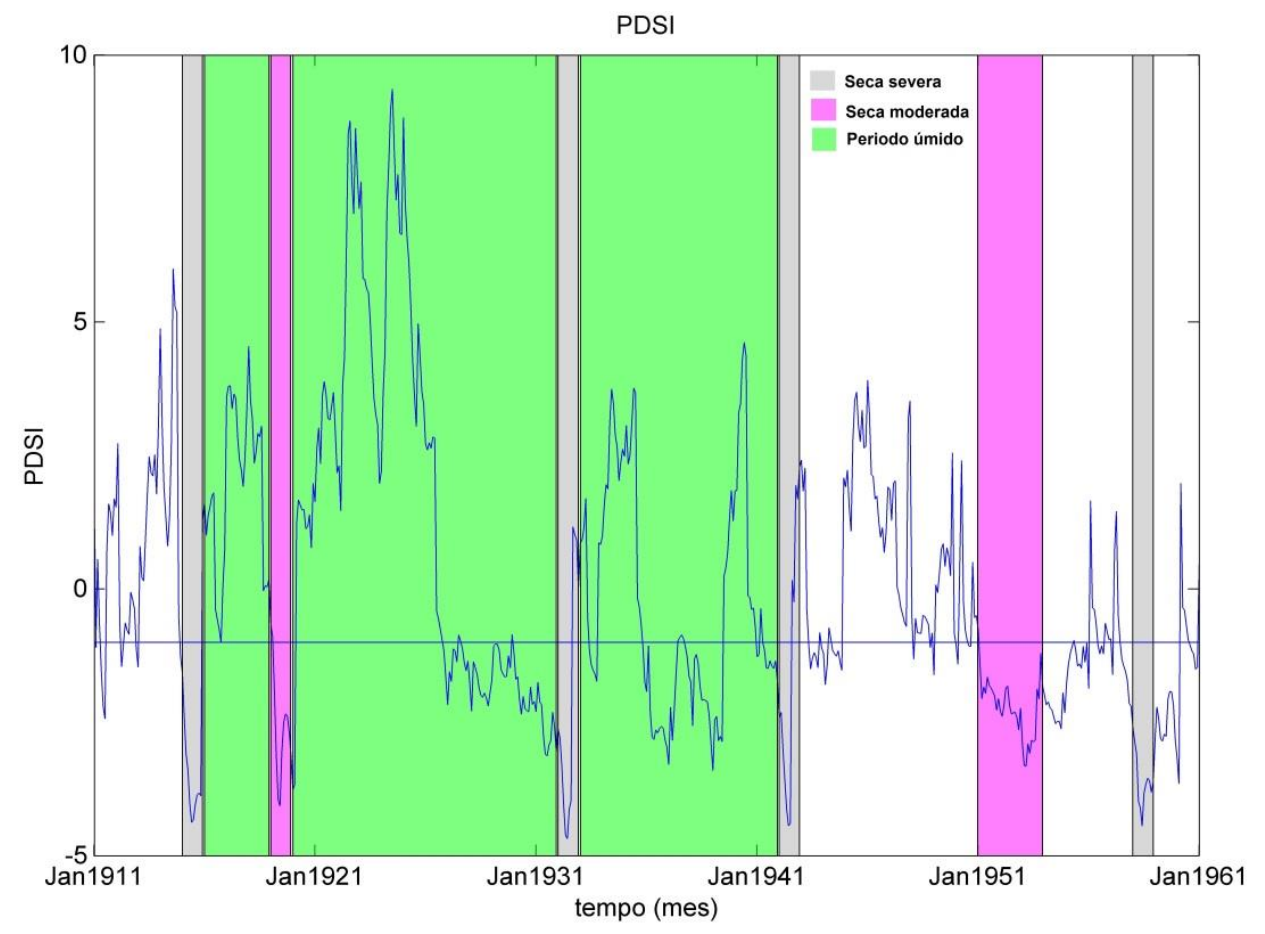

Figura 25 - PDSI da bacia contribuinte ao reservatório do Castanhão. Área em verde corresponde ao período úmido, em lilás, é uma seca moderada e em cinza, uma seca severa. 


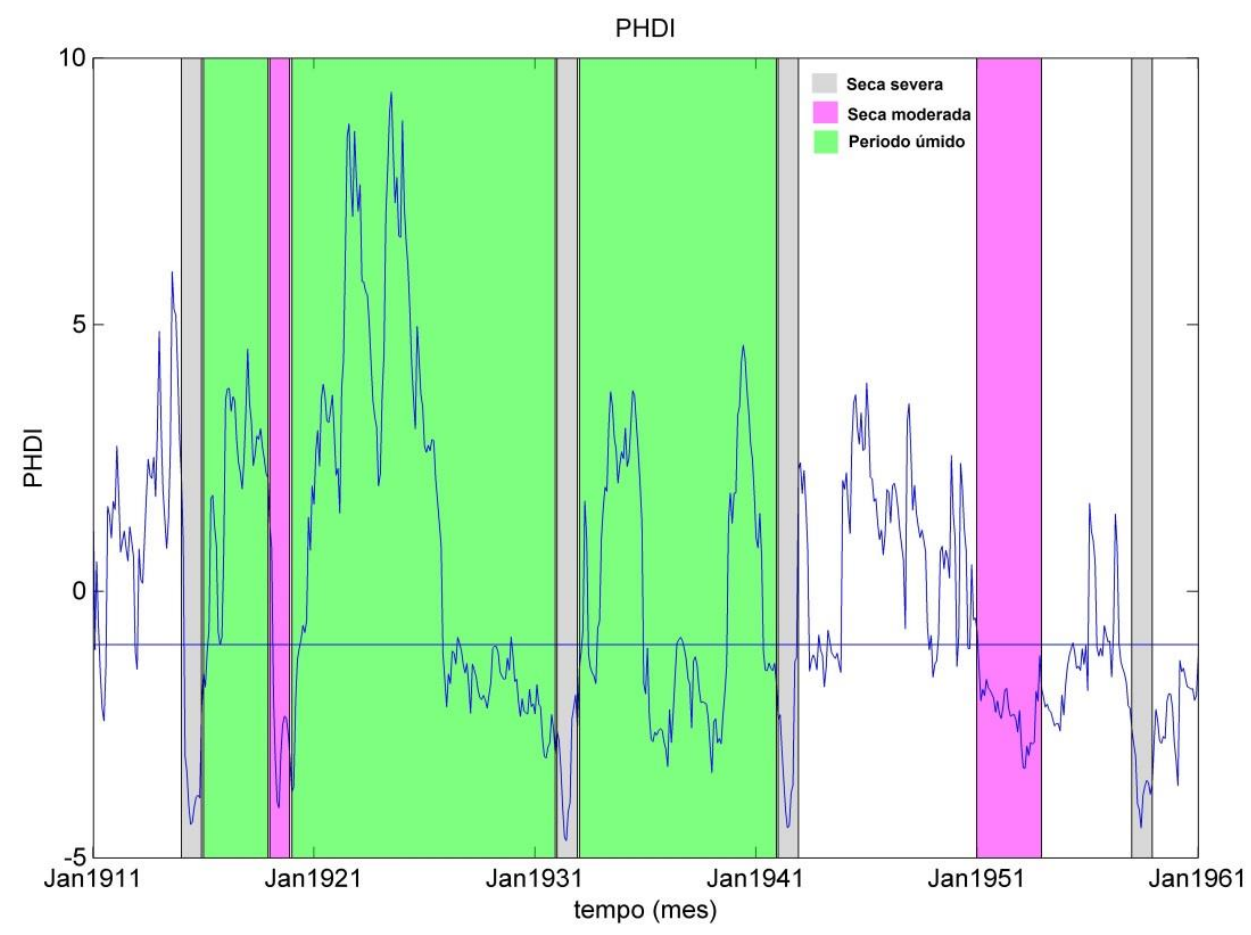

Figura 26 - PHDI da bacia contribuinte ao reservatório do Castanhão. Área em verde corresponde ao período úmido, em lilás, é uma seca moderada e em cinza, uma seca severa.

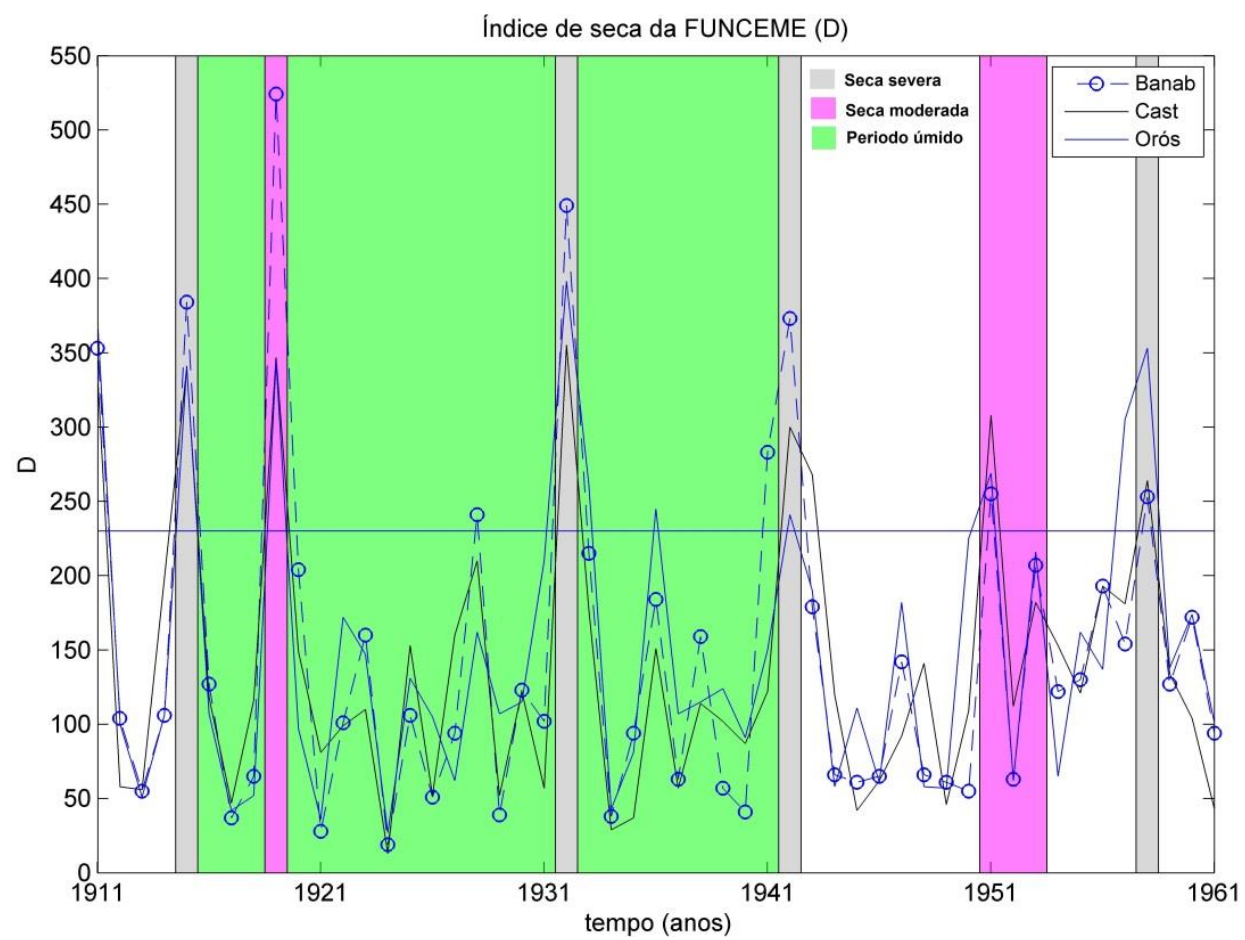

Figura 27 - Índice da FUNCEME da bacia contribuinte ao reservatório do Castanhão. Área em verde corresponde ao período úmido, em lilás, é uma seca moderada e em cinza, uma seca severa. 
Todos os índices caracterizam a seca de 1919 com uma severidade igual ou superior a de 1915. Pompeu Sobrinho (1982) relata, entretanto, que o primeiro evento foi um período seco curto, desencadeando menores impactos na população.

Dentre as ferramentas apresentadas nas Figuras 23 a 27, apesar de apenas o PHDI, ter sido originalmente proposto como um índice hidrológico, o SPI12, o SPEI12 e o índice da FUNCEME, por considerarem uma estação chuvosa completa, poderiam também ser utilizados para indicar secas hidrológicas. Os relatos apresentados por Pompeu Sobrinho (1982) afirmam que alguns reservatórios do Ceará apresentavam níveis satisfatórios de água em 1919. Esses índices, entretanto, mostram valores de severidade muito próximos aos de 1915, quando foi relatada uma seca hidrológica, o que indica que esses índices não foram capazes distinguir essa seca da meteorológica.

A maior parte dos índices confirma a informação relatada por Souza e Medeiros Filho (1983) de que a seca de 1958 foi a mais severa da década de 50. Apenas o índice da FUNCEME, calculado com os dados das bacias do Castanhão e do Banabuiú, apresentou a seca de 1951 como a mais severa desse período.

A fim de realizar uma análise quantitativa do desempenho desses índices na identificação das secas ocorridas no passado, decidiu-se empregar um conjunto de métricas definidas anteriormente, que descrevem os erros e acertos dessa análise. Os resultados obtidos com base nos limiares sugeridos pelos próprios autores dos índices, com exceção do elaborado pela FUNCEME, são apresentados na Tabela 15.

Tabela 15 - Verificação dos erros e acertos dos índices na determinação da ocorrência da seca.

\begin{tabular}{|c|c|c|c|c|c|c|c|c|c|}
\hline & & \multicolumn{3}{|c|}{ Avaliação Anual } & \multicolumn{5}{|c|}{ Avaliação da Transição dos Estados } \\
\hline Índice & Bacias & Correto & $\begin{array}{c}\text { Falso } \\
\text { Alarme }\end{array}$ & Missed & Acertos & $\begin{array}{l}\text { Término } \\
\text { Correto }\end{array}$ & $\begin{array}{c}\text { Falso } \\
\text { Término }\end{array}$ & $\begin{array}{l}\text { Início } \\
\text { Correto }\end{array}$ & $\begin{array}{l}\text { Falso } \\
\text { Início }\end{array}$ \\
\hline $\begin{array}{c}\text { SPI12 } \\
(-1)\end{array}$ & \multirow{3}{*}{ Banab. } & 0,728 & 0,090 & 0,611 & 0,520 & 1,000 & 0,455 & 0,235 & 0,500 \\
\hline $\begin{array}{c}\text { SPEI12 } \\
(0)\end{array}$ & & 0,644 & 0,448 & 0,176 & 0,430 & 0,429 & 0,333 & 0,800 & 0,500 \\
\hline $\begin{array}{c}\text { PDSI } \\
(-1)\end{array}$ & & 0,716 & 0,324 & 0,206 & 0,515 & 0,667 & 0,200 & 0,643 & 0,500 \\
\hline
\end{tabular}


Tabela 15. Continuação.

\begin{tabular}{|c|c|c|c|c|c|c|c|c|c|}
\hline $\begin{array}{c}\text { PHDI } \\
(-1) \\
\end{array}$ & \multirow{2}{*}{ Banab. } & 0,686 & 0,353 & 0,235 & 0,495 & 0,417 & 0,375 & 0,769 & 0,375 \\
\hline $\begin{array}{c}\mathrm{D} \\
(235)\end{array}$ & & 0,780 & 0,030 & 0,580 & 0,620 & 1,000 & 0,500 & 0,440 & 0,110 \\
\hline $\begin{array}{c}\text { SPI12 } \\
(-1)\end{array}$ & \multirow{5}{*}{ Cast. } & 0,806 & 0,030 & 0,500 & 0,657 & 1,000 & 0,333 & 0,500 & 0,182 \\
\hline $\begin{array}{c}\text { SPEI12 } \\
(0)\end{array}$ & & 0,634 & 0,448 & 0,206 & 0,420 & 0,385 & 0,375 & 0,750 & 0,438 \\
\hline $\begin{array}{c}\text { PDSI } \\
(-1)\end{array}$ & & 0,745 & 0,279 & 0,206 & 0,604 & 0,786 & 0,154 & 0,714 & 0,333 \\
\hline $\begin{array}{c}\text { PHDI } \\
(-1) \\
\end{array}$ & & 0,735 & 0,279 & 0,235 & 0,584 & 0,643 & 0,250 & 0,714 &, 231 \\
\hline $\begin{array}{c}\mathrm{D} \\
(235) \\
\end{array}$ & & 0,770 & 0,010 & 0,640 & 0,600 & 1,000 & 0,640 & 0,390 & 0,000 \\
\hline $\begin{array}{c}\text { SPI12 } \\
(-1)\end{array}$ & \multirow{5}{*}{ Orós } & 0,767 & 0,075 & 0,528 & 0,578 & 0,750 & 0,455 & 0,389 & 0,222 \\
\hline $\begin{array}{c}\text { SPEI12 } \\
(0)\end{array}$ & & 0,663 & 0,418 & 0,176 & 0,460 & 0,500 & 222 & ,727 &, 500 \\
\hline $\begin{array}{c}\text { PDSI } \\
(-1)\end{array}$ & & 0,755 & 0,279 & 0,176 & 0,594 & 0,643 & 0,182 & 0,800 & 0,333 \\
\hline $\begin{array}{c}\text { PHDI } \\
(-1)\end{array}$ & & 0,735 & 0,265 & 0,265 & 0,554 & 0,583 & 0,222 & 0,688 & 0,389 \\
\hline $\begin{array}{c}\mathrm{D} \\
(235)\end{array}$ & & 0,810 & 0,030 & 0,500 & 0,680 & 1,000 & 0,330 &, 530 & 0,100 \\
\hline $\begin{array}{c}\text { SPI12 } \\
(-1)\end{array}$ & \multirow{4}{*}{ Cor. } & 0,730 & 0,108 & 0,595 & 0,545 & 1,000 & 0,250 & 0,333 & 0,455 \\
\hline $\begin{array}{c}\text { SPEI12 } \\
(0)\end{array}$ & & 0,649 & 0,432 & 0,189 & 0,382 & 0,600 & 0,182 & 0,500 & 0,762 \\
\hline $\begin{array}{c}\text { PDSI } \\
(-1)\end{array}$ & & 0,696 & 0,320 & 0,270 & 0,468 & 0,733 & 0,154 & 0,615 & 0,636 \\
\hline $\begin{array}{c}\text { PHDI } \\
(-1)\end{array}$ & & 0,688 & 0,280 & 0,378 & 0,432 & 0,667 & 0,200 & 0,375 & 0,667 \\
\hline $\begin{array}{c}\text { SPI12 } \\
(-1)\end{array}$ & \multirow{4}{*}{ Açu } & 0,757 & 0,068 & 0,595 & 0,573 & 1,000 & 0,400 & 0,333 & 0,400 \\
\hline $\begin{array}{l}\text { SPEI12 } \\
(0)\end{array}$ & & 0,640 & 0,459 & 0,162 & 0,391 & 0,467 & 0,222 & 0,818 & 0,625 \\
\hline $\begin{array}{c}\text { PDSI } \\
(-1)\end{array}$ & & 0,723 & 0,293 & 0,243 & 0,523 & 0,733 & 0,154 & 0,667 & 0,524 \\
\hline $\begin{array}{c}\text { PHDI } \\
(-1)\end{array}$ & & 0,696 & 0,307 & 0,297 & 0,477 & 0,462 & 0,143 & 0,563 & 0,500 \\
\hline
\end{tabular}

A Tabela 15 mostra que todos os índices apresentam uma proporção relativamente alta da identificação dos anos secos ou normais (Correto), com valores variando aproximadamente entre 0,70 e 0,80. Esse fato pode causar uma falsa impressão de qualidade, pois ignora a frequência com que tais índices identificam à seca quando a mesma não ocorre (Falso 
alarme), ou quando deixam de identificar quando a mesma foi relatada (Missed). O SPI12, por exemplo, possui um nível muito pequeno de Falso Alarme, com um valor máximo de 10\%, porém, níveis muito elevados de Missed, variando entre 0,50 e 0,60. Desempenho bastante similar foi encontrado para o índice da FUNCEME.

O SPEI12, por sua vez, apresenta um comportamento oposto ao SPI12, com valores entre 0,40 e 0,50 para Falso Alarme e em torno de 0,20 para Missed. Os valores de desempenho são muito dependentes do limiar empregado para identificação da seca, de forma que a diferença entre os desempenhos do SPI12 e SPEI12 deve ter muito mais relação com o limiar empregado do que com os índices propriamente ditos.

A Tabela 15 também apresenta o desempenho na identificação dos erros e acertos nas transições de estado. Vale a pena chamar a atenção do PDSI, principalmente no que concerne aos términos de seca, com valores entre 0,60 e 0,80 (Término e início corretos) e em torno de 0,20 para Falso Término. Quando se observa o Falso início, verifica-se uma elevação dessa taxa para valores de até 0,64 no caso da bacia do Coremas.

Ao se analisarem simultaneamente as taxas de início e término corretos e falsos, verifica-se que apenas o PDSI e o PHDI referentes às bacias do Orós e do Castanhão foram os que apresentaram os melhores valores dessas taxas. Apesar de outros índices terem apresentado taxas de início e término correto superiores a 0,6 ; quando se verificam os valores das taxas de início e término falso, muitas vezes encontram-se valores próximos a 0,5. Isso mostra que metade dessas situações foi indicada de forma errada, o que pode desencadear muitos erros no processo de tomada de decisão. O desempenho desses índices poderia ser potencializado caso eles fossem mais bem ajustados à região Nordeste. Essa melhora poderia ser alcançada, caso fosse aplicada a metodologia do sc-PDSI.

Vale lembrar mais uma vez que os resultados dependem dos valores de limiar escolhidos para cada índice. Pode-se observar que existe um mecanismo de troca (trade-off) entre os objetivos de desempenho. Por exemplo, para melhorar o desempenho do índice na identificação correta da passagem de um ano normal para um ano seco (Início correto), existe uma tendência em reduzir o desempenho em identificar o término da seca, ou seja, da passagem de um ano seco para um ano normal (Término correto). 
Apesar de os resultados apresentados na Tabela 15 caracterizarem o desempenho de cada índice em diversas dimensões do problema de identificação das secas, não é possível tirar conclusões definitivas porque desempenhos superiores poderiam ser obtidos caso limiares diferentes fossem empregados na avaliação. Portanto, decidiu-se refazer o estudo de verificação, porém dessa vez, as métricas de desempenho foram calculadas não apenas para um valor único de limiar, mas para toda uma faixa de valores. Essa análise permite ter uma visão mais clara do papel do limiar no desempenho dos índices.

As Figuras 28 a 37 apresentam os resultados obtidos para a bacia do Orós. Em todos os índices, à medida que o valor do limiar empregado para a indicação da seca diminui (tornase mais negativo), observa-se um aumento da quantidade de eventos de seca que não são identificados pelos índices (Missed) e uma redução dos Falsos Alarmes, o que faz sentido. À medida que o limiar se aproxima de zero, o inverso ocorre, ocorrendo uma tendência de aumento do número de vezes que o índice identifica seca, resultando num aumento de Falsos Alarmes e uma redução do número de vezes em que a seca ocorre, mas o índice não é capaz de identificá-la. Como era de se esperar, uma lógica semelhante é observada nos resultados referentes às transições de estado. À medida que o limiar se aproxima de zero, observa-se um aumento do número de eventos de início de seca (transição de um ano normal para um ano seco) corretamente identificados pelos índices e consequente redução da identificação correta dos términos de seca. A frequência de Falsos términos e Falsos inícios também é afetada de maneira similar pelo valor do limiar.

Esses resultados permitem identificar, para as diferentes regiões avaliadas, quais seriam os limiares mais adequados para cada um dos índices. Na verdade, a definição do limiar para cada índice está associada ao nível de aversão ao risco do tomador de decisão e aos possíveis custos e benefícios de diferentes decisões gerenciais atreladas ao valor dos índices. Portanto, pode-se dizer que os gráficos, em si, já seriam considerados os produtos finais dessa análise. Porém, apresenta-se, na sequência, um pequeno exercício de análise baseada única e exclusivamente nas métricas de desempenho obtidas. Por exemplo, no caso do SPI para a bacia contribuinte ao reservatório Orós, percebe-se que para um limiar próximo a zero, é possível restringir os índices de Falso alarme e Missed a 25\%, mantendo o nível de Correto na casa dos $75 \%$, além de propiciar uma taxa de identificação correta de início e término de seca entre 50 e $80 \%$. O SPEI se comporta de forma similar ao SPI, já que os mesmos apresentam valores muito próximos. 


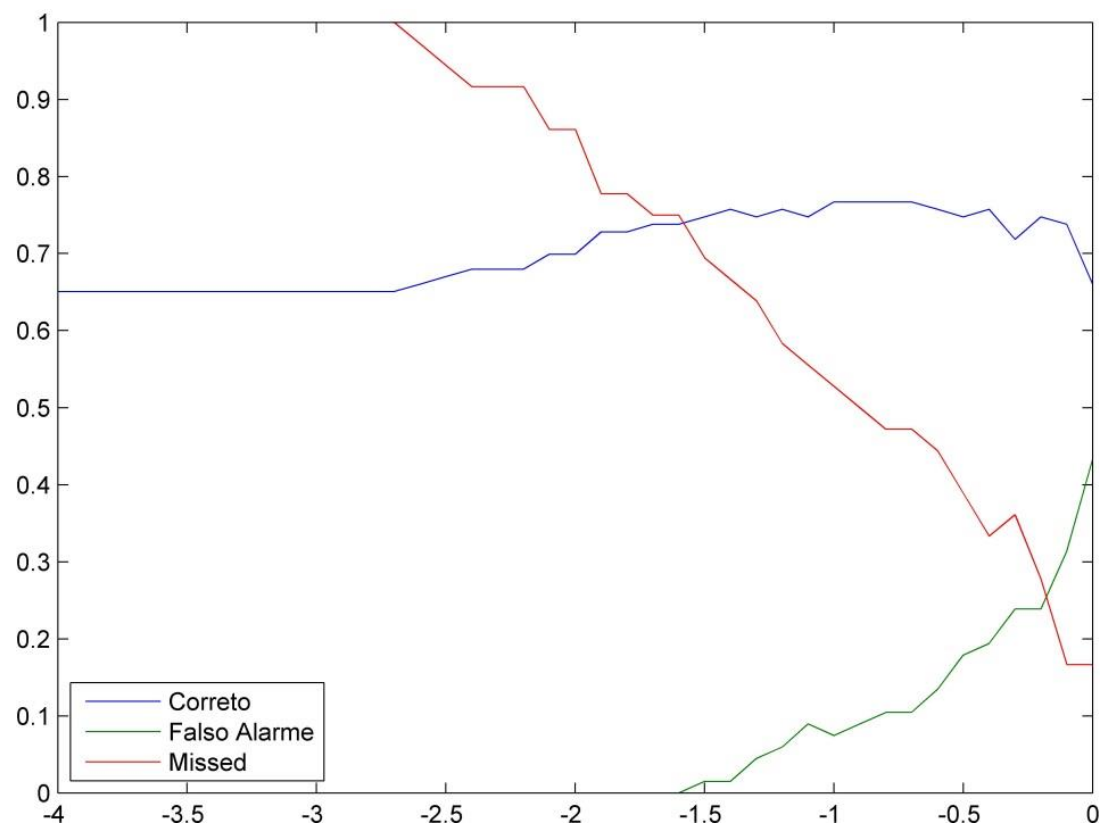

Figura 28 - Percentuais de erros e acertos na indicação da ocorrência da seca na bacia do Orós, segundo o SPI.
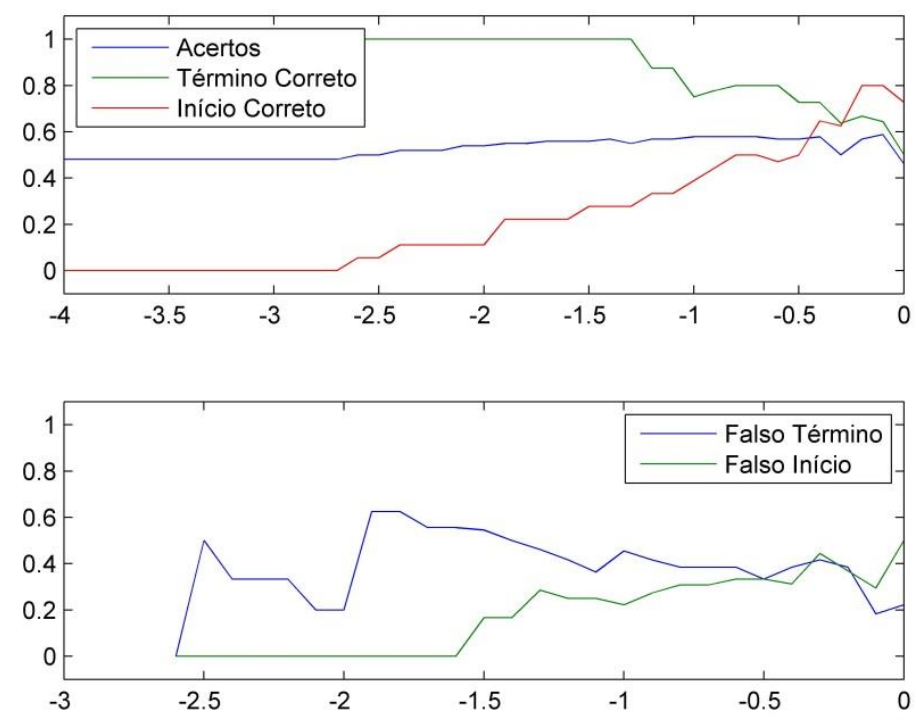

Figura 29 - Percentuais de erros e acertos na indicação da mudança ou não da condição de período seco ou úmido na bacia do Orós, segundo o SPI. 


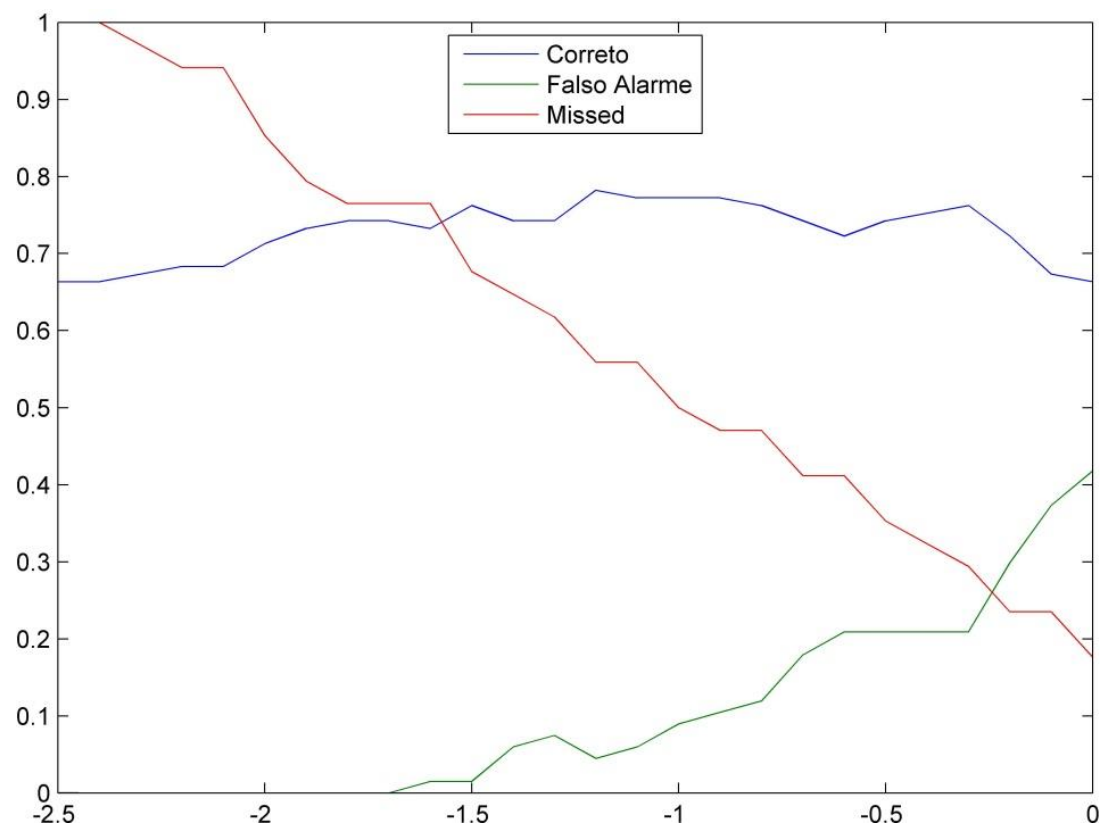

Figura 30 - Percentuais de erros e acertos na indicação da ocorrência da seca na bacia do Orós, segundo o SPEI.
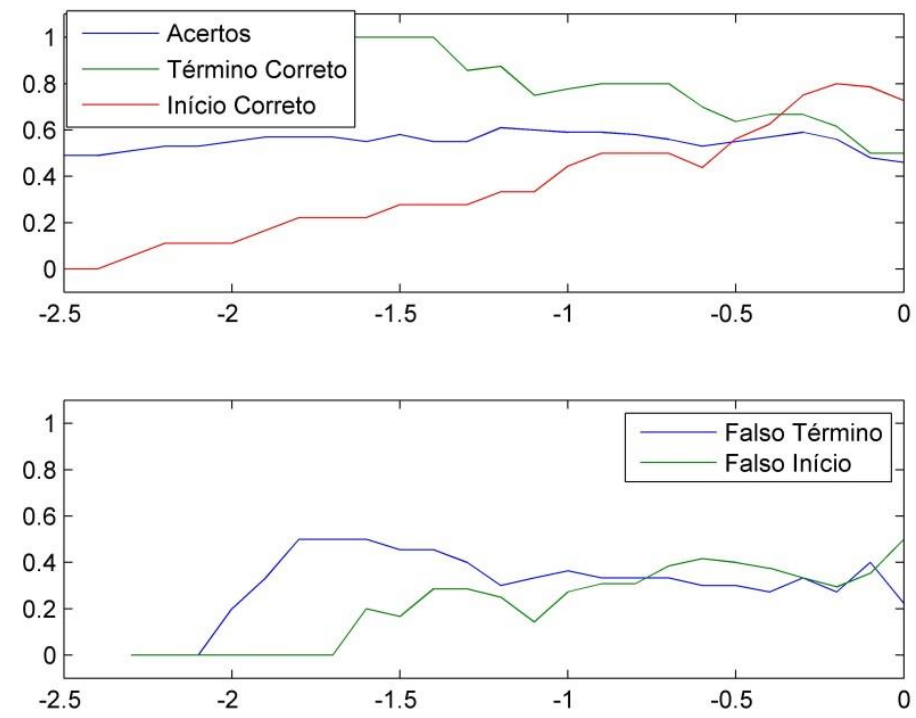

Figura 31 - Percentuais de erros e acertos na indicação da mudança ou não da condição de período seco ou úmido na bacia do Orós, segundo o SPEI. 


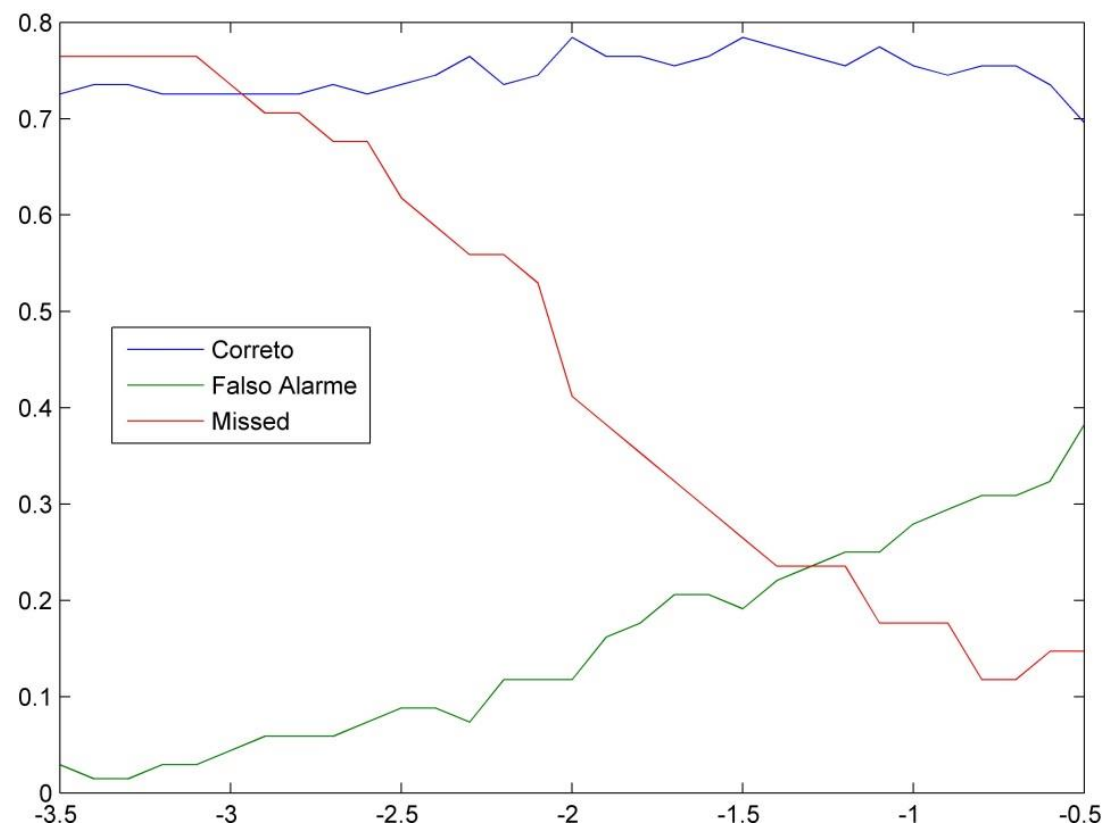

Figura 32 - Percentuais de erros e acertos na indicação da ocorrência da seca na bacia do Orós, segundo o PDSI.
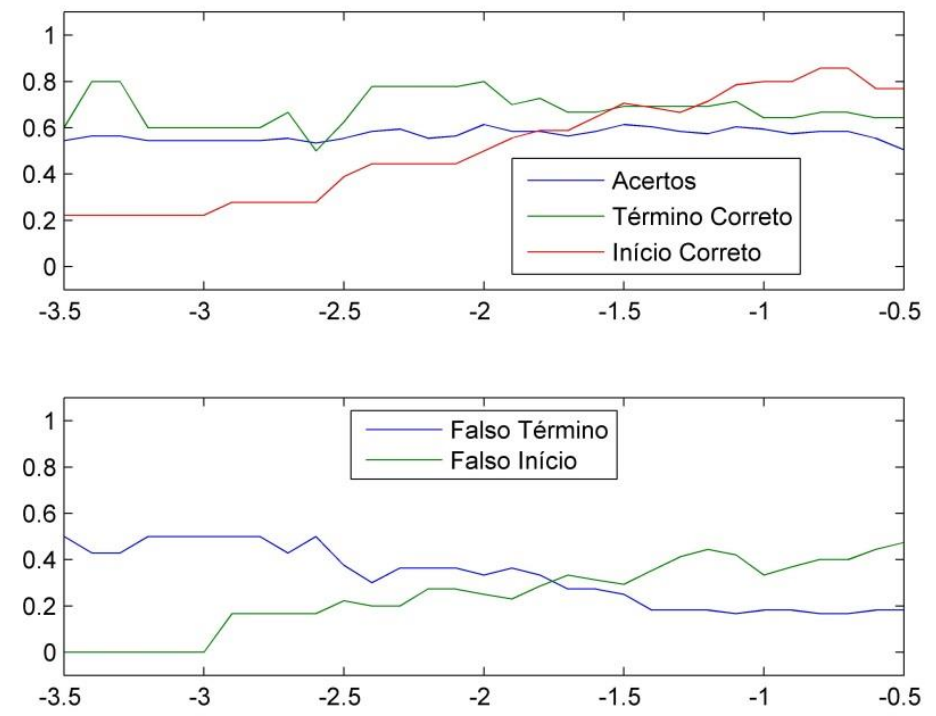

Figura 33 - Percentuais de erros e acertos na indicação da mudança ou não da condição de período seco ou úmido na bacia do Orós, segundo o PDSI. 


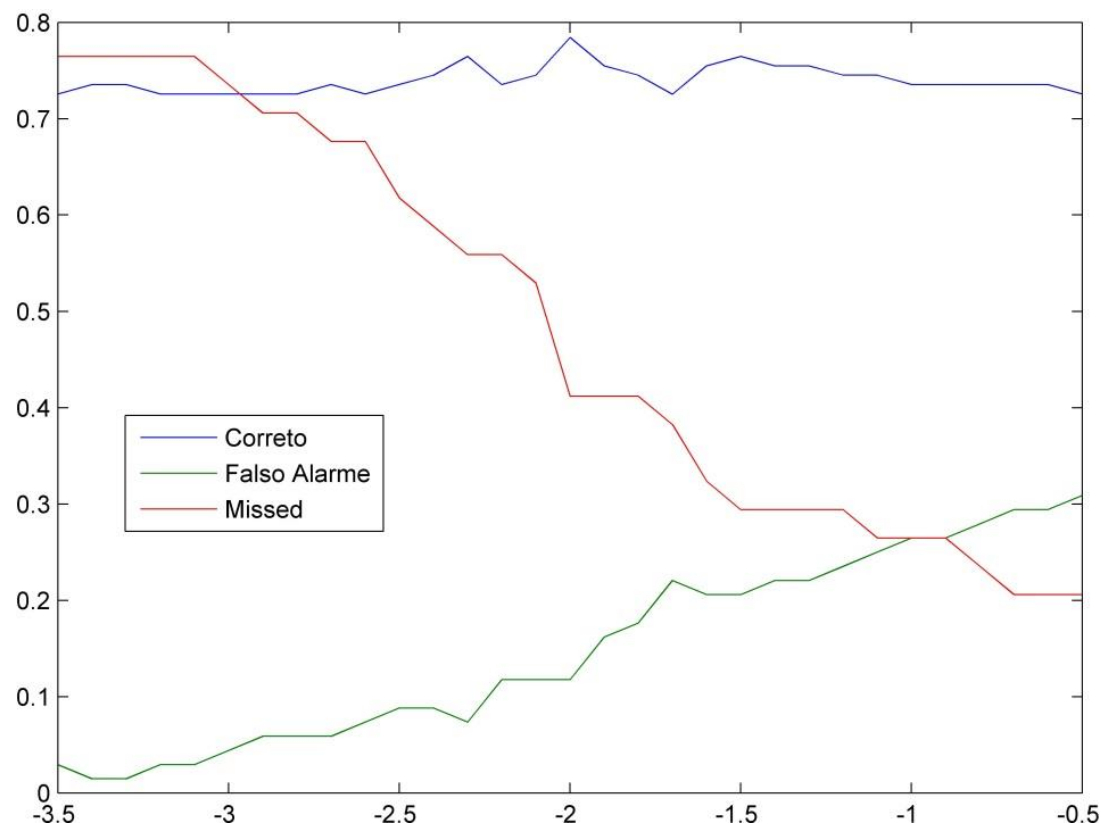

Figura 34 - Percentuais de erros e acertos na indicação da ocorrência da seca na bacia do Orós, segundo o PHDI.
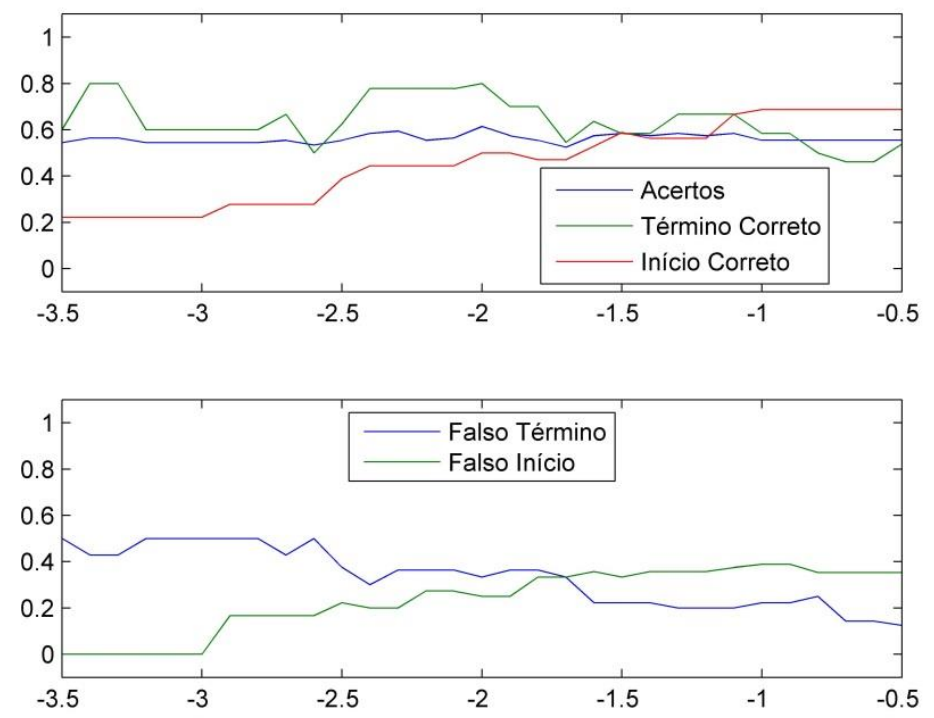

Figura 35 - Percentuais de erros e acertos na indicação da mudança ou não da condição de período seco ou úmido na bacia do Orós, segundo o PHDI.

O PDSI não apresenta uma significativa melhoria de desempenho em relação ao SPI e o SPEI. Pelas Figuras 32 e 33 pode-se propor um valor limite superior a -1,5. Nessa região podem-se alcançar percentuais de erros na indicação da seca (Falso alarme e Missed) próximos a 0,2 e acertos de 0,75 . Em relação aos acertos na determinação do início e o fim da seca os melhores percentuais variam em torno de 0,5 e 0,8. O PHDI possui taxas de 
desempenho próximas ao PDSI, podendo-se propor a mesma faixa de limiares que esse índice.

Destaca-se, portanto, que, embora os índices de Palmer tenham uma metodologia mais completa que a utilizada na obtenção do SPI e do SPEI, por considerarem as características do meio e os processos hidrológicos de forma mais ampla que os outros dois índices, eles apresentam um desempenho semelhante ao do SPI e do SPEI.

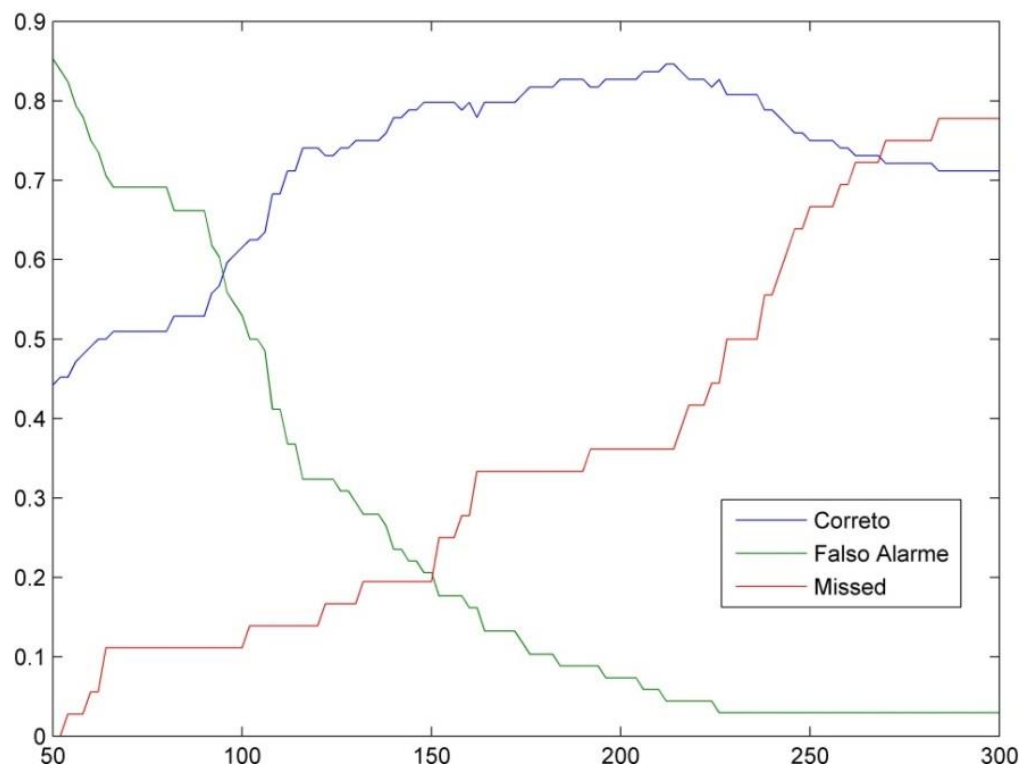

Figura 36 - Percentuais de erros e acertos na indicação da ocorrência da seca na bacia do Orós, segundo o índice da FUNCEME.
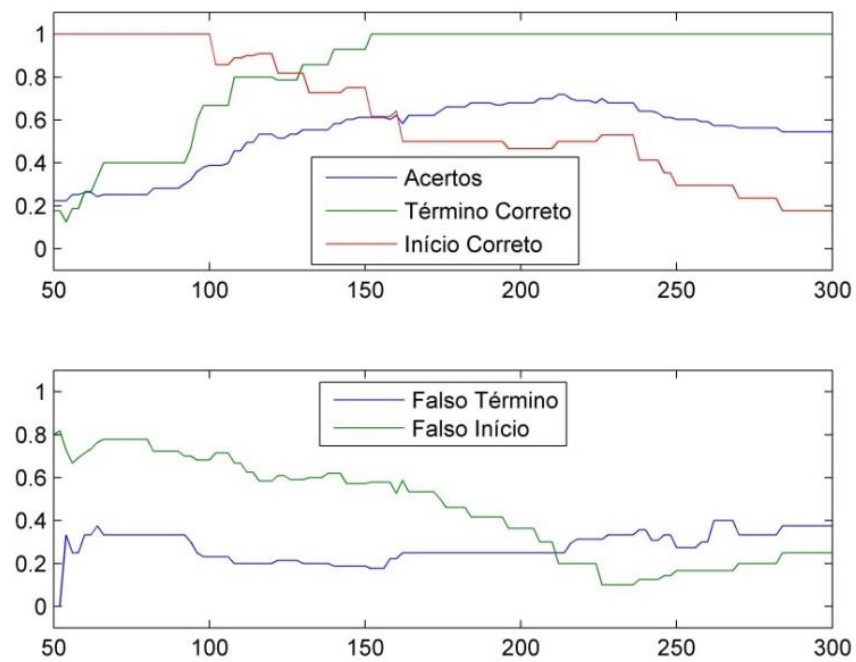

Figura 37 - Percentuais de erros e acertos na indicação da mudança ou não da condição de período seco ou úmido na bacia do Orós, segundo o índice da FUNCEME. 
Dentre os índices de seca, apenas o da FUNCEME, apresenta uma significativa melhora na quantidade de acertos, para as amplitudes dos limites estudados. Esse comportamento está relacionado ao caráter inversamente proporcional do mesmo em relação aos outros índices. Portanto, quanto maior for o seu valor, haverá uma maior quantidade de secas indicadas corretamente, mas após o valor de aproximadamente 200, essa métrica se reduz, em virtude de haver um crescimento mais íngreme das secas que não são indicadas pelo índice. Destaca-se também que essas diferenças também estão relacionadas à amplitude de valores dessa ferramenta, que é significativamente superior a dos demais.

Quando se analisa a capacidade de indicar a seca corretamente ao longo de uma passagem de tempo, com exceção do índice da FUNCEME, novamente se verifica que quando se quantifica todos os tipos de acerto não são verificadas significativas variações dessa métrica.

Por fim, para o índice da FUNCEME, pode-se sugerir um valor de limiar superior a 150, quando os erros na determinação das secas (Falso alarme e Missed) são aproximadamente 0,2 e os acertos atingem valores entre 0,7 e 0,8. Nessa faixa, apesar da redução dos acertos na determinação do início e o término, observasse valores mínimos próximos a 0,6. Esse comportamento também é considerado semelhante ao dos demais índices.

\section{2- IDENTIFICAÇÃO DAS SECAS HISTÓRICAS COM O USO DO NDVI E DA UMIDADE DO SOLO MODELADA}

\subsection{1- Uso do NDVI como índice de seca}

Essa mesma avaliação das séries temporais dos índices também foi feita com o NDVI, para determinar se o mesmo pode ser utilizado na identificação desse fenômeno. Entretanto, ao se compararem os valores médios do NDVI para as bacias contribuintes aos reservatórios analisados com as secas históricas, nota-se que o mesmo apresenta um comportamento variável ao longo do tempo, porém com grau de variabilidade praticamente constante, independentemente da ocorrência de um déficit de precipitação, como mostra a Figura 38. Ao longo dos anos avaliados, o NDVI sempre cresceu durante os meses pertencentes à quadra chuvosa e diminuiu nos demais, o que demonstra que o mesmo não é um bom parâmetro para indicar a incidência das secas. Optou-se, então, por não calcular a 
correlação entre o NDVI com os demais índices de seca e com as variáveis que indicam as variações do meio em virtude da incidência da seca.

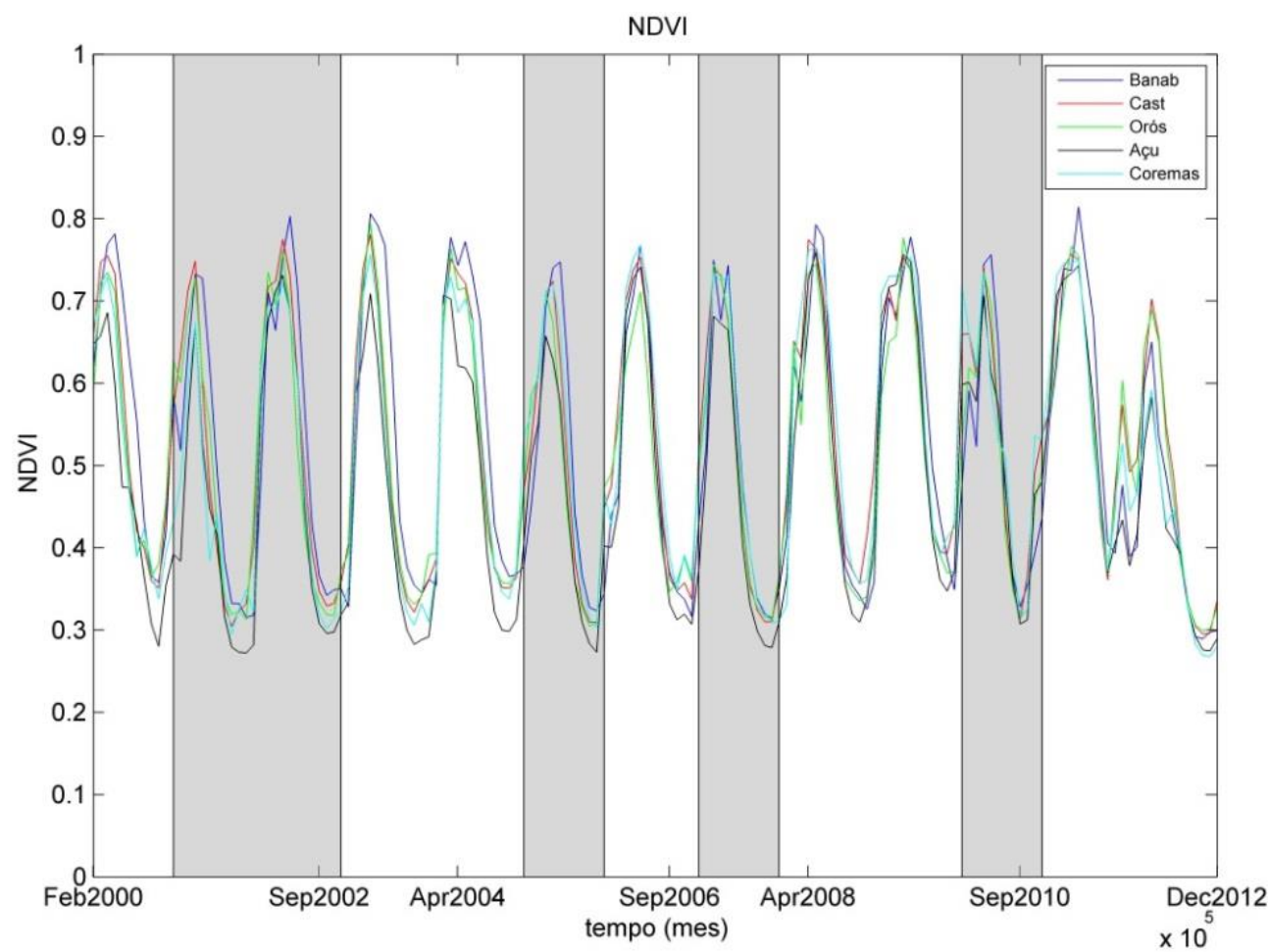

Figura 38 - Série temporal do NDVI.

Na tentativa de avaliar se o uso de valores médios de NDVI nas bacias resultava em uma suavização excessiva do referido índice, e, portanto, uma maior dificuldade em identificar a ocorrência de secas, procurou-se realizar a mesma análise com os valores de NDVI estimados por pontos de grande. Entretanto, mesmo com essa nova análise, não foram observadas alterações significativas desse índice durante os anos de seca. Esse comportamento constante do NDVI avaliado por bacia e por pontos de grade também pode ser comprovado ao se calcular o coeficiente de variação mensal, que atingiu valores baixos, sendo o valor máximo, dentre todas as áreas avaliadas, de 0,35 na bacia do Açu.

\subsection{2- Uso da Umidade do Solo como índice de seca}

Apesar do gráfico da série temporal da umidade do solo ter uma tendência semelhante à do NDVI, observa-se que a amplitude dos picos, alcançados durante os meses da quadra chuvosa, reduzem durante os anos de seca. 
Para avaliar se essa variação dos valores da umidade do solo modelada pela ESRL e pelo MUSAG durante os anos secos, foi realizada a mesma avaliação feita com o NDVI. Entretanto, como essas umidades possuem unidades distintas foi necessário fazer uma padronização prévia dos valores. Com esse intuito, inicialmente, se verificou quais eram os valores máximos anuais de cada uma das variáveis, o que permitiu uma melhor visualização da tendência das mesmas. Por meio dessa etapa foram compostas duas séries anuais dos valores de umidade, que foram, posteriormente, padronizados por meio da subtração de cada elemento pelo valor médio e depois a divisão dos mesmos pelo desvio padrão da respectiva série. Os resultados referentes à bacia do Orós são apresentados na Figura 39.

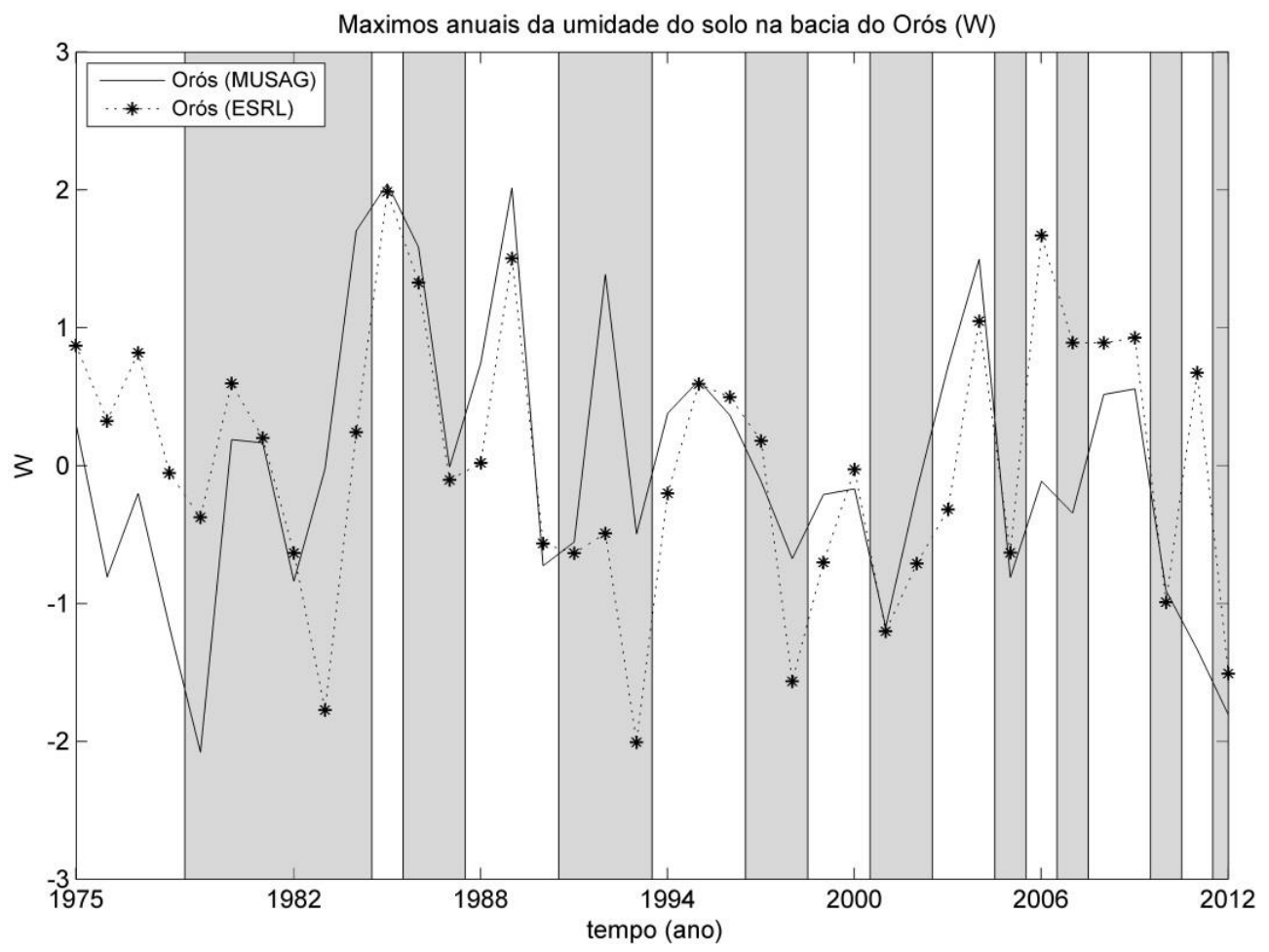

Figura 39 - Comparação das séries temporais dos valores máximos anuais da umidade do solo padronizados disponibilizado pela ESRL e obtidos pelo MUSAG na bacia do Orós.

Além dessa variação durante os anos secos, muitos dos vales dos gráficos ocorrem durante os anos em que foram relatadas secas históricas, as quais são representadas pelas regiões sombreadas de cinza. Entretanto, caso fosse estabelecido um limiar que indique o início da seca, percebe-se a ocorrência de alguns erros na percepção desse evento. Um exemplo ocorre entre os anos de 1991 e 1993, durante os quais houve relatos de seca, mas a umidade gerada pelo MUSAG apresenta um pico de magnitude próxima à indicada durante anos considerados normais. 
Para entender melhor o comportamento dessas variáveis na indicação das secas foi feita uma quantificação simplificada dos erros e acertos, considerando apenas a capacidade de cada variável de determinar as secas em cada ano. Os resultados desses cálculos para a bacia do Orós são apresentados nas Figuras 40 e 41.

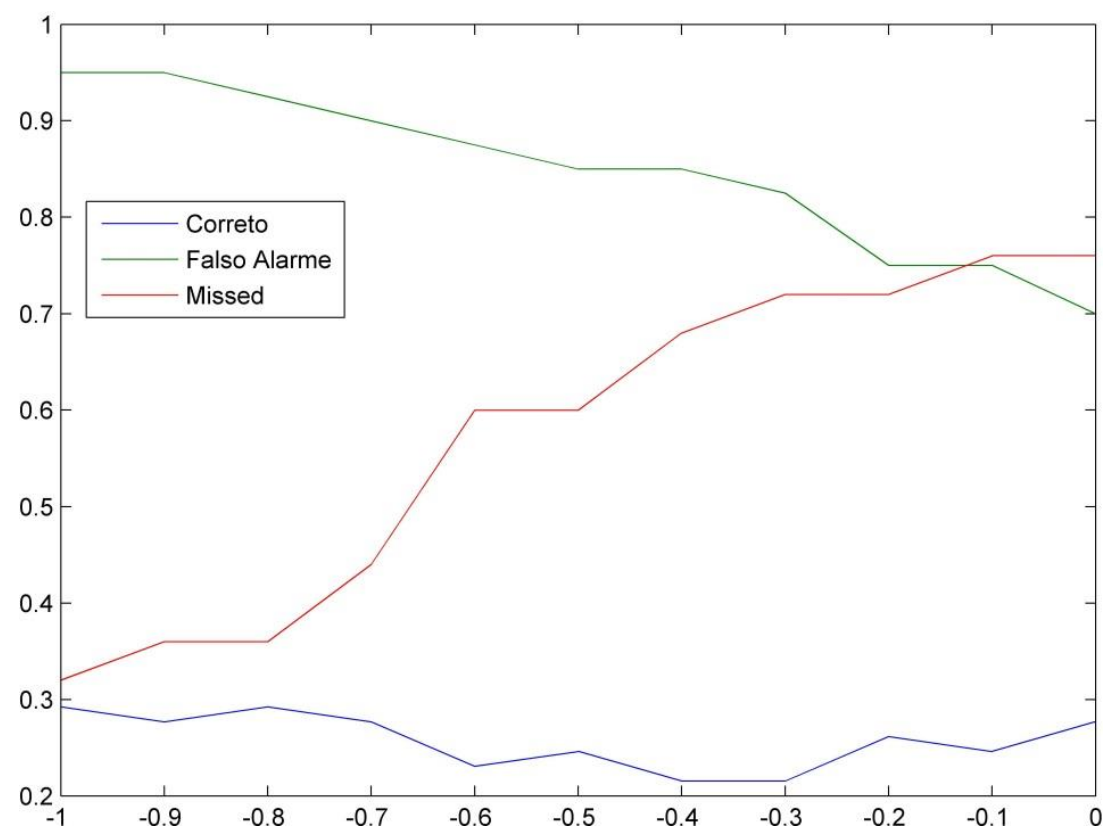

Figura 40 - Percentuais de erros e acertos na indicação da ocorrência da seca na bacia do Orós, segundo a umidade disponibilizada pela ESRL.

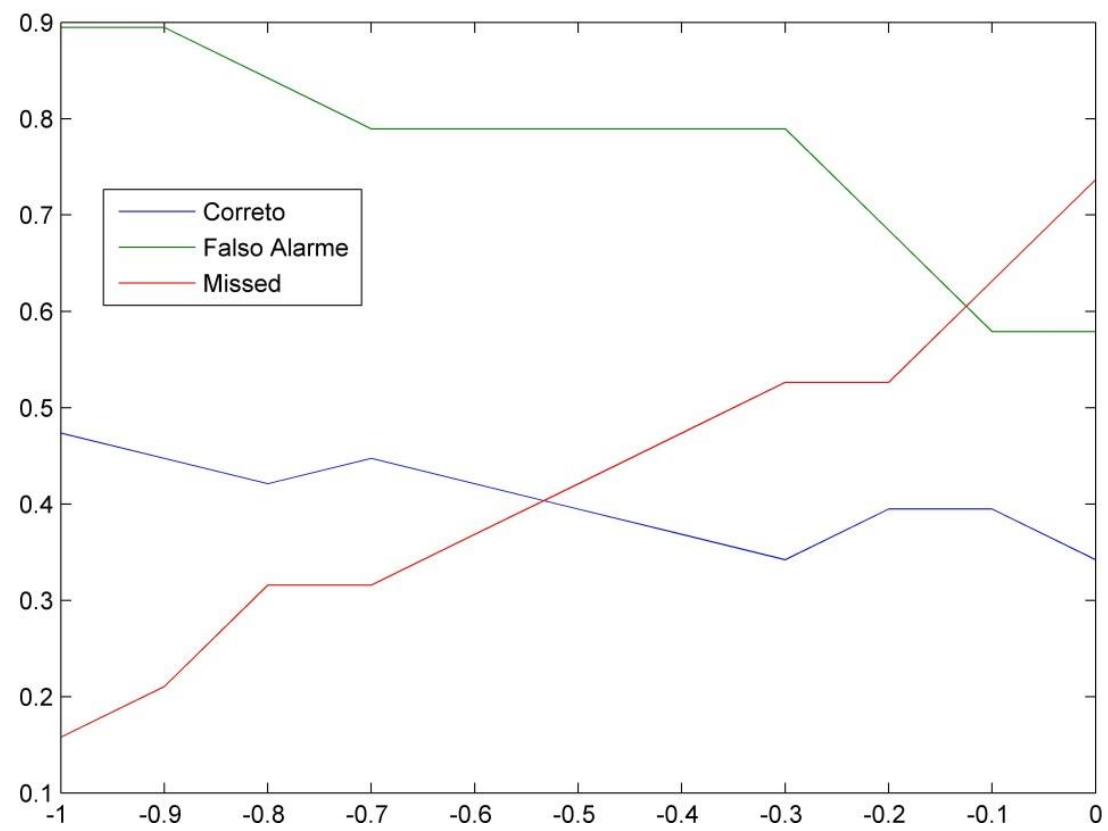

Figura 41 - Percentuais de erros e acertos na indicação da ocorrência da seca na bacia do Orós, segundo a umidade modelada pelo MUSAG. 
Os gráficos mostram que as taxas de acertos são significativamente mais baixas que as de erros, com percentuais variando entre 0,2 e 0,3 no caso da umidade disponibilizada pelo ESRL e entre 0,3 e 0,5 para a umidade modelada pelo MUSAG. Já o percentual mínimo dos dois tipos de erros (Falso Alarme e Missed) alcançou um valor significativamente mais elevado, sendo de aproximadamente 0,6 para a umidade do solo do MUSAG.

Destaca-se, porém que os resultados da umidade gerada pelo MUSAG possuem um desempenho sensivelmente melhor que os dados do ESRL, mostrando que, em virtude do MUSAG utilizar informações que caracterizam de forma mais detalhada as bacias do estado do Ceará, o mesmo consegue identificar de forma um pouco mais eficiente os impactos desencadeados pela seca.

Apesar desses problemas é importante destacar que não se sabe os tipos de seca foram evidenciados nesses anos, portanto, os períodos de seca que não concordaram com os dados dos modelos, podem não ser caracterizados como seca agrícola, quando se percebe uma redução na disponibilidade de água no solo. Não se dispõe também de uma base de dados que descreva a sequência dos impactos evidenciados durante os anos descritos como secos, o que permitiria a identificação do momento em que a redução na intensidade da chuva desencadeou uma diminuição da umidade do solo e, consequentemente, da produção agrícola.

Os dados de umidade do solo do MUSAG disponibilizados pela FUNCEME são diários. Para utilizá-los, no presente trabalho, foi feita uma série mensal, composta pela média dos valores de umidade diários de cada mês, da qual foram extraídos os máximos anuais. É importante destacar, entretanto, que, como não foi feita uma avaliação prévia do comportamento desses dados diários, o valor da média mensal pode ter sido influenciado por valores máximos presentes na série diária. Outro problema nessa análise, foi a perda de parte das informações contidas nos dados, em virtude da conversão dos dados da escala diária para a mensal. 


\section{3- VERIFICAÇÃO DA CAPACIDADE DE OS ÍNDICES DE SECA DE IDENTIFICAREM OS IMPACTOS DA SECA NO MEIO}

Este item avalia o grau de correlação existente entre os índices de seca e variáveis ambientais que refletem os impactos gerados por uma eventual redução do nível de precipitação, quais sejam, o volume acumulado nos reservatórios ao final de cada período analisado, a vazão média do período, considerando apenas os meses de janeiro a maio, e o valor máximo de umidade do solo em cada período. Como explicado anteriormente, essa avaliação foi feita com base no coeficiente de correlação de Spearman.

Como na região estudada as chuvas, normalmente, ocorrem durante os meses que compõem o que se conhece como quadra chuvosa, fevereiro, março, abril e maio, optou-se por fazer as análises mensais apenas durante esse intervalo de tempo.

A Figura 42 mostra os valores da correlação de Spearman entre o índice da FUNCEME médio das bacias do Ceará e a vazão afluente aos reservatórios do Banabuiú, Castanhão e Orós, o volume dos mesmos e a umidade do solo oriunda da ESRL e modelada pelo MUSAG.

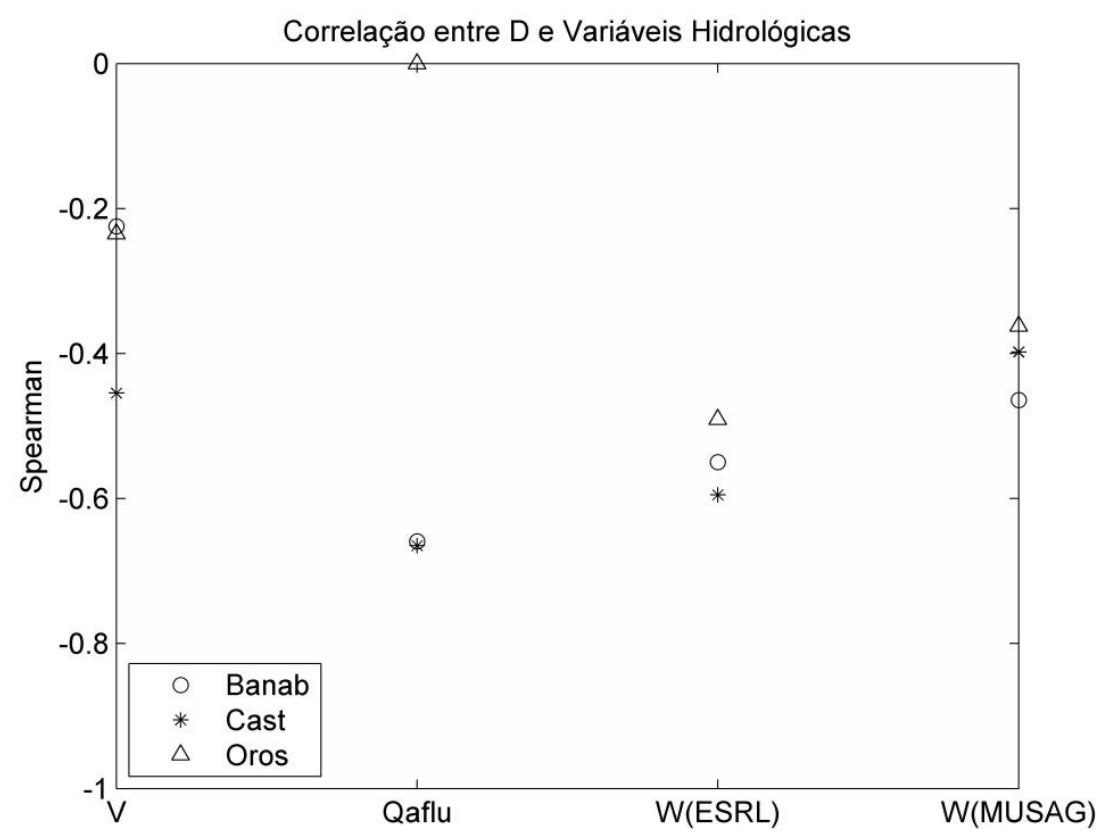

Figura 42 - Coeficiente de Spearman entre o índice da FUNCEME das bacias do Banabuiú, Castanhão, Orós, e a vazão (Q) afluente, o volume (V) desses reservatórios e a umidade do solo. 
Dentre as variáveis comparadas ao índice da FUNCEME, a vazão foi a que apresentou melhores resultados, com exceção da bacia do Orós. Esse bom desempenho pode estar relacionado à metodologia de cálculo da correlação, que considerou a média das vazões durante os meses de fevereiro a maio, por ser um período em que normalmente se observa a incidência de precipitação, havendo muitos valores de vazão nulos nos outros meses. Além de que o índice da FUNCEME utiliza, no seu calculo, apenas os valores de precipitação diária dos meses da quadra chuvosa.

A variação do volume armazenado nos reservatórios depende de uma grande heterogeneidade de fatores, como o local de ocorrência das chuvas e a política de operação do mesmo, não havendo, portanto, a interferência apenas de fatores climáticos nas alterações dessa variável. Outro fator que intervém nessas variações é o caráter intra-anual ou plurianual dos reservatórios. No primeiro, não existe uma transferência de água entre os diferentes anos hidrológicos, a qual ocorre no segundo caso. Ressalta-se, entretanto, que, no presente trabalho, não foi feita uma distinção de quais fatores desencadearam as variações dos volumes e das características dos reservatórios. Percebe-se, portanto, que os resultados obtidos na associação dos índices de seca com os volumes dos reservatórios não são conclusivos, havendo a necessidade da realização de novos estudos que considerem essas características dos reservatórios.

Essa grande complexidade, desencadeia uma maior lentidão nas mudanças dessa variável, as quais podem não ter sido identificadas após os quatro meses em que são calculados os veranicos necessários para a obtenção do índice da FUNCEME.

Como esse índice considera apenas as chuvas e a amplitude do veranico, ele pode não conter informações suficientes que expliquem as mudanças na umidade do solo, como o tipo de solo e o volume de vazios. Essa carência de informações sobre o solo da região analisada explica a não obtenção de bons valores de correlação ao se associar essa ferramenta com os dois tipos de umidade do solo.

Novamente foi feita a comparação do índice desenvolvido pela FUNCEME com as variáveis que indicam o comportamento do meio sob determinadas condições meteorológicas. A localização desses dados, entretanto, foi referente aos postos pluviométricos da FUNCEME, no caso da umidade do solo modelada pelo MUSAG, e aos 
pontos da base de dados do CRU, para os demais dados. Como ocorreu na análise na bacia, a Figura 43 mostra que essa ferramenta não é um bom indicador da variação do nível dos reservatórios.

Quando se observarem os resultados da comparação com a vazão afluente, entretanto, verifica-se uma redução da capacidade de se identificar o comportamento da recarga do reservatório em relação à análise dos dados das bacias. Isso pode ser relacionado à variabilidade espacial dos dados. Em relação à umidade do solo também se observa valores de correlação médios baixos, sendo similaridade com a umidade gerada pelo MUSAG sensivelmente melhor que a disponibilizada pela ESRL.
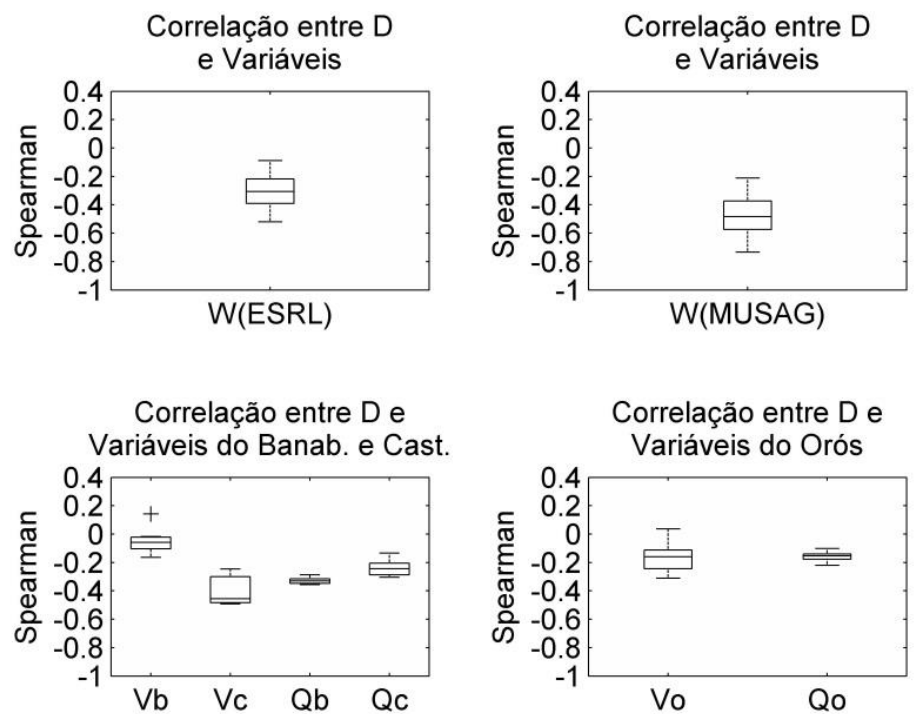

Figura 43 - Coeficiente de Spearman entre variáveis hidrológicas e o índice da FUNCEME.

Ao se comparar a umidade do solo gerada pela ESRL aos índices de seca mensais das bacias contribuintes aos reservatórios destacados no presente trabalho, durante os meses chuvosos, como se observa na Figura 44, verifica-se que o PDSI e o PHDI foram os que melhor explicaram as mudanças dessa variável. Essas ferramentas consideram o AWC, que representa o espaço disponível para o armazenamento de água no solo, o que pode ser associado a essa maior conformidade.

O índice Z, apesar de também considerar o AWC, não utiliza, no seu cálculo, o valor do índice no mês anterior, o que pode justificar a maior discrepância desse índice em relação 
aos dados de umidade do solo. Isso é relacionado ao fato de que o valor da umidade do solo, a cada instante, depende da quantidade de água disponível no solo e, consequentemente da chuva, que ocorreu no instante anterior. Essa metodologia de cálculo também explica porque esse índice apresentou um comportamento mais próximo do SPI e do SPEI mensais, que dos demais índices de Palmer.
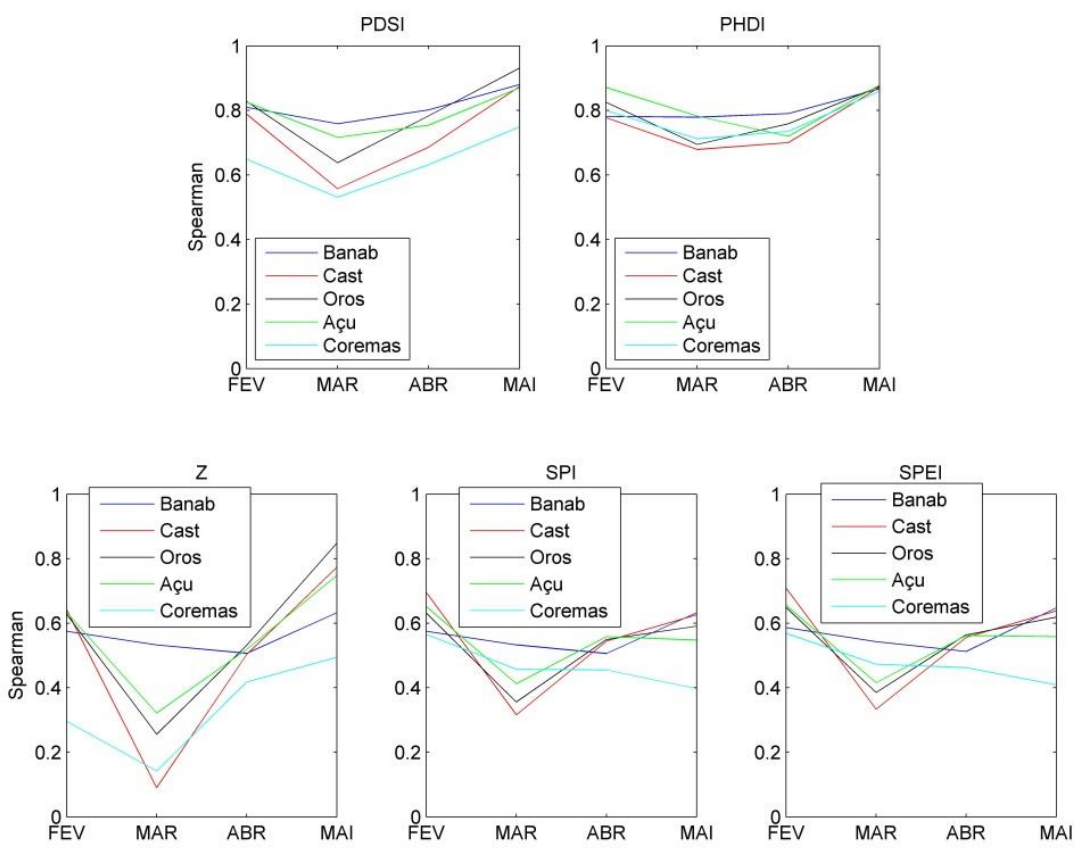

Figura 44 - Coeficiente de Spearman entre a umidade do solo disponibilizada pelo ESRL e os índices de seca médios das bacias.

Essa relação, porém não condiz com o relatado na literatura. Muitos autores descrevem o índice $\mathrm{Z}$ como, dentre as ferramentas de Palmer, o que melhor detecta a ocorrência de secas agrícolas, em virtude do mesmo responder rapidamente as mudanças de umidade do solo (Keyantash e Dracup, 2002).

Também foi feita a comparação dos índices de seca com os valores de umidade gerada pelo MUSAG nas bacias do Ceará, cujos resultados são apresentados na Figura 45. Ressalta-se que esse modelo gera valores diários e os índices são mensais, assim, para possibilitar essa análise, foi feito o cálculo da média dos valores de umidade diária em cada mês. O gráfico revela um comportamento que não condiz com os resultados apresentados na Figura 44, já que os valores da correlação da umidade com o PDSI e o PHDI foram inferiores as dos demais índices. 

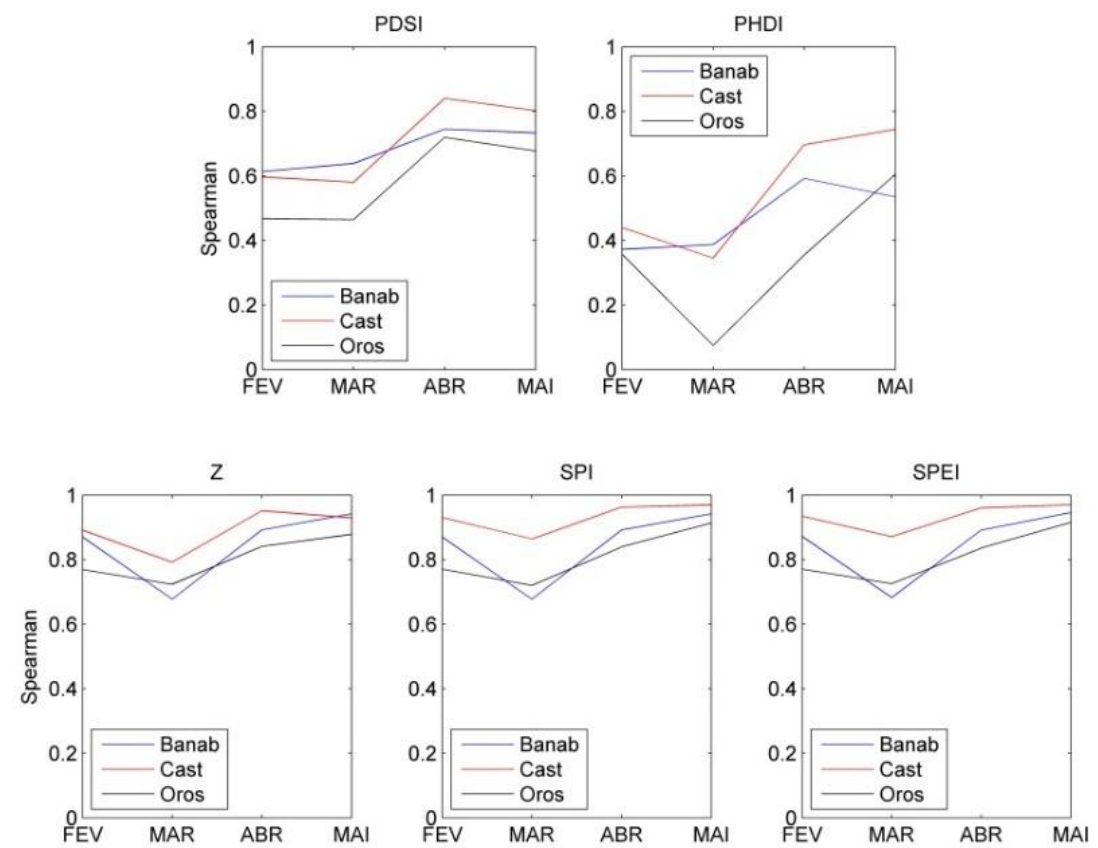

Figura 45 - Coeficiente de Spearman entre a umidade do solo gerada pelo MUSAG e os índices de seca das bacias do Ceará.

Como o SPI e o SPEI podem ser calculados para maiores períodos de tempo, optou-se por compará-los com o valor máximo da umidade do solo em cada período correspondente. A Figura 46 mostra as correlações obtidas ao se associar esses índices das bacias contribuintes aos reservatórios com as umidades disponibilizadas pela ESRL.
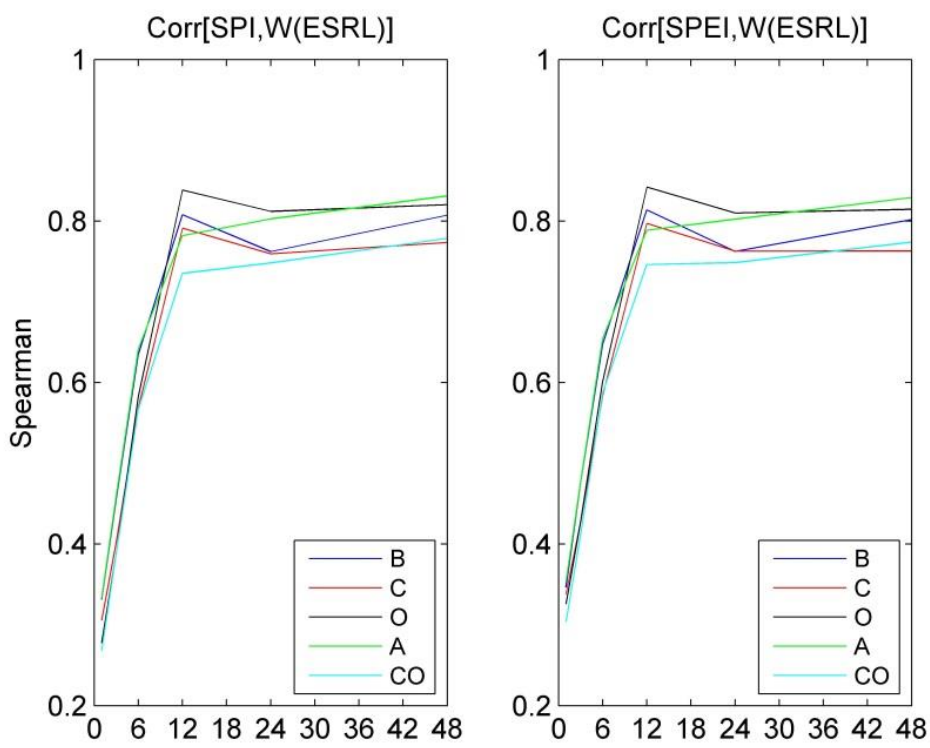

Figura 46 - Coeficiente de Spearman entre SPI, o SPEI médios das bacias e a umidade do solo disponibilizada pela ESRL. 
Os valores do coeficiente de Spearman mostram que o SPI e o SPEI conseguem explicar melhor as variações da umidade do solo à medida que os períodos de acréscimo dos dados de entrada crescem. Isso mostra que, apesar dessas ferramentas não considerarem as propriedades do solo, elas podem representar bem as variações da umidade, desde que os dados de entrada estejam acumulados em períodos maiores ou iguais a, pelo menos, doze meses. A escolha desse período mínimo se deve ao fato de que, a partir do mesmo, os valores de correlação se estabilizam.

Essa mesma avaliação, utilizando os dados de umidade calculados pelo MUSAG, a qual é apresentada na Figura 47, mostra que os valores máximos das correlações são alcançados quando são avaliados períodos de acumulação de doze meses. Esse comportamento novamente confirma que o SPI e o SPEI de 12 meses são mais eficientes na identificação das secas agrícolas.
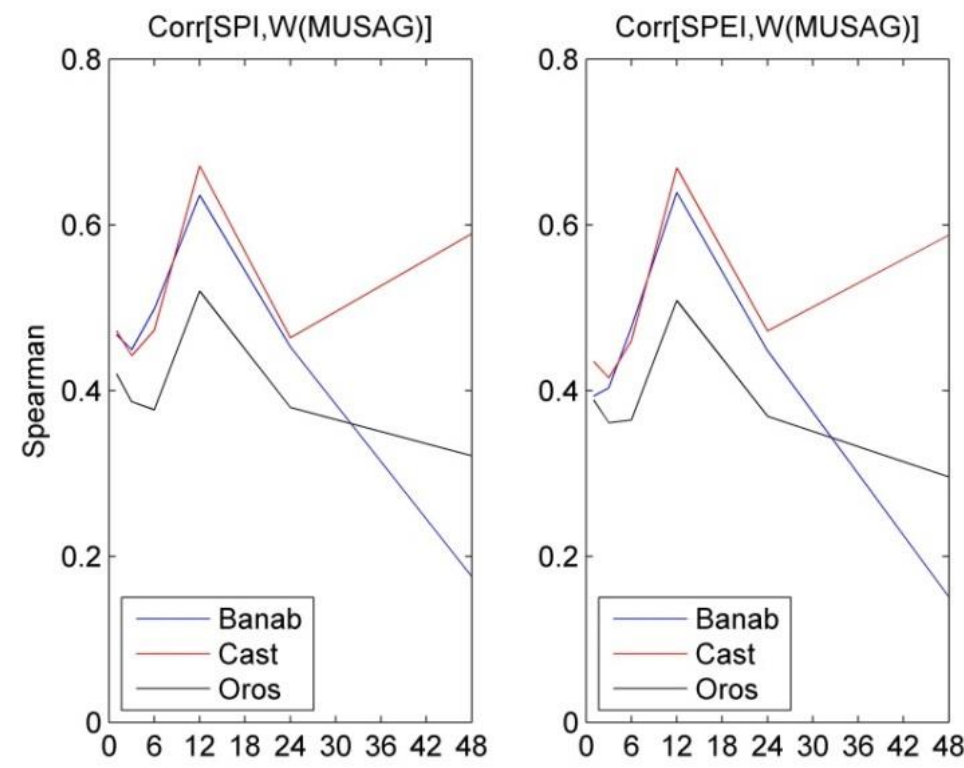

Figura 47 - Coeficiente de Spearman entre SPI, o SPEI médios das bacias e a umidade do solo gerada pelo MUSAG.

Os valores do coeficiente de Spearman entre os índices de seca, cuja localização corresponde à grade de pontos dos dados do CRU no Ceará, e a umidade do solo disponibilizada pela ESRL são apresentados na Figura 48. Essa análise mostra que, como ocorreu quando se compararam os índices de seca das bacias com essa variável, o PDSI e o 
PHDI, calculados com base nos dados do CRU, foram os índices que conseguiram representar de forma mais satisfatória as variações na umidade do solo.
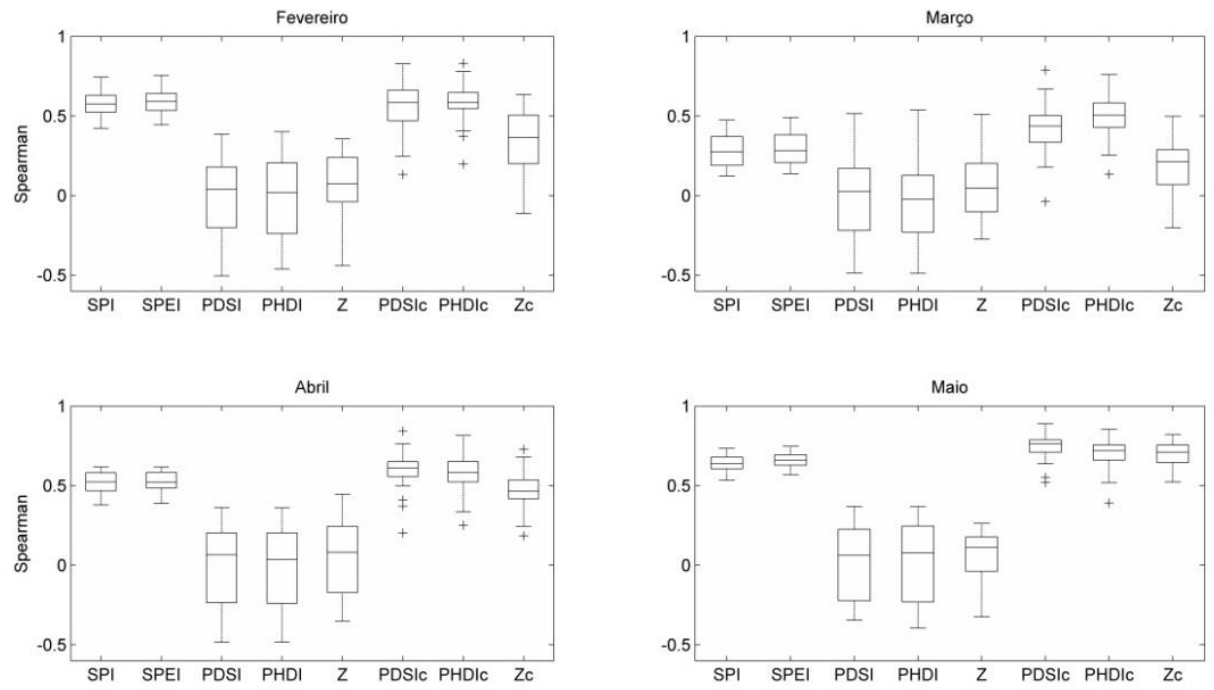

Figura 48 - Coeficiente de Spearman entre os índices de seca e a umidade do solo disponibilizado pelo ESRL nos pontos do CRU.

Os valores médios de correlação entre os índices calculados nos pontos referentes às estações pluviométricas da FUNCEME, no estado do Ceará, e a umidade do solo, modelada pelo MUSAG, foram inferiores aos obtidos quando se avaliou os dados das bacias, como se verifica na Figura 49. Os índices de Palmer utilizados na presente análise foram calculados com base nos dados do CRU, em virtude dessa base de dados disponibilizar uma série mais longa de valores de precipitação, como relatado anteriormente.

Ao se observarem os valores dessas correlações por pontos, constata-se uma maior variabilidade que no caso da avaliação feita com os dados concedidos pela ESRL. Essa maior dispersão dos dados é desencadeada pelo maior detalhamento, pelo MUSAG, das características da região analisada. Em decorrência dessa maior instabilidade dos dados, optou-se por analisar a distribuição espacial dos mesmos no mês de maio, que corresponde ao final da estação chuvosa, como mostra a Figura 50. A determinação da extensão das regiões influenciadas pelo valor das correlações de cada ponto foi feita por meio da metodologia dos polígonos de Thiessen. 

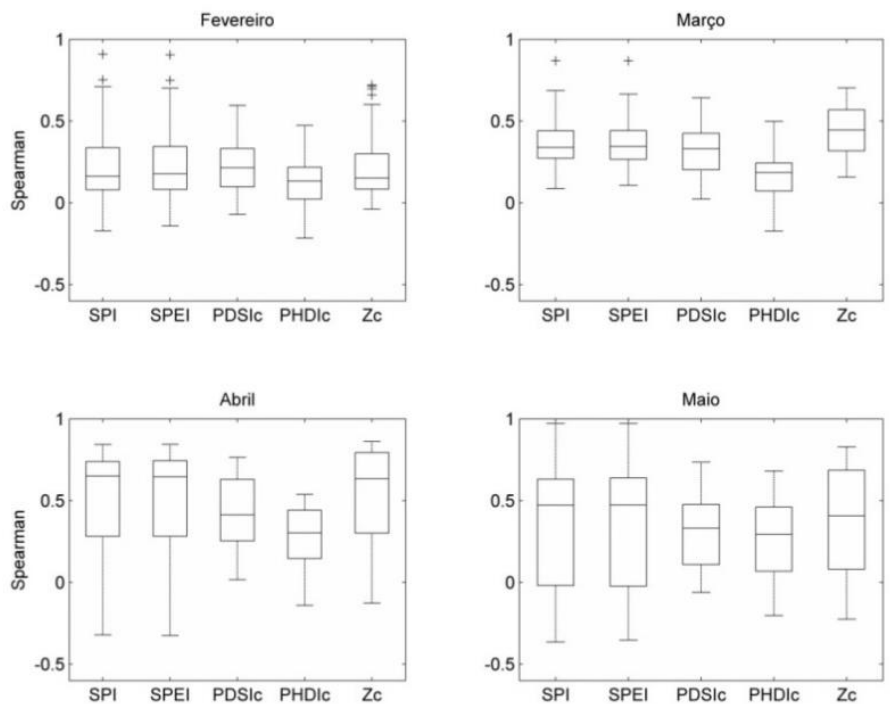

Figura 49 - Coeficiente de Spearman entre os índices de seca e a umidade do solo gerada pelo MUSAG nos pontos referentes aos postos pluviométricos da FUNCEME.

Para facilitar o entendimento da Figura 50, foi atribuída à cor branca para as regiões cujos valores do coeficiente de Spearman não eram significativos. Como a correlação pode assumir valores positivos e negativos, a determinação desses valores foi feita com base nas hipóteses abaixo.

$$
\begin{array}{ll}
\mathrm{H}_{0}: & \mathrm{r}=0 \text { (correlação não significativa) } \\
\mathrm{H}_{1}: & \mathrm{r} \neq 0 \text { (correlação significativa) }
\end{array}
$$

A amostra de dados analisada, no presente trabalho, tem um tamanho, segundo Press et al. (2007), considerado moderado, com um número de elementos superior a dez. Essa característica permitiu a adoção da transformação de Fisher, apresentada na equação 41, para obter o valor de $\mathrm{F}(\mathrm{r})$, necessário para o cálculo da significância, realizado por meio da equação 42.

$$
\begin{aligned}
& F(r)=\frac{1}{2} \ln \frac{1+r}{1-r} \\
& z=\sqrt{\frac{n-3}{1-r^{2}} F(r)}
\end{aligned}
$$


em que r é o valor da correlação de Spearman e z é a normal padrão, calculada por meio da padronização do valor de $\mathrm{r}\left(z=\frac{r-\mu}{\sigma}\right.$, sendo $\mu$ a média e $\sigma$ o desvio padrão do conjunto de valores dessa variável), admitindo que o mesmo segue uma distribuição normal.

Assim, considerando que a região de rejeição seja de $10 \%$, se admitiu que os valores de correlação não significativos eram aqueles com uma probabilidade de verificação de abaixo de $5 \%$ ou acima de $95 \%$.

Essa métrica mostrou que os valores de correlação do SPI e do SPEI, os quais apresentaram comportamento muito próximo, possuem os percentuais de valores de correlação não significativos um pouco menores que os dos índices de Palmer. Entretanto, a quantidade de valores de correlação entre 0,5 e 1 dos índices de Palmer foi superior às desses índices. Isso mostra que a umidade modelada pelo MUSAG pode estar mais bem relacionada com os índices de Palmer. O resultado oposto, que foi visualizado ao se comparar os valores médios dessas ferramentas, nas bacias do Ceará, com a umidade do MUSAG, pode ter sido desencadeado pela suavização dos valores dessa variável em virtude da aplicação da metodologia dos Polígonos de Thiessen. 

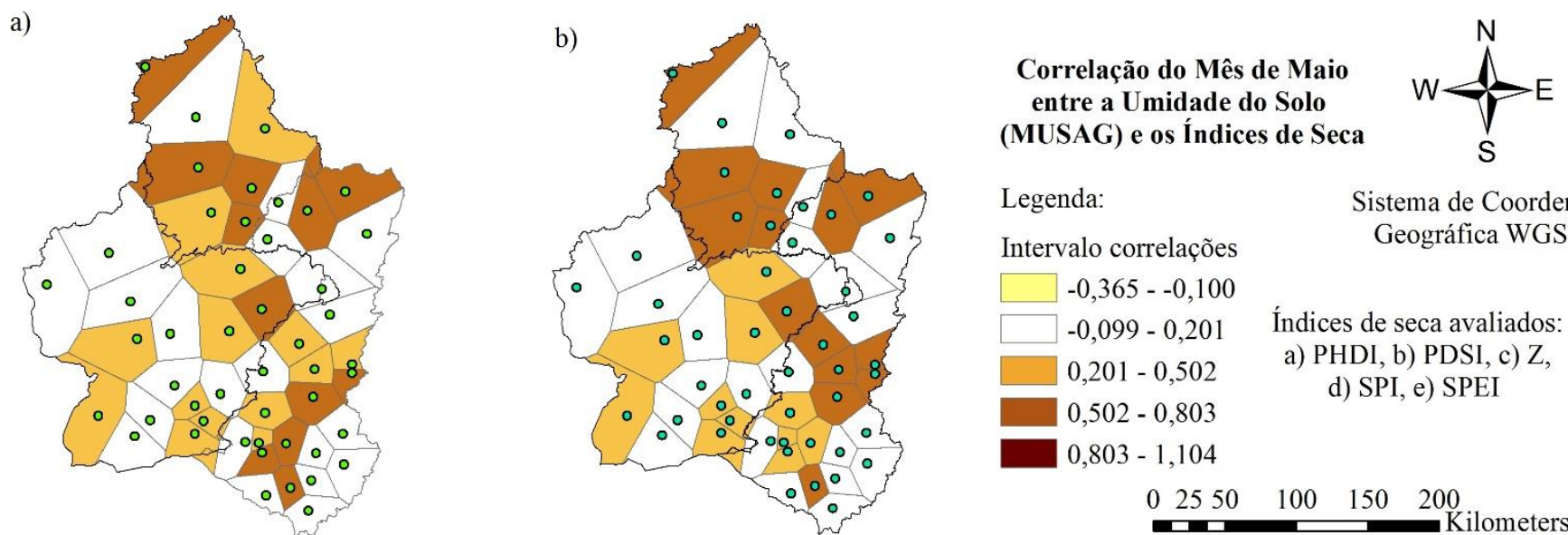

(MUSAG) e os Índices de Seca

Legenda:

Sistema de Coordenada

Intervalo correlações Geográfica WGS84

$\square-0,365--0,100$

$-0,099-0,201$ Índices de seca avaliados:

$0,201-0,502 \quad$ a) PHDI, b) PDSI, c) Z,

$0,201-0,502 \quad$ d) SPI, e) SPEI

$0,502-0,803$

$0,803-1,104$

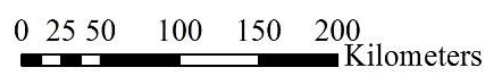

c)

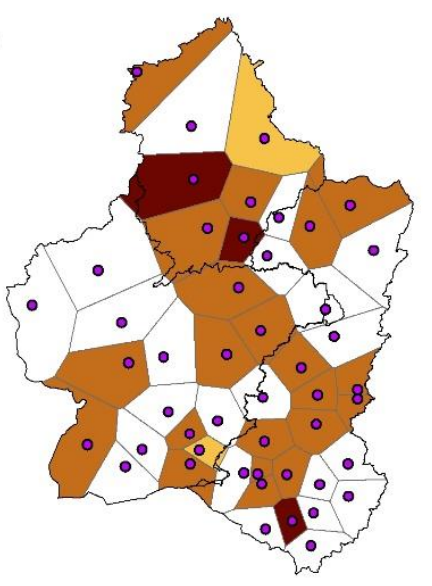

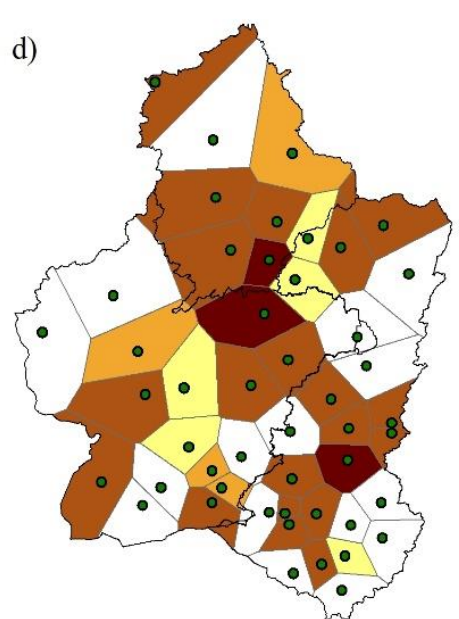

e)

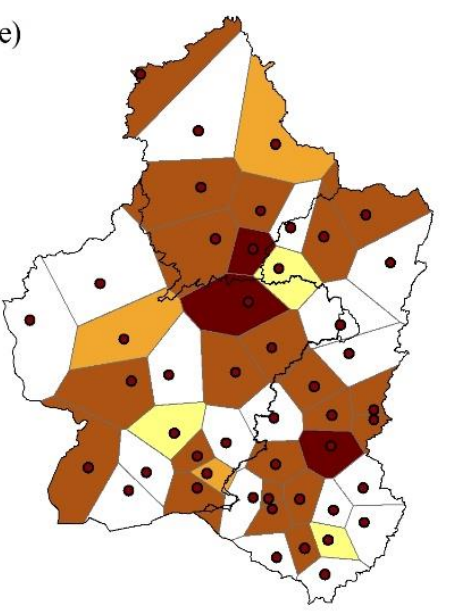

Figura 50 - Coeficiente de correlação de Spearman do mês de maio entre a umidade do solo gerada pelo MUSAG e os índices de seca (o intervalo de -0,099 a 0,201 representa as regiões onde os valores de correlação não são significativos). 
No caso dos pontos referentes à base de dados do CRU, os quais são pertencentes à bacia do Piranhas Açu, novamente, o PDSI e o PHDI apresentaram os melhores valores de correlação com a umidade mensal do solo disponibilizada pela ESRL, como se visualiza na Figura 51.
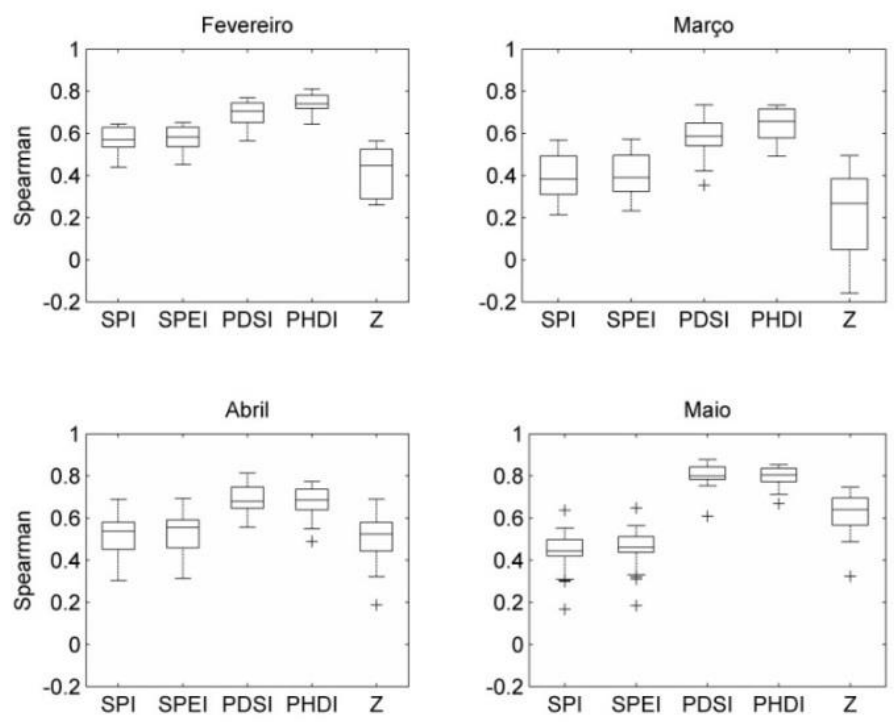

Figura 51 - Coeficiente de Spearman entre os índices de seca e a umidade do solo disponibilizada pela ESRL nos pontos da bacia Piranhas Açu.

A comparação entre o SPI e o SPEI acumulados, por meio da correlação de Spearman, com o valor máximo da umidade do solo da ESRL, em cada período, nos pontos referentes à base de dados do CRU, é apresentado na Figura 52. Novamente, percebe-se que o aumento desse tempo desencadeia uma melhor representação das mudanças da quantidade de água contida no solo.

Como constatado no estudo por bacias, também se têm um aumento da correlação quando se avalia, nos pontos referentes aos postos pluviométricos da FUNCEME, o SPI e o SPEI acumulados em períodos de até doze meses e a umidade do MUSAG, como mostra a Figura 53. O decréscimo desses valores de correlação quando se utiliza períodos superiores a 12 meses, também foi verificado ao se associar a umidade da ESRL com esses índices meteorológicos, apesar dessa queda ocorrer de forma menos acentuada. Essa similaridade entre essas análises sugere que, quando se estuda a seca agrícola, é melhor se utilizar índices acumulados no período de um (1) ano. 

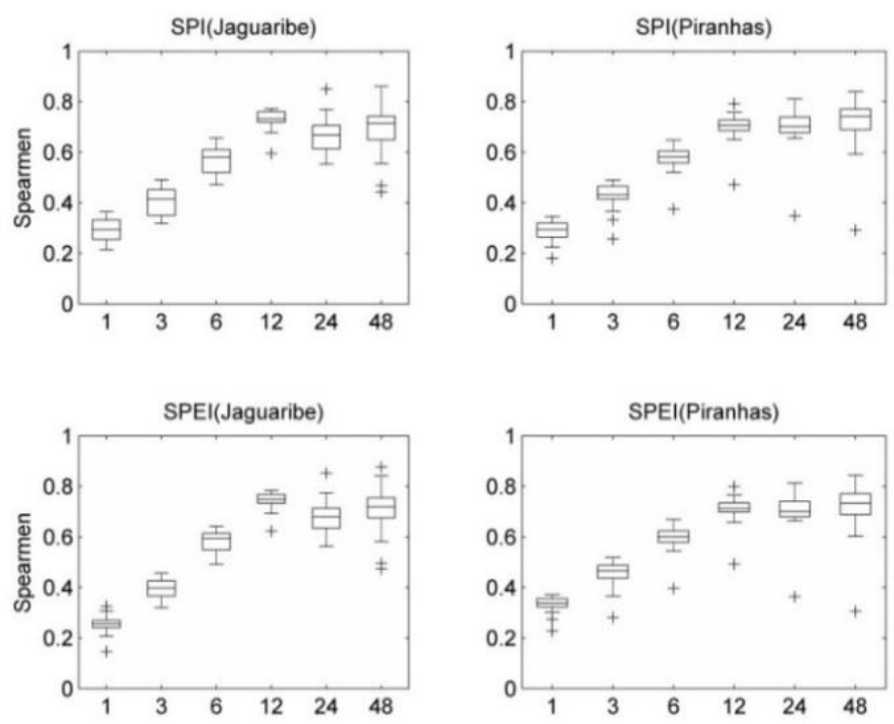

Figura 52 - Coeficiente de Spearman entre o SPI, SPEI e a umidade do solo disponibilizada pelo ESRL.
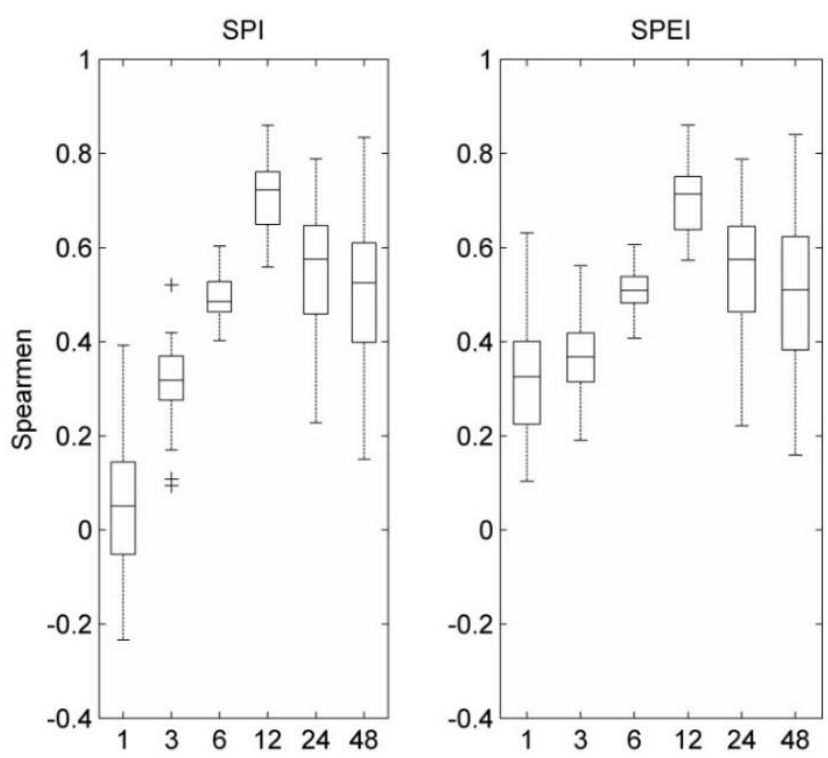

Figura 53 - Coeficiente de Spearman entre o SPI, SPEI e a umidade do solo gerada pelo MUSAG.

A variabilidade espacial das correlações entre esses índices acumulados em períodos de um (1) ano (SPI, SPEI), além do índice da FUNCEME, com a umidade do solo gerada pelo MUSAG, nos pontos correspondentes aos postos pluviométricos da FUNCEME, é apresentada na Figura 54. Também foi feita a identificação dos valores não significativos dessas correlações. Como ocorreu nas demais análises, para todos os períodos avaliados o SPI e o SPEI apresentam comportamentos muitos próximos. 

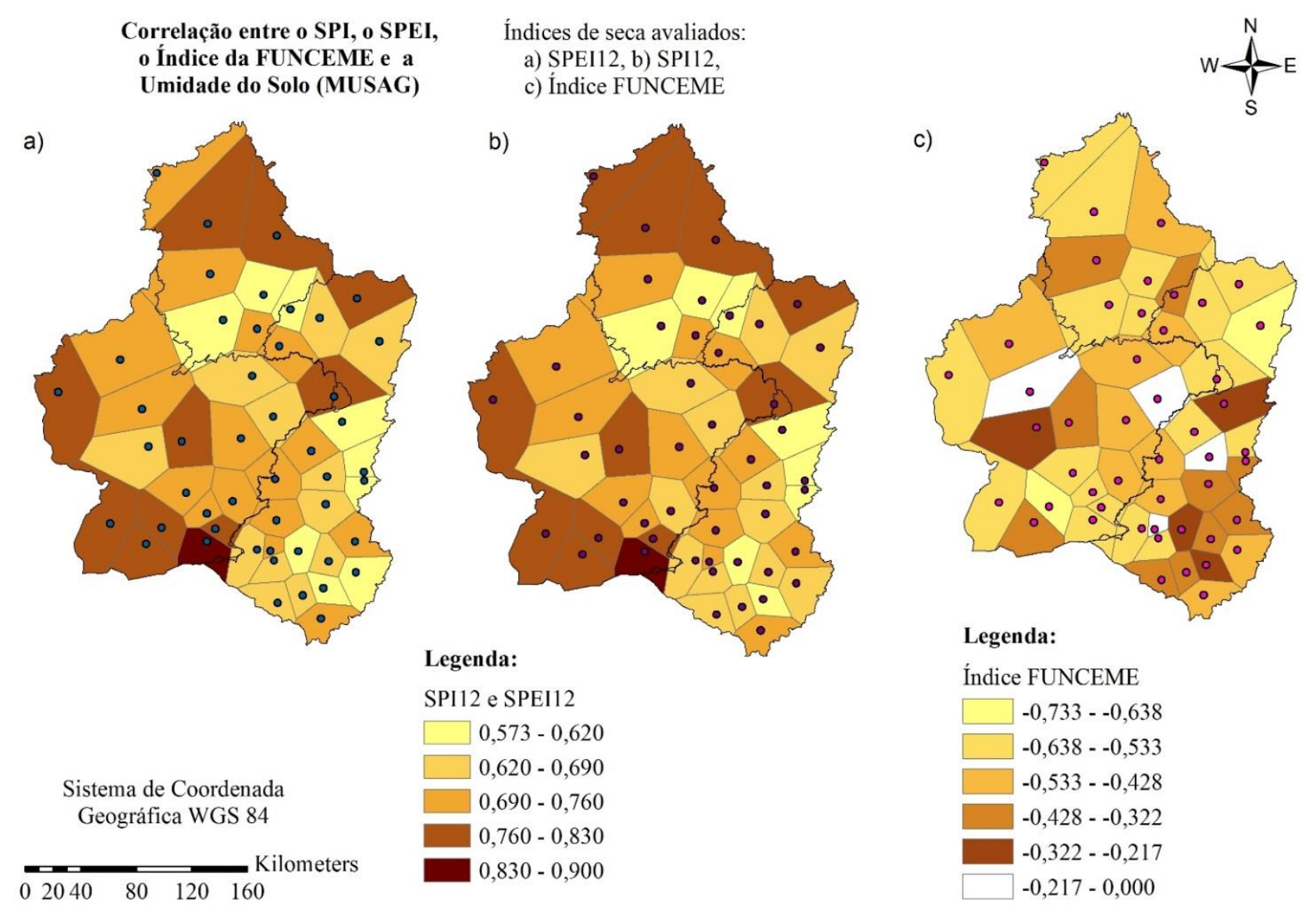

Figura 54 - Coeficiente de correlação de Spearman entre o SPEI12, SPI12 e a umidade do solo gerada pelo MUSAG (o intervalo de -0,217 a 0,00 representa as regiões onde os valores de correlação entre o índice da FUNCEME e a umidade do MUSAG não são significativos). 
O índice da FUNCEME apresenta uma maior discrepância entre os valores de correlação nos pontos das bacias localizadas no estado do Ceará, sendo menos que a metade dos mesmos inferiores a -0,5. Essa relação, já que essa ferramenta é inversamente proporcional à umidade, mostra que o período de quatro (4) meses, que é utilizado para a obtenção do índice da FUNCEME, não foi satisfatório para verificar as mudanças na umidade do solo gerada pelo MUSAG.

A Figura 55 mostra as comparações feitas entre o SPI e o SPEI médios nas bacias, os quais foram acumulados para diferentes períodos de tempo, com o volume armazenado nos reservatórios e as vazões afluentes aos mesmos. Os resultados revelam que, de forma semelhante ao que foi verificado ao se comparar esses índices com a umidade do solo, em geral, à medida que se aumenta o período de abrangência dos índices, consegue-se obter uma maior conformidade dos mesmos com as variações do volume dos reservatórios e das vazões afluentes.
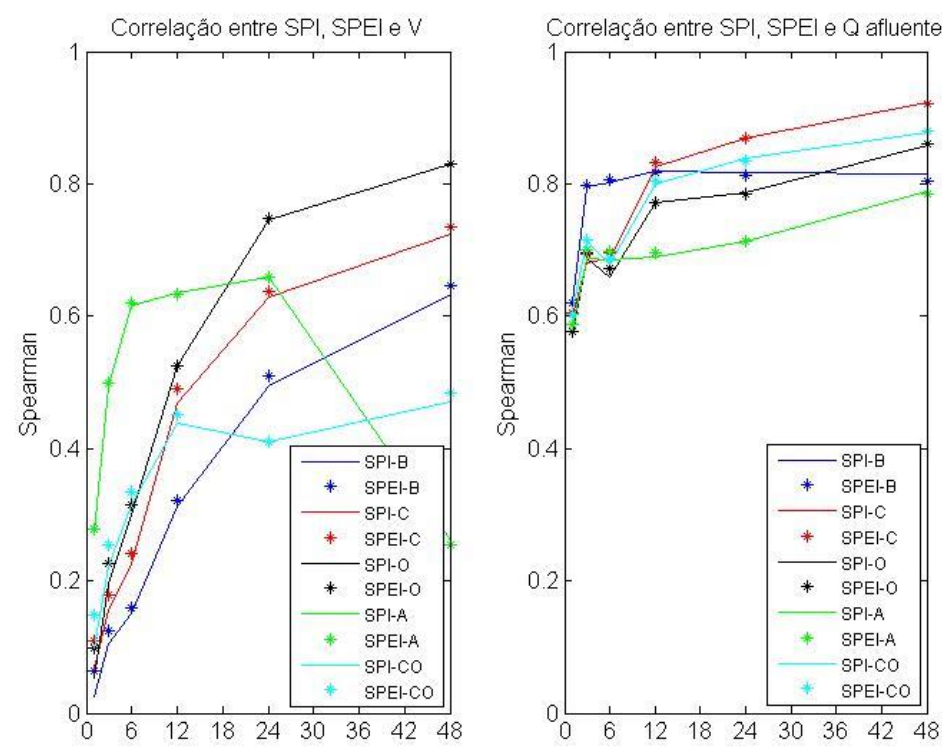

Figura 55 - Variação do coeficiente de Spearman do SPI e SPEI com as vazões (Q) afluentes e os volumes (V) dos reservatórios.

Apesar dessa melhora nos valores das correlações com os volumes, é importante destacar que não foi considerada, nos cálculos das correlações, a influência das regras de operação dos reservatórios. Isso impossibilita a análise dos dados de forma conclusiva, já que os valores dessa variável não dependem apenas pelas condições climáticas. 
As bacias localizadas nos estados do Rio Grande do Norte e a Paraíba foram as que alcançaram os piores resultados das correlações com os volumes. Esse comportamento pode estar relacionado à utilização de diferentes premissas para a operação dos reservatórios, além de que os dados foram disponibilizados por diferentes fontes. A diminuição dos valores de correlação referentes à bacia do Coremas, quando se analisa períodos de 48 meses, pode estar relacionada à menor disponibilidade de dados, os quais se estendem apenas durante os anos de 2006 a 2012, enquanto os demais têm uma maior base de dados.

As correlações do SPI e do SPEI acumulados com a média das vazões, também crescem à medida que se aumenta o período de acumulação do índice, obtendo-se bons resultados do coeficiente de Spearman, próximos a 0,6; mesmo quando as variáveis mensais são analisadas. Esses resultados mostram que esses índices representam bem as variações das vazões em todos os períodos avaliados.

Ao se associar o SPI acumulado nos pontos da base de dados do CRU, com as vazões médias afluentes aos reservatórios, em geral, como ocorreu na análise com os valores médios dos índices, têm-se um acréscimo na capacidade de identificar as mudanças dessa variável à medida que se aumenta o período de acumulação. Isso pode ser observado nas Figuras 56 e 57. Não foram apresentados os resultados dessa mesma análise com o SPEI em função do mesmo apresentar resultados muito próximos aos do SPI.

Ao se comparar a série completa dos índices de Palmer, calculados com os dados das bacias hidrográficas, com o volume dos reservatórios e as vazões afluentes aos reservatórios, como se pode visualizar na Figura 58, verifica-se que os três índices conseguem representar satisfatoriamente as mudanças nas vazões afluentes aos reservatórios, com valores médios próximos a 0,6. De forma oposta, os volumes apresentam valores médios de correlação com esses índices baixos. 

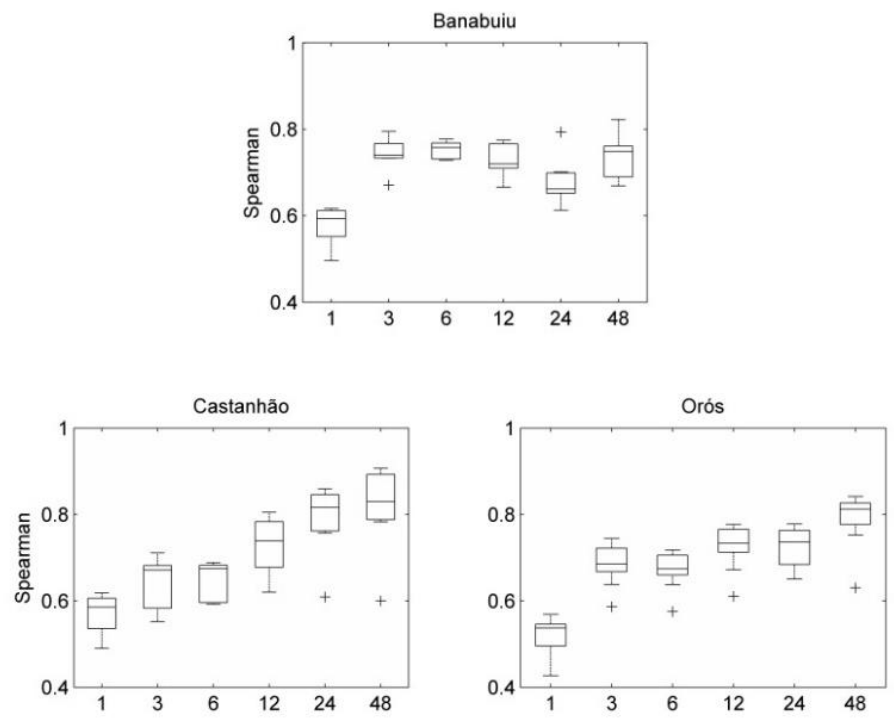

Figura 56 - Variação dos coeficientes de Spearman entre os SPI, por pontos, acumulados em diversas escalas de tempo e as vazões afluentes aos reservatórios do Castanhão, Banabuiú e Orós.
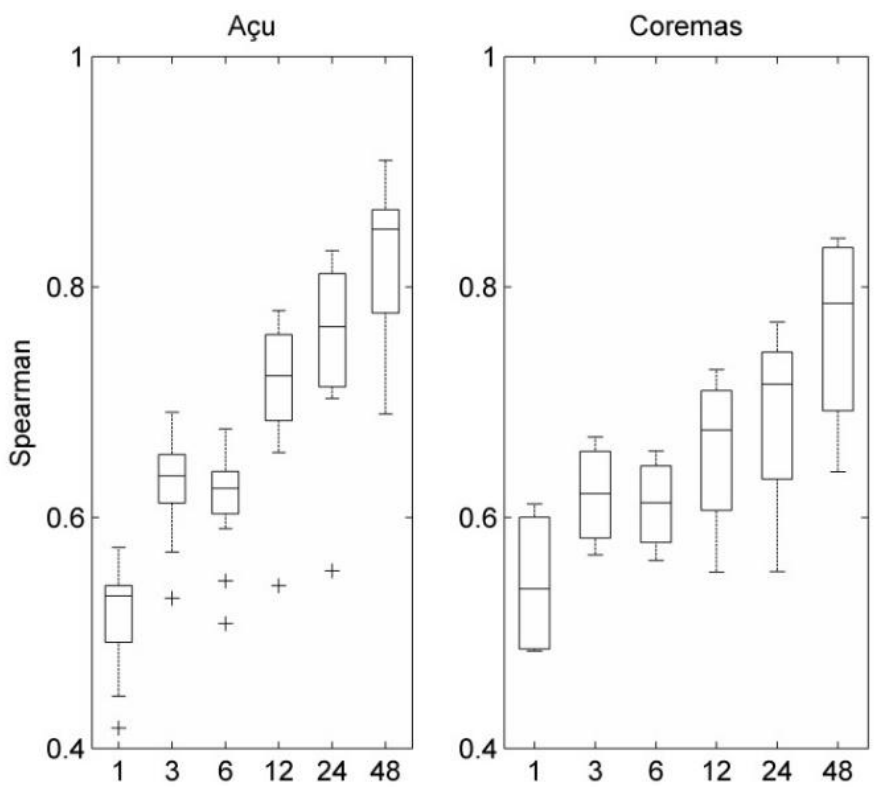

Figura 57 - Variação do coeficiente de Spearman entre os SPI, por pontos, acumulados em diversas escalas de tempo e as vazões afluentes aos reservatórios do Açu e Coremas. 

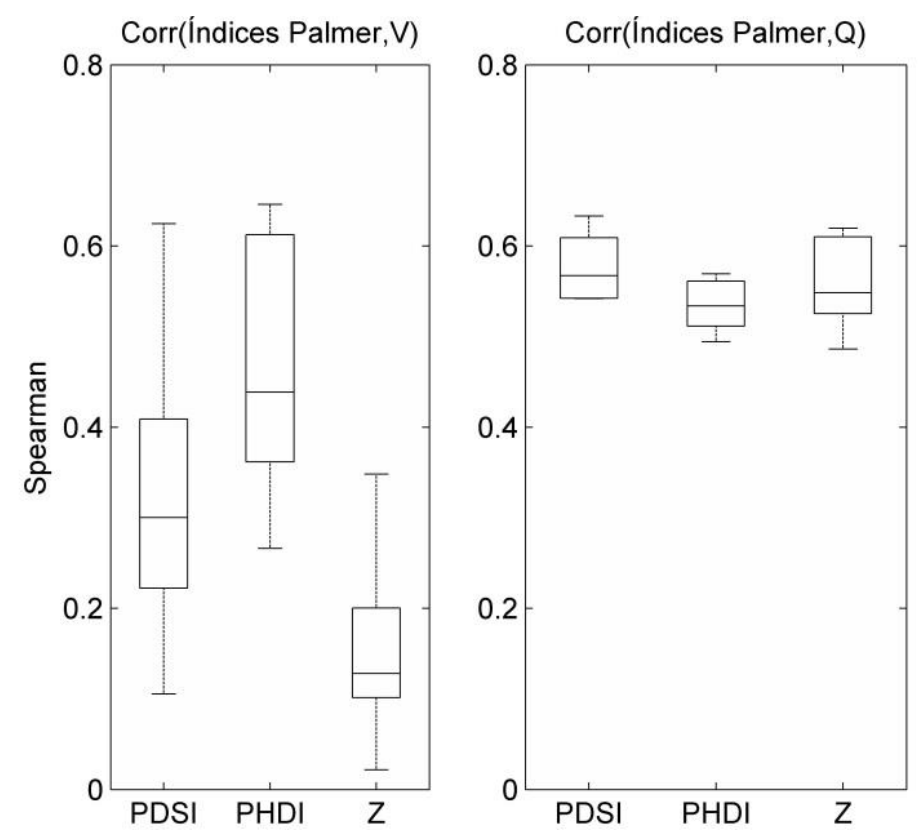

Figura 58 - Coeficiente de Spearman entre os índices de Palmer das bacias, o volume (V) armazenado nos reservatórios e as vazões $(\mathrm{Q})$ afluentes aos mesmos.

Dentre os índices elaborados por Palmer (1965), o que apresenta uma maior conformidade com o volume é o PHDI, apesar de o valor médio ser baixo, o que condiz com relatado por Karl et al. (1987). O autor afirma que, diferente do PDSI, que muda abruptamente seu valor no último mês de incidência do evento de seca, o PHDI apresenta uma variação mais gradual quando está retornando as condições normais. É interessante ressaltar que os índices de Palmer apresentam um desempenho semelhante ao SPI e o SPEI mensais para representar as vazões afluentes aos reservatórios.

Na Figura 59 são apresentadas as comparações dos índices de Palmer nos pontos da base de dados do CRU e as vazões afluentes aos reservatórios estudados. Em todas as situações investigadas foram obtidos valores muito próximos de correlação, com exceção das análises que envolveram os índices calculados com a série de precipitação fornecida pela FUNCEME. Os resultados das correlações obtidas com os dados dos pontos foram inferiores aos referentes às bacias, com valores médios entre 0,4 e 0,5 ; mostrando que as variações das vazões afluentes aos reservatórios não são bem explicadas pelos índices de Palmer. 

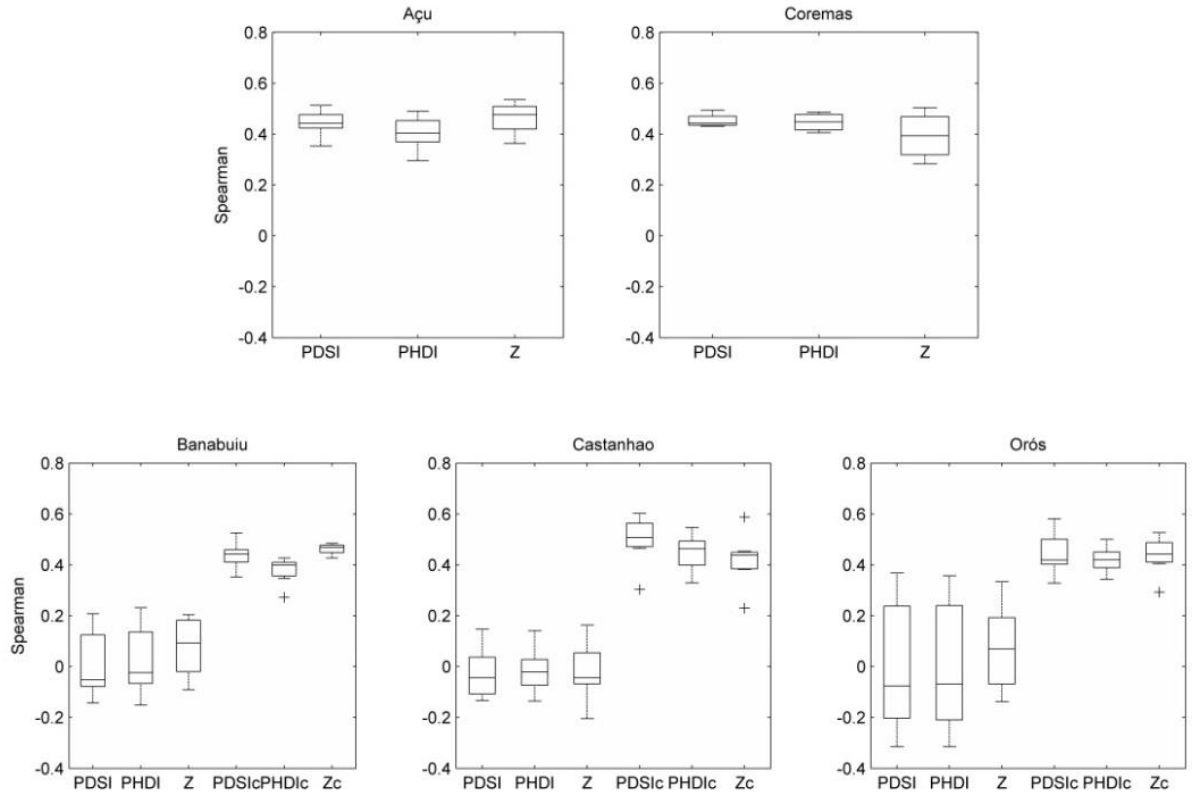

Figura 59 - Coeficiente de Spearman entre os índices de Palmer nos pontos da base de dados do CRU e as vazões afluentes aos reservatórios.

Nos gráficos da Figura 60 pode-se verificar como varia a correlação entre o SPI nos pontos da base de dados do CRU localizados no Ceará, em cada uma das escalas de tempo desse índice, e os volumes dos reservatórios do Castanhão, Banabuiú e Orós. Novamente, como os resultados das correlações do SPEI são muito próximas as do SPI, as mesmas não foram apresentados os resultados do mesmo.
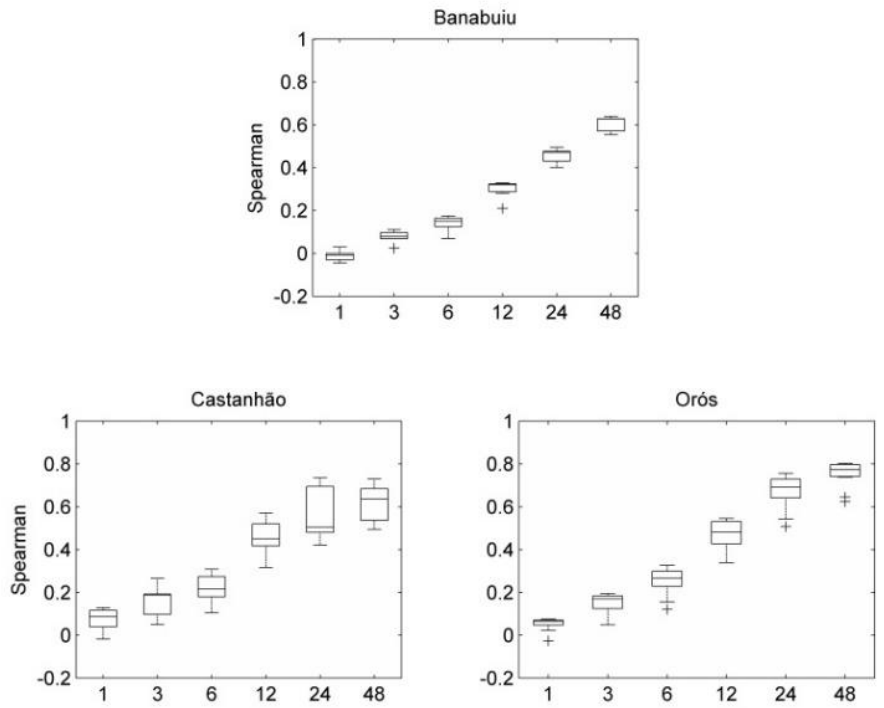

Figura 60 - Variação do coeficiente de Spearman entre os SPI, por pontos, acumulados em diversas escalas de tempo e os volumes dos reservatórios do Castanhão, Banabuiú e Orós. 
Apesar de esse índice considerar apenas dados de precipitação, à medida que se aumenta o período de acumulação dessa variável, têm-se uma melhor associação do mesmo com os volumes dos reservatórios. Ressalta-se novamente que não foi considerada a interferência humana nos valores dessa variável.

Essa mesma comparação, mas utilizando os pontos pertencentes às bacias do Coremas e do Açu, apresentada na Figura 61, mostra que o comportamento verificado na análise dos valores médios dessas áreas se repete ao observado na avaliação dos valores dos índices nos pontos. Ocorre um decréscimo da correlação dos pontos localizados na bacia do Coremas a partir do SPI de 12 meses, além de que, no caso dos pontos localizados na bacia do Açu, os valores de correlação são inferiores aos das demais regiões.
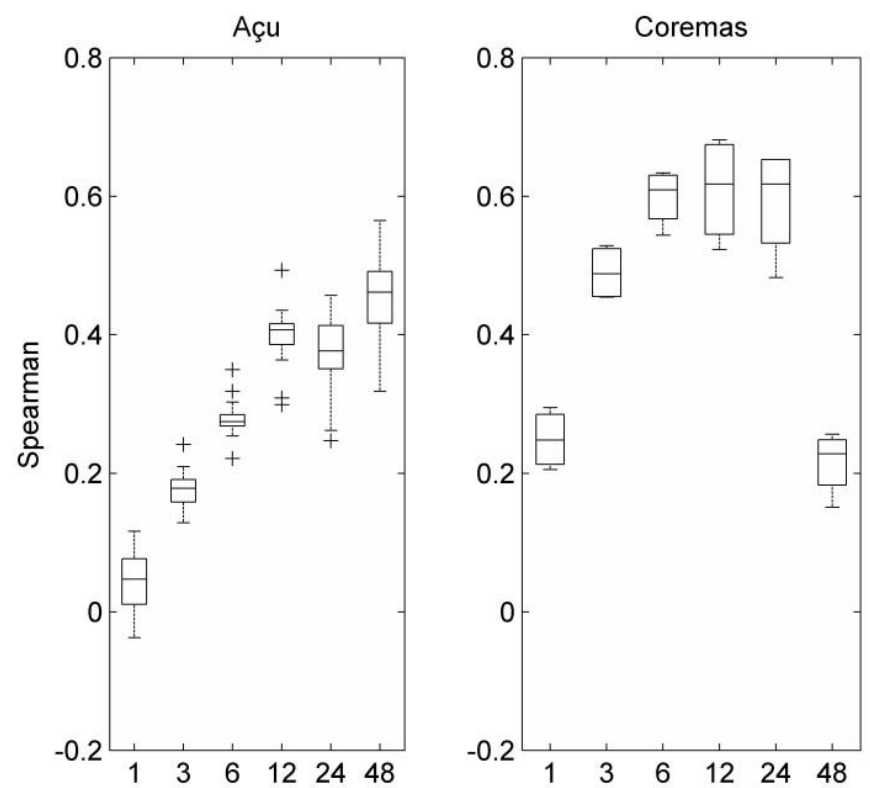

Figura 61 - Variação do coeficiente de Spearman entre os SPI, por pontos, acumulados em diversas escalas de tempo e os volumes dos reservatórios do Açu e Coremas.

Na Figura 62 é apresentada a correlação de Spearman, calculada nos pontos da base de dados do CRU, entre os índices propostos por Palmer e os volumes dos cinco (5) reservatórios abordados no presente trabalho. Os valores dessas correlações nos pontos pertencentes às bacias do estado do Ceará, com exceção da contribuinte ao reservatório do Banabuiú, mostram que novamente o PHDI foi o índice que alcançou os melhores valores médios de correlação, com resultados próximos de 0,6 nas bacias do Coremas, Castanhão e Orós. Apesar desse desempenho, não se pode dizer que esse índice consegue representar 
satisfatoriamente as variações dessa variável em virtude de não se ter considerado, no presente trabalho, as regras de operação dos reservatórios.
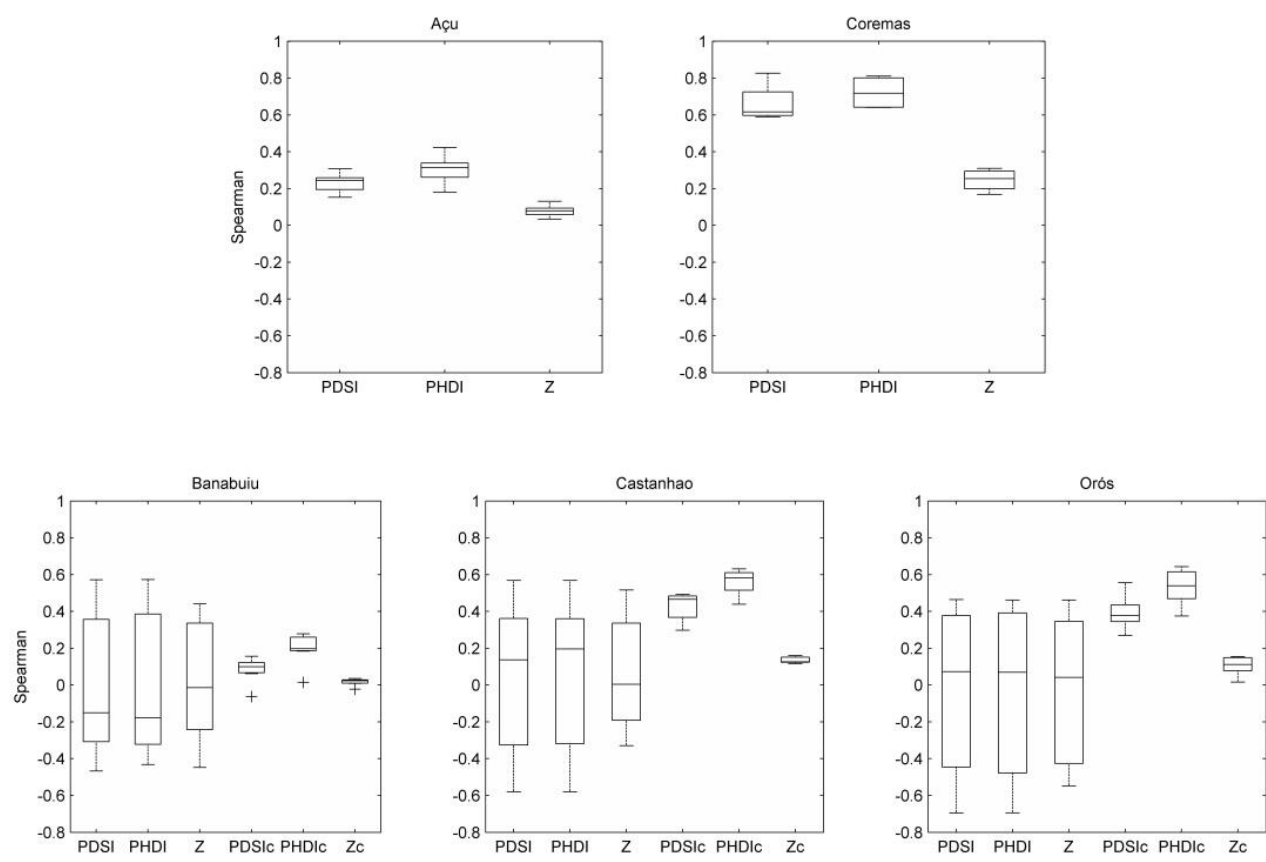

Figura 62 - Coeficiente de Spearman, por pontos, entre os índices de Palmer, por pontos, e o volume dos reservatórios.

\section{4- DETERMINAÇÃO DA SIMILARIDADE ENTRE OS ÍNDICES DE SECA}

A métrica do coeficiente de Spearman também foi utilizada para auxiliar na identificação da similaridade entre os resultados dos índices de seca. Assim, inicialmente se verificou a semelhança do comportamento dos índices referentes às bacias contribuintes aos reservatórios do Banabuiú, Castanhão, Orós, Açu e Coremas.

A Figura 63 mostra a relação entre o SPI e os demais índices. Apesar de o SPEI considerar a evapotranspiração potencial além da chuva, a sua tendência varia de forma bastante similar a do SPI, o qual depende exclusivamente da precipitação. Assim, não serão apresentados os valores das correlações do SPEI com os demais índices, já que os resultados serão os iguais aos do SPI. 

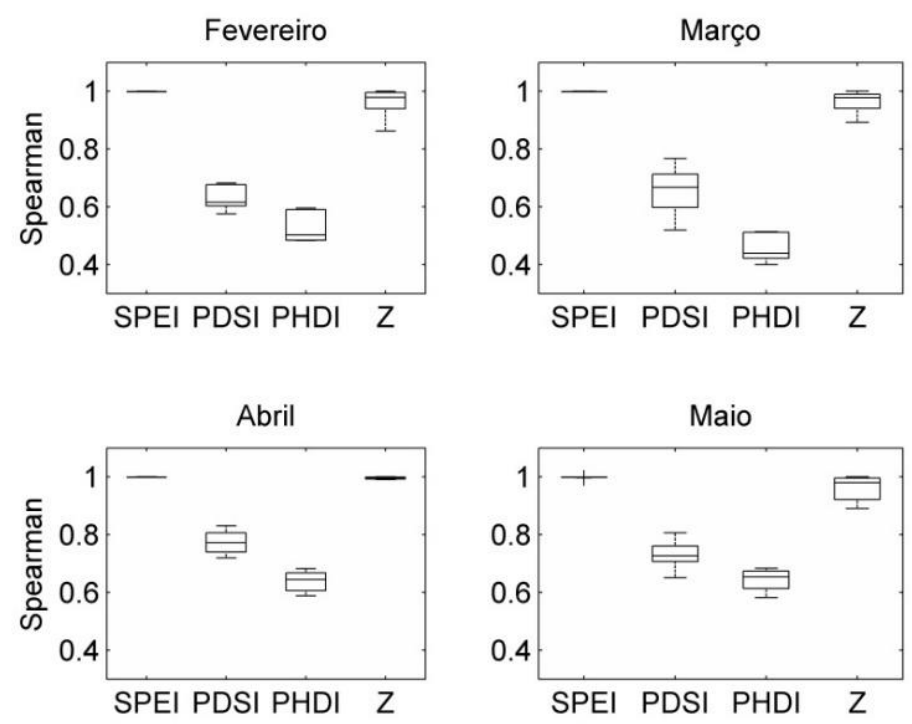

Figura 63 - Coeficiente de Spearman entre o SPI das bacias do Banabuiú, Castanhão, Orós, Açu e Coremas, e os índices de seca.

Destaca-se ainda, que o desempenho do índice $\mathrm{Z}$ também se assemelha bastante ao SPI e ao SPEI. Essa característica pode estar relacionada à metodologia de cálculo do mesmo, que se baseia no déficit de precipitação e não considera variáveis de meses anteriores, como ocorre com o PDSI e o PHDI. É interessante ressaltar que, apesar do SPI e do SPEI também apresentarem bons valores de correlação com o PDSI, esses índices apresentam resultados distintos. Portanto, não se recomenda a substituição do PDSI pelo SPI ou o SPEI.

Essa comparação entre os índices também foi feita com os valores dos mesmos nos pontos de grade do CRU. Assim, ao se avaliar os coeficientes de correlação entre o SPI e os demais índices de seca calculados nos pontos pertencentes às bacias contribuintes aos reservatórios do Banabuiú, Castanhão e Orós, observa-se, novamente, que o SPEI é o que mais se assemelha ao SPI, alcançando valores de correlação muito próximos de um (1) em todos os meses analisados, como apresenta a Figura 64. 

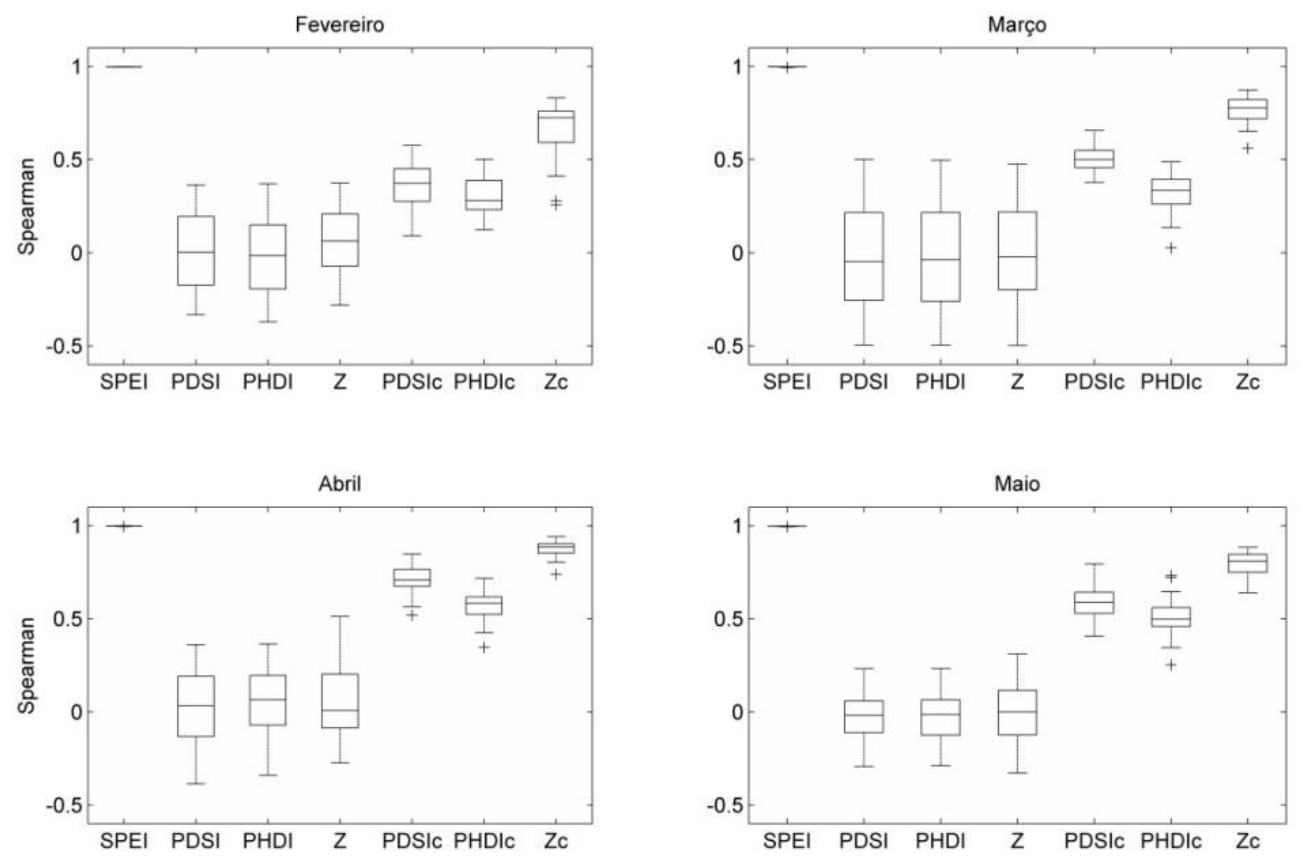

Figura 64 - Coeficiente de Spearman entre o SPI e os índices de seca por pontos.

Os índices compostos por Palmer, calculados com a série de precipitações observadas fornecidas pela FUNCEME, não apresentam as secas nos mesmos instantes que o SPI e o SPEI, exibindo correlações médias próximas a zero (0). Essa disparidade entre os resultados dos índices de Palmer e do SPI, entretanto não ocorre quando se utiliza os dados de precipitação do CRU, os quais estão disponíveis por um período mais extenso que os da série da FUNCEME por pontos. Dentre esses índices, o $\mathrm{Z}$ foi o que se mostrou mais condizente com o SPI, o que pode ser devido ao mesmo, como relatado anteriormente, ser o único que não considera as informações dos meses anteriores no cálculo do valor final.

Ao se fazer essa mesma comparação, mas utilizando as séries de dados dos pontos localizados na bacia do Piranhas Açu, cujos resultados são mostrados na Figura 65, também se nota que, além do SPEI, o índice Z também apresenta resultados mais próximos aos do SPI. 

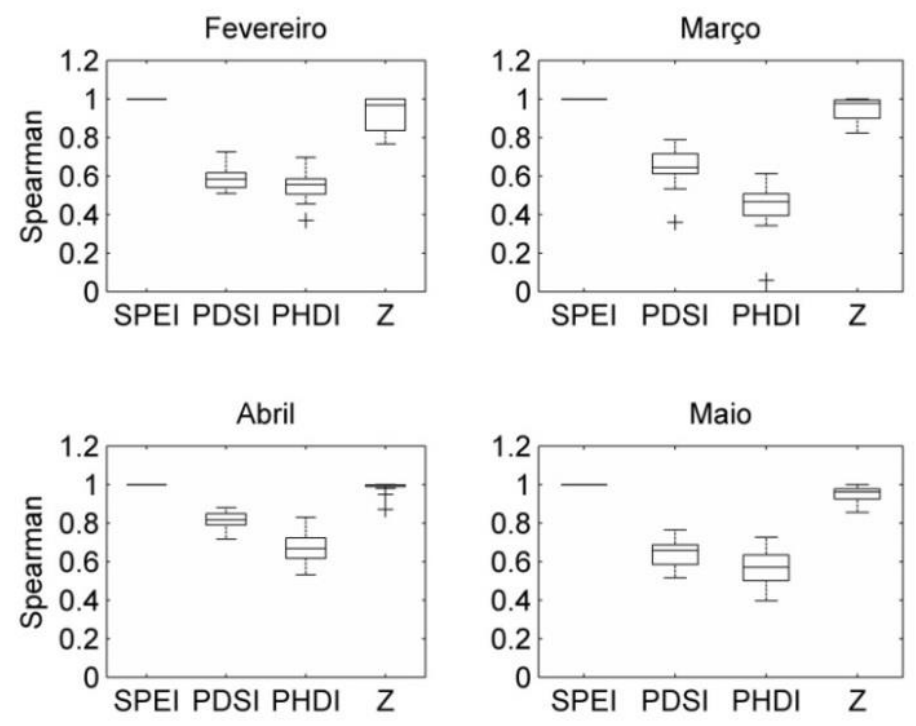

Figura 65 - Coeficiente de Spearman entre os índices de seca e o SPI da bacia do Piranhas Açu por pontos.

Como o índice da FUNCEME foi obtido com base nos valores diários de precipitação referentes aos quatro meses da quadra chuvosa, ao compará-lo com os índices acumulados, preferiu-se utilizar o SPI e o SPEI de seis (6) e doze (12) meses que terminassem em maio, como mostrado na Figura 66. Isso foi feito para impossibilitar a influência das chuvas que ocorrem na quadra chuvosa do ano seguinte nos valores finais do índice

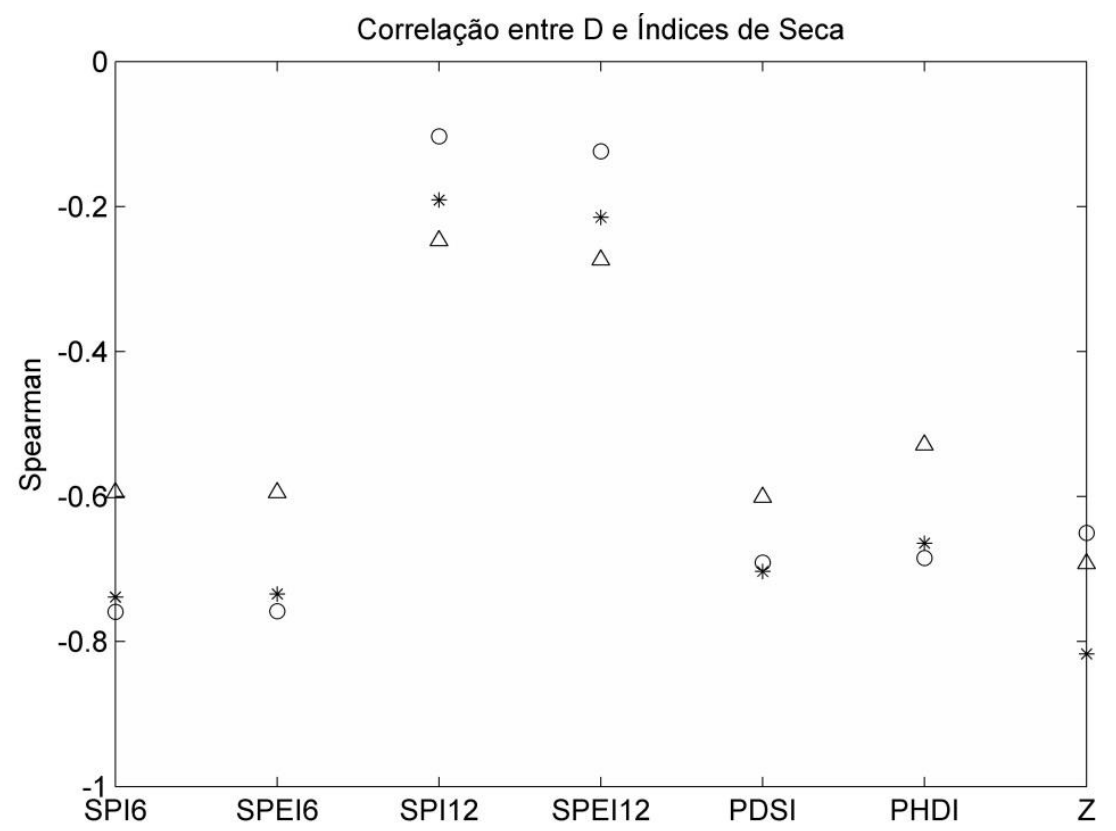

Figura 66 - Coeficiente de Spearman entre o índice da FUNCEME das bacias do Banabuiú, Castanhão, Orós, e os índices de seca médio na bacia. 
Os índices que apresentam a menor similaridade com o índice da FUNCEME são o SPI e o SPEI de um (1) ano. Esse resultado pode ter sido influenciado pela ocorrência de chuvas eventuais durante os meses que não pertencem à quadra chuvosa.

A Figura 67 mostra, novamente, que o SPI e o SPEI calculados para um período de seis (6) meses apresentam a melhor correlação, dentre os índices analisados, com o do índice da FUNCEME. Ressalta-se, entretanto uma diminuição dos valores médios das correlações por pontos em relação a essa mesma análise feita com os valores dos índices médios nas bacias, além da maior variabilidade dos dados. Esse comportamento mostra que todos os índices estudados apresentam resultados diferentes dos índices da FUNCEME, não sendo capazes de substituir o mesmo, caso não se disponha de dados necessários para o cálculo dessa ferramenta.

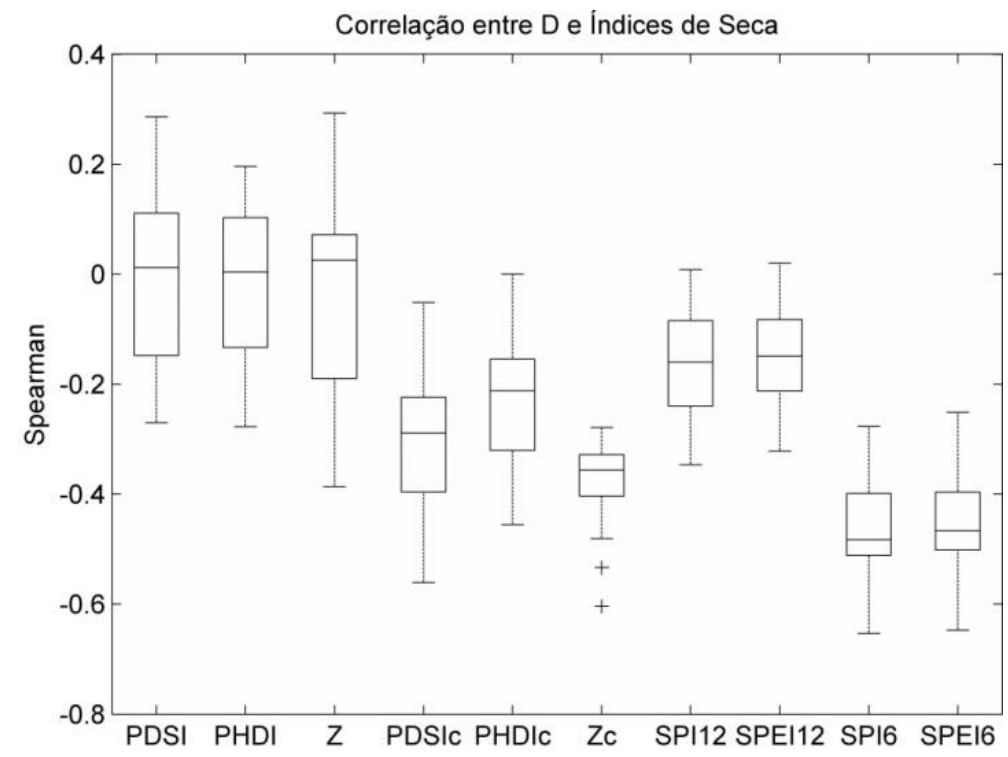

Figura 67 - Coeficiente de Spearman entre os índices de seca e o índice da FUNCEME por pontos.

\section{5- VERIFICAÇÃO DA CAPACIDADE DE PREVISÃO DO SPI}

A eficácia das previsões da seca realizadas com o SPI mensal e trimestral, referentes às bacias do Castanhão Banabuiú e Orós, foi determinada a partir da obtenção do BS, do coeficiente de Spearman e do $\mathrm{SS}_{\mathrm{D}}$. Esse índice foi calculado com as previsões climáticas realizadas pela FUNCEME. 
De maneira geral, os resultados do $\mathrm{SS}_{\mathrm{D}}$, nos três reservatórios, foram positivos em pelo menos em uma das datas de emissão das previsões. Esses valores dessa métrica mostram que nessas situações o SPI teve um desempenho superior a previsão probabilística realizada com base na climatologia.

Ao se comparar os resultados do SPI mensal, obtidos com as precipitações previstas e observadas, percebe-se que grande parte desses valores foram superiores a zero, optou-se, portanto, por calcular o RPSS adotando uma faixa de avaliação da amostra diferentes da proposta por McKee et al. (1993), como relatado anteriormente.

Para permitir um melhor entendimento dos resultados do $\mathrm{SS}_{\mathrm{D}}$ se comparou graficamente os valores do SPI previsto com o observado. Nesse diagrama também são apresentados os limites das previsões do SPI que são realizadas segundo a climatologia, com base, portanto nos dados históricos, sendo representadas pelos percentiles de 0,25 e 0,75.

No caso das previsões referentes à bacia contribuinte ao reservatório do Banabuiú os melhores resultados do $\mathrm{SS}_{\mathrm{D}}$ foram obtidos quando se consideraram a TSM persistida. Os valores positivos dessa métrica estão relacionados às previsões geradas em janeiro e fevereiro para março e abril, sendo os melhores resultados do SPI, quando o $\mathrm{SS}_{\mathrm{D}}$ alcançou valores próximos a 0,4; mostrados na Figura 68.

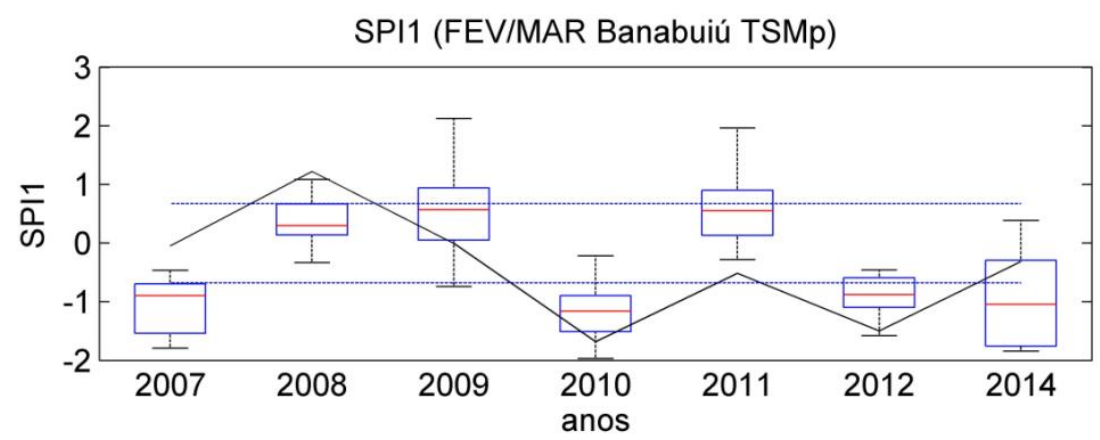

Figura 68 - Comparação do SPI mensal previsto, da bacia do Banabuiú, gerado com a TSM persistida e o observado (linha azul pontilhada: climatologia, linha preta contínua: SPI observado).

Observa-se que, apesar dos valores do SPI observado não terem coincidido com as medianas da previsão, em todos os anos, os mesmo se encontram na mesma direção de cada boxplot. Existe ainda uma proximidade entre os conjuntos dos valores das previsões de todos os anos com os limites da climatologia. 
Para a bacia do Castanhão, foram obtidos valores positivos do $\mathrm{SS}_{\mathrm{D}}$ referentes às previsões emitidas em janeiro para os meses de janeiro a maio, com base na TSM persistida e prevista. Os resultados do SPI em que as previsões representaram de forma mais eficaz as secas observadas segundo esse índice calculados com os dois tipos de discretização do RPSS, usando os limites de -2; -1,5; -1; 0 e -1; 0; 1, são apresentados respectivamente nas Figuras 69 e 70. Nessas duas situações o $\mathrm{SS}_{\mathrm{D}}$ assumiu valores máximos de 0,24 e 0,33; respectivamente.

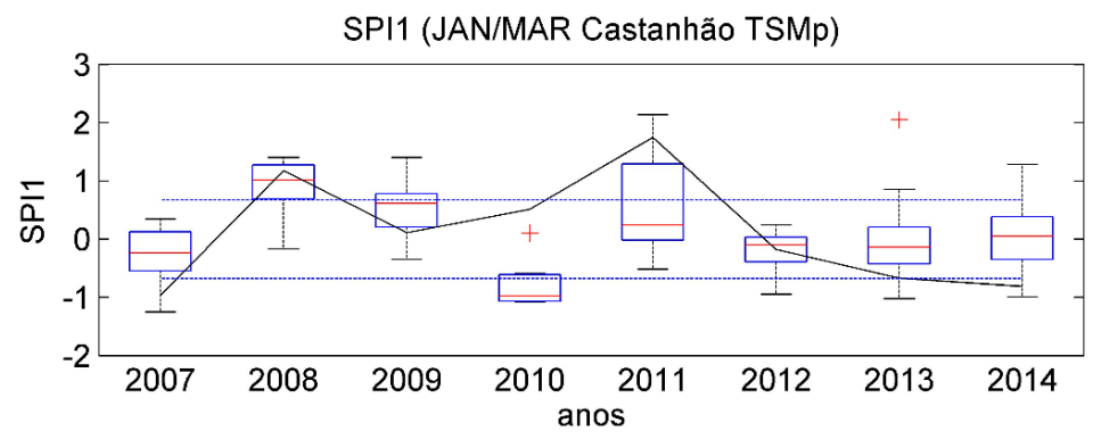

Figura 69 - Comparação do SPI mensal previsto, da bacia do Castanhão, gerado com a TSM persistida e o observado (linha azul pontilhada: climatologia, linha preta contínua:

SPI observado).

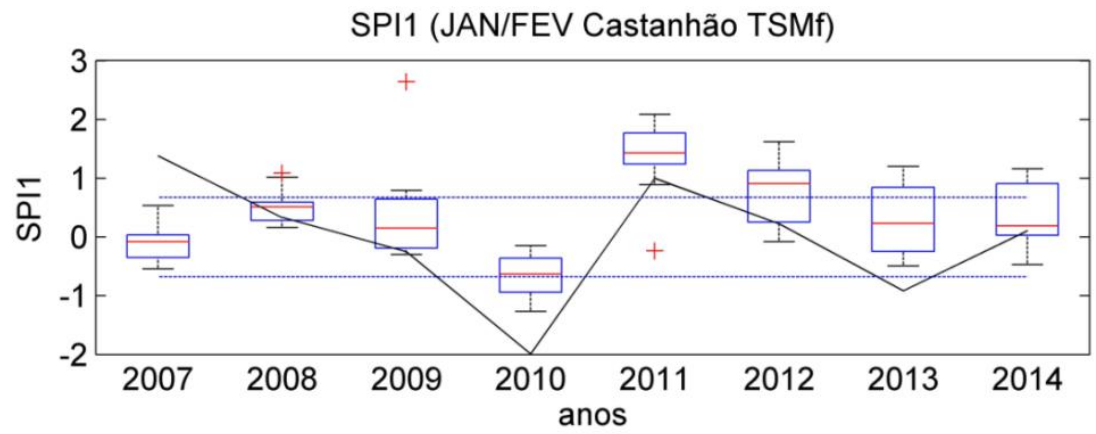

Figura 70 - Comparação do SPI mensal previsto gerado, da bacia do Castanhão, com a TSM prevista e o observado (linha azul pontilhada: climatologia, linha preta contínua: SPI observado).

Ao se comparar os comportamentos dos valores observados e previstos do SPI mensais apresentados nas Figuras 69 e 70 observa-se um melhor desempenho da metodologia fundamentada na TSM persistida. O primeiro diagrama mostra que as informações fornecidas pelo SPI previsto apresentam uma melhor qualidade que a climatologia, com exceção do ano de 2010.

Em relação à bacia contribuinte ao Orós os valores positivos mais elevados do $\mathrm{SS}_{\mathrm{D}}$, pertinentes às previsões emitidas em janeiro para janeiro, fevereiro, abril e maio, e em 
fevereiro para abril, foram alcançados quando se considerar a TSM prevista na obtenção das previsões meteorológicas da FUNCEME. A Figura 71 mostra um dos melhores resultados da previsão das secas segundo o $\mathrm{SPI}$, quando o $\mathrm{SS}_{\mathrm{D}}$ atingiu valores máximos de 0,29 .

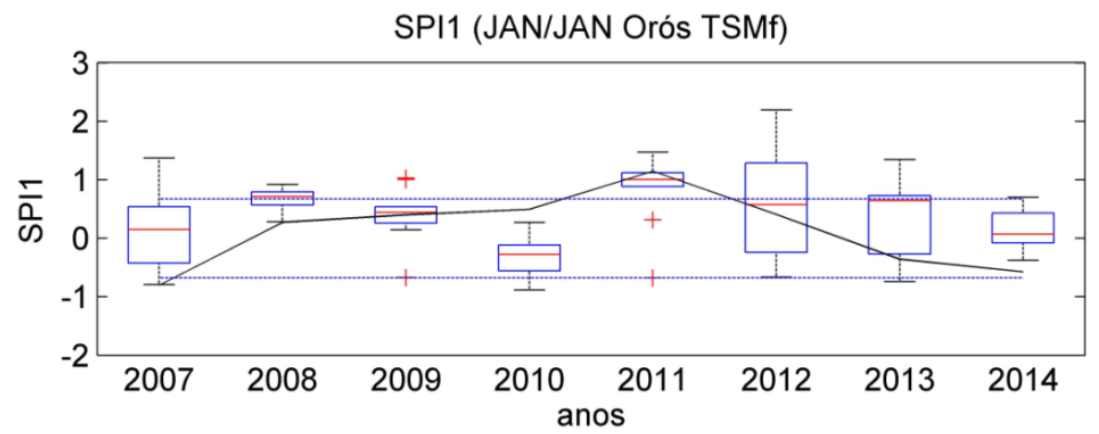

Figura 71 - Comparação do SPI mensal persistida gerado, da bacia do Orós, com a TSM prevista e o observado (linha azul pontilhada: climatologia, linha preta contínua: SPI observado).

Ao se avaliar os valores do SPI trimestrais calculados com os dados da bacia do Banabuiú, verifica-se que os melhores resultados do $\mathrm{SS}_{\mathrm{D}}$ foram calculados com base nas previsões emitidas em janeiro e fevereiro para MAM e AMJ, quando se considera a TSM prevista. $\mathrm{O}$ comportamento dos valores do SPI que atingiram uma melhor qualidade da previsão, em comparação à climatologia, a qual alcançou um $\mathrm{SS}_{\mathrm{D}}$ máximo de aproximadamente 0,55 ; é apresentado na Figura 72.

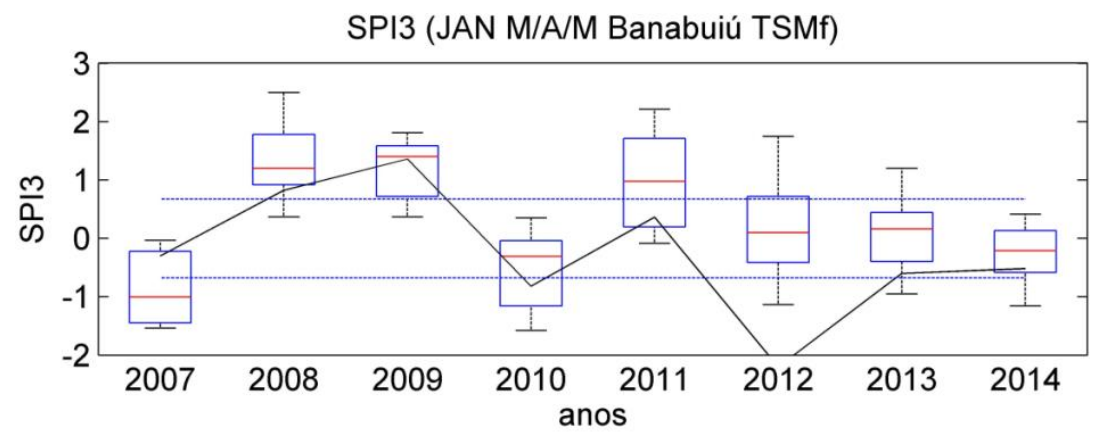

Figura 72 - Comparação do SPI trimestral previsto, da bacia do Banabuiú, gerado com a TSM prevista e o observado (linha azul pontilhada: climatologia, linha preta contínua: SPI observado).

De acordo com a Figura 72, apenas no ano de 2012 a previsão da seca com o SPI e com a climatologia apresentaram tendências diferentes dos valores observados. Nos demais anos, entretanto, observa-se uma maior similaridade das previsões com esse SPI que com a climatologia. 
Em relação à bacia do Orós, as secas com o SPI foram previstas de maneira mais eficaz, segundo o $\mathrm{SS}_{\mathrm{D}}$, quando se utilizou os valores das precipitações emitidas janeiro e fevereiro, com base na TSM prevista, para MAM. A Figura 73 mostra os valores da previsão com o SPI que tiveram o melhor desempenho comparado com a climatologia, quando se atingiu um $\mathrm{SS}_{\mathrm{D}}$ de 0,45 .

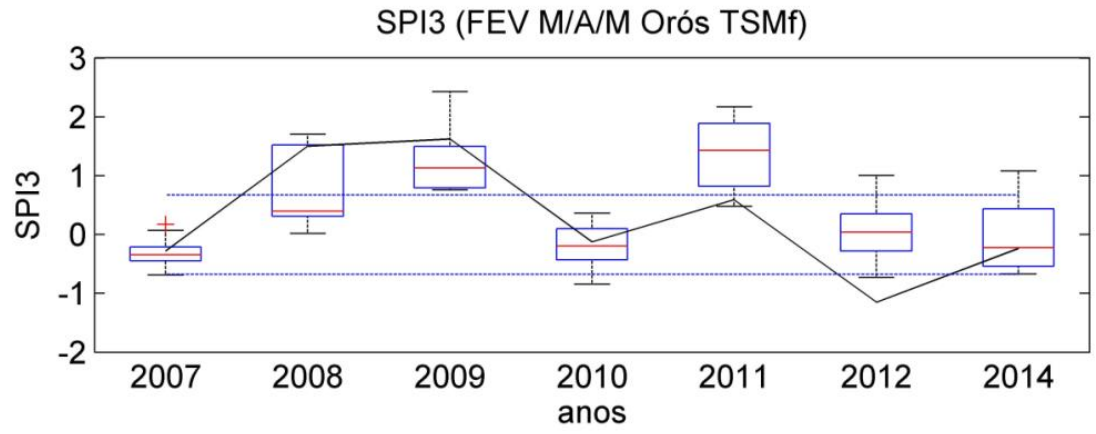

Figura 73 - Comparação do SPI trimestral previsto, da bacia do Orós, gerado com a TSM prevista e o observado (linha azul pontilhada: climatologia, linha preta contínua: SPI observado).

Na maior parte dos anos, o SPI da bacia do Orós apresentou uma maior proximidade com os valores observados, em comparação a climatologia. Entretanto, a Figura 73 mostra que o SPI gerado no ano de 2012 foi o que mais se distanciou do observado.

Diferente das outras bacias, no Castanhão os valores do SPI que se mostraram mais eficazes foram gerados com base na TSM persistida. Essas previsões foram emitidas em janeiro para JFM e FMA. Os valores do SPI da última situação, quando foram verificados valores de $\mathrm{SS}_{\mathrm{D}}$ máximos de 0,4; são apresentados na Figura 74.

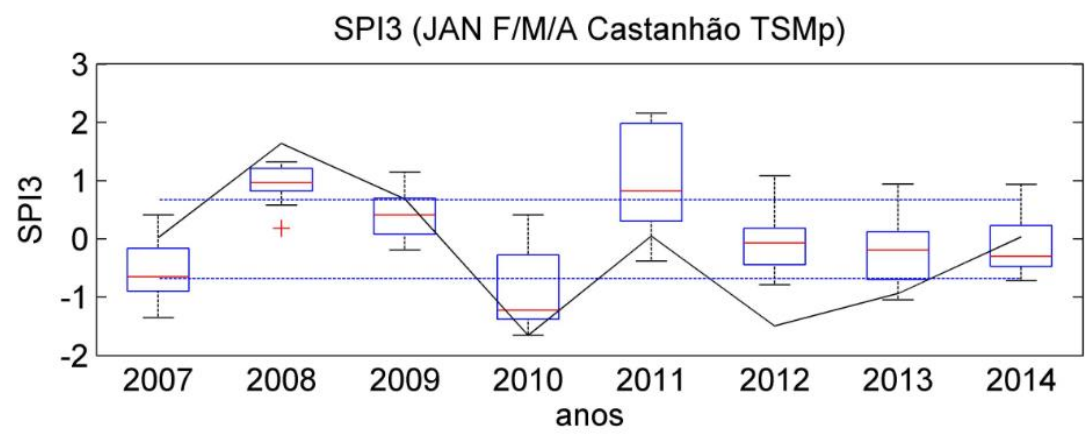

Figura 74 - Comparação do SPI trimestral previsto, da bacia do Castanhão, gerado com a TSM persistida e o observado (linha azul pontilhada: climatologia, linha preta contínua: SPI observado). 
Destaca-se ainda que em todas as situações analisadas do SPI mensal e trimestral a maior parte dos valores positivos do $\mathrm{SS}_{\mathrm{D}}$ foi constatada em meses pertencentes à quadra chuvosa, o que favorece a possibilidade de utilização dos mesmos na previsão de secas, já que, na região estudada, esse evento normalmente é constatado quando se verifica um déficit de precipitação nesse período.

Outra informação importante é que a maior parte dos resultados do $\mathrm{SS}_{\mathrm{D}}$, obtidos com base nas previsões climatológicas que usam a TSM persistida e prevista, são próximos, apresentando frequências semelhantes de resultados positivos. Isso mostra que essas duas metodologias de previsão podem ser adotadas na antecipação dos eventos de seca.

Outra métrica em que foram obtidos bons resultados para as previsões da seca segundo o SPI mensal e trimestral de meses pertencentes à quadra chuvosa foi o BS com o limiar referente à seca média e severa estabelecido por McKee et al. (1993), sendo a maior parte dos valores inferiores a 0,3 .

Foram também calculados os coeficientes de correlações de Spearman obtidos por meio da comparação da média dos membros dos conjuntos de previsões e as observações do SPI mensal e trimestral. Os melhores valores dessa métrica foram atingidos para o SPI trimestral em todas as bacias, o que mostra uma maior correspondência entre os dados previstos e observados quando utiliza o valor acumulado da precipitação prevista. 


\section{7- CONCLUSÕES E RECOMENDAÇÕES}

A maior parte dos índices de seca abordados no presente trabalho é largamente utilizada em estudos que tentam identificar a ocorrência de secas. Poucas dessas pesquisas, entretanto, fazem uma avaliação da eficiência dos mesmos com base nas características das secas que ocorrem em diversas regiões.

Um problema que tende a limitar o desenvolvimento desses estudos é a carência, em diversas regiões, de uma base de dados que descreva as secas que ocorreram no passado, indicando como se desenvolveram os impactos desencadeados por elas. Essas bases de dados deveriam envolver, por exemplo, o detalhamento de quais regiões foram afetadas e a sequência dos impactos.

Apesar dessa deficiência de dados, o presente trabalho, com base na avaliação dos valores de determinados índices durante os períodos considerados historicamente secos, verificou que o SPI, o SPEI, o PDSI, o PHDI e o índice desenvolvido pela FUNCEME conseguem identificar diversas secas que ocorreram na região do Nordeste semiárido. Esse reconhecimento, entretanto, está associado a diferentes tipos de erros, já que cada um desses índices foi proposto para identificar diferentes tipos de secas e as que foram abordadas no trabalho não foram diferenciadas quanto ao tipo, meteorológicas, agrícolas e hidrológicas. Essas deficiências podem desencadear problemas no processo de tomada de decisão, como gastos desnecessários.

O NDVI é um índice que frequentemente é utilizado em pesquisas que tentam entender o mecanismo das secas. Constatou-se, porém, apesar do pequeno período de análise, que o mesmo apresenta uma tendência variável ao longo do tempo, porém com grau de variabilidade praticamente constante, não se alterando durante os anos considerados secos. O uso do mesmo para auxiliar no monitoramento das secas na região analisada no presente trabalho, portanto, não é aconselhado.

O SPEI e o SPI são índices de elevada transparência e simplicidade de cálculo, podendo facilmente ser operacionalizados em um sistema de prevenção contra eventos extremos. Dentre os diversos períodos de acumulação em que os mesmos podem ser calculados, 
verificou-se que os períodos de 12 meses conseguem representar melhor os eventos de seca e alguns dos impactos desencadeados, como a redução da umidade do solo e da vazão.

Muitos autores consideram o PDSI mais completo que os demais índices avaliados no presente trabalho (SPI, SPEI e o índice da FUNCEME), em função dele possuir uma metodologia que considera os processos que ocorrem no meio de forma mais detalhada. Apesar dessa maior complexidade, que faz com que esse índice seja mais difícil de ser calculado e compreendido, o PDSI apresentou resultados muito próximos ao SPI12 e o SPEI12, quando se avaliaram os erros e acertos na indicação da ocorrência da seca. Essa ferramenta ainda alcançou menores valores de correlação quando comparados as variáveis que indicam o impacto da seca. Destaca-se, entretanto, que a metodologia original de cálculo do PDSI utiliza informações de algumas cidades dos Estados Unidos na determinação das suas equações. É importante destacar que existe uma variação desse índice, que não foi aplicada no presente trabalho, o sc-PDSI, o qual emprega as características da área estudada para formular as suas equações.

O índice da FUNCEME também apresentou uma capacidade de identificar os eventos de seca semelhante as do SPI12 e SPEI12, com base na quantificação dos erros e acertos na indicação dos eventos históricos que incidiram na região Nordeste. Essa ferramenta, entretanto, em virtude do seu período de acumulação, não consegue captar, de forma eficiente, as mudanças da vazão e da umidade do solo.

Por meio dos gráficos que mostram os resultados dos cálculos dos erros e acertos dos índices na identificação das secas, puderam-se propor novos valores limiares. Para um trabalho futuro, outra maneira de se determinar esses valores, seria com base na obtenção da probabilidade de ocorrência das secas. Com essa informação, poderia se identificar quais os valores de cada índice conseguiram indicar as secas com maior eficiência.

Destaca-se, contudo, que a quantificação dos erros e acertos na identificação das secas se baseou em determinadas considerações para definir os anos secos, pois a maior parte dos índices tem uma escala mensal, mas as secas descritas pelos autores referenciados no presente trabalho são anuais. Nota-se a necessidade de se realizarem novos estudos que consigam verificar, de forma mais detalhada, quais são as possíveis sequências de valores 
dos índices de seca e em quais situações se poderia afirmar que o ano foi seco, com base nessas ferramentas mensais.

Em relação às analises envolvendo o volume dos reservatórios, é importante ressaltar que não foi considerada a intervenção humana nesses valores, além das características dos reservatórios. Não se pode dizer, portanto, que as variações dos volumes utilizados nesse trabalho sejam determinadas apenas pelos fatores climáticos associados às secas. Existe, assim, a necessidade de se desenvolverem novos projetos, que façam um detalhamento das características desses reservatórios. Outra questão importante que deve ser observada nesses estudos, é que, apenas após longos períodos, a redução da precipitação começa a influenciar no valor do volume dos reservatórios, em virtude do grande magnitude dos mesmos. Assim, quando se estuda esses dados, é aconselhável que se utilize índices que trabalham com grandes amplitudes, como 24 e 48 meses, no caso do SPI e do SPEI.

No âmbito da umidade do solo, os dados gerados pelo MUSAG tiveram um desempenho, na indicação das secas, um pouco melhor que os valores da ESRL. Deve-se destacar, entretanto, que não se fez uma distinção dos tipos das secas consideradas no presente trabalho, se foram meteorológicas, agrícolas ou hidrológicas. Outro fato que pode ter influenciado nesses resultados, foi o cálculo da média diária, para a obtenção dos dados mensais, o que resultou na perda de parte das informações contidas nos dados.

Para que um cultivo agrícola se desenvolva, é necessário que se forneça para o solo, de forma constante, uma quantidade de água mínima para a sobrevivência das plantas. Assim, seria interessante o desenvolvimento de estudos que utilizassem a média de valores pertencentes a determinados períodos, ao invés da média diária.

Também foi analisada a capacidade de previsão do SPI mensal e trimestral, por meio do cálculo do $\mathrm{SS}_{\mathrm{D}}$. Essa métrica mostrou indícios de que esse índice consegue antecipar os eventos de seca com uma maior qualidade que a climatologia. Esses resultados, entretanto, não são conclusivos, havendo a necessidade de se realizarem estudos que sejam capazes de descrever, de forma mais ampla, os valores observados e previstos do índice, além de verificar se os valores considerados como observados condizem com a realidade. 


\section{8- REFERÉNCIAS BIBLIOGRÁFICAS}

Abbaspour, K.C.; Yang, J.; Mximov, I.; Siber, R.; Bogner, K.; Mieleitner, J.; Zobrist, J.; Srinivasan, R. (2007). Modelling hydrology and water quality in the prealpine/alpine Thur watershed using SWAT. Journal of Hydrology, 333, 413 - 430. Alley, W.M. (1984). The Palmer Drought Severity Index: Limitations and Assumptions. Journal of Climate and Applied Meteorology, 23, 1100-1109.

Anuário de Monitoramento Quantitativo dos Açudes Gerenciados pela Cogerh. (2009). Estado do Ceará. Fortaleza: Companhia de Gestão dos Recursos Hídricos COGERH, 2009.

Araghinejad, S. (2010). An Approach for Probabilistic Hydrological Drought Forecasting, water resour manage, 25, 191-200.

Atlas Brasil: abastecimento urbano de água por estado. 2010. vol. 2. Brasília. Agência Nacional de Águas, Engecorps/Cobrape.

Barua, S. (2012). Drought Assessment and Forecasting Using a Nonlinear Aggregated Drought Index. Tese de Doutorado, Victoria University, Australia, 178p.

Batjes, N.H. (2002). ISRIC-WISE Global Data Set of Derived Soil Properties on a 0.5 by 0.5 Degree Grid. Report 2002/3. International Soil Reference and Information Centre.

Bhalme, H. N.; Mooley, D. A. (1980). Large-Scale Droughts/Floods and Monsoon Circulation. Monthly Weather Review, 108, 1197-1211.

Brasil, Lei n ${ }^{\circ} 13.153$, de 30 de Julho de 2015. Institui a Política Nacional de Combate e Prevenção à Desertificação e Mitigação dos Efeitos da Seca e seus instrumentos. Disponível em: http://www.planalto.gov.br/ccivil_03/_Ato20152018/2015/Lei/_leis2015.htm. Acesso em: 03 de agosto de 2015.

Byun, H. R.; Wilhite, D. A. (1999). Objective Qualification of Drought Severity and Duration, American Meteorological Society, 12, 2747-2756

Campos, J. N. B. (1994). Vulnerabilidade do Semi-Árido às Secas, sob o Ponto de Vista dos Recursos Hídricos. Ministério da Integração Nacional.

Carvalho, O. de. (2012). As secas e seus impactos. In: A questão da Água no Nordeste. Centro de Gestão e Estudos Estratégicos, Agência Nacional de Águas - Brasília, DF. Castro, A. L. C. de. (2003). Manual de desastres: desastres naturais. Ministério da Integração Nacional. Brasília. 
Choi, M.; Jacobs; J. M.; Anderson; M. C.; Bosch; D. D. (2013). Evaluation of drought indices via remotely sensed data with hydrological variables, Journal of Hydrology, 476, 265-273.

Conejo, J. G. L. (Coord.). (2007). Disponibilidade e demandas de recursos hídricos no Brasil. Agência Nacional de Águas. Brasília.

Cunha, L. V. da; Vlachos, E.; Yevjevich V. (1983). Drought, Environment and Society. In: Cunha, L. V. da; Vlachos, E.; Yevjevich V., Coping with Droughts. Book Crafters. Colorado. U.S.

Dool, H. V. D.; Huang, J; Fan, Y. (2003). Performance and analysis of the constructed analogue method applied to U.S. soil moisture over 1981-2001. Journal of Geophysical Research. 108. 1 - 16.

Drought Management Centre for South-Eastern Europe. (2015). Drought Monitoring Bulletin. Disponível em: < http://www.dmcsee.org/en/drought_monitor/> Acesso em: 02 de agosto de 2015.

Fan, F. M. (2014). Previsão por Conjunto de Vazões Afluentes a Reservatórios em Grandes Bacias Hidrográficas Brasileiras. Tese de Doutorado, Universidade Federal do Rio Grande do Sul.

Finan, T. J.; Nelson, D. R. (2001). Making rain, making roads, making do: in Ceará, Northeast Brazil. Climate research. 19, 97-108.

Fleig, A. K.; Tallaksen, L. M.; Hisdal, H.; Demuth, S. (2006). A global evaluation of streamflow drought characteristics, Hydrology Earth Science, 10, 535-552.

Garcia, A. K. M.; Neves, F. de C. (2003) Fortaleza Sombria: O cotidiano nos abarracamentos durante a seca (1877-1880). In: ANPUH - XXII Simpósio Nacional de História. Joao Pessoa.

Garen, D. C. (1993). Revised Surface-Water Supply Index for Western United States. J. Water Resour. Plann. Manage, 119(4), 437-454.

Garrote, L.; Martin-Carrasco, F.; Flores-Montoya, F.; Iglesias, A. (2007). Linking Drought Indicators to Policy Actions in the Tagus Basin Drought Management Plan, Water Resources Management, 21, 873-882.

Gatto, L. C. S. (1999). Diagnóstico Ambiental da Bacia do Rio Jaguaribe: Diretrizes Gerais para a Ordenação Territorial. Ministério De Planejamento e Orçamento. Salvador. Bahia.

Gregoric, G. e Susnik, A. (2015). Drought in Sought-Easterm Europe: Monitoring and Management. In: Andreu, J.; Solera, A.; Paredes-Arquiola, J.; Haro-Monteagudo, D.; 
Lanen, H. A. J. V. (2015). Drought Research and Science-Policy Interfacing. Taylor and Francis Group. London.

Gutiérrez, A. P. A.; Engle, N. L.; Nys, E. de; Molejón, C.; Martins, E. S. (2014). Drought preparedness in Brazil. Weather and Climate Extremes, 3, 95-106.

Hannaford, J.; Lloyd-Hughes, B.; Keef, C.; Parry, S.; Prudhomme, C. (2010) Examining the large-scale spatial coherence of European drought using regional indicators of precipitation and streamflow deficit, Hydrological Processes, 25, 1146-1162.

Harris, I.; Jones, P. D.; Osborn, T. J.; Lister, D. H. (2013). Updated high-resolution grids of monthly climatic observations - the CRU TS3.10 Dataset, international journal of climatology, 34, $623-642$.

Hayes, M.; Svoboda, M.; Wall, N.; Widhalm, M. (2011). The Lincoln Declaration on Drought Indices: Universal Meteorological Drought Index Recommended. Bull. Amer. Meteor. Soc., 92, 485-488.

Heim, Jr., R. R. (2002). A Review of Twentieth-Century Drought Indices Used in the United States. Bull. Amer. Meteor. Soc., 83, 1149-1165.

Huang, J.; Dool, H. M. V. D.; Georgarakos, K. P. (1995). Analysis of Model-Calculated Soil Moisture over the United States (1931 - 1993) and Applications to Long-Range Temperature Forecasts. Journal of Climate, 9, 1350 - 1362.

Jacobi, J.; Perrone, D.; Duncan, L. L.; Hornberger, G. (2013). A tool for calculating the Palmer drought indices.

Juhasz, T.; Kornfield, J. (1978). The Crop Moisture Index: Unnatural Response to Changes in Temperature. Journal of applied meteorology. 17. $1864-1866$.

Karl, T. R. (1983) Some Spatial Characteristics of Drought Duration in the United States. Journal of Climate and applied meteorology, 22, 1356-1366.

Karl, T.; Quinlan, F.; Ezell, D. S. (1987). Drought Termination and Amelioration: Its Climatological Probability. Journal of Climate and Applied Meteorology, 26, 11981209

Keyantash J.; Dracup J. A. (2002) The Quantification of Drought: An Evaluation of Drought Indices. Bull. Amer. Meteor. Soc., 83, 1167-1180.

-; - (2004). An aggregate drought index: Assessing drought severity based on fluctuations in the hydrologic cycle and surface water storage. Water resources research, 40, 1-13.

Kogan, F. N. (1995). Droughts of the Late 1980s in the United States as Derived from NOAA Polar-Orbiting Satellite Data. Bull. Amer. Meteor. Soc., 76, 655-668. 
Lanen, H. A. J. V.; Tallaksen, L. M.; Assimacopoulos, D.; Stahl, K.; Wolters, W.; Andreu, J.;Seneviratne, S. I.; Stefano, L. De; Seidl, I.; Rego, F. C.; Massarutto, A.; Garnier, E. (2015). Forestering Drought research and Science-Policy Interfacing: Achievenments of the DROUGHT-R\&SPI Project. In: Andreu, J.; Solera, A.; Paredes-Arquiola, J.; Haro-Monteagudo, D.; Lanen, H. A. J. V. (2015). Drought Research and Science -Policy Interfacing. Taylor and Francis Group. London. Lorenzo-Lacruz, J.; Vicente-Serrano, S. M.; López-Moreno, J. I.; Begueíra, S.; GarcíaRuiz, J. M. (2010). The impacto f droughts and water management on various hydrological systems in the headwaters of the Tagus River (central Spain). Journal of Hydrology, 386, 13-26.

Marton, D.; Starý, M.; Mensik, P.; Paseka, S. (2015). Hydrological Reliability Assessment of Water Management Solution of Reservoir Storage Capacity in Conditions of Uncertainty. In: Andreu, J.; Solera, A.; Paredes-Arquiola, J.; Haro-Monteagudo, D.; Lanen, H. A. J. V. (2015). Drought Research and Science -Policy Interfacing. Taylor and Francis Group. London.

Marengo, José A. (2006). Mudanças Climáticas Globais e Seus Efeitos Sobre a Biodiversidade. Biodiversidade. Ministério do Meio Ambiente. Secretaria de Biodiversidade e Florestas. Brasília.

—. (2008). Vulnerabilidade, Impactos e Adaptação à Mudança do Clima no Semi-Árido do Brasil. Parcerias Estratégicas.

Martins, E. S. P. R.; Braga, C. F. C.; Nys, E. de; Souza Filho, F. de A. de; Freitas, M. A. de S. (2013). Série Água Brasil 8: Impacto das Mudanças do Clima e Projeções de Demanda Sobre o Processo de Água em Duas Bacias do Nordeste Semiárido. $1^{\text {a }}$ Edição. Brasília.

McKee T. B.; Doesken N. J.; Kleist J. (1993). The Relationship of Drought Frequency and Duration to Time Scales. In: Eighth Conference on Applied Climatology. Anahaim, C.A.

Mendes, P. R.; Almeida, T. de. (2012). Introdução ao Processamento de Imagens de Sensoriamento Remoto. Brasília.

Mishra, A. K.; Singh V. P. (2010). A review of drought concepts, Journal of Hydrology, 391, 202 - 216.

Molinas, P. A.; Andrade, F. C. M. de. (1993). Modelo de Umidade do Solo para Atividades Agrícolas. Simpósio Brasileiro de Recursos Hídricos, 10, e Simpósio de Recursos Hídricos do Cone Sul, 1, 1993, Gramado: SBRH, 1993, 8, 136-145. 
Mu, Q.; Heinsch F. A.; Zhao M.; Running S. W. (2007). Development of a global evapotranspiration algorithm based on MODIS and global meteorology data, Remote Sensing of Environment, 3, 519-536.

Mu, Q.; Zhao M.; Kimball J. S.; McDowell N. G.; Running S. W. (2013). A Remotely Sensed Global Terrestrial Drought Severity Index. Bull. Amer. Meteor. Soc., 94, 83 98.

Müller, W.; Appenzeller, C.; Doblas-Reyes, F. J.; Liniger, M. A. (2005). A Debiased Ranked Probability Skill Score to Evaluate Probabilistic Ensemble Forecast with Small Emsemble Size. Jounal of Climate, 18, 1513 - 1523.

Narasimhan, B.; Srinivasan. (2005). Development and evaluation of Soil Moisture Deficit Index (SMDI) and Evapotranspiration Deficit Index (ETDI) for agricultural drought monitoring, Agricultural and Forest Meteorology, 133, $69-88$.

Nobre, P. (2012). As origens das aguas no Nordeste. In: A questão da Água no Nordeste. Centro de Gestão e Estudos Estratégicos, Agência Nacional de Águas. - Brasília, DF: Centro de Gestão e Estudos Estratégicos.

NTSG - Numerical Terra dynamic Simulation Group. Disponível em:

<http://www.ntsg.umt.edu/> Acesso em: 04 de maio de 2014.

Nys, E. de; Engle, N.; Abicalil, T.; Carballo, D. A.; Freitas, P.; Molejón, C.; Pedroso, F. (2014). Série Água Brasil: Convivência com o Semiárido e Gestão da Seca no Nordeste do Brasil: Uma Nova Perspectiva. Brasília. 8 p.

Palmer, W. C. (1965). Meteorological Drought: Meteorological drought. Research Paper No. 45, U.S. Department of Commerce Weather Bureau, Washington, D.C.

Pereira Junior, J. de S. (2007). Nova delimitação do Semi-Árido Brasileiro. Disponível em: <http://bd.camara.gov.br> Acesso em: 06 de agosto de 2015.

Pompeu Sobrinho, T. (1982). História das Secas (Século XX). Mossoró. RN.

PSD - Physical Sciences Division. Disponível em: < http://www.esrl.noaa.gov/psd/> Acesso em 2 de maio de 2014.

Pozzi, W.; Sheffield, J.; Stefanski, R.; Cripe, D.; Pulwarty, R.; Vogt, J. V.; Heim Jr, R. R.; Brewer, M. J.; Svoboda, M.; Westerhoff, R.; Dijk, A. I. J. M. V.; Lloyd-Hughes, B.; Pappenberger, F.; Werner, M.; Dutra, E.; Wetterhall, F.; Wagner, W.; Schubert, S.; Mo, K.; Nicholson, M.; Bettio, L.; Nunez, L.; Beek, R. V.; Bierkens, M.; Gonçalves, L. G. de; Mattos, J. G. Z. de.; Lawford, R.; (2013). Toward Global Drought Early Warning Capability: Expanding International Cooperation for the Development of a Framework for Monitoring and Forecasting. Bull. Amer. Meteor. Soc., 94, 776-785. 
Redmond, K. T. (2002). The depiction of drought: a commentary. Bull. Amer. Meteor. Soc., 83, 1143-1147.

Reis, D. S. Jr; Nascimento, L. S. V.; Martins, E. S. P. R. (2007). Avaliação do ensemble da previsão climática de chuva no estado do Ceará com base em modelos numéricos de clima. In: XVII Simpósio Brasileiro de Recursos Hídricos, Anais do XVII Simpósio Brasileiro de Recursos Hídricos.

RP-03 - Diagnóstico da Bacia do Rio Piranhas-Açu. 2012. IBI ENGENHARIA, Agência Nacional de Águas. Disponível em:

http://www.cbhpiancopiranhasacu.org.br/site/14a-reuniao-da-ctpi-em-caico-discutiurelatorio-de-diagnostico-do-prh-da-bacia-piranhas-acu/. Acesso em: 29 de abril de 2014.

Senado Federal (1997) Comissão "El Niño” relatório final. Brasília.

Shafer, B. A.; Dezman, L. E. (1982). Development of a Surface Water Supply Index (SWSI) to assess the severity of drought conditions in snowpack runoff areas. In: Proceedings of the (50th) 1982 Annual Western Snow Conference, pp 164-75 Fort Collins, CO: Colorado State University.

Shuttleworth, W.J. (2012). Terrestrial Hydrometeorology. John Wiley \& Sons, Ltd.

Souza Filho, F. A. (2003). Variabilidade e Mudança Climática nos Semi-Áridos Brasileiros. In: Tucci C. E. M. e Braga, B., Clima e recursos Hídricos no Brasil. ABRH. Porto Alegre.

Souza, I. de; Medeiros Filho, J. (1983). Os Desagregados da Seca: uma análise sóciopolítica das secas do Nordeste. Vozes. Petrópolis. RJ.

Sun, L.; Moncunill; D. F.; Li, H.; Moura, A. D.; Souza Filho, F. A. (2005). Climate Downscaling over Nordeste, Brazil, Using the NCEP RSM97. Journal of Climate, 18, 551-567.

—; —; - ; Ward, M. N. (2006). Climate Variability and Corn Yields in Semiarid Ceará, Brazil. Journal of Applied Meteorology and Climatology, 46, 226-240.

Sung, J. H.; Chung, E.S. (2013). Development of streamflow drought severity-durationfrequency curve using threshold level method. Hydrol. Earth System Sciences, 10, 14675-14704.

Svoboda, M. (2000). An Introduction to the Drought Monitor. Drought Network News (1994-2001). Disponível em: http://digitalcommons.unl.edu/droughtnetnews/80. Acesso em: 26 de fevereiro de 2014. 
Termos de Referência para a Elaboração do Plano de Recursos Hídricos da Bacia do Rio Piranhas-Açu. 2010. IBI Engenharia Consultiva, Agência Nacional de Águas. Disponível em: http://piranhasacu.ana.gov.br/. Acesso em: 29 de abril de 2014.

Thomas, J; Kornfield, J. (1978) The Crop Moisture Index: Unnatural Response to Changes in Temperature. Journal of Applied. Meteorology, 17, 1864-1866.

Universidade Federal de Santa Catarina. Centro Universitário de Estudos e Pesquisas sobre Desastres. 2011: Atlas brasileiro de desastres naturais 1991 a 2010: volume Ceará. Centro Universitário de Estudos e Pesquisas sobre Desastres. UFSC. Florianópolis. Vieira Neto, J. F. Plano de Gerenciamento das Águas da Bacia do Rio Jaguaribe. Disponível em: < http://portal.cogerh.com.br/eixos-de-atuacao/estudos-eprojetos/planos-de-bacias/plano-de-gerenciamento-da-bacia-do-rio-jaguaribe > . Acesso em maio de 2013.

Vicente-Serrano S. M.; Beguería S.; López-Moreno J. I. (2009). A Multi-Scalar Drought Index Sensitive to Global Warming: the Standardized Precipitation Evapotranspiration Index - SPEI. Journal of Climate, 23, 1696-1718.

—; Beguería, S.; Lorenzo-Lacruz, J.; Camarero, J. J.; López-Moreno, J. I.; Azorin-Molina, C; Revuelto, J.; Morán-Tejeda, E.; Sanchez-Lorenzo, A. (2012). Performance of Drought Indices for Ecological, Agricultural, and Hydrological Applications. Earth Interact., 16, 1-2.

Zargar, A.; Sadiq R.; Naser B.; Khan F. I. (2011). A review of drought indices. Environmental Reviews, 19, 333-349.

Webb, R.S.; Rosenzweig, C.E.; Levine, E.R. (1993). Specifying Land Surface Characteristics in General Circulation Models: Soil Profile and Derived WaterHolding Capacities. Global Biogeochemical Cycles, 7(1), 97-108, doi:10.1029/92GB01822.

Wells, N.; Goddard, S.; Hayes, M. J. (2004). A Self-Calibrating Palmer Drought Severity Index, American Meteorological Society, 17, 2335-2351.

Wilhite, D. A. e Svododa M. D.; Hayes M. J. (2006). Understanding the complex impacts of drought: A key to enhancing drought mitigation and preparedness, water resource manage, 21, 763-774.

Wilhite, D. A. e Buchanan-Smith, M. (2005). Drought as Hazard: Understanding the Natural and Social Context. In: Wilhite, D. A., Drought and Water Crises Science, Technology, and Management Issues. Taylor \& Francis Group. Nova York. 
Wilks, D. S. (2006). Statistical methods in the atmospheric sciences. $2^{\text {a }}$ edição. Academin Press. California.

World Meteorological Organization. (2006). Drought monitoring and early warning: concepts, progress and future challenges.

Yevjevich, V. (1967). An objective approach to definitions and investigations of continental hydrologic droughts. Hydrology papers 23. Colorado State University. Fort Collins, USA. 